\title{
An Assessment of the Risk of Transporting Uranium Hexafluoride by Truck and Train
}

August 1978

Prepared for the U.S. Department of Energy under Contract EY-76-C-06-1830

Pacific Northwest Laboratory Operated for the U.S. Department of Energy by 


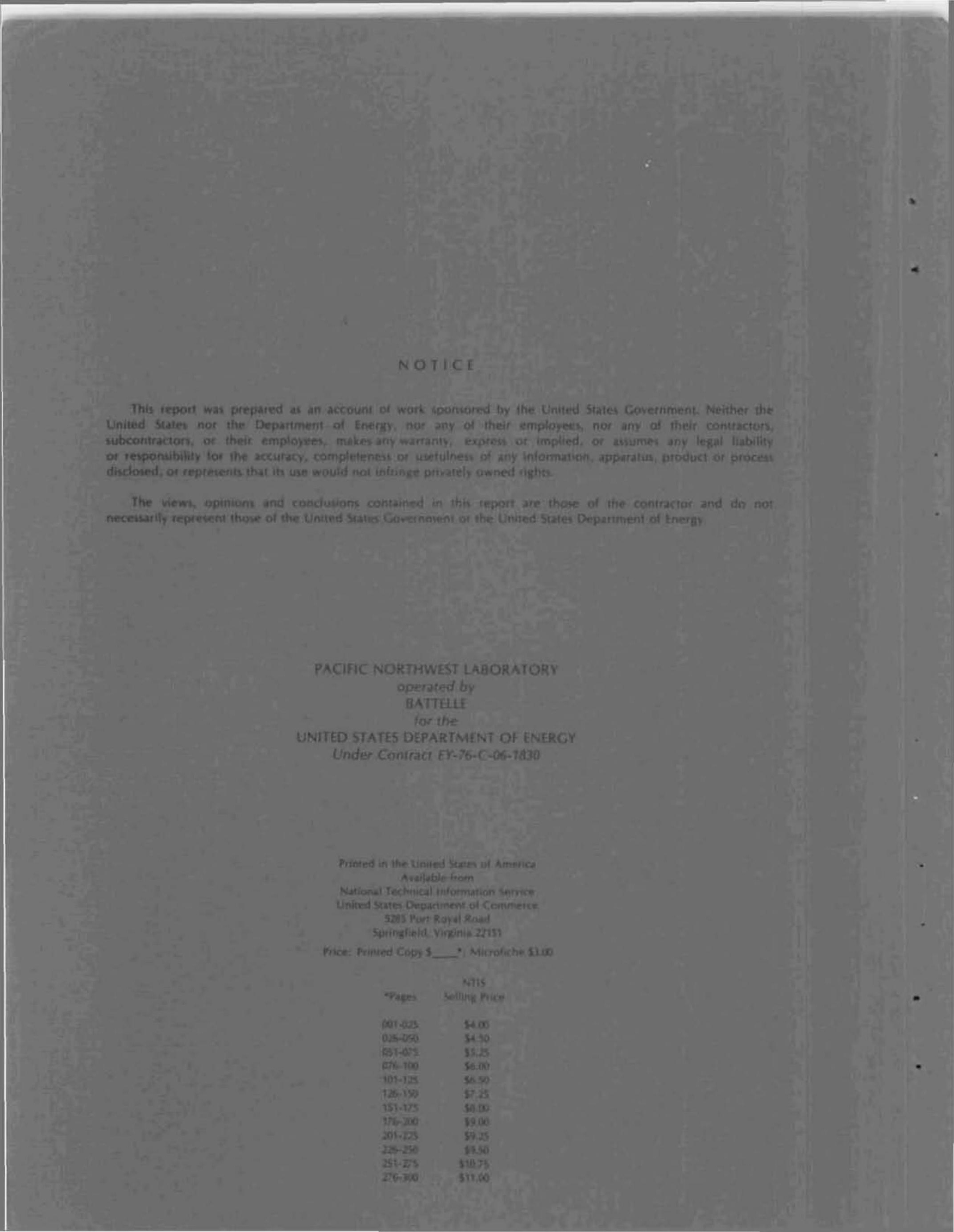


AN ASSESSMENT OF THE RISK

OF TRANSPORTING URANIUM HEXAFLUORIDE

BY TRUCK AND TRAIN

C. A. Geffen

J. F. Johnson

D. K. Davis

J. R. Friley

B. A. Ross

August 1978

Prepared for

the U.S. Department of Energy

under Contract EY-76-C-06-1830

Pacific Northwest Laboratory

Richland, Washington 99352 


\section{CONTENTS}

1.0 INTRODUCTION . . . . . . . . . . . . . . . . . . . $1-1$

REFERENCES. • . . . . . . . . . . . . . . . 1-3

2.0 SUMMARY. . . . . . . . . . . . . . . . . . . . 2-1

REFERENCES. . . . . . . . . . . . . . . . . . 2-5

3.0 TRANSPORTATION RISK ASSESSMENT METHODOLOGY . . . . . . . . . 3-1

3.1 HISTORY . . . . . . . . . . . . . . . . . . 3-1

3.2 RISK ASSESSMENT MODEL . . . . . . . . . . . . . . $3-2$

3.2.1 System Description. . . . . . . . . . . 3-4

3.2.2 Release Sequence Identification. . . . . . 3-6

3.2.3 Release Sequence Evaluation . . . . . . . . 3-7

3.2.4 Risk Calculation and Assessment. . . . . . . 3-9

REFERINCES. . . . . . . . . . . . . . . . . . 3-11

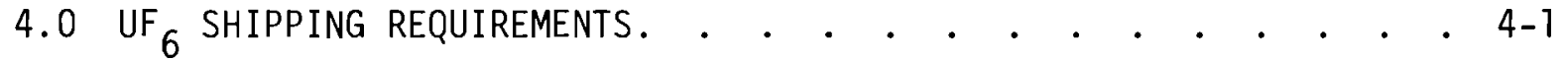

$4.1 \mathrm{UF}_{6}$ PRODUCTION PLANTS . . . . . . . . . . . . . 4-1

4.2 ENRICHMENT (GASEOUS DIFFUSION) PLANTS . . . . . . . . 4-2

4.3 FUEL FABRICATION PLANTS. . . . . . . . . . . . . 4-3

4.4 SHIPPING DISTANCES AND AMOUNTS . . . . . . . . . . 4-3

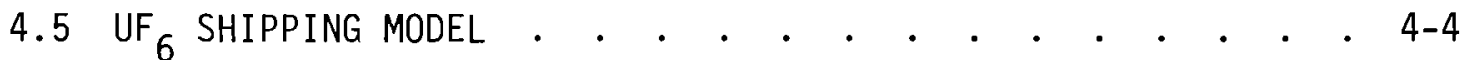

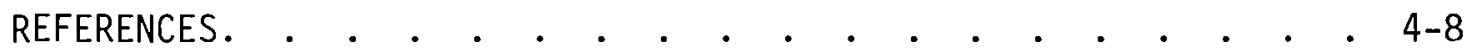

5.0 TRANSPORTATION ACCIDENT ENVIRONMENT . . . . . . . . . . . . 5-1

5.1 TRUCK ACCIDENT ENVIRONMENT. . . . . . . . . . . . . 5-1

5.2 TRAIN ACCIDENT ENVIRONMENT. . . . . . . . . . . . . 5-4 REFERENCES. . . . . . . . . . . . . . . . . . . 5-8 
6.0 PACKAGE FAILURE THRESHOLDS . . . . . . . . . . . . . . . $6-1$ REFERENCES. . . . . . . . . . . . . . . . . . 6-3

7.0 CONDITIONS OF CONTAINERS DURING TRANSPORT . . . . . . . . . .

7.1 SCOPE OF SURVEY • . . . . . . . . . . . . . . . .

7.2 RESULTS OF SURVEY. . . . . . . . . . . . . . . . 7-2

8.0 RELEASE SEQUENCE IDENTIFICATION. . . . . . . . . . . . . . 8-1

8.1 FAULT TREE CONSTRUCTION. . . . . . . . . . . . . .

8.2 FAULT TREES FOR SHIPMENT OF UF 6 • . . . . . . . . . . 8-3

8.3 RELEASE SEQUENCES. . . . . . . . . . . . . . . . 8-11

REFERENCES. . . . . . . . . . . . . . . . . . . 8-23

9.0 RELEASE SEQUENCE EVALUATION . . . . . . . . . . . . . . . 9-1

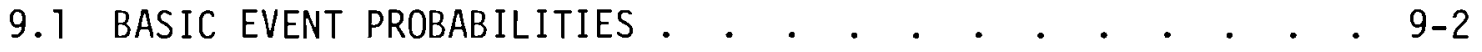

9.1.1 Two and One-Half Ton (Type 30B) Cylinder Transported by Truck With Overpack. . . . . . . . . . 9-2

9.1.2 10-Ton (Type 48X) Cylinder Transported by Truck Without Overpack. . . . . . . . . . . . . 9-18

9.1.3 10-Ton (Type 48X) Cylinder Transported by Truck With Overpack . . . . . . . . . . . . . 9-25

9.1.4 14-Ton (Type 48Y) Cylinder Transported by Train . . 9-30

9.1.5 14-Ton (Type 48Y) Cylinder Transported by Truck . . 9-35

9.2 RELEASE SEQUENCE PROBABILITIES . . . . . . . . . . . 9-37

9.3 RELEASE FRACTIONS. . . . . . . . . . . . . . . . 9-39 REFERENCES. . . . . . . . . . . . . . . . . . . 9 942

10.0 EVALUATION OF ENVIRONMENTAL CONSEQUENCES. . . . . . . . . . . 10-1

10.1 HEALTH EFFECTS. . . . . . . . . . . . . . . 10-1

10.1.1 Effects of Hydrogen Fluoride Gas . . . . . . 10-1

10.1.2 Effects of Uranyl Fluoride . . . . . . . 10-2 
10.2 METEOROLOGY. . . . . . . . . . . . . . . . . 10-6 10.3 DEMOGRAPHY . . . . . . . . . . . . . . . . . 10-8 10.4 ATMOSPHERIC DISPERSION MODEL . . . . . . . . . . . 10-12 10.5 ESTIMATED EXPOSURE FREQUENCY . . . . . . . . . . . 10-15 REFERENCES. . . . . . . . . . . . . . . . . . . 10-19

11.0 THE RISK OF SHIPPING URANIUM HEXAFLUORIDE BY TRUCK AND RAIL . . 11-1

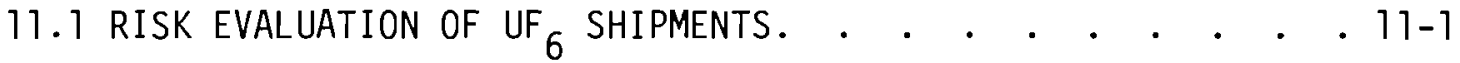
11.2 MAJOR CONTRIBUTORS TO OVERALL RISK . . . . . . . . 11-5 11.3 RISK SENSITIVITY STUDIES . . . . . . . . . . . . 11-6 11.4 MULTIPLE CONTAINER FAILURE ANALYSIS. . . . . . . . . 11-9 REFERENCES. . . . . . . . . . . . . . . . . . . 11-12 APPENDIX A - UF 6 SHIPPING CONTAINER AND TRANSPORT MODE DESCRIPTION. • A-1

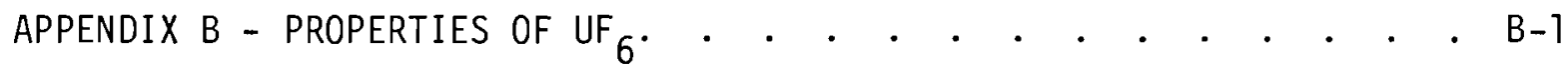
APPENDIX $C$ - FAILURE THRESHOLD DETERMINATION FOR UF 6 CONTAINERS. . $\quad c-1$ APPENDIX D - FRACTIONAL MILEAGE OF SHIPPING ROUTE BY POPULATION ZONE . D-1 


\section{$\underline{\text { TABLES }}$}

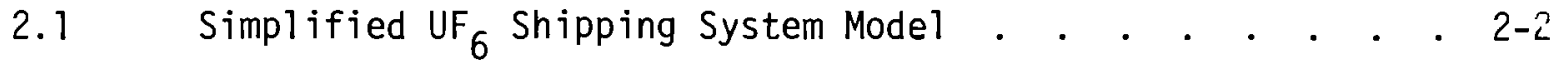

4.1 Fuel Fabrication Plants. . . . . . . . . . . . . 4-4

4.2 Shipping Distances $(\mathrm{km})$.

4.3 Estimated UF 6 Shipments (metric tons) . • . . . . . 4-6

5.1 Definition of Typical Freight Train as Used in This Study . 5-5

6.1 Summary of $U_{6}$ Cylinder Failure Thresholds . • • . . 6-2

7.1 Data Bank-Package Closure Experience Obtained by Survey (For

Period 1971-1975). . . . . . . . . . . . . . . 7-3

8.1 Fault Tree Symbolism. • . • . . . . . . . . . 8-2

8.2 Listing of Basic Events for Analysis of Cylinders Without

Overpack. . . . . . . . . . . . . . . . . 8-9

8.3 Listing of Basic Events for Analysis of Cylinders with

Overpack. . . . . . . . . . . . . . . . . . 8-18

8.4 Listing of 14-Ton (48Y) UF6 Cylinder (Transported by Rail)

Fault Tree Release Sequences... . . . . . . 8-20

8.5 Listing of 10-Ton (48X) UF 6 Cylinder (Transported by Truck) Fault Tree Release Sequences. Cylinder Remains Inside the Overpack.

8.6 Listing of 10-Ton (48X) UF 6 Cylinder (Transported by Truck)

Fault Tree Release Sequences. Cylinder is Lost from the

Overpack.

9.1 Release Sequences and Probabilities for 14-Ton UF6 Rail

Shipments . . . . . . . . . . . . . . . 9-38

9.2 Release Sequences for 14-Ton Cylinder Grouped According to Release Fraction... . . . . . . . . . . 9-41

10.1 Health Effects of HF. . . . . . . . . . . . 10-2

10.2 Assumed Effects of HF on Humans . . . . . . . . . 10-3

10.3 Isotopic Composition of $3.2 \% 235$ Unriched UF 6 . . . . 10-3 
10.4 Dose to Critical Organ Via Inhalation (Soluble) Dose in Rem-m ${ }^{3}$. . . . . . . . . . . . . . . . 10-4 Ci-Sec

10.5 Dose to Critical Organ Via Inhalation (Insoluble) Dose in

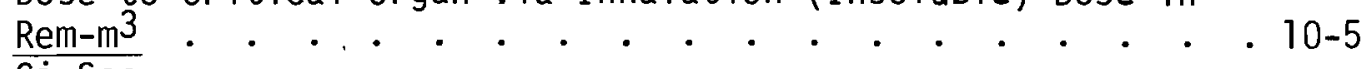
$\overline{\mathrm{C} i-\mathrm{SeC}}$

10.6 Assumed Limits and Effects of $\mathrm{UO}_{2} \mathrm{~F}_{2} \cdot \quad \cdot \quad \cdot \quad \cdot \quad \cdot \quad \cdot \quad \cdot \quad \cdot \quad$ • $10-6$

10.7 Average Windspeed/Stability Characteristics . . . . . 10-7

10.8 Projected Population Density and Land Area by Zone and Population Classes . . . . . . . . . . . . 10-10

10.9 UF $_{6}$ Shipping and Receiving Facilities . • • • • • •

10.10 Fractional Mileage of Shipping Routes by Population Zone. . 10-11

10.11 Values of $\sigma_{y}$ for Pasquill Stability Categories . . . . 10-13

10.12 Values of $\sigma_{z}$ for Pasquill Stability Categories . . . 10-13

11.1 Simplified UF 6 Shipping System Model . • • • • • •

11.2 Summary of $U_{6}$ Shipping System Risks . • • • • • • •

11.3 Risk Sensitivity Cases for $U_{6}$ Shipments . . . . . . . 11-8

A.1 General Data for UF6 Cylinder Model 30A Other Descriptive
Terminology Used -2 1/2-ton UF6, 1-Ton Chlorine . . . A-2

A.2 General Data for UF6 Cylinder Model 30B Other Descriptive Terminology Used $-21 / 2$-ton . . . . . . . . . . A-3

A.3 General Data for UF 6 Cylinder Model 48X Other Descriptive Terminology Used - 10-Ton... . . . . . . . . A-4

A.4 General Data for UF6 Cylinder Model $48 \mathrm{Y}$ Other Descriptive Terminology Used - 14-Ton . . . . . . . . . . . . A-5

D. 1 Fractional Mileage of Shipping Routes by Population Zones

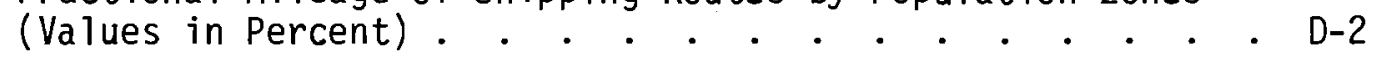

D.2 UF 6 Shipping and Receiving Facilities . . . • • • • • • 


\section{FIGURES}

2.1 Risk Spectra for Individual Transport Modes and Total for

Shipping System • • • • • . • . . . . . 2-4

3.1 Model to Calculate the Risk of Shipping Energy Materials. . 3-5

4.1 Simplified Flow Diagram for UF 6 • • • • • • • • • • •

4.2 Simplified UF 6 Shipping Model. • • • • • • • • • • •

5.1 Cumulative Distribution of Fire-Accident Duration for Truck

Transport of Nonflammable Cargo . . . . . . . . . 5-2

5.2 The Expected Maximum Velocity Change Given a Shipment Truck

Subjected to a Random Accident Sample . . . . . . 5-3

5.3 Duration Probability of Train-Fire Accidents Involving Large

Packages. . . . . . . . . . . . . . . 5-4

5.4 Cumulative Distribution for the Expected Severity of Impact

Forces in Rail Accidents . . . . . . . . . . . 5-6

8.1 UF 6 Fault Tree for Cylinders Transported Without Overpack - 8-4

8.2 Fault Tree for the Shipment of UF $_{6}$ Cylinder In Overpacks. * 8-12

9.1 Remaining Steps in the Risk Evaluation. . . . . . . . 9-1

10.1 Population Zones and UF 6 Shipping and Receiving Facilities . 10-9

10.2 Area Within Isopleths for a Ground-Level Source. . . . . 10-14

11.1 Risk Spectra for Individual Transport Modes and Total For

Shipping System . . . . . . . . . . . . . . 11-3

11.2 Risk Spectrum for Shipment of $U_{6}$ and Other Risk Spectra. . 11-4

11.3 Risk Spectra for Sensitivity Cases . . . . . . . . . . 11-7

11.4 Number of Cylinders Exposed to Fire as Related to Fuel Pool

Size. . . . . . . . . . . . . . . . . . . 11-10

11.5 Risk Spectrum of Single and Multiple Container Failure

Evaluations. . . . . . . . . . . . . . . . . 11-11

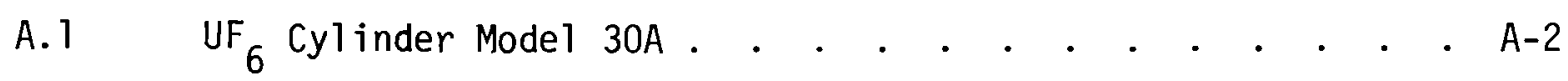


A.2 $\mathrm{UF}_{6}$ Cylinder Model 30B . . . . . . . . . . . . . A-3

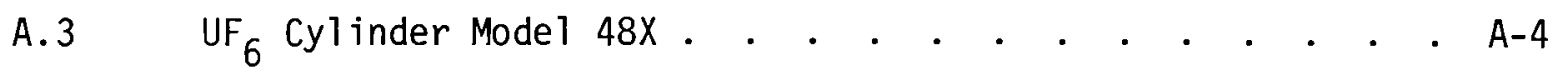

A.4 UF 6 Cylinder Model 48Y . . . . . . . . . . . . . A-5

A.5 Horizontally-Loaded Protective Outer Package for UF ${ }_{6}$ Cylinder

Models $30 \mathrm{~A}$ and $30 \mathrm{~B}$. . $^{\circ}$. . . . . . . . . . A-6

A.6 Protective Shipping Package for $\mathrm{UF}_{6}$ Cylinder Model 48X . A-7

A.7 Four 10-Ton Cylinders . . . . . . . . . . . . . A-9

A.8 Two 10-Ton Cylinders. . . . . . . . . . . . A-9

A.9 Five 2 1/2-Ton Cylinders in Protective Outer Packages. . . A-10

A.10 One 10-Ton Cylinder in a Protective Outer Package . . . . A-10

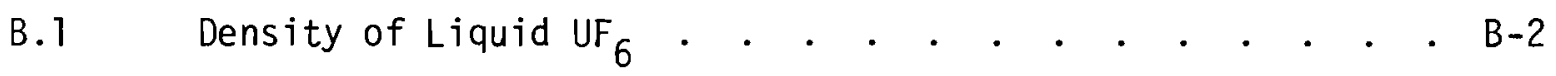

B.2 Phase Diagram of $\mathrm{UF}_{6}$.

C.1 Diagram of 30B Cylinder With Overpack Parted by

Impact Forces . . . . . . . . . . . . . . . C C-7 


\subsection{INTRODUCTION}

Radioactive materials, in a variety of physical and chemical forms, have been routinely transported between various nuclear facilities for many years. The safety record for these shipments has been excellent. As the nuclear industry grows, it is expected that the number of shipments made annually will increase. To insure the health and safety of the general public, industry and government agencies are continually improving their level of understanding of the safety-related aspects of transporting nuclear and other energy materials.

Research programs are one method of improving the level of understanding. Such a research program is being conducted by Pacific Northwest Laboratory (PNL) for the Transportation Branch of the Department of Energy in the Division of Environmental Control Technology. The objective of this continuing program is to develop a methodology for quantitatively assessing the safety of transporting energy materials and to apply it to current and future shipping systems. Risk analysis was the technique selected for this assessment. Through analysis of risk, consequences of postulated releases of energy materials during transport can be put into perspective by viewing the events relative to their expected frequency of occurrence.

Risk, as used in the context of this report, is the product of the probability of a release of material to the environment and the consequences resulting from the release. There are two measures of the risk that are of importance in a risk assessment. The first is the total risk, a numerical value which is the sum of the risk associated with each particular loss. In order to perform the summation, al1 risks must be expressed with respect to the same time interval (e.g., per year). Although the total risk is an important measure, it gives only the loss that would be expected on the average during the reference time interval. The range of losses which could be experienced is not discernable. For example, the risk associated with an accident that occurs once a year and results in one fatality is the same (i.e., one fatality/year) as that from an accident which occurs once in ten years but results in ten fatalities. In a plot of the expected frequency of 
$\mathrm{N}$ or more fatalities as a function of $\mathrm{N}$, these two accidents would appear as discrete points. The second measure of risk is a curve called a risk spectrum, which is generated by connecting such points. The risks associated with two activities are similar only if they have the same total risk (risk magnitude) and the same risk spectrum. Both risk measures are used in this report.

The risk methodology was initially applied to the shipment of plutonium by truck (1) and has subsequently been applied to the shipment of plutonium by rail $(\bar{C})$ and air, $(3)$ and the shipment of gasoline by truck. (4) This report presents the results of an assessment of the risk of transporting uranium hexafluoride by truck and rail. The general risk methodology used in this assessment, as well as in the previous risk studies, is also reviewed. 


\section{REFERENCES}

1. T. I. McSweeney, R. J. Ha11 et a1., An Assessment of the Risk of Transporting Plutonium Oxide and Liquid Plutonium Nitrate by Truck. BNWL-1846, Battelle, Pacific Northwest Laboratories, Richland, WA, August 1975.

2. R. J. Hall et al., An Assessment of the Risk of Transporting Plutonium Dioxide and Liquid Plutonium Nitrate by Train. BNWL-1996, Battelle, Pacific Northwest Laboratories, Richland, WA, February 1977.

3. T. I. McSweeney, J. F. Johnson, An Assessment of the Risk of Transporting Plutonium Dioxide by Cargo Aircraft. BNWL-2030, Battelle, Pacific Northwest Laboratories, Richland, WA, June 1977.

4. R. E. Rhoads and J. F. Johnson, Risks in Transporting Materials for Various Energy Industries. BNWL-SA-6547, prepared for publication in Nuclear Safety, 19(2), Battelle, Pacific Northwest Laboratories, Richland, WA, March 1978. 


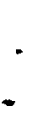

$-$ 


\subsection{SUMMARY}

This report is the fifth in a series of studies of the risk of transporting potentially hazardous energy materials. (a) The report presents an assessment of the risk of shipping uranium hexafluoride $\left(\mathrm{UF}_{6}\right)$ by truck and rail.

The general risk assessment methodology, summarized in Section 3, used in this study is that developed for the first study in this series. (1) The assessment includes the risks from release of uranium hexafluoride during truck or rail transport due to transportation accidents. The contribution to the risk of deteriorated or faulty packaging during normal transport was also considered.

The report is sectioned to correspond to the specific analysis steps of the risk assessment model. The transportation system and accident environment are described in Sections 4 and 5 . Calculation of the response of the shipping system to forces produced in transportation accidents are presented in Section 6 and the results of a survey to determine the condition of the package during transport are presented in Section 7 . Sequences of events that could lead to a release of radioactive material from the shipping cask during transportation are postulated in Section 8 using fault tree analysis. These release sequences are evaluated in Sections 9 through 11, to determine both the likelihood and the possible consequences of each release. Supportive data and analyses are given in the appendices.

The results of the risk assessment have been related to the year 1985, when it is projected that $100 \mathrm{GW}$ of electric power will be generated annually by nuclear power plants. It was estimated that approximately 46,000 metric tons (MT) of natural $\mathrm{UF}_{6}$ and 14,600 MT of enriched UF 6 would be shipped in the reference year. Additional assumptions used for the analysis are:

- Fuel cycle facilities operating in 1985 are those operating or in the planning/construction stages during 1978.

- Shipping systems and regulations are the same as in 1978.

(a) The others are listed as References $1,3,4$ and 5 . 
- No significant changes in the nuclear industry occur which would change the amounts of materials projected for 1985.

- The material transported is used to satisfy the requirements of commercial reactors; military uses have not been considered in this study.

Natural uranium hexafluoride is transported from $\mathrm{UF}_{6}$ conversion plants to enrichment facilities; enriched $U_{6}$ is transported between the enrichment plants and from the enrichment plants to fuel fabrication facilities. Five container types/transportation modes ${ }^{(a)}$ have been assumed to be used for these shipments:

- 30B (2 1/2-ton) cylinders with overpack by truck

- $48 x$ (10-ton) cylinders without overpack by truck

- $48 X$ (10-ton) cylinders with overpack by truck

- 48Y (14-ton) cylinders without overpack by truck

- 48y (14-ton) cyliaders without overpack by rail.

Characteristics of the shipping model developed from these assumptions are shown in Table 2.1. Other shipping conditions or different shipping regulations could result in different risks than those reported in this study. However, the methodology is capable of analyzing the risks under any shipping conditions.

TABLE 2.1. Simplified UF 6 Shipping System Mode1

\begin{tabular}{|c|c|c|c|c|c|c|c|c|}
\hline $\begin{array}{l}\text { Shipping } \\
\text { Container }\end{array}$ & $\begin{array}{c}\text { Transport } \\
\text { Mode }\end{array}$ & $\begin{array}{c}\text { Amount/ } \\
\text { Container (MT) }\end{array}$ & $\begin{array}{l}\text { Containers/ } \\
\text { Shipment }\end{array}$ & $\begin{array}{c}\text { Shipment } \\
\text { Origin/ } \\
\text { Destination } \\
\end{array}$ & $\begin{array}{l}\text { Material } \\
\text { Shipped/ } \\
\text { Year (MT) }\end{array}$ & $\begin{array}{l}\text { "umber } \\
\text { of Ship- } \\
\text { ments yyear }\end{array}$ & $\begin{array}{c}\text { Average } \\
\text { Shipment } \\
\text { Distance }(\mathrm{km})\end{array}$ & Accident/kin \\
\hline \multirow[t]{2}{*}{$\begin{array}{l}2.5 \text {-ton (3OB) } \\
\text { With Overpack }\end{array}$} & Truck & 2.28 & 5 & $\begin{array}{l}\text { Enrichment/ } \\
\text { Fabrication }\end{array}$ & 7.466 & 650 & 1,050 & $1.55 \times 10^{-6}$ \\
\hline & & & & $\begin{array}{l}\text { Enrichment/ } \\
\text { Exports }\end{array}$ & & & & \\
\hline $10-\tan (48 x)$ & Truck & 9.54 & 2 & $\begin{array}{l}\text { Conversion/ } \\
\text { Enrichment }\end{array}$ & 9,000 & 470 & 1.040 & $1.55 \times 10^{-6}$ \\
\hline $\begin{array}{l}\text { 10-ton }(48 x) \\
\text { With Overpack }\end{array}$ & Truck & 9.54 & 1 & $\begin{array}{l}\text { Enrichment/ } \\
\text { Enrichment }\end{array}$ & 1,300 & 140 & 420 & $1.55 \times 10^{-6}$ \\
\hline $14-\operatorname{ton}(48 Y)$ & Truck & 12.5 & 1 & $\begin{array}{l}\text { Conversion/ } \\
\text { Enrichment }\end{array}$ & 21,800 & 1,750 & 375 & $1.55 \times 10^{-6}$ \\
\hline \multirow[t]{2}{*}{$14-\operatorname{ton}(48 Y)$} & Rail & 12.5 & 4 & $\begin{array}{l}\text { Import/ } \\
\text { Enrichment }\end{array}$ & 21,000 & 420 & 800 & $6.21 \times 10^{-6}$ \\
\hline & & & & $\begin{array}{l}\text { Enrichment/ } \\
\text { Enrichment }\end{array}$ & & & & \\
\hline
\end{tabular}

(a) "2 1/2-ton" cylinder has a nominal capacity of 2.27 metric tons $(5,000$ 1b) of $\mathrm{UF}_{6}$. However, because the design of the container as a "2 1/2-ton" cylinder is common practice in the U.S. nuclear industry, this nomenclature has been used in this document. These remarks also apply to the "10-ton" (9.1 MT) and "14-ton" (12.7 MT) cylinders. 
Based on the shipping system outlined above, it is estimated that trucks carrying $U_{6}$ in any of the four cylinder types will be involved in an accident about three times in a year. Train accidents involving UF 6 shipments (in 14-ton cylinders) are expected to occur approximately twice every year. However, most of these accidents would not be severe enough to result in a release of uranium hexafluoride. It was estimated that a truck accident that could result in a release of material from the cylinder would occur once in about 33 years; train accidents resulting in a release would occur once every 100 years. These accidents are not expected to result in measurable consequences to the general public. The frequency of an accident resulting in one or more fatalities from release of $U_{6}$ during a shipment was estimated to be one in about 120,000 years for truck shipments and one about every 10,000 years for rail shipments.

The consequences of the postulated releases were estimated based on the characteristics and amount of radioactive material released to the environs, the weather conditions at the time of the accident, and the population density downwind from the accident scene. The likelihood and the consequences for these postulated releases have been coupled and expressed as risk spectra.

The risk spectrum for transporting $\mathrm{UF}_{6}$ is shown in Figure 2.1. The risk spectrum is a plot of the estimated number of fatalities versus the estimated frequency of an event resulting in that number of fatalities or greater. For example, the estimated probability that a shipment (by truck or rail) of UF 6 will be involved in an accident resulting in one or more fatalities during the reference year is $1.09 \times 10^{-4}$. The estimated probability of an event resulting in ten or more fatalities is $7.00 \times 10^{-6}$. Risk spectra for other risks to which society is exposed $(2)$ have been included in the figure for comparison. The curves in Figure 2.1 indicate that the risk of transporting $\mathrm{UF}_{6}$ in the reference year is much less than the risk to society from natural events or man-caused events and comparable to the risks of transporting plutonium. $(1,3,4)$ It should be noted that fatalities resulting from plutonium releases are long term (30 years or more) while $U_{6}$ release fatalities are acute or short term. 
Sensitivity studies were performed to determine the most important contributors to the risk of shipping $\mathrm{UF}_{6}$. These studies are described in Section 11. It was found that fatalities were likely to result from the release of $\mathrm{UF}_{6}$ only when an intact $\mathrm{UF}_{6}$ cylinder failed explosiveiy in an accidentcaused fire. The primary risk associated with transporting $\mathrm{UF}_{6}$ is chemical in nature, with essentially no contribution to fatalities from its radiological properties. Hydrogen fluoride (HF) gas, produced when $\mathrm{UF}_{6}$ combines with moisture in the air, was the cause of all fatalities calculated in the risk assessment. The sensitivity studies also showed that the risk is dependent on the level of evacuation assumed.

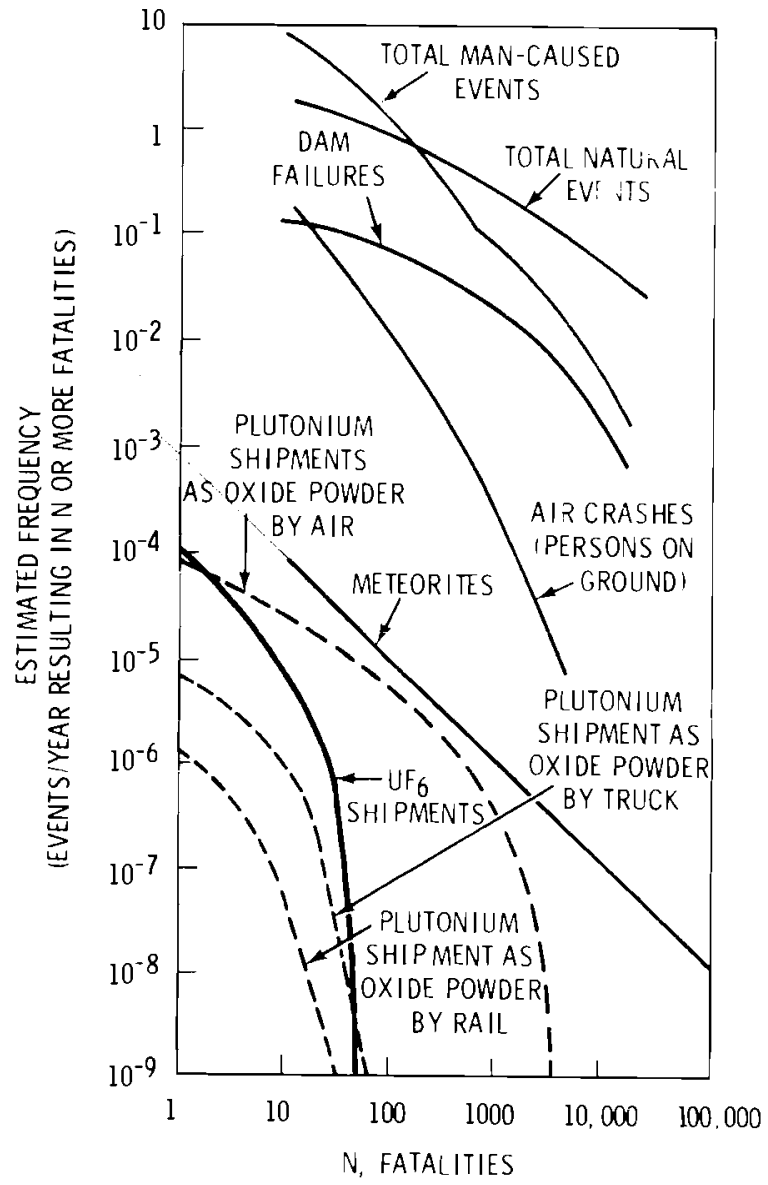

FIGURE 2.1. Risk Spectra for Individual Transport Modes and Total for Shipping System 


\section{REFERENCES}

1. T. I. McSweeney, R. J. Hall et a1., An Assessment of the Risk of Transporting Plutonium 0xide and Liquid Plutonium Nitrate by Truck. BNWL-1846, Battelle, Pacific Northwest Laboratories, Richland, WA, August 1975.

2. Reactor Safety Study: "An Assessment of Accident Risks in U.S. Commercial Nuclear Power Plants." WASH 1400, U.S. Nuclear Regulatory Commission, Washington, DC, October 1975.

3. R. J. Hall et a1., An Assessment of the Risk of Transporting Plutonium Dioxide and Liquid Plutonium Nitrate by Train. BNWL-1996, Battelle, Pacific Northwest Laboratories, Richland, WA, February 1977.

4. T. I. McSweeney and J. F. Johnson, An Assessment of the Risk of Transporting Plutonium Dioxide by Cargo Aircraft. BNWL-2030, Battelle, Pacific Northwest Laboratories, Richland, WA, June 1977.

5. R. E. Rhoads and J. F. Johnson, Risks in Transporting Materials for Various Energy Industries. BNWL-SA-6547, prepared for publication in Nuclear Safety 19(2), Battelle, Pacific Northwest Laboratories, Richland, WA, March 1978. 
.

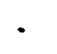




\subsection{TRANSPORTATION RISK ASSESSMENT METHODOLOGY}

This risk assessment represents the fifth in a series of analyses of the transportation of hazardous energy materials. The history of the methodology and a brief summary of the risk assessment model used in all studies to date is presented below.

\subsection{HISTORY}

The risk methodology used in this and earlier transportation risk studies evolved from a number of risk analysis models originally developed for use in the nuclear industry. The risk methodology was initially suggested as a method of selecting an acceptable site for nuclear power facilities. (1) The product of the probability of a radioactive material release, expressed in terms of reactor years between releases, and the consequences of that release, in curies, was used as the measure of risk.

Developments in the area of health effects of radiation exposure allowed the use of individual mortality as the measure of release consequences in later studies. $(2,3,4)$ The units of risk became the probability of an individual mortality in any operation year. Analyses $(5,6)$ were further expanded to show that the risk level individuals are willing to accept is related to the benefits received by the individual. For small benefits, it was determined that an individual will accept low-risk activities, where the probability of the activity producing a fatality is lower than $10^{-7}$ per year. (5) For activities with higher benefits, the individual is willing to accept higher levels of risk. The use of health effects in expressing risk generates more meaningful comparisons among risk assessments. In the Reactor Safety Study, ${ }^{(7)}$ for example, the risk of operating a nuclear power plant was compared to the risks from natural disasters and man-caused events such as accidents.

The risk assessment methodologies discussed above have been 7 imited to analyses of fixed facilities with a well-defined population distribution. The population in the immediate vicinity of the plant (the exclusion area) 
is controlled by the facility operator. The population distribution in the vicinity of a transportation accident, however, is highly variable. Transportation accidents may occur in rural areas (with very low population densities), in suburban areas, or in urban areas (with relatively high population densities). A variety of geographic and meteorological conditions can also be encountered, since transportation accidents can occur at virtually any location along the shipping route. The variability in population distribution, geography and meteorology in transportation accidents adds a degree of complexity not found in risk assessments of activities at fixed sites.

A number of methodologies have been developed to analyze the transport of hazardous materials. One, used by the University of Southern California (8) in a study for the Department of Transportation, is based on accident case histories. However, this technique cannot be applied to all energy material shipments since the accident experience may be extremely limited or the accident data may not have been collected in a way that permits accurate assessment.

Another technique, developed by Holmes and Narver, was used to determine the risk of transporting bioweapons ${ }^{(9)}$ and radioactive material. (10) These analyses were performed for shipments of material along a selected route. However, the methodology is limited in that only one average number for the risk is obtained. It would be more useful to know how the risk varies with route, weather, population, material form and accident severity. The variability of risk with possible transport conditions could then be considered.

\subsection{RISK ASSESSMENT MODEL}

The risk assessment model used in this analysis of the transport of energy materials was developed in conjunction with a method developed at PNL to analyze the risks associated with nuclear fuel cycle operations. The methodology provides a flexibility not available in previous transportation risk studies, since it permits the risk to be analyzed for a spectrum of population densities and weather conditions that can be encountered along shipping routes. The model uses one fundamental equation: 


$$
R=\sum_{i} R_{i}
$$

The total system risk $R$ is the sum of the risks of all accidental releases of material as denoted by the subscript $i$. Only accidental releases are considered in the model. The risk of an individual release is the product of the consequences of the release and the probability of its occurrence. In the current formulation of the model, each term in Equation 1 is expanded into two expressions which have more physical significance. The expanded equation for $R_{i}$ is:

$$
R_{i}=\left(\begin{array}{llll}
A & F_{R_{i}} & \times & P_{R_{i}}
\end{array}\right) \times\left(\begin{array}{cccc}
\Sigma & C_{E_{i, q}} & & P_{E_{q}} \\
q & & &
\end{array}\right)
$$

The first expression, $A F_{R_{j}} \times P_{R_{j}}$, can be thought of as a probabilistic source term for each identified release sequence. The first factor in this term, $A F_{\mathrm{R}_{j}}$, represents the amount of material released in the $i^{\text {th }}$ release sequence. It is the product of the amount of material present in a shipment (A) and the fraction of that material lost to the environment in the $i^{\text {th }}$ release sequence $\left(F_{R_{j}}\right)$. This factor can be considered a source term for the $i^{\text {th }}$ chain of events or failures which end with a release of material. The second factor, $P_{R_{j}}$, is the probability that the release sequence will occur during transport.

The second expression in Equation 3-2 ( $\left.\sum_{\mathrm{q}} C_{E i, q} \times P_{E q}\right)$, represents the consequences of a unit release of material (unit source term) under probabilistically weighted weather conditions and population distributions. The consequences of a unit release of material are evaluated in the expression $\mathrm{C}_{E_{i, q}}$. The subscript $\mathrm{q}$ is added to show that this factor is a function of the specific weather conditions existing at the time of the release and the population exposed to the release. The consequences can be expressed in a variety of ways, depending on the material being studied, although risk comparisons can be more readily made if the consequences are expressed as health effects. The final factor in this expression, $P_{E q}$, is the joint probability of encountering a particular set of weather conditions within a specific population zone. 
The methodology used to provide input data for solution of the above equations involves four components:

- System Description

- Release Sequence Identification

- Release Sequence Evaluation

- Risk Calculation and Assessment

These four components, shown graphically in Figure 1, are described in detail below. Step numbers correspond to the number shown in the figure.

\subsubsection{System Description}

The basic information on the shipping system to be analyzed is collected. Most of the information is already available or easily derived. A complete description of the transportation system generally consists of seven steps, which are shown in Figure 3.1.

Project industry characteristics are determined in step 1. Included in this segment is a description of projected facilities and industry needs for the reference year. Material type, amounts, origins, and destinations are specified in the second step. The third step presents a description of the important physical and chemical characteristics of the material being shipped. For example, an important property of liquid materials is the vapor pressure exerted as a result of elevated temperatures in an accident environment. Powdered materials require specification of the particle size distribution. For radioactive materials, isotopic contents must also be included.

In the remaining four steps, the transportation system is described. In step 4 , the transportation mode is specified, and the vehicles used are describer. Weight and space limitations (and in the case of radioactive materials shipments, heat, geometry, dose and criticality limits) must be specified here so that amount of material per shipment and the required number of shipments can be calculated. 


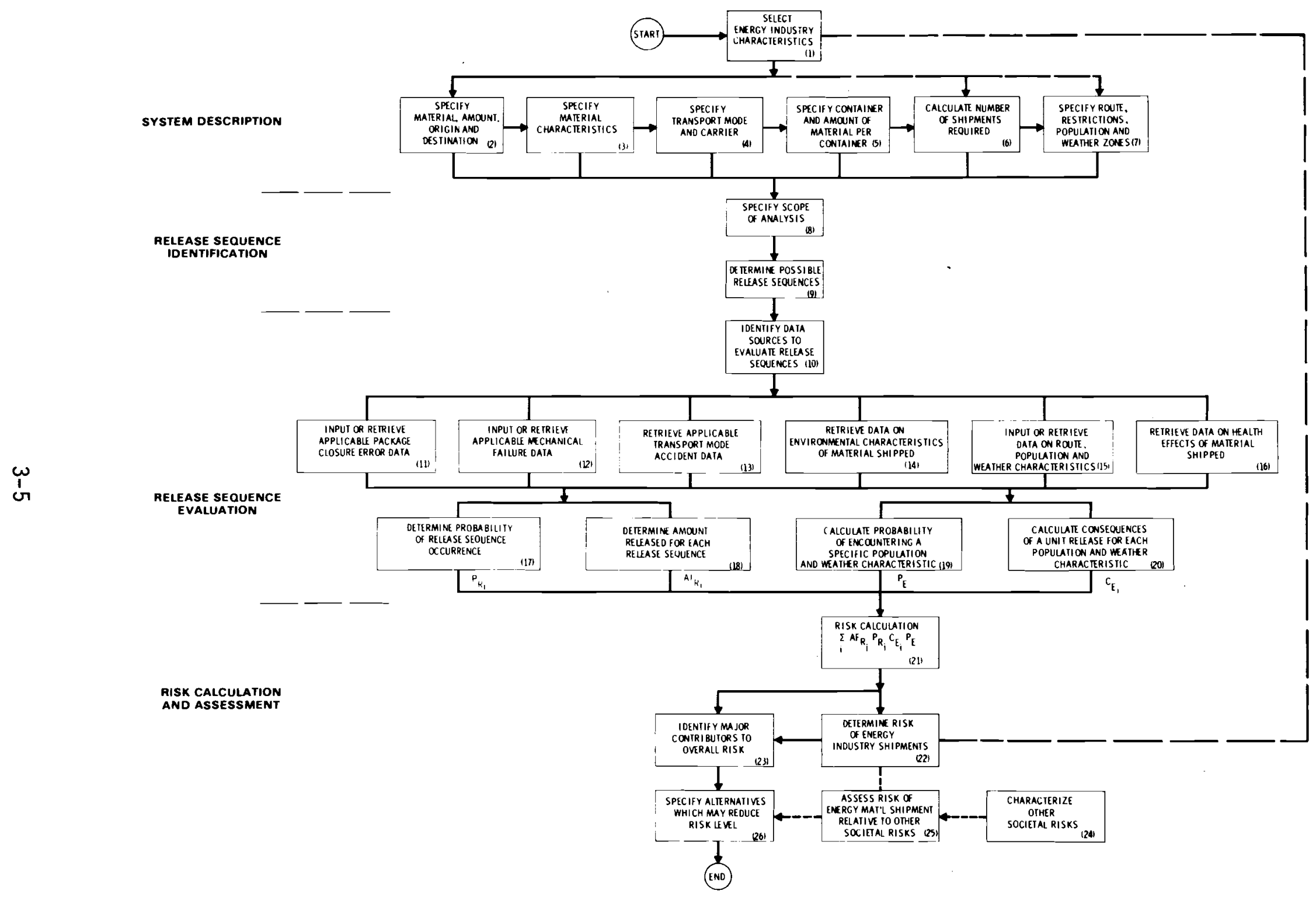

FIGURE 3.1. Model to Calculate the Risk of Shipping Energy Materials 
The container used to carry the material is considered in step 5. For DOT Specification or approved containers, the container designation is enough to completely describe the container. Nonstandard containers require sufficient input to permit evaluation of failure paths later in the analysis. Step 6 of the system description involves the calculation of the number of shipments required to transport the amounts of material specified in step 2, in the vehicles and containers given in steps 4 and 5 .

In the final step of the system description, the shipping route is divided and each segment is described in terms of type of route, shipping, population and weather characteristics. With the completion of this step, the entire transportation system has been described.

\subsubsection{Release Sequence Identification}

The next component in the risk assessment process is the identification of the sequences of events that could lead to release of material from the transport vehicle. These release sequences may be identified in a variety of ways. It is felt that the most complete listings of release sequences are obtained by deductive reasoning processes that work backwards from the occurrence of a release to identify the sequences of events that must occur to cause this system failure. Fault tree analysis provides a systematic method for performing these deductive reasoning processes. The fault tree that is constructed in these analyses also provides a compact notation for displaying large numbers of release sequences. Computer codes, such as the Fault ${ }^{(11)}$ code used at PNL, can be used to quickly and accurately perform the Boolean algebra that reduces the fault tree to a series of release sequences or "cut sets" required for subsequent steps in the analysis.

Before the possible release sequences are identified (step 9), the scope of the analysis must be delineated (step 8). Only those release sequences within the selected scope of analysis are evaluated in subsequent steps in the model. Completed studies using this risk assessment model have considered releases from two general causes. In addition to releases caused by forces produced in transportation accidents, releases resulting from package closure errors, substandard packaging construction or deterioration in 
packaging condition in the normal transportation environment have been considered. Failure associated with deliberate sabotage or diversion attempts has not been considered, but the techniques used in the model are sufficiently general to permit consideration of these events if failure rate (probability) data were available.

\subsubsection{Release Sequence Evaluation}

This step consists of two basic parts: 1) estimation of release sequence probabilities and 2) evaluation of the potential consequences of each release sequence.

The release sequence factors (denoted by the subscript "R" in Equation 3-2) represent the probability that a certain amount of material will be released. The evaluation of these factors requires information from the following data bases, shown in Figure 3.1 as steps 11-14:

- Package Closure Error Data (11)

- Mechanical Failure Data (12)

- Transport Mode Accident Data (13)

- Data on Environmenta 1 Characteristics of Material Shipped (14)

Release sequence probabilities are obtained by estimating the probability of each of the events that must occur to produce a system failure. This requires either historical data or development of information on the response of the shipping system to normal and transport accident forces (to determine the level of forces required to produce a system failure) and knowledge of the forces.

Package closure data (step 11) have been obtained by surveying facilities routinely receiving the material under study. Mathematical analysis or data available from testing programs is generally used to determine system failure thresholds (step 12). This can be combined with accident environment data, such as that developed at Sandia Laboratories ${ }^{(12)}$, or statistical analysis of other accident data to determine failure probabilities (step 13). The behavior of the material in the environment (step 14) depends entirely upon the material under consideration. 
With the information from steps 11 to 14, the probability of a reiease is evaluated and the source term for each release is characterized (steps 17 and 18 in Figure 3.1). Generally, the probability of a release sequence occurring is first evaluated and the source term is then determined for release sequences which have non-zero probabilities. Release fractions $\left(F_{R_{j}}\right)$ used for various release sequences and environmental conditions are determined after carefully examining the individual release sequences.

The "A" factor in Equation 2 includes terms which relate the total amount of material shipped to the fraction that is potentially dispersible. This fraction is a function of the number of containers damaged and the amount of material spilled. After these terms have been evaluated for each release sequence, the source term analys is is complete.

The consequences of a system failure depend on the type of failure that has occurred, the location of the failure along the shipping route and the weather and population conditions at the time of failure. The consequences of the failure sequences may be determined by mathematical modeling, from historical accident data and/or from information from tests that have been conducted with the material being shipped. In general, consequences must be evaluated for each type of failure that can occur for each combination of weather condition and population distribution that can be encountered along the route. The probability of encountering the various population distributions and weather conditions along the route must also be determined.

The environmental terms in Equation 2 are denoted by a subscript $E$. The factor $P_{E}$ represents the probability that a given set of weather and popula tion density characteristics will be encountered in a region, while $C_{E_{j}}$ repre. sents the consequences of a unit release occurring in that region. The consequences of hazardous chemical releases can be directiy expressed as health effects. However, the consequences of radioactive materials must initially be calculated as a population dose in units of man-rem to a selected organ of reference and then converted to health effects. 
The evaluation of these two environmental consequences terms requires input from three data bases:

- Data on Environmental Characteristics of Material Shipped (14)

- Data on Route, Population, and Weather Characteristics (15)

- Data on Health Effects of Material Shipped (16)

The environmental behavior characteristics and health effects of the material depend on the material itself and must be developed individually for each study. Data for step 15 are available from U.S. Census data (13) and summaries of regional weather data compiled by the U.S. Weather Bureau. (14)

Information from steps 14 to 16 is used to evaluate the probability of experiencing a given set of weather conditions and population characteristics. (steps 19 and 20) The expanded form of $P_{E}$ is:

$$
P_{E_{j, k, 1}}=P_{j / k} \times P_{k} \times P_{1} \text {. }
$$

The subscripts $j, k$ and 1 refer to the multiplicity of environmental conditions which could exist at the location of the accident. For example, the variable $P_{j / k}$ may be the probability of experiencing the $j$ th atmospheric stability classification when the $k^{\text {th }}$ wind speed exists, the variable $P_{k}$ the probability of encountering the $k^{\text {th }}$ wind speed category and the variable $P_{1}$ the probability of encountering a specified population distribution.

\subsubsection{Risk Calculation and Assessment}

The final component in the risk assessment is to sum and evaluate the risks associated with the applicable release sequences. The steps involved in this component are shown graphically in Figure 3.1.

The overall risk calculation for each release sequence is described by Equations 3-1 and 3-2. These release sequence risks are added to determine the risk associated with individual shipping routes, which are weighted according to the amounts being shipped along each route. The overall transportation risk (total risk) is the sum of risks from these weighted 
routes. The risk is also expressed in terms of a risk spectrum (plot of magnitude of consequence versus frequency of events resulting in that magnitude consequence or a more severe consequence).

The results are then analyzed to determine the primary contributors to the risk (step 23) and to specify and evaluate alternatives that could reduce the system risk, if the current risk is judged by society to be unacceptable. Since the information to verform the risk assessment has been developed in discrete data blocks, sensitivity studies can also be carried out to test the effect on the system risk of assumptions and approximations that were made to develop key pieces of information. This may identify areas where further analysis is required or delineate the limitations of the assessment. 


\section{REFERENCES}

1. F. R. Farmer, "Reactor Safety and Siting: A Proposed Risk Criterion." Nuclear Safety. $\underline{8}: 539,1967$.

2. H. J. Otway and R. C. Erdmann, "Reactor Siting and Design From a Risk Viewpoint." Nuclear Engineering and Design. 13:365, 1970.

3. M. Meleis and R. C. Erdmann, "The Development of Reactor Siting Criteria Based Upon Risk Probability." Nuclear Safety. 13:22, 1972.

4. G. D. Be11, "Safety Criteria, "Quantitative Safety Analysis." Nuclear Engineering and Design. 13:183-244, 1970.

5. C. Starr, "Benefit-Cost Studies in Socio-Technical Systems." Proceedings of Conference on Hazard Evaluation and Risk Analysis, Houston, TX, 18-19 August 1971, National Academy of Sciences, Washington, DC.

6. C. Starr, M. A. Greenfield and D. F. Hausknecht, "A Comparison of Public Health Risks: Nuclear vs. Oil Fired Power Plants." Nuclear News 15(10):37, 1972 .

7. Reactor Safety Study. WASH-1400, U.S. Nuclear Regulatory Commission, Washington, DC, October 1975.

8. G. P. Jones and R. W. Barrow, Risk Analys is in Hazardous Materials Transportation. RAPO-72-106, U.S. Department of Transportation, Office of Hazardous Materials, Washington, DC, November 1972.

9. B. J. Garrick, W. C. Gekler, O. C. Baldonado, H. K. Elder and J. E. Shapley, A Risk Model for the Transport of Hazardous Materials. HN-204, Holmes and Narver, Inc., Los Angeles, CA, August 1969.

10. C. V. Hodge and 0. C. Baldonado, "Risk Analys is of Shipments in the Nuclear Power Industry." Proceedings of the 4 th International Symposium on Packaging and Transportation of Radioactive Materials, CONF-740901, September 22-27, 1974.

11. P. J. Pelto, W. L. Purcel1, MFAULT: A Computer Program For Analyzing Fault Trees. BNWL-2145, Battelle, Pacific Northwest Laboratories, Richland, WA, November 1977.

12. R. K. Clarke et al., Severities of Transport Accidents. SLA-74-0001, Sandia Laboratories, ATbuquerque, NM, JuTy 1976. 
13. U.S. Bureau of the Census, County and City Data Book, 1967, (A Statistical Abstract Supplement). U.S. Department of Commerce, Washington, DC, 1967.

14. U.S. Weather Bureau, Climatological Data Summaries. U.S. Department of Commerce National Climatic Center, Asheville, NC. 


\section{$4.0 \quad U_{6}$ SHIPPING REQUIREMENTS}

As discussed in Section 3, the $U_{6}$ risk assessment is based on a specific set of $U_{6}$ shipping requirements. In using such a shipping model, a year of interest is required as an input specification. The particular year considered in this study is 1985, or a year in which 100 one-thousand megawatt electric capacity reactors are expected to be operating in the U.S. This basis of 100 reactors was chosen to allow comparisons with relative risks involved in shipping plutonium dioxide and plutonium nitrate, which were determined in earlier studies. $(1,2,3)$

The materials to be shipped are natural and slightly enriched UF 6 . The enriched $U F_{6}$ transported in this shipping model is assumed to be enriched to $3.03 \%{ }^{235} \mathrm{U}$. (a) Although small quantities of $\mathrm{UF}_{6}$ enriched to $93 \%{ }^{235} \mathrm{U}$ will be transported in 1985, the amounts involved are projected to be insignificant compared to the amounts of natural and slightly enriched materials. The shipping regulations for these highly enriched materials also differ greatly from those used in this study. For these reasons, shipments of $93 \%$ enriched $U_{6}$ were not included in this study. A simple flow diagram for the interplant movement of $U_{6}$ is shown in Figure 4.1 .

\subsection{UF $\quad$ PRODUCTION PLANTS $^{-}$}

Uranium hexafluoride is produced from uranium ore concentrates at two production plants, located at Metropolis, Illinois, and Sequoyah, Oklahoma. The total amount of natural $U_{6}$ required to meet existing U.S. enrichment contracts in 1985 is about 46,000 metric tons (MT). (4) Two-thirds of this total $(30,820 \mathrm{MT})$ is assumed to be produced at domestic plants, and will be used to satisfy domestic fuel and stockpile requirements. The remaining amount $(15,180 \mathrm{MT})$ is assumed to be imported from foreign sources, enriched in the

(a) It is expected that two-thirds of the reactors in the reference year will be pressurized water reactors, requiring UF6 enriched to approximately $3.2 \%$ $235 \mathrm{U}$; one-third will be boiling water reactors, requiring $2.7 \%$ uranium enrichment. The enriched $U_{6}$ transported in this shipping model is thus assumed to be enriched to $3.03 \% 235 \mathrm{U}$. 
U.S. and returned to the country of origin. For the purposes of this study, foreign $\mathrm{UF}_{6}$ will not be used to satisfy domestic requirements.

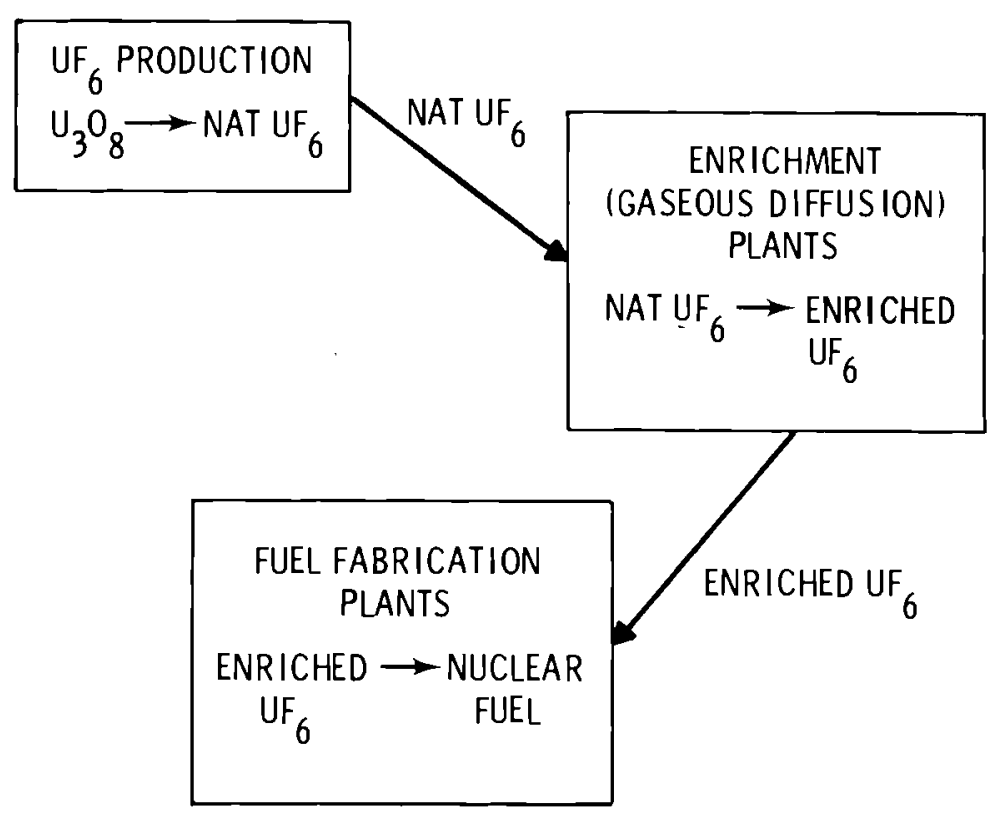

FIGURE 4.1. Simplified Flow Diagram for $\mathrm{UF}_{6}$

Although it is possible that some $U_{6}$ may be supplied by recycle from reprocessing plants in the future, current policies and events suggest this alternative to be unlikely by 1985 . Thus, recycled uranium was not included as a source of $\mathrm{UF}_{6}$ for this study.

\subsection{ENRICHMENT (GASEOUS DIFFUSION) PLANTS}

From the production plants, the $\mathrm{UF}_{6}$ is sent to an enrichment facility. There are currently three enrichment (gaseous diffusion) plants operating in the U.S. Each plant is capable of producing a different maximum enrichment of $\mathrm{UF}_{6}$ : the Paducah, Kentucky plant, a $0.96 \%$ enrichment product; Oak Ridge, Tennessee, $4 \%$ enriched $\mathrm{UF}_{6}$; and Portsmouth, Ohio, a maximum of $96 \%$ enriched material. It is assumed that the current allocation of $\mathrm{UF}_{6}$ between enrichment plants prevails in the reference year. The Paducah facility thus receives $20 \%$ of the natural $U_{6}$, while the other two plants receive equal portions of the remaining material. The $\mathrm{UF}_{6}$ is enriched to $0.96 \%{ }^{235} \mathrm{U}$ at the Paducah 
plant. Each of the other enrichment facilities receives half of this product and completes the enrichment to $3.03 \%$. Interplant shipments originating at the Paducah facility total 5,825 MT in the reference year. Some enriched $\mathrm{UF}_{6}$ also travels between 0ak Ridge and Portsmouth. (15) Shipments from Oak Ridge to Portsmouth total 1,340 MT.

The depleted UF 6 (tails) left over after the enrichment process is a potential resource if it is decided to manufacture mixed oxide fuels in the future. Projections for the 1980s, however, are for $100 \%$ storage of tails at the enrichment piants.

For the purposes of this study, it wi11 be assumed that $50 \%$ of the slightly enriched UF 6 (less than $5 \%{ }^{235} \mathrm{U}$ ) produced in the 1980 s will come from each of the plants at 0ak Ridge and Portsmouth. As mentioned earlier, the Portsmouth plant can enrich UF 6 to $93 \%$, but projections show that less than 20 MT of material of this type will be needed in the reference year. ${ }^{(6)}$ Since this is less than $0.3 \%$ of the total amount of $U_{6}$ produced, it will be neglected in this analysis.

\subsection{FUEL FABRICATION PLANTS}

Current fuel fabrication plants and their locations are shown in Table 4.1. Having announced no expansion plans, these facilities are assumed to be the same as those that will be operating in 1985. Of the estimated 7,460 MT of enriched $U_{6}$ produced in the reference year, $67 \%$, or some $5,000 \mathrm{MT}$, wil1 be distributed to these plants. The remaining 33\% (2,460 MT) wi11 be shipped to foreign users. The allocation of enriched UF 6 between fuel fabrication plants is based on approximate market shares as reflected in 1976 deliveries to these plants from enrichment facilities. (5)

\subsection{SHIPPING DISTANCES AND AMOUNTS}

Shipping distances between the various facilities are shown in Table 4.2. For this analysis, it was assumed that all foreign material enters and leaves the United States through the ports of Baltimore, Maryland and Norfolk, 
Virgina. All shipments of enriched $U_{6}$ currently leave from the east coast. Amounts shipped, based on industry characteristics presented above, are summarized in Table 4.3.

\section{TABLE 4.1. Fuel Fabrication Plants}

$\begin{array}{ll}\text { General Electric } & \text { Wilmington, NC } \\ \text { Babcock \& Wilcox } & \text { Apollo, PA } \\ \text { Exxon Nuclear Company } & \text { Richland, WA } \\ \text { Nuclear Fuel Services } & \text { Erwin, TN } \\ \text { Westinghouse } & \text { Columbia, SC } \\ \text { Combustion Engineering (a) } & \text { Hematite, MO }\end{array}$

(a) This plant is presently being used as a conversion facility to change $\mathrm{UF}_{6}$ to $\mathrm{UO}_{2}$. It is a major receiver, and for the purposes of this study will be considered a fabrication plant.

\section{$4.5 \mathrm{UF}_{6}$ SHIPPING MODEL}

This study represents a departure from the format used in earlier risk assessments. Previous studies $(1,2,3)$ analyzed the risk involved in shipping a11 material used in the reference year by one transportation mode. Results of a survey of current receivers of $\mathrm{UF}_{6}$ (Section 7) showed that certain transportation modes dominate certain portions of the system. For example, the survey showed that $100 \%$ of the $U_{6}$ received by fuel fabricators in the period 1971-1975 was shipped by truck. Other facilities, such as the enrichment plants, generaliy receive materials both by truck and rail, and occasionally by piggyback (truck trailer mounted on rail car). To further complicate matters, $U_{6}$ is shipped in a variety of containers (Appendix A). For enrichment 
levels below $1 \%$, bare 10 -ton ${ }^{(a)}$ and 14 -ton capacity cylinders are used. When the enrichment level exceeds $1 \%$ (but is less than $4.5 \%$ ) $21 / 2$-ton and 10 -ton-cylinders with protective overpacks must be used. When considering the four different types of packages and three modes of transportation, a total of 12 combinations are possible.

To accurately represent and yet reasonably evaluate the $\mathrm{UF}_{6}$ shipment system, some simplifying assumptions were made. Piggyback shipments were combined with rail shipments to reduce transportation modes to two. Assumptions on container types reduced the number of cylinder configurations to four: 1) 14-ton cylinders; 2) 10-ton cylinders without overpack; 3) 10-ton cylinders with overpacks; and 4) 2 1/2-ton cylinders with overpacks. A diagram of the modified shipping system is shown in Figure 4.2.

(a) A "10-ton" cylinder has a nominal capacity of 9.1 MT (20,000 1b) of UF 6 . However, because the designation of the container as a "10-ton" cylinder is common practice in the U.S. nuclear industry, this nomenclature has been used in this document. These remarks also apply to the "14-ton" (12.7 MT) and "2 1/2-ton" (2.3 MT) cylinders. 


\section{TABLE 4.2. Shipping Distances (km)}

To Enrichment Plants

From Paducah, KY Oak Ridge, TN Portsmouth, $\dot{O H}$

To Fuel Fabrication Plants

Production Plants

Metropolis, IL

Sequoyah, OK

Foreign Sources:

Bal timore-P. O.E.

Norfolk-Pे.0.E.

$\begin{array}{rlr}20 & 500 & 610 \\ 720 & 1080 & 1310 \\ & & \\ 1290 & 870 & 690 \\ 1170 & 730 & 630\end{array}$

Enrichment Plants

Paducah, KY

Oak Ridge, TN

Portsmouth, $\mathrm{OH}$

480

590
420

720

880

3840

230

460

780

870

730

$\begin{array}{llllll}850 & 480 & 3660 & 420 & 730 & 770\end{array}$

630

$\stackrel{+}{a}$

\section{TABLE 4.3. Estimated UF 6 Shipments (Metric Tons)}

To Enrichment Plants

Paducah, KY Oak Ridge, TN Portsmouth, OH Wilmington, NC Apollo, PA Richland, WA Erwin, TN Columbia, SC Hematite, MO $\overline{\text { Baltimore, MD US Norfolk, VA }}$

To Fuel Fabrication Plant
From

Production Plants

Metropolis, I

Sequoyah, OK

Foreign Sources:

Bal timore-P, 0.E.

Norfolk-P.0.E.

Enrichment Plants

Paducah, KY

Oak Ridge, TN

Portsmouth, $\mathrm{OH}$

$\begin{array}{lll}3600 & 7200 & 7200 \\ 2560 & 5130 & 5130 \\ & & \\ 1520 & 3040 & 3040 \\ 1520 & 3040 & 3040\end{array}$

2910
870

$$
2910
$$

170
170

170
170

100
100

$\begin{array}{ll}1000 & 170 \\ 1000 & 170\end{array}$

$\begin{array}{ll}610 & 610 \\ 610 & 610\end{array}$




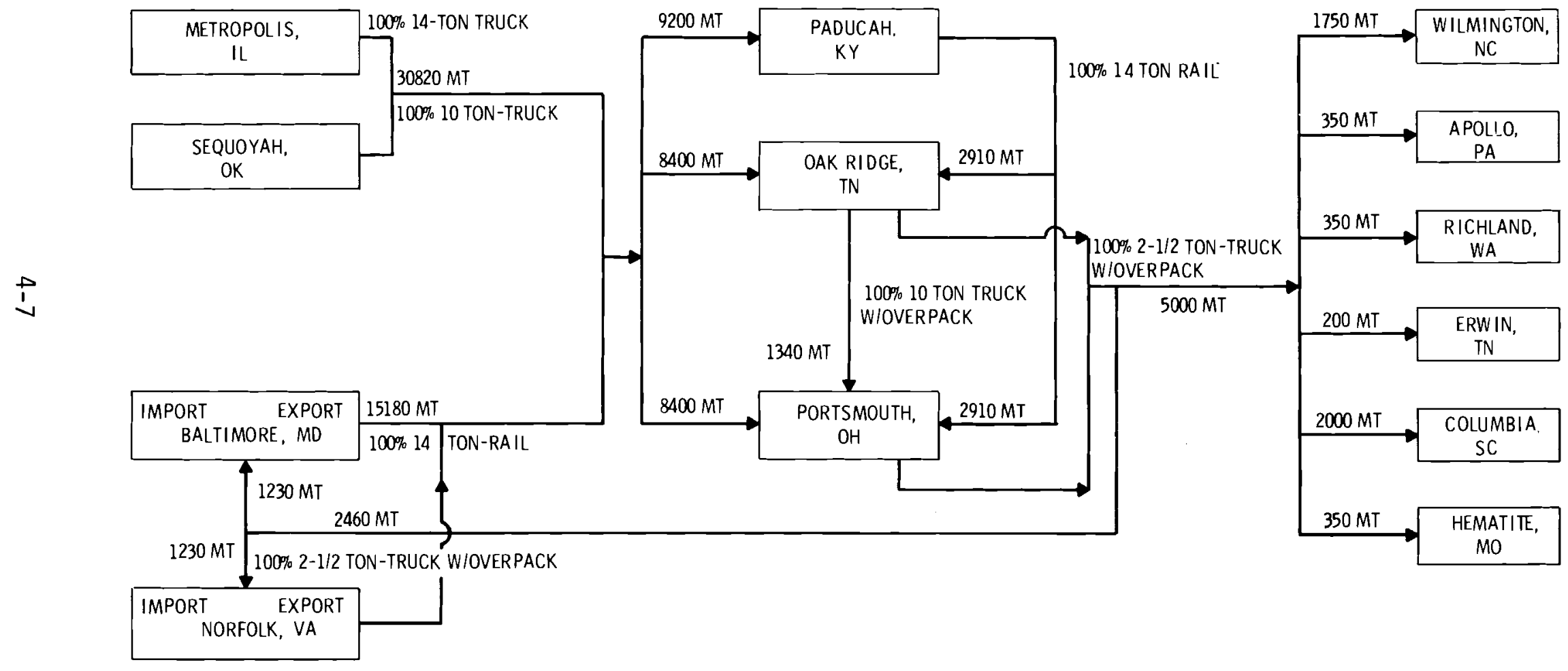

FIGURE 4.2. Simplified $U_{6}$ Shipping Model 


\section{REFERENCES}

1. T. I. McSweeny, R. J. Ha11 et al., An Assessment of the Risk of Transporting Plutonium Oxide and Liquid Plutonium Nitrate by Truck. BNWL-1846, Battelle, Pacific Northwest Laboratories, Richland, WA, September 1975.

2. R. J. Hall et a1., An Assessment of the Risk of Transporting Plutonium Dioxide and Liquid PTutonium Nitrate by Train. BNWL-1996, Battel7e, Pacific Northwest Laboratories, Richland, WA, February 1976.

3. J. F. Johnson and T. I. McSweeney, An Assessment of the Risk of Transporting Plutonium Dioxide by Cargo Aircraft. BNWL-2030, Battelle, Pacific Northwest Laboratories, Richland, WA, June 1977.

4. Nuclear Fuel. p. 11, December 12, 1977.

5. W. Jimison, National Energy Transportation. Volume 1 - Current Systems and Movements, Congressional Research Service Publication, No. 95-15, May 1977.

6. J. 0. Blomeke, C.W. Kee, and R. Salmon, "Shipments in the Nuclear Fuel Cycle Projected to the Year 2000." Nuclear News: p. 62, June 1975. 


\subsection{TRANSPORTATION ACCIDENT ENVIRONMENT}

Shipping container failure during an accident occurs when the forces generated in the accident exceed the mechanical strength of the container. Since this risk assessment is concerned with the shipment of $U_{6}$ via two modes, truck and rail, this section discusses the forces or stresses which may be generated in both truck and rail accident environments. Section 6 discusses the mechanical strength of the various UF $_{6}$ containers. The use of results from Sections 5 and 6 to estimate the likelihood of container failure in an accident is demonstrated in Section 9.

\subsection{TRUCK ACCIDENT ENVIRONMENT}

For the purpose of this analysis, the stresses present in a truck accident have been divided into three categories: fire, impact and puncture. other stresses, such as crush and immersion, contributed insignificantly to the likelihood of $U_{6}$ cylinder failures and were not included. The three significant accident stresses are discussed below.

Fire

Fire accident environment data used in this study were developed by Sandia Laboratories from accident reports compiled by the Bureau of Motor Carrier Safety. These data were also used in a Monte Carlo program to model the probability distribution of fire durations.

Based on the Sandia compilation of the truck accident environment, fire can be expected to occur in $1.6 \%$ of a 11 truck accidents. The mean temperature of the fire is $1000^{\circ} \mathrm{C}\left(1840^{\circ} \mathrm{F}\right)$ and the duration of the fire can range from a few minutes to several hours. The expected duration of fires for nonflammable cargos is shown in Figure 5.1 .

Because of the fire pool sizes and the general nature of the truck accidents used in the Sandia analysis, it was conservatively assumed that in a 11 truck accident fires, the cargo was at least partially exposed to the fire. 


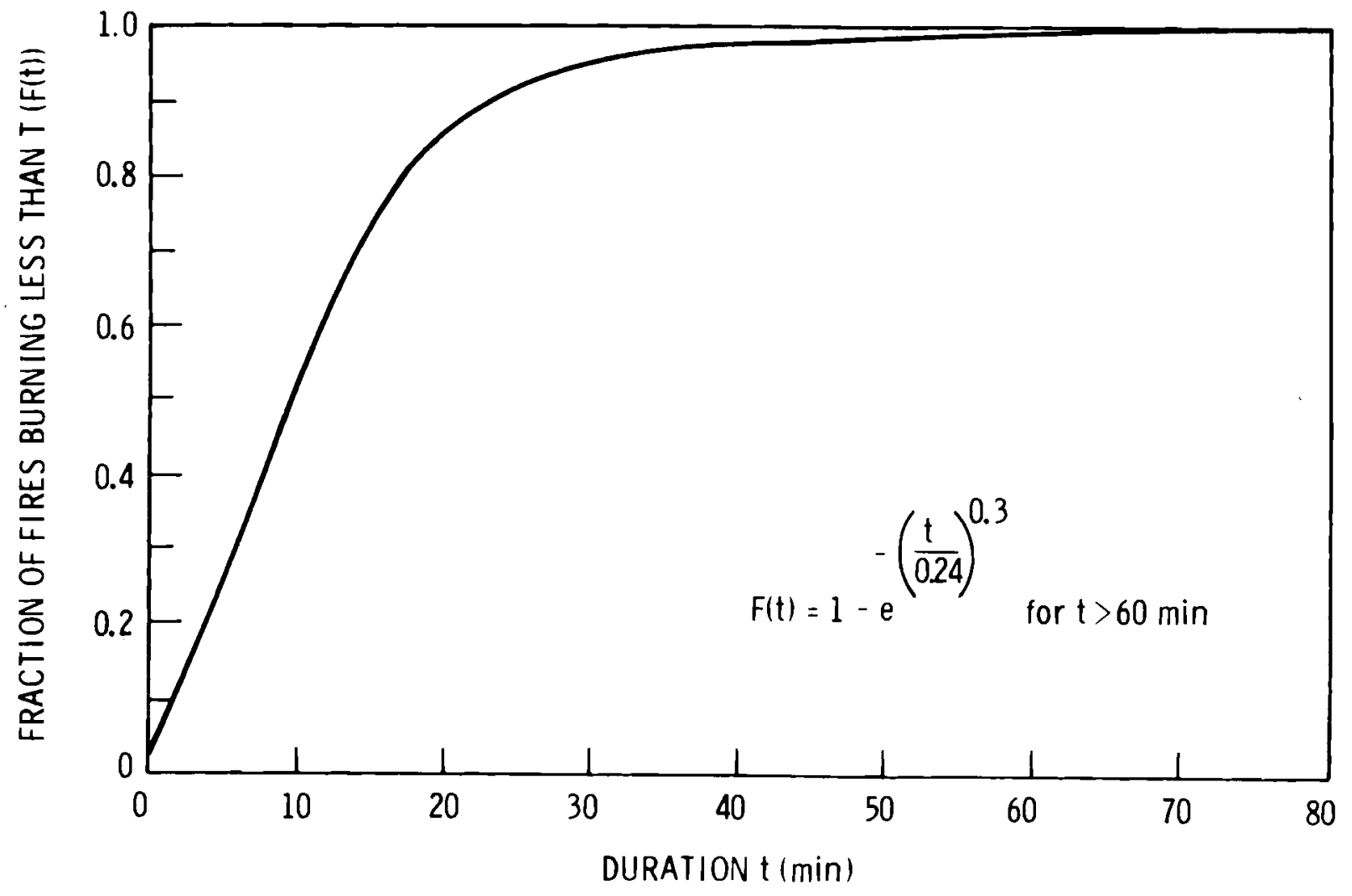

FIGURE 5.1. Cumulative Distribution of Fire-Accident Duration for Truck Transport of Nonflammable Cargo (from Reference 1)

Impact

The impact environment for an accident involving a truck carrying a large container is taken from information developed at Sandia Laboratories. The statistical information provided by Sandia was developed from Bureau of Motor Carrier Safety (BMCS) data. The BMCS data were used by Sandia Laboratories in a Monte Carlo computer simulation to estimate the impact environment experienced by a large truck in an accident. The results of this analysis for a truck with a gross weight of $32,000 \mathrm{~kg}(70,000 \mathrm{lbs})$ are presented in Figure 5.2, which shows the magnitude of the velocity change versus the expected frequency of occurrence of that velocity change in an accident. 


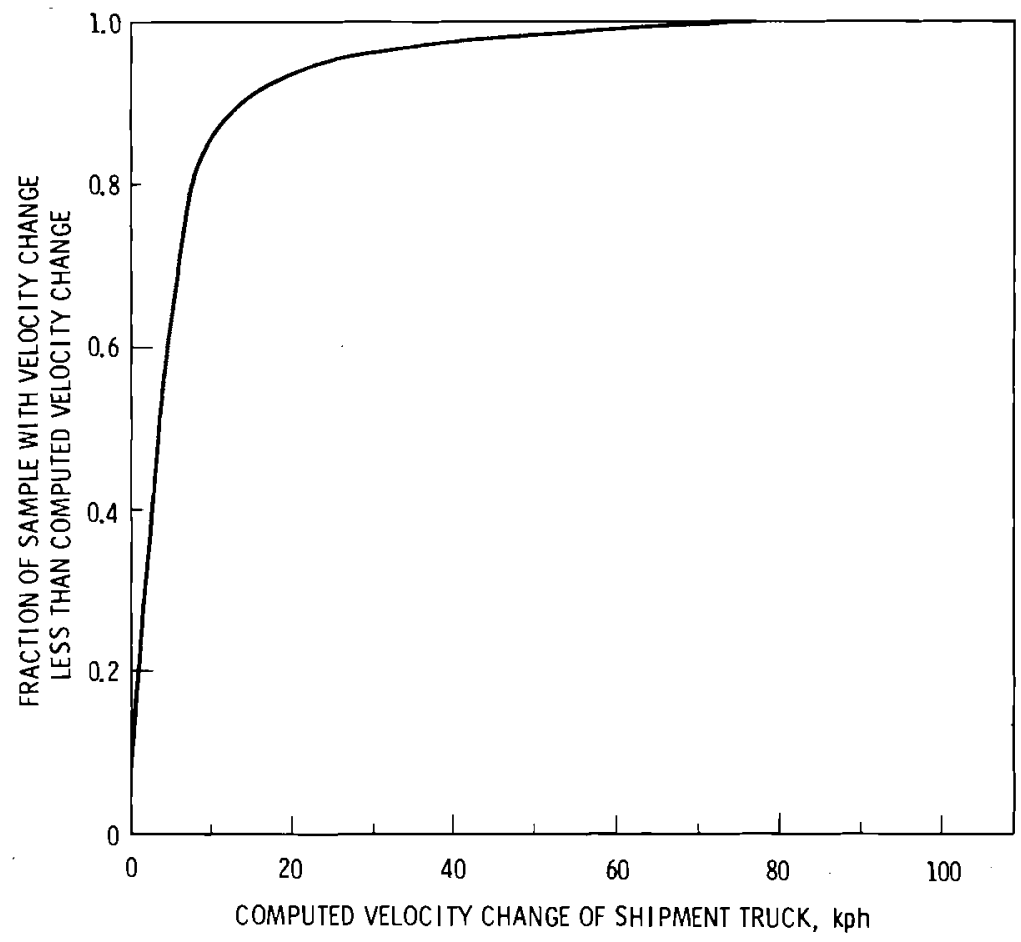

FIGURE 5.2. The Expected Maximum Velocity Change Given a Shipment Truck Subjected to a Random Accident Sample (From Reference 1)

\section{Puncture}

A general description of the puncture environment present in accidents involving large truck-mounted containers is not available. However, the Office of Hazardous Materials (OHM) of the U.S. Department of Transportation (DOT) collects data on releases of hazardous materials during transportation. An incident report is required to be made by all carriers of hazardous mater.ials in interstate commerce whenever a release occurs from the package or transport vehicle. The reported release does not have to be the result of a transportation accident. Unfortunately, insufficient data are available on $\mathrm{UF}_{6}$ cylinder (or other similar container) failures in accidents to accurately describe the puncture environment.

To obtain an understanding of the puncture environment, it was necessary to modify material used in a previous risk assessment on the shipment of 
gasoline. (2) In that study, DOT-OHM figures for gasoline tank failures were used to describe the puncture environment in gasoline truck accidents. Compared to $\mathrm{UF}_{6}$ containers, gasoline tankers are relatively fragile; therefore, it was necessary to modify the gasoline puncture rates. By taking into account the difference in energy needed to puncture these two different containers, an estimate of the puncture frequency of $1.35 \times 10^{-4}$ per accident was derived.

\subsection{TRAIN ACCIDENT ENVIRONMENT}

As in the truck accident environment, only three categories of accident stresses were considered in the train accident environment: fire, impact and puncture. Other stresses were not considered because of their insignificant contributions to the likelihood of a UF 6 container failure.

Fire

Data from Sandia's accident environment study (1) indicate that approximately $1 \%$ of the collision and derailment accidents involving trains resulted in fire. Sandia further determined that the average fire temperature is approximate $1 y 1000^{\circ} \mathrm{C}\left(1840^{\circ} \mathrm{F}\right)$. Fire durations shown in Figure 5.3 range from minutes to hours.

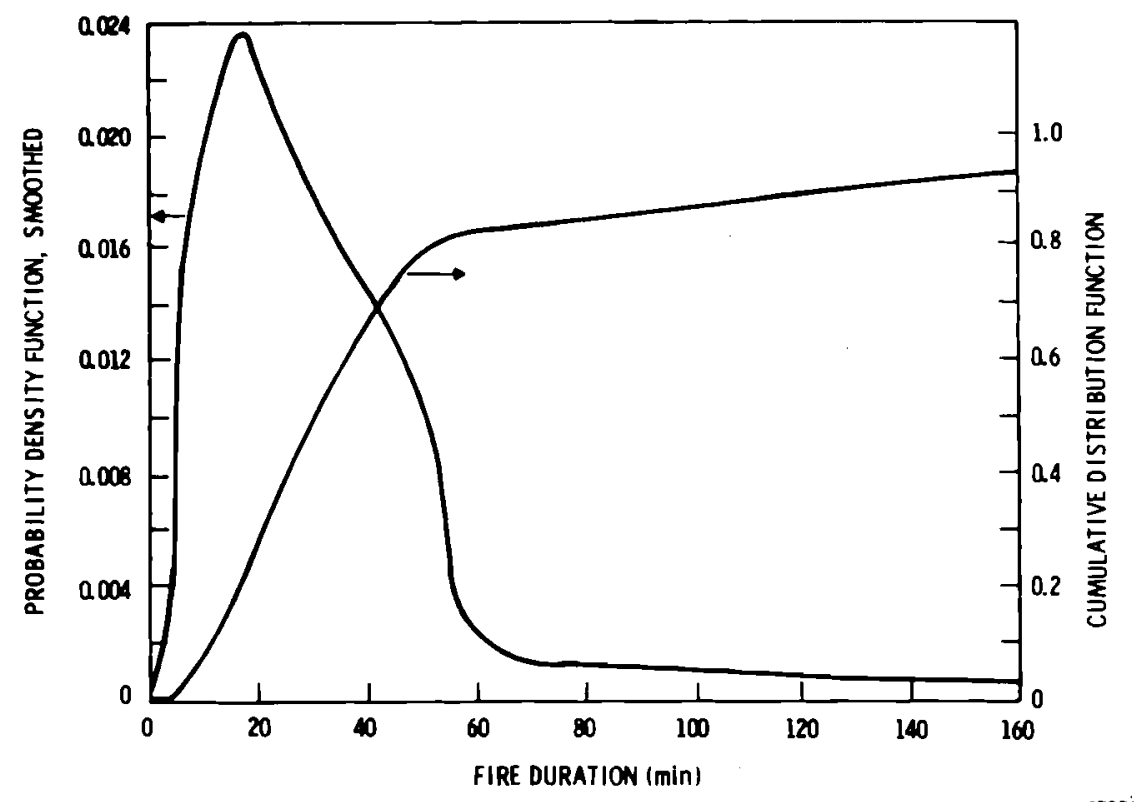

FIGURE 5.3. Duration Probability of Train-Fire Accidents Involving Large Packages (From Reference 1) 
The data shown in Figure 5.3 do not attempt to address the question of how frequently a container will be exposed to these fires (as is required for a risk analysis). If the fire source is primarily locomotive fuel, a boxcar near the end of the train obviously has a low probability of being threatened; if the commodities within the boxcar are on fire, the exposure probability is much greater.

Using the sample train described in the Sandia analysis and presented in Table 5.1, (1) and assuming: 1) a random distribution of cars in the train except for locomotives and caboose, and 2) that a car carrying UF 6 cylinders is threatened by fire only if one of the cars adjacent to it is a loaded tank car or locomotive, it was determined that the $\mathrm{UF}_{6}$-carrying car would be exposed to a fire in $14 \%$ of all accidents involving fire. This means that a fire will occur in train accidents at a rate of approximately $1.74 \times 10^{-8}$ per car km.

TABLE 5.1. Definition of Typical Freight Train as Used in This Study

\begin{tabular}{|c|c|c|c|}
\hline Type of Car & $\begin{array}{l}\text { Number } \\
\text { Fu11 }\end{array}$ & Other & $\begin{array}{l}\text { Number } \\
\text { Empty }\end{array}$ \\
\hline Locomotive & & 3 & \\
\hline Plain Boxcar & 7 & & 6 \\
\hline Equipped Boxcar & 4 & & 3 \\
\hline Gondola & 4 & & 3 \\
\hline Open Hopper & 8 & & 6 \\
\hline Covered Hopper & 4 & & 3 \\
\hline Flat Car & 3 & & 2 \\
\hline Refrigerator Car & 2 & & 2 \\
\hline Tank Car & 4 & & 3 \\
\hline Other Car & 1 & & 1 \\
\hline Caboose & & 1 & \\
\hline
\end{tabular}


Impact

A description of the impact environment for accidents involving large railcar-mounted shipping containers was derived from information supplied by Sandia. (1) As was done in the case for truck impact, existing accident data were analyzed and a cumulative distribution for the expected severity of impact forces in rail accidents determined. Such a distribution is shown in Figure 5.4. In this case, the severity of the impact forces is expressed as a net velocity change.

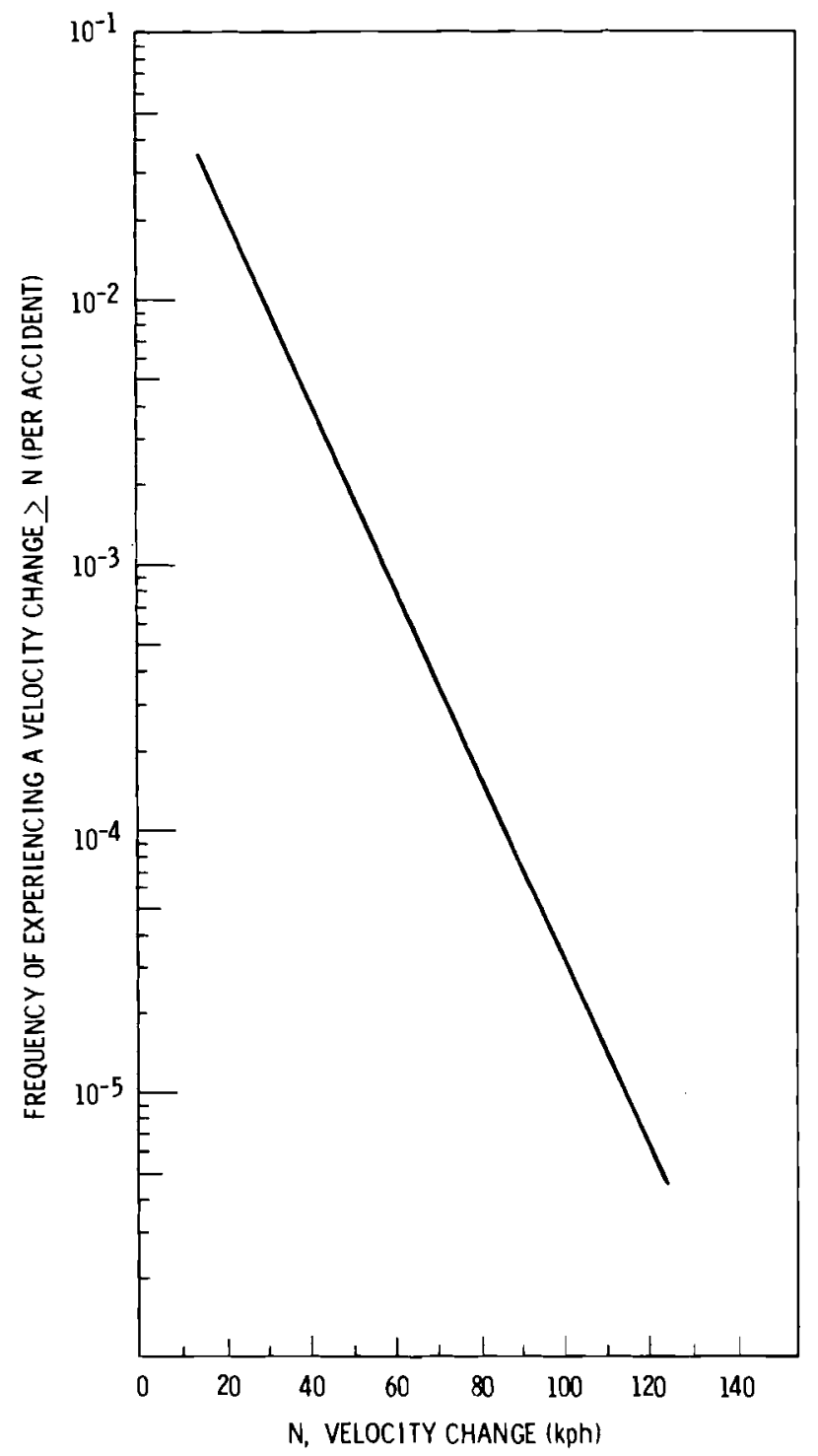

FIGURE 5.4. Cumulative Distribution for the Expected Severity of Impact Forces in Rail Accidents 


\section{Puncture}

A description of the puncture environment associated with large railcarmounted containers was obtained from information developed by Sandia. (1) Existing accident data on tank car punctures were used to estimate the expected frequency of a puncture situation, given a train accident. These estimates represent conservative judgments of puncture probabilities for the railmounted $\mathrm{UF}_{6}$ cylinders. Estimated probabilities of puncture are $6.4 \times 10^{-4}$ per train accident, or $7.1 \times 10^{-4}$ per collision or derailment accident. 


\section{REFERENCES}

1. A. W. Dennis, J. T. Foley, W. F. Hartman and D. W. Larson, Severities of Transportation Accidents Involving Large Packages. SAND 77-0001, Sandia Laboratories, Albuquerque, NM, May 1978.

2. R. E. Rhoads and J. F. Johnson, Risks in Transporting Materials for Various Energy Industries. BNWL-SA-6547, prepared for publication in Nuclear Safety, 19(2), Battelle, Pacific Northwest Laboratories, Richland, WA, March 1978. 


\subsection{PACKAGE FAILURE THRESHOLDS}

The previous section described the environment imposed on containers during truck and rail accidents. Estimates of failure thresholds for $\mathrm{UF}_{6}$ shipping containers are presented in this section. The concept of a failure threshold (a point below which all "identical" packages will survive and above which they will all fail) is a simplification of this application of the risk model since mechanical failure points of containers are distributed in stress level. There is a most probable level that will result in failure, but in any group of "identical" containers there are some that will fail above or below this most probable value. It is felt that the simplifications in this section are consistent with the detail in the knowledge of the accident environment and that the analysis gives a reasonable estimate of the risk of package failure in an accident. The results of this section must be used in conjunction with other information on the stresses to which the package may be exposed in order to assess whether or not the package will fail in the accident environment. These assessments are made in Sections 9 and 11.

The package failure threshold estimates presented here were obtained using mathematical analysis, the results of tests which have been conducted on the containers, and engineering estimates. Only thresholds relating to the accident environment and posing a threat to the cylinder (fire, impact, puncture) were evaluated. : :here assumptions were required to carry out the analysis, conservative assumptions were made.

Fire failure threshold estimates were determined using the results of tests conducted at 0ak Ridge, $\mathrm{TN}^{(1)}$ and a simplified heat transfer model. The fire tests were carried to failure; results were scaled to determine estimates of failure times for various sized cylinders.

Impact failure threshold estimates were derived from the results of full-scale experiments on 10-ton cylinders conducted at Paducah, KY. $(2,3)$ Failure thresholds for cylinders with overpacks were estimated using mathematical models and data from tests conducted at 0ak Ridge. ${ }^{(4)}$ The impact analysis was limited to cases of side drop or loading (i.e., the axis of the 
package perpendicular to the direction of the applied load). Side loading was assumed to be the predominant orientation in an accident environment.

Puncture failure thresholds were estimated through the use of data obtained from the tests conducted at Paducah. ${ }^{(2,3)}$ Puncture failure of overpacks and cylinders was estimated using the results of prototype overpack tests. $(4,5)$

Details of these analyses are presented in Appendix C. Failure threshold estimates are summarized in Table 6.1.

$\underline{T A B L E \text { 6.1. }}$ Summary of $U_{6}$ Cylinder Failure Thresholds

\begin{tabular}{|c|c|c|c|c|c|}
\hline \multicolumn{2}{|c|}{$\begin{array}{l}\text { Fire } \\
\text { (time to failure } \\
\text { in } 800^{\circ} \mathrm{C} \text { fire) }\end{array}$} & \multicolumn{2}{|c|}{$\begin{array}{c}\text { Impact } \\
\text { (drop height onto } \\
\text { unyielding surface) }\end{array}$} & \multicolumn{2}{|c|}{$\begin{array}{c}\text { Puncture } \\
\text { (drop height onto } 15-\mathrm{cm} \\
\text { diameter puncture piston) }\end{array}$} \\
\hline $\begin{array}{l}\text { Without } \\
\text { Overpack }\end{array}$ & $\begin{array}{c}\text { With } \\
\text { Overpack }\end{array}$ & $\begin{array}{l}\text { Wi thout } \\
\text { Overpack }\end{array}$ & $\begin{array}{c}\text { With } \\
\text { Overpack }\end{array}$ & $\begin{array}{l}\text { Wi thout } \\
\text { Overpack }\end{array}$ & $\begin{array}{c}\text { With } \\
\text { Overpack }\end{array}$ \\
\hline $29 \mathrm{~min}$. & $83 \mathrm{~min}$. & $9 \mathrm{~m}$ & $22.5 \mathrm{~m}$ & $3.2 \mathrm{~m}$ & $4.2 \mathrm{~m}$ \\
\hline $46 \mathrm{~min}$. & $156 \mathrm{~min}$. & $9 \mathrm{~m}$ & $12.4 \mathrm{~m}$ & $1.0 \mathrm{~m}$ & $1.6 \mathrm{~m}$ \\
\hline 48 min. &.- & $9 \mathrm{~m}$ & -- & $80 \mathrm{~cm}$ & -- \\
\hline
\end{tabular}




\section{REFERENCES}

1. A. J. Mallet, ORDGP Container Test and Development Program Fire Tests of UF Filled Cylinders. K-D-1894, Union Carbide Corporation, Nuclear Division, Oak Ridge, TN, January 1966.

2. W. R. Pedigo et a1., Testing of Ten-Ton Uranium Hexafluoride Cylinders. KY-500, Union Carbide Corporation, Nuclear Division, Paducah, KY, October 1965.

3. E. W. Richardson and S. Bernstein, Additional Testing of Ten-Ton Uranium Hexafluoride Cylinders. KY-631, Union Carbide Corporation, Nuclear Division, Paducah, KY, September 1971.

4. A. J. Mallett and C. E. Newlon, Protective Shipping Packages for 30-InchDiameter UF 6 Cylinders. K-1686, Union Carbide Corporation, Nuclear Division Oak Ridge, TN, April 1967.

5. L. J. Hansen, "The Paducah Tiger: A Type B Overpack for Ten-Ton Uranium Hexafluoride Shipments." Proceedings of the 4th International Symposium on Packaging and Transportation of Radioactive Materials, CONF-740901, September 1974. 


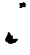

-

$-$

- 


\subsection{CONDITIONS OF CONTAINERS DURING TRANSPORT}

To adequately analyze the response of a $\mathrm{UF}_{6}$ cylinder to an accident situation, it was necessary to determine the general package condition during normal transport. To obtain a data bank of container conditions during normal transport for use in the risk analysis, a survey was conducted of facilities which routinely receive $\mathrm{UF}_{6}$. This section presents the results of that survey.

\subsection{SCOPE OF SURVEY}

The initial step in developing the survey was to determine its contents: the areas to be covered and the container types to be evaluated. Determination of the package condition information required was carried out simultaneously with development of the release sequence evaluation fault trees (Section 8). It was determined to evaluate the package condition of the four containers considered in this study: the model 30(A\&B) - 21/2-ton cylinder with overpack; the $48 \mathrm{X}$ - 10-ton cylinder with overpack; the $48 \mathrm{X}$ cylinder without overpack; and the 48Y - 14-ton cylinder without overpack. Each of the cylinders was examined in detail to determine packaging conditions which would contribute to a material release. A list of these conditions was developed into the survey questionnaire.

In an attempt to determine the relative use of different $\mathrm{UF}_{6}$ shipment modes, a short section on type of transport used was added to the questionnaire.

Since this study considered all of the expected major receivers of $\mathrm{UF}_{6}$ (see Section 5), these facilities were asked to participate in the survey. A list of the participants include:

Westinghouse Electric Corporation Columbia, SC

EXXON Nuclear Corporation Richland, WA
General Electric Company Wilmington, NC

Babcock and Wilcox Apollo, PA 
Kerr-McGee Nuclear Corporation Oklahoma City, OK

Nuclear Fuel Services, Inc.

Erwin, TN

Combustion Engineering, Inc.

Hematite, MO
Union Carbide Corporation

Paducah, KY

Union Carbide Corporation

Oak Ridge, TN

Goodyear Atomic Corp.

Portsmouth, $\mathrm{OH}$

The survey was designed to cover the period from 1971 to 1975. However, since many replies to specific questions were made using best recollections, information received in the survey could easily be from outside of this time period.

\subsection{RESULTS OF SURVEY}

A copy of the questionnaire with overall results of the survey is shown in Table 7.1 .

Even though the information obtained in the survey provides a reasonably good base for the risk assessment model, certain limitations should be recognized. First, as previously mentioned, many of the observations were made from personnel recollections and, as such, the time period of all of the observations is not certain. Second, in the years since 1971, quality assurance (QA) and quality control (QC) requirements have been strengthened, resulting in a significant reduction in packaging errors. Because of these factors, the results presented in Table 7.1 are considered to be conservative and not necessarily representative of current packaging conditions during transport. 


\section{TABLE 7.1. Data Bank-Package Closure Experience Obtained by Survey (For Period 1977-1975)(a)}

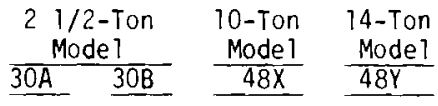

A. PACKAGES RECEIVED

1975

1974

1973

1972

1971

TOTAL

B. GENERAL CONDITION OF SHIPMENT (1971-1975)

1. Do you formally examine and record the condition of received cylinders?

2. Is the H/U ratio veridied upon receipt?

3. Number of times H/U ratio exceeded specified limits.

4. Number of times enrichment exceeded specified limits.

5. Number of cylinders received overfilled.

6. itumber of cylinders received overpressurized

7. Ilumber received with contamination $\left(U_{6} F_{6}\right.$, $\mathrm{UO}_{2} \mathrm{~F}_{2}$, etc.) outside cylinder.

C. CYLIHDER CORDITION (1971-1975)

1. Rumber of cylinders removed from service due to deterioration.

2. Number of cylinders with badly corroded shells

3. Number of cylinders received without required protective valve cover.

4. Number of cylinders received with welds damaged (example, vessel freshly dented in area of weld resulting in possible partial weld failure, etc.).

D. VALVE CONOITION (1971-1975)

1. Number of cylinders requiring valve replacement.

2. Number of cylinders with valve and/or vessel threads partially stripped.

3. Number of cylinders with valve crossthreaded

4. Number of cylinders with valve not completely closed.

5. Number of cylinders with valve loose or insufficient threads engaged.

6. Number of cylinders received with valve damaged (example, valve bent and fresh metal exposed at coupling, etc.)

$\begin{array}{rrrr}431 & 526 & 1104 & 1967 \\ 579 & 691 & 825 & 1447 \\ 461 & 688 & 1032 & 1029 \\ 324 & 750 & 1383 & 1205 \\ 695 & 517 & 2644 & 663 \\ 2540 & 3172 & 69344 & 6311\end{array}$

Yes 8,1 . No Ans. No $=1$

Yes $=22=$ No Ans. No $=6$ (Inspect but do not record)

$\begin{array}{rrrr}0 & 0 & 0 & 0 \\ 0 & 1 & 0 & 0 \\ 0 & 0 & 0 & 0 \\ 1 & 0 & 20 & 56 \\ 0 & 0 & 0 & 0\end{array}$

$\begin{array}{llll}1 & 2 & 0 & 0 \\ 0 & 0 & 0 & 0 \\ 0 & 0 & 0 & 0 \\ 7 & 0 & 1 & 0\end{array}$

$\begin{array}{cccc}13 & 28 & 60 & 86 \\ 0 & 5 & 0 & 0 \\ 0 & 7 & 0 & 0 \\ 0 & 0 & 0 & 0 \\ 0 & 0 & 7 & 19 \\ & & & 5\end{array}$


E. PLUG CONDITION (1971-1975)

1. Number of cylinders requiring plug replacement.

2. Number of cylinders with plug loose or with insufficient threads engaged.

3. Number of vessels with plug and or vessel threads partially stripped.

4. Number of vessels with plug crossthreaded

5. Number of cylinders received with plug damaged from rough treatment during handling or shipping (example, plug bent and fresh metal exposed at coupling, etc.).

$\begin{array}{llll}0 & 0 & 0 & 0 \\ 0 & 0 & 0 & 0 \\ 0 & 0 & 0 & 0 \\ 0 & 0 & 0 & 0\end{array}$

$\begin{array}{llll}0 & 0 & 0 & 0\end{array}$

F. OVERPACK CONDITIONS (1971-1975)

1. Number of cylinders received in overpack.

$\begin{array}{rrrr}2480 & 3164 & 878 & 0 \\ 0 & 0 & 0 & 0 \\ 0 & 0 & 0 & 0 \\ 0 & 0 & 0 & 0 \\ 3 & 1 & 0 & 0 \\ \sim 40 & \sim 40 & 0 & 0 \\ & & & \\ 0 & 0 & 0 & 0 \\ \sim 20 & \sim 16 & 0 & 0\end{array}$

2. Number of cylinder's received without overpack when required.

3. Number of cylinders received with gross damage to overpack.

4. Number of cylinders received without sealing gasket in overpack

5. Number received with deteriorated gasket.

6. Number received with closure bolts loose.

7. Number with missing closure bolts:

a. all closure bolts missing

b. some closure bolts missing

8. Number received with damaged overpack mating surface.

$\begin{array}{llll}7 & 5 & 0 & 0\end{array}$

\section{G. TRANSPORTATION MODE}

Approximate Percentage of Cylinders Received By:
1. Rail
2. Truck
3. Piggyback (Truck on Rail car)
4. Other (please specify)

TOTAL

\begin{tabular}{rrrr}
0 & 3 & 12 & 14 \\
88 & 97 & 88 & 62 \\
12 & 0 & 0 & 24 \\
0 & 0 & $\underline{0}$ & $-\underline{0}$ \\
\hline$-100 \%$ & $100 \%$ & $100 \%$ & $100 \%$
\end{tabular}

H. DO FUTURE PLANS (NEXT 10 YEARS) INCLUDE FACILITIES TO HANDLE 10-AND/OR 14-TON UF 6 CYLINDERS IF SUCH FACILITIES DO NOT CURRENTLY EXIST?

TaT If accurate numbers are not available, approximate values or estimates based on best recollections can be used and are requested.

COMMENTS 


\subsection{RELEASE SEQUENCE IDENT IFICATION}

Very few transportation accidents involving large containers filled with $\mathrm{UF}_{6}$ have occurred in the past. Therefore, possible ways that releases could occur (release sequences) must be identified by a reasoning process. The information presented in Sections 5.0, 6.0 and 7.0 gives a basis for identifying events or combinations of events which could result in the release of $\mathrm{UF}_{6}$.

This section describes a formalized procedure for identifying combinations of conditions which could result in a release. The first step in the procedure is to develop fault trees using the techniques described in Section 8.1. Section 8.2 presents the fault trees developed for truck and train shipment of $\mathrm{UF}_{6}$ in large containers. The second step in the procedure is to develop a list of release sequences from the fault tree. The development of these release sequences will be discussed in Section 8.3.

\subsection{FAULT TREE CONSTRUCTION}

The fault tree analysis technique was developed in the 1960s in the aerospace industry to identify equipment design deficiencies before actual space flight. The procedure assumes a failure and works backwards to identify basic component failures which could cause or contribute to that failure. These failure sequences are also called cut sets. The fault tree should be related to individual components for which failure data are available. For instance, in an electronic circuit the basic failure might occur in a resistor. However, fault trees are seldom developed to that degree of detail, but rather are constructed in terms of basic system modules. Using the electronic example, one would trace the possible failure only to the amplifier which contained the resistor. Such a fault tree is called a Top Level Fault Tree since it usually identifies only large systems which could result in a failure. Table 8.1 gives the various fault tree symbols and their meanings.

The methodology applied to transportation of $\mathrm{UF}_{6}$ involves the postulation of a release of $\mathrm{UF}_{6}$ during transport and the examination of the series of events which must have occurred to cause the release. Quantification of 


\section{TABLE 8.1. Fault Tree Symbolism}

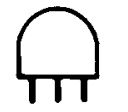

output

"AND" logic gate. The simultaneous occurrence of inputs is required to cause an output.

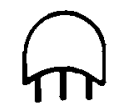

output

"OR" logic gate

The occurrence of any one of the inputs will result in an output.

inputs

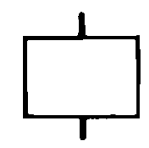

Fault event that results from the logical operation of two or more fault events. It is always the output from a logic gate.

Basic fault event. It requires no further development. Data regarding frequency and mode of failure can be derived empirically.

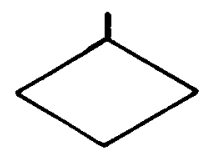

Inferred fault event. Any failure except a primary failure which is not developed further due to lack of information, time or money or due to the low probability of occurrence. It can also be used where other analyses give sufficient information to indicate that further analysis would be redundant.

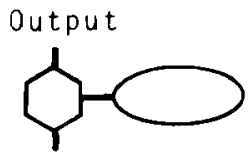

"Inhibit" gate. The condition specified in the oval is required for an input fault event to result in an output event. This condition is frequently a design limit which will not transmit a failure until the design limits have been exceeded.

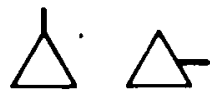

Transfer symbol denoting that failure also impacts on other branches of fault tree. A line at the apex of the triangle represents a "transfer in." A line in the side represents a "transfer out." A number is placed in the triangle to identify transfer locations.

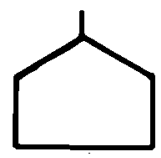

"House" defines an event that must occur, or is expected to occur, due to design and normal operating conditions. 
the release requires specifications of an ordered sequence of events or accident scenarios. The fault tree is used as the basis for estimating the total release probability. The tree is then broken down into all the possible release sequences, to obtain essentially all the accident scenarios. When properly applied, the accident scenarios obtained from using the fault tree methodology are likely to be more complete than an alternative method of trying to list all the accident scenarios without the aid of any formalized reasoning process.

\subsection{FAULT TREES FOR SHIPMENT OF UF 6}

The system studied in this risk assessment involves four shipping packages (30B-cylinders with overpack, 48X-cylinders, 48X-cylinders with overpack, 48Y-cylinders) and two transportation modes, truck and rail. It would therefore seem obvious to develop eight fault trees to determine all possible release sequences. In an effort to reduce the number of fault trees required for the analysis, fault trees which were not dependent on the mode of transportation were developed. Furthermore, it was found that the cylinders were all basically similar except for size. Therefore, only two fault trees were needed: one for cylinders shipped with protective packages and one for cylinders without.

Fault Tree for Cylinder Without Overpack

The fault trees for $\mathrm{UF}_{6}$ shipments in cylinders without protective overpacks were developed for normal truck and rail transport on primary highways and railways in the United States. The effects of sabotage or natural disasters were not included in this analysis. The analysis considers the combined effects of the accident environment and packaging condition. Based on these criteria, the fault tree shown in Figure 8.1 was developed to determine applicable failure sequences for the bare cylinders. A list of identified events or failure elements which could contribute to a release are shown in Table 8.2. 


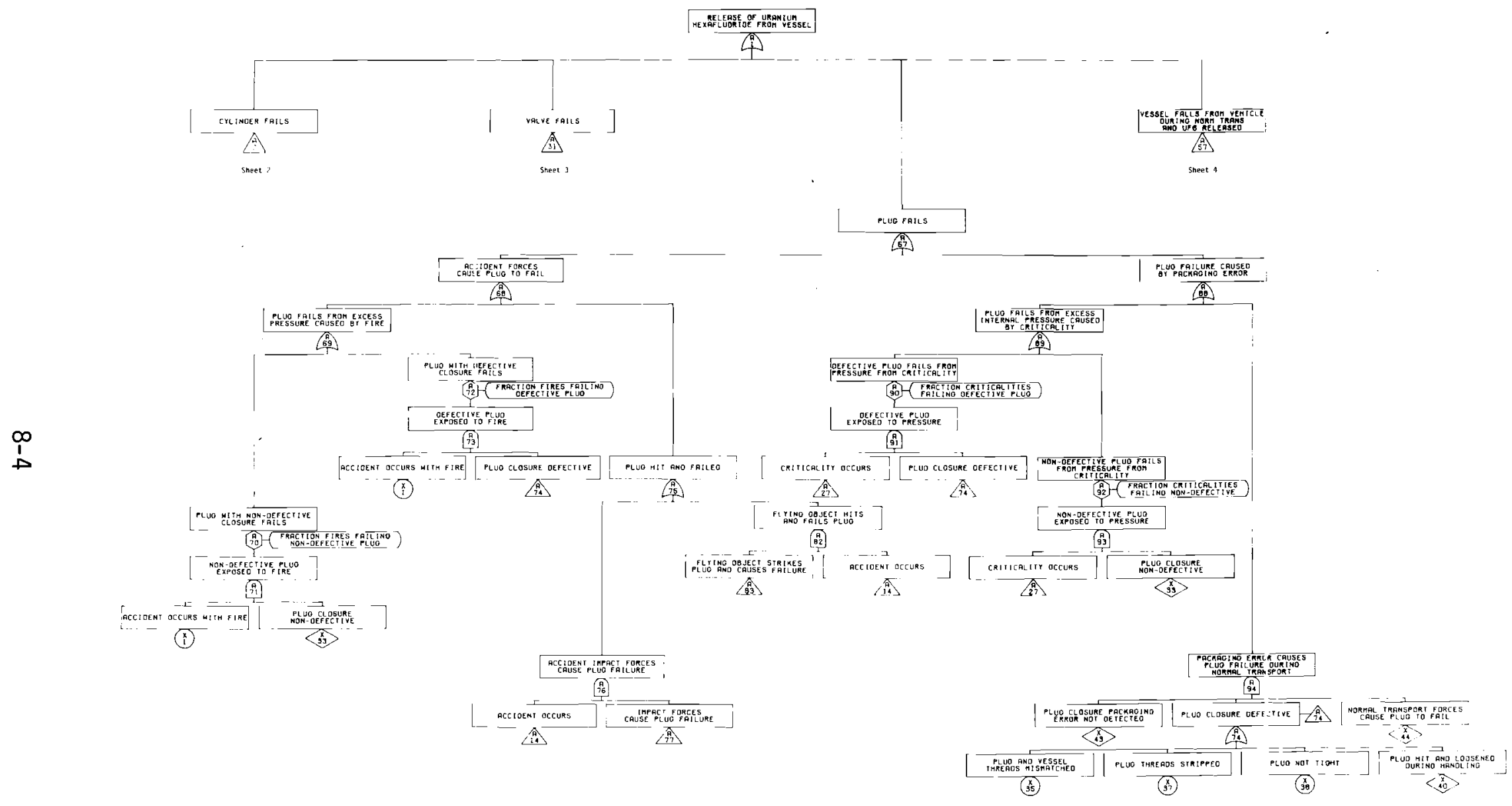

FIGURE 8.1. UF 6 Fault Tree for Cylinders Transported Without Overpack 


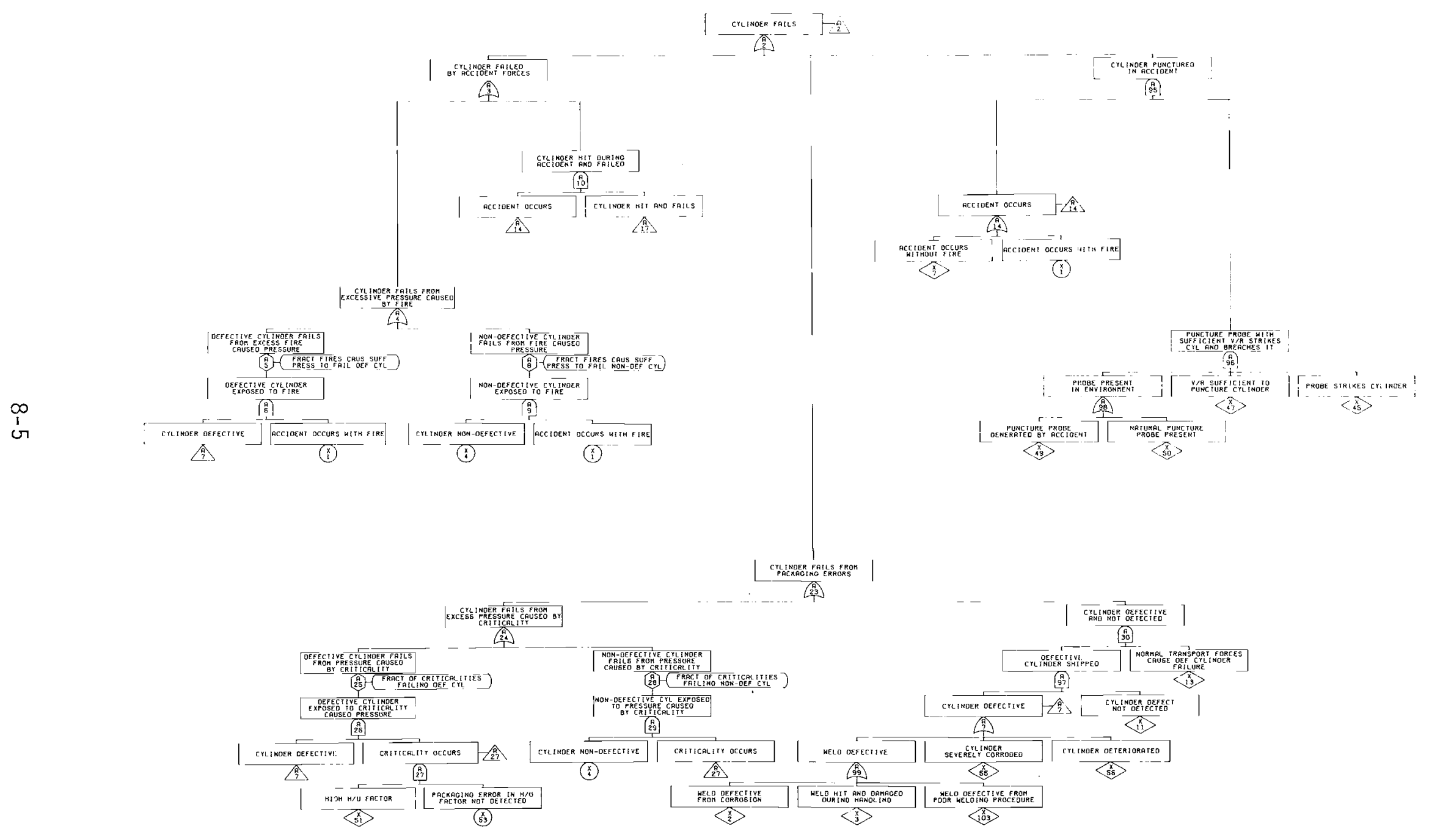

FIGURE 8.1, Page 2. (Cont'd) 


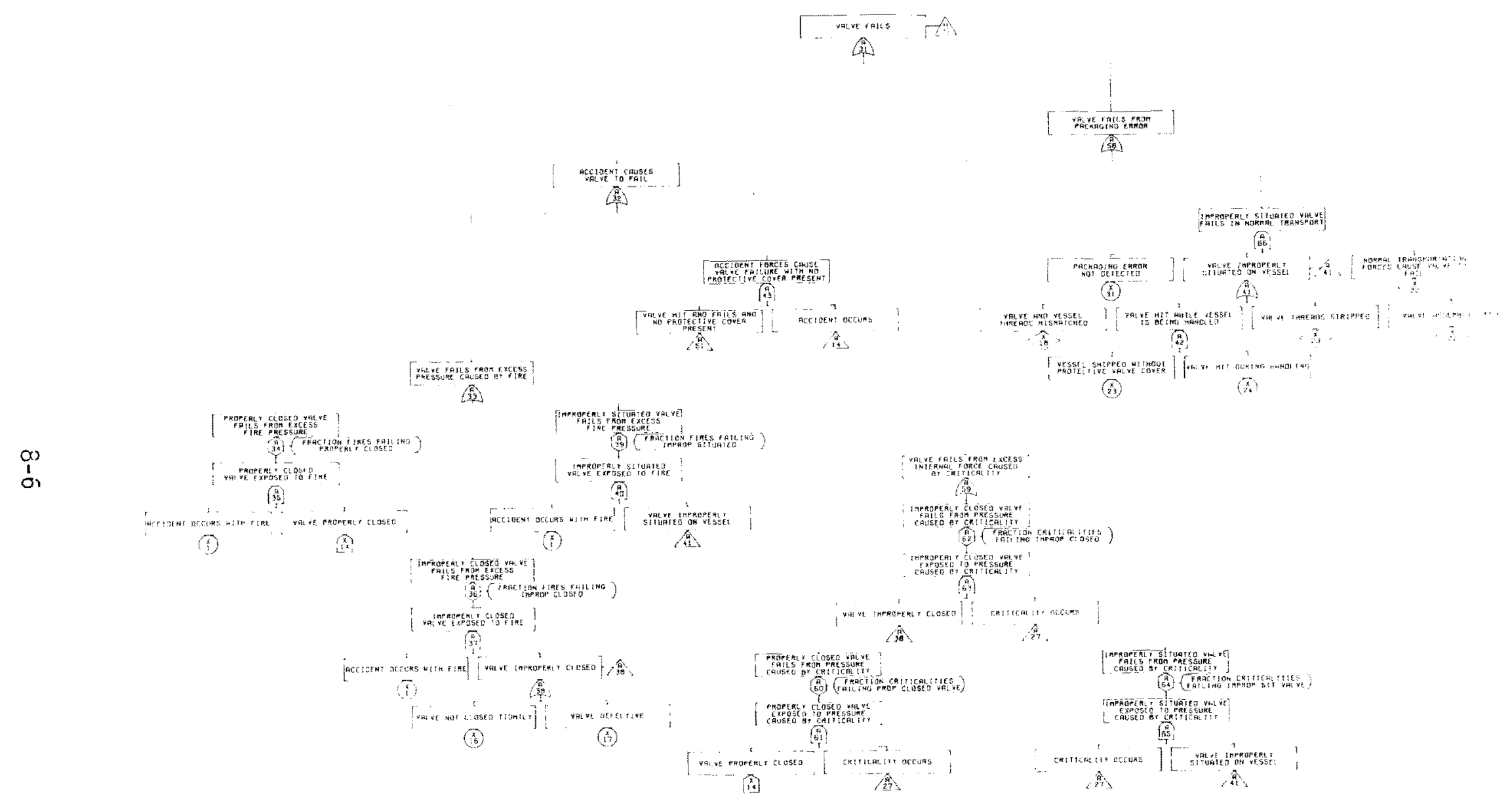

FIGURE 8.1, Page 3. (Cont'd) 


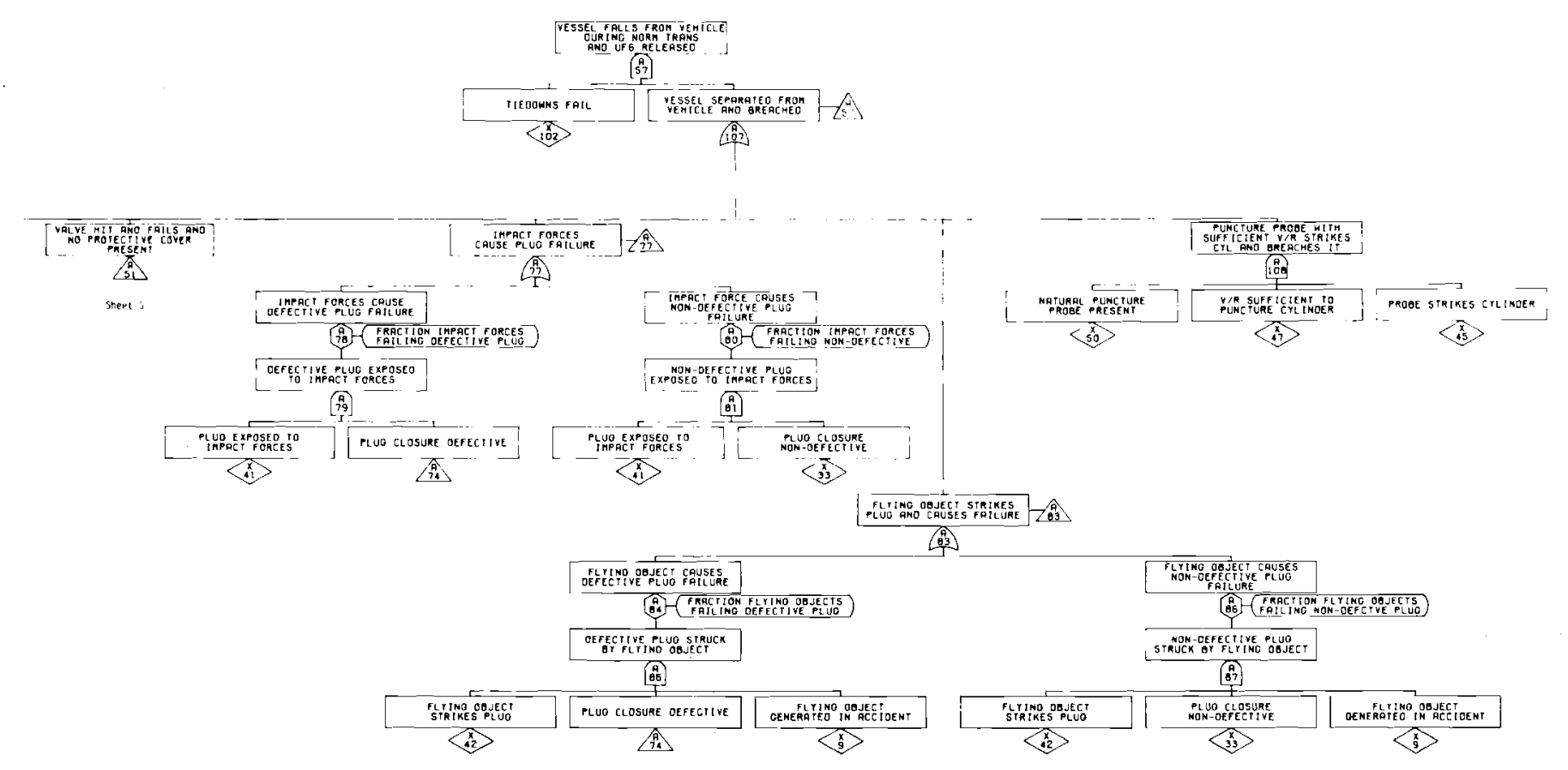

\section{FIGURE 8.1, Page 4. (Cont'd)}



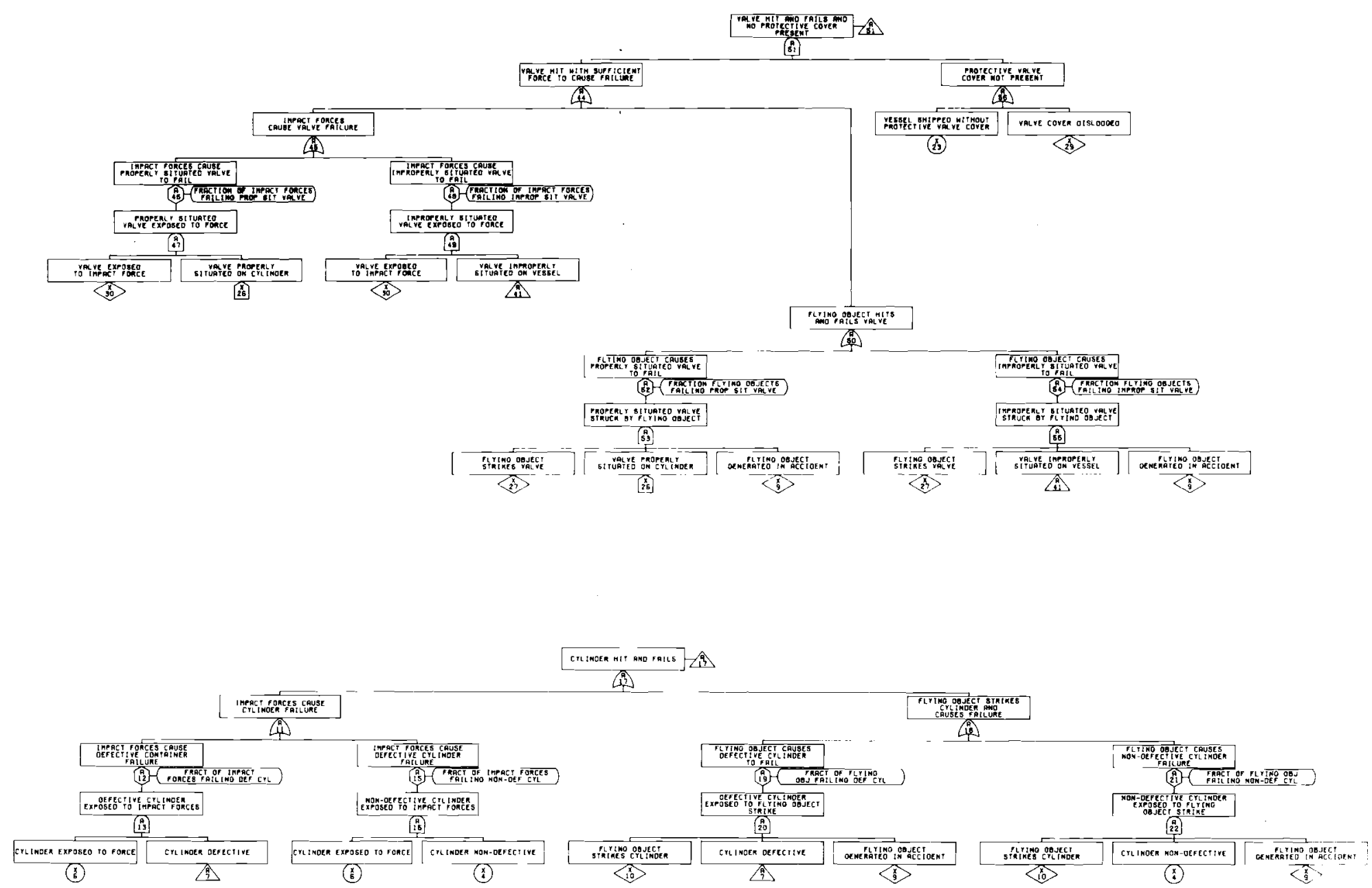

FIGURE 8.1, Page 5. (Cont'd) 
TABLE 8.2. Listing of Basic Events for Analys is of Cylinders Wi thout Overpacks

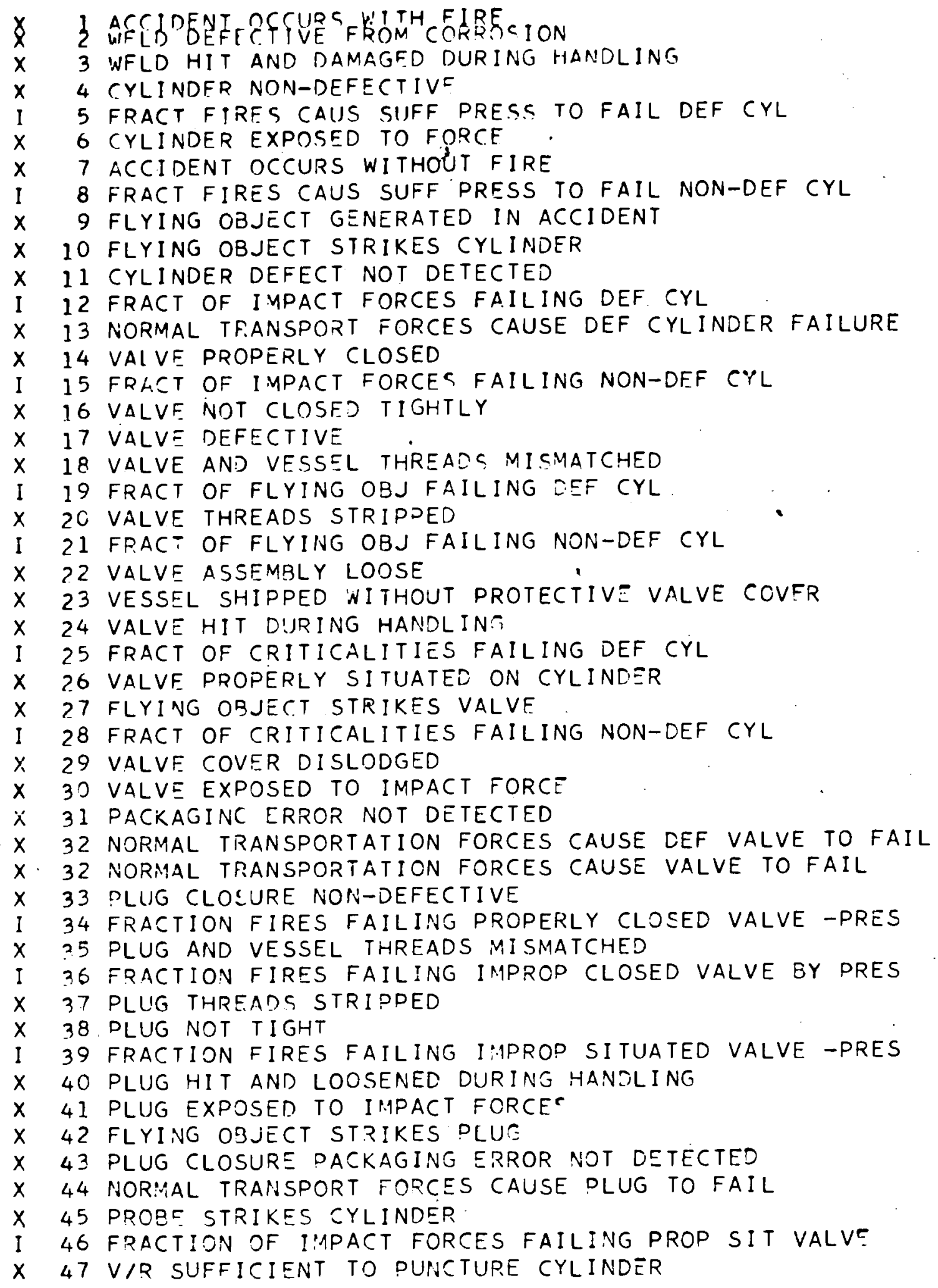


TABLE 8.2. (Continued)

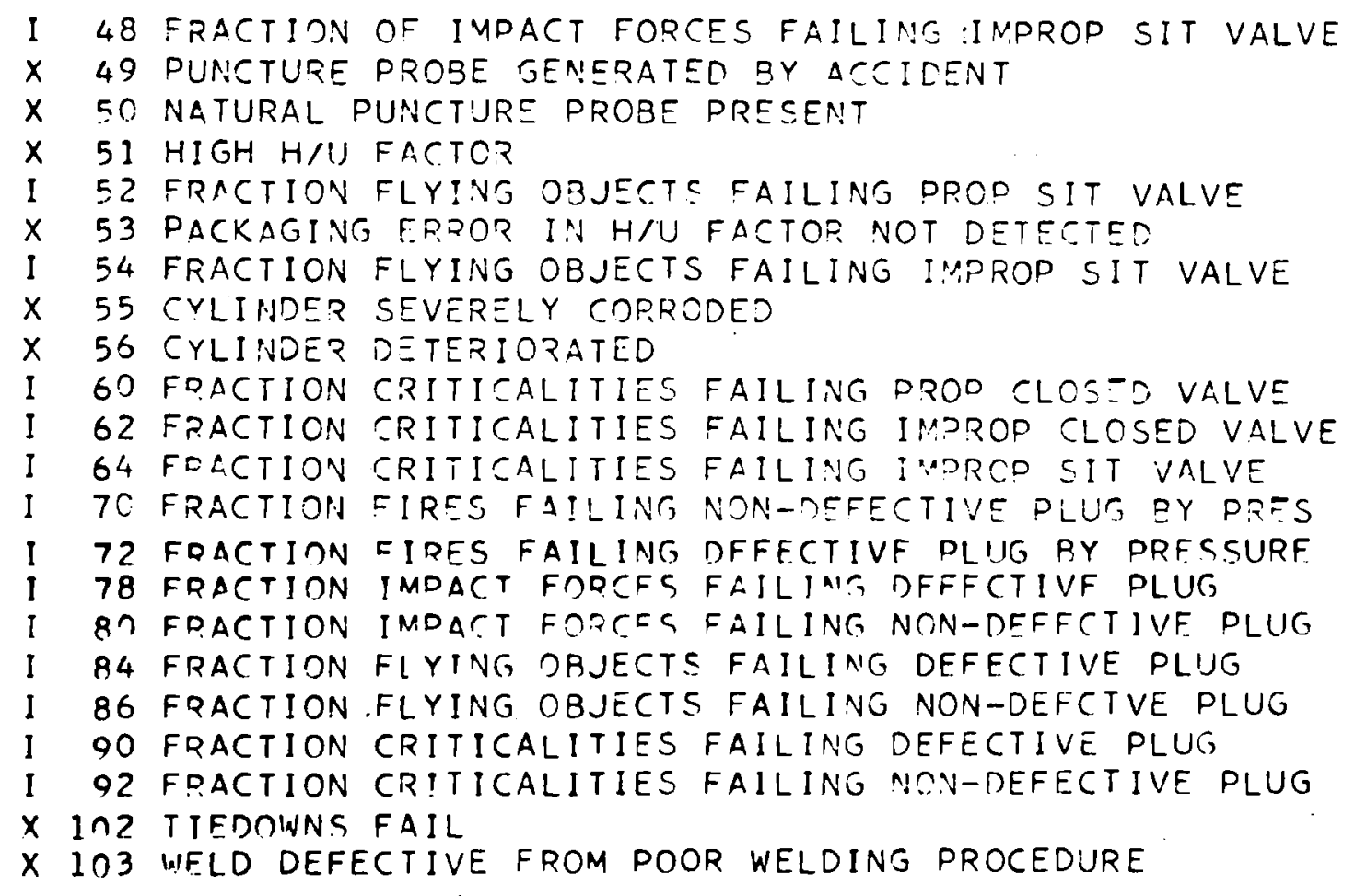




\section{Fault Tree for Cylinders With Overpack}

The fault tree for $\mathrm{UF}_{6}$ shipments in cylinders with overpacks was developed using the same criteria as the non-overpack fault tree, the only major difference being inclusion of a branch describing the failure of the overpack. Since it is possible for a cylinder to be lost from the overpack during the accident (and to keep the size of the tree manageable), it was necessary to analyze the overpack case in two steps. First, the tree was analyzed assuming that the cylinder remained in the overpack. The second step assumed that the cylinder was lost from the overpack and utilized the fault tree for the nonoverpack case with appropriate event probabilities. The entire cylinder with overpack analysis included the combined results of the two cases. The fault tree developed to describe the cylinder with overpack is shown in Figure 8.2. A list of failure elements is presented in Table 8.3.

\subsection{RELEASE SEQUENCES}

The fault tree can be thought of as a compact notation for identifying and displaying large numbers of release sequences. For larger trees, it is often helpful to utilize computer programs to perform the Boolean algebra that reduces the fault tree to a series of release sequences or "cut sets". The computer code MFAULT ${ }^{(1)}$ was used for this analysis.

Partial listings of the release sequences identified by fault tree analys is are presented in Tables 8.4,8.5 and 8.6. Table 8.4 presents the release sequences for the 14 -ton (48Y) UF ${ }_{6}$ cylinder transported by train as an example of the release sequences found for cylinders without overpacks. A sample of the release sequences for cylinders with overpacks is shown in Tables 8.5 and 8.6; these particular sequences are for the 10-ton cylinder with overpack transported by truck. Only those cut sets which are expected to occur once in every $10^{15}$ shipments are presented. Duplicate cut sets are automatically el iminated by the computer code. A list of release sequences for other combinations of container types and transport modes was also developed, but has not been presented here. 


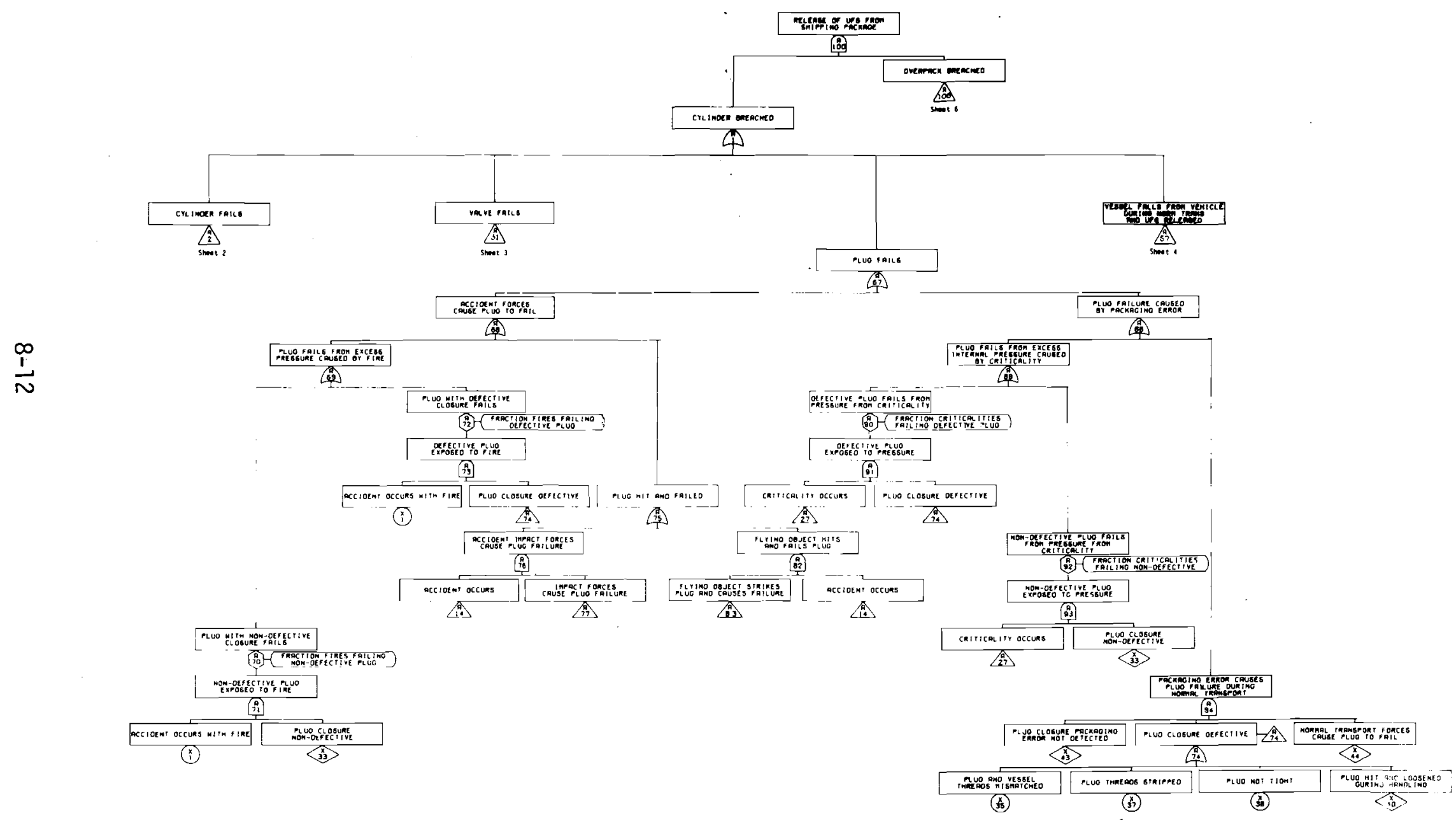

FIGURE 8.2. Fault Tree for the Shipment of $\mathrm{UF}_{6}$ Cylinder in Overpacks 


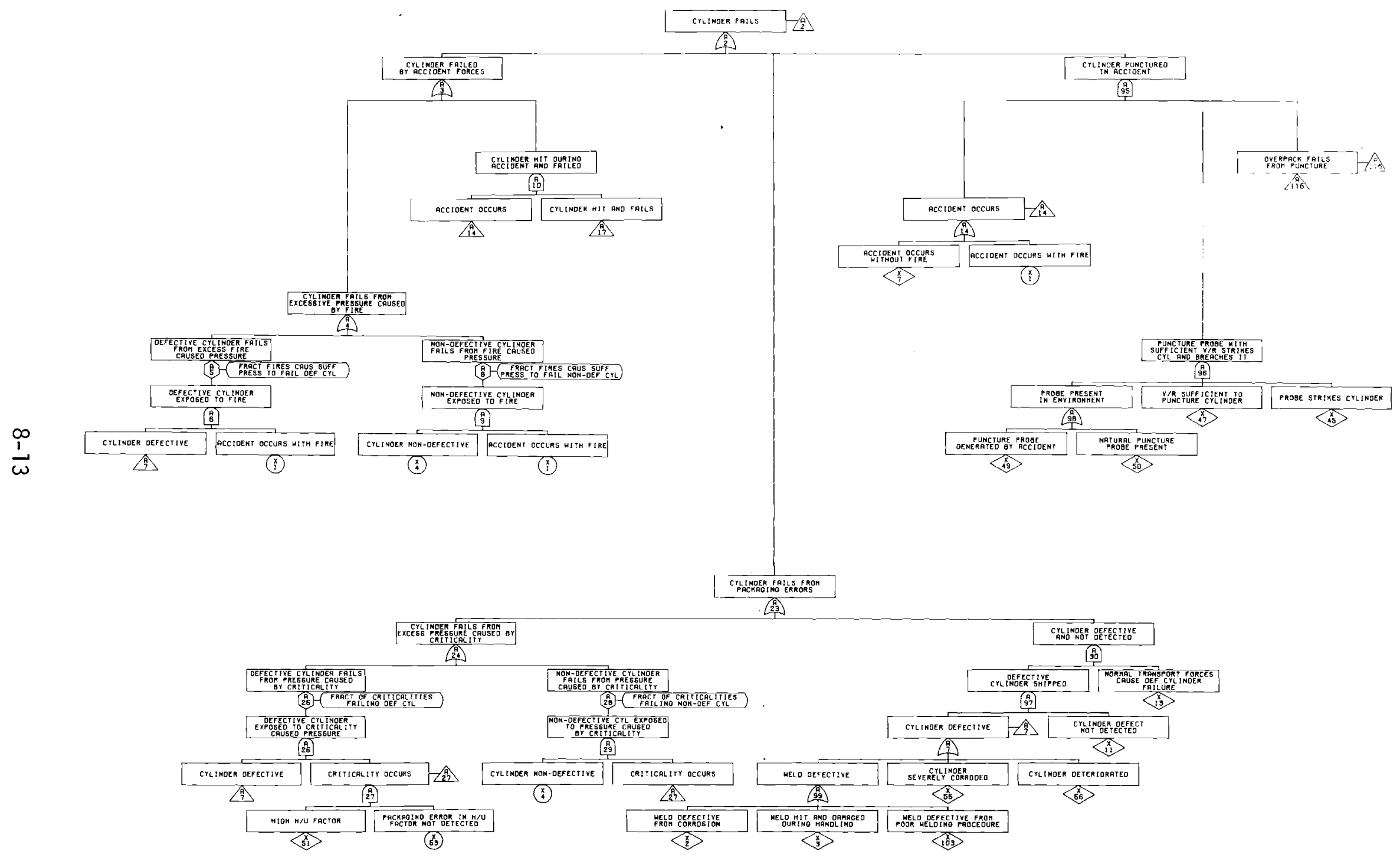

FIGURE 8.2, Page 2. (Cont'd) 


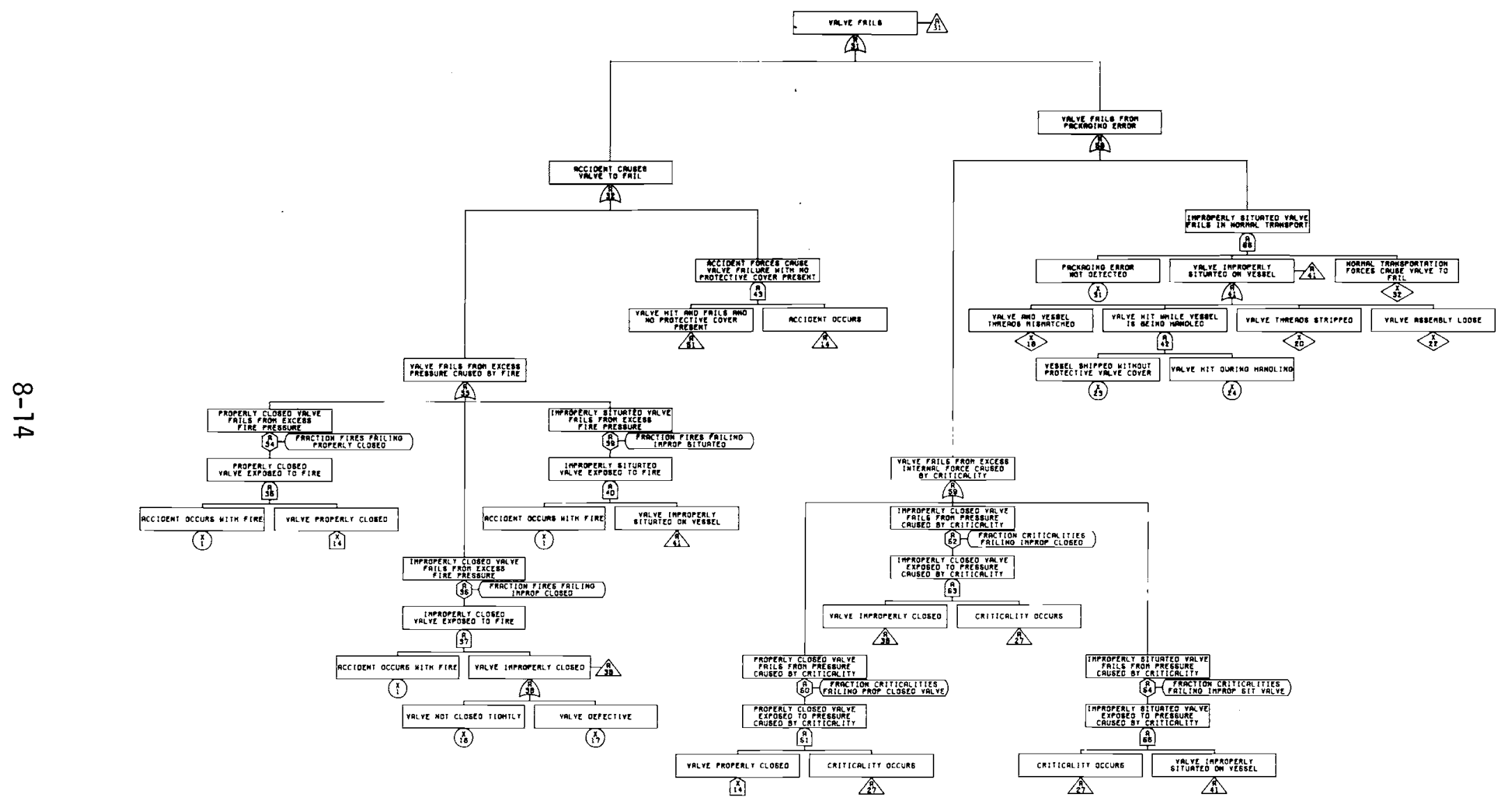

FIGURE 8.2, Page 3. (Cont'd) 


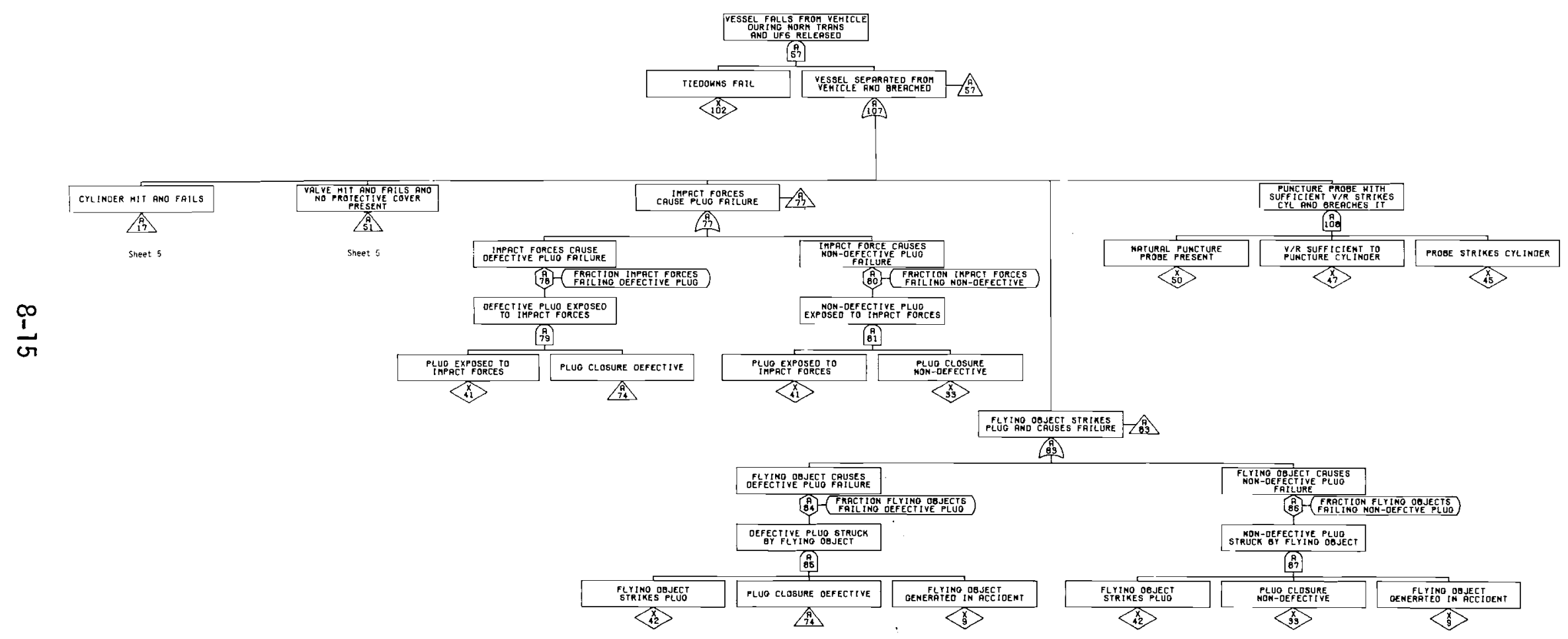

FIGURE 8.2, Page 4. (Cont'd) 

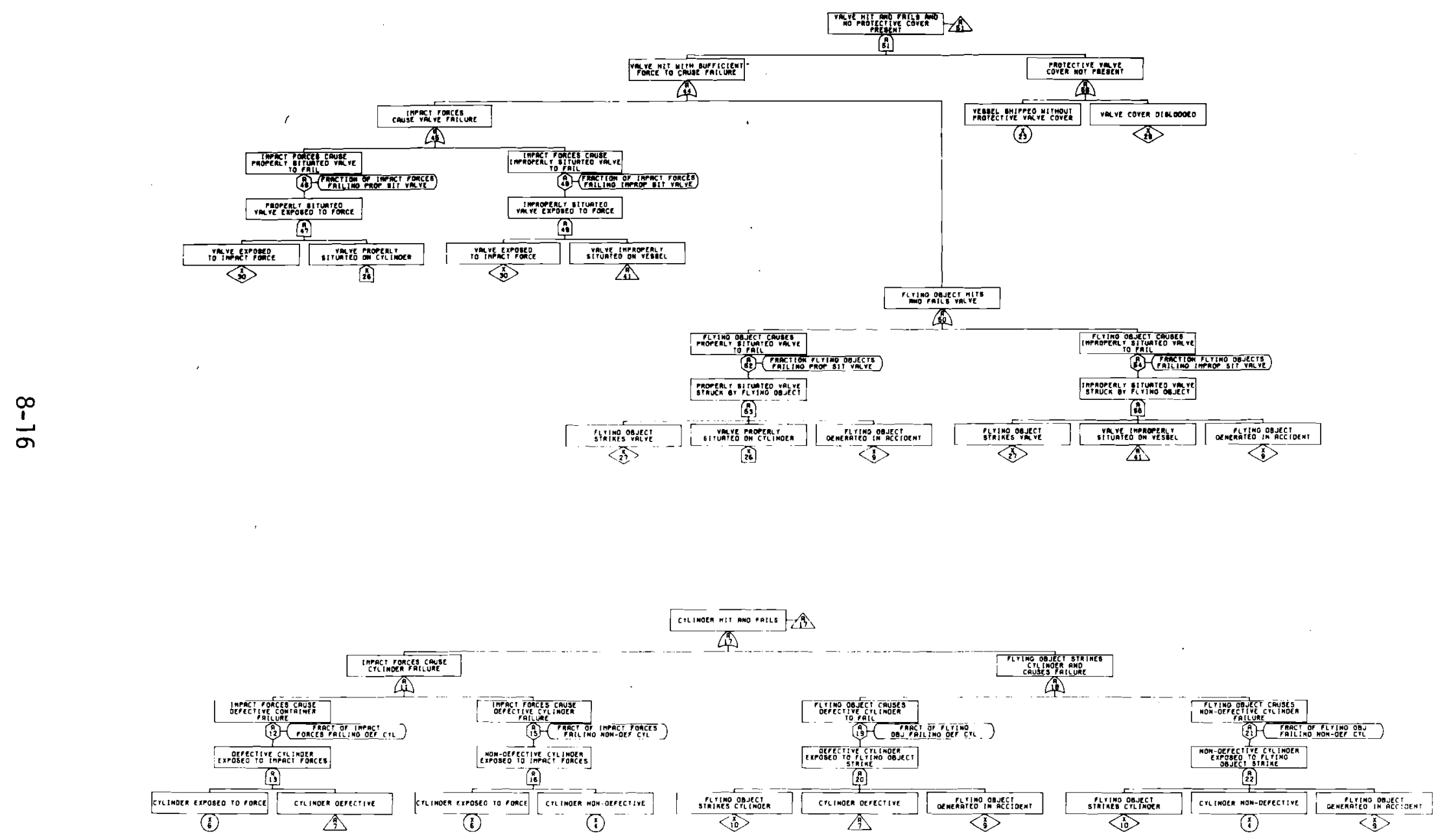

FIGURE 8.2, Page 5. (Cont'd) 


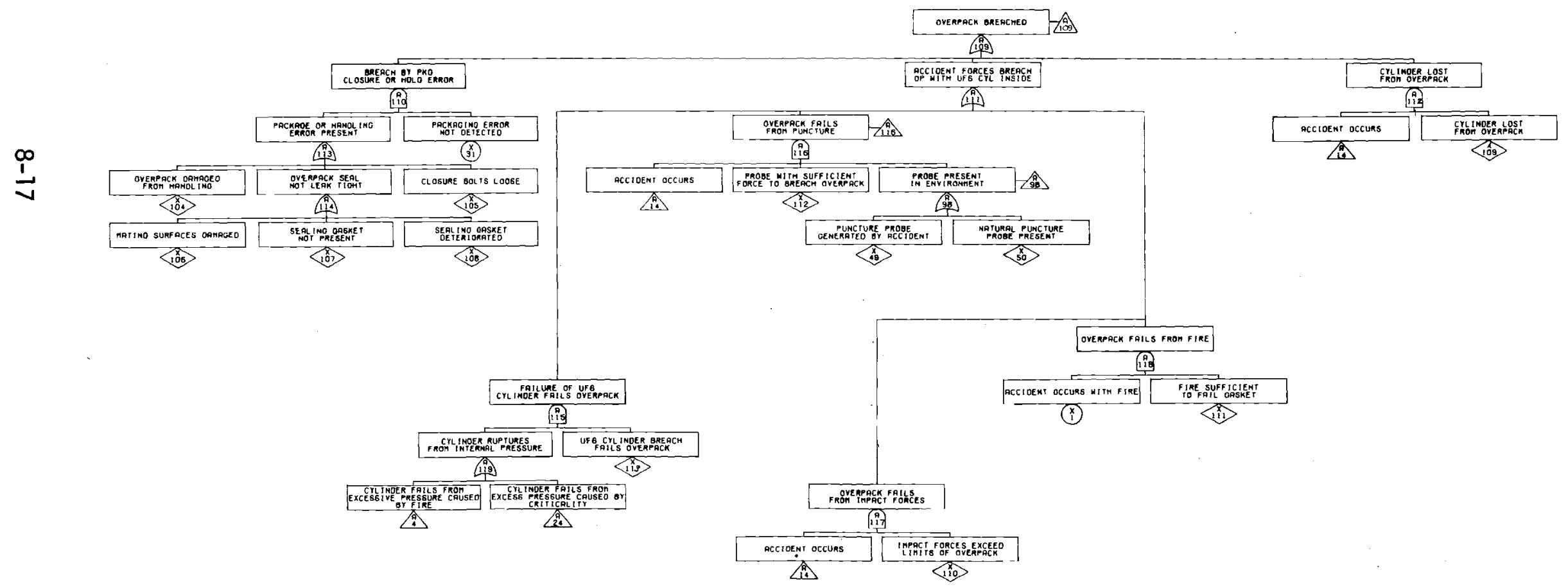

FIGURE 8.2, Page 6. (Cont'd) 
TABLE 8.3. Listing of Basic Events for Analysis of Cylinders with Overpacks

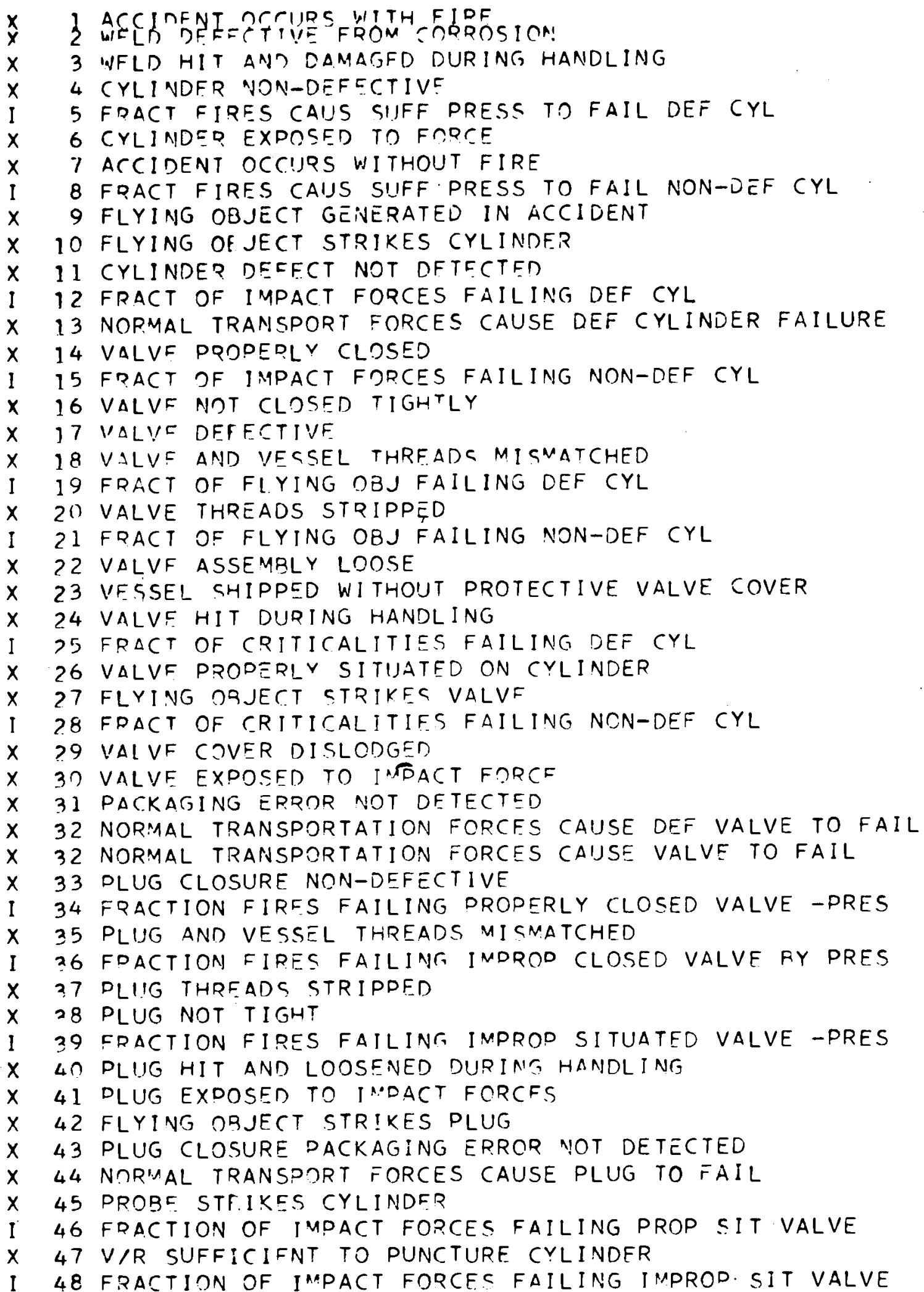




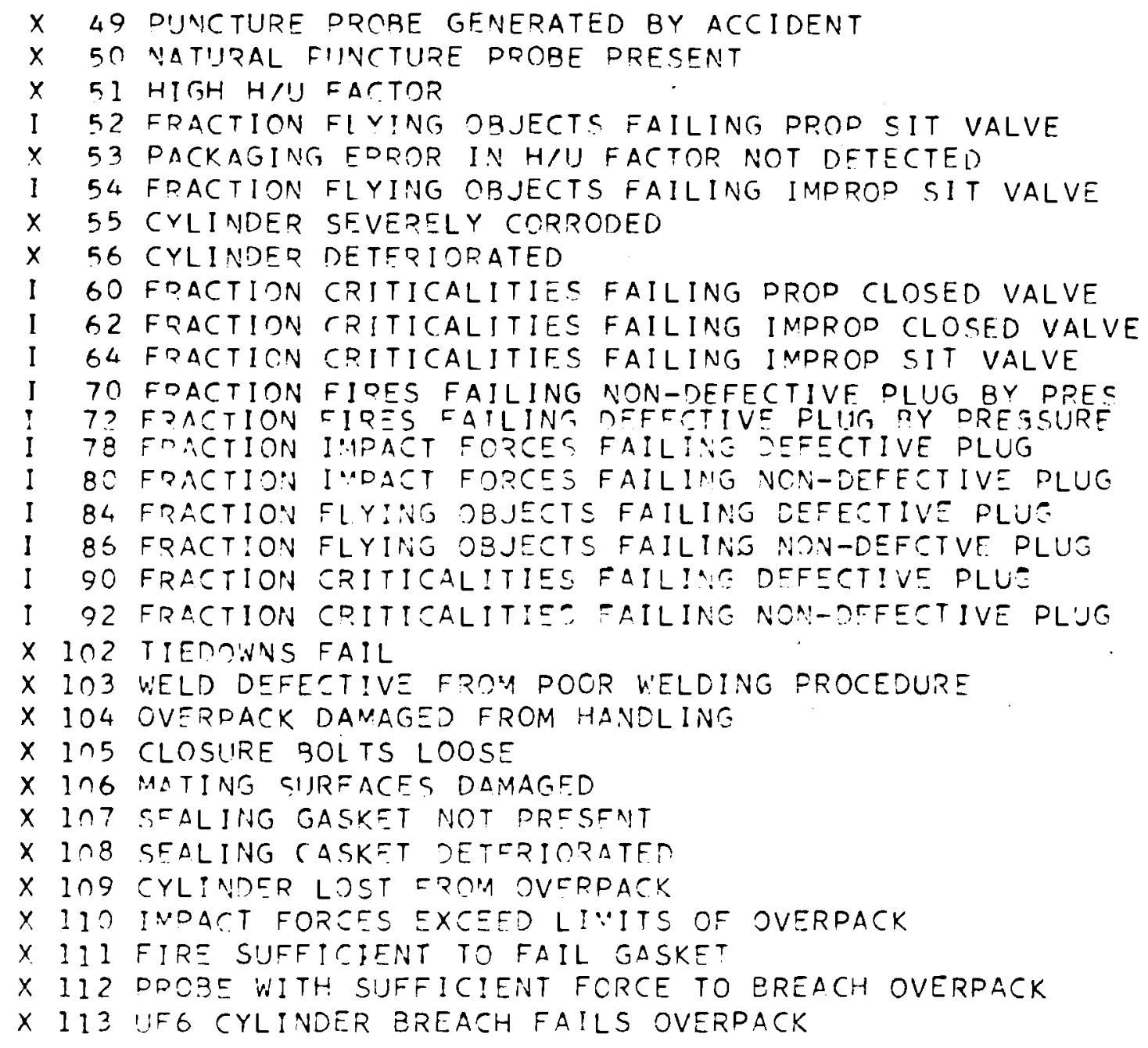


TABLE 8.4. Listing of 14-Ton (48Y) UF 6 Cylinder (Transported by Rail) Fault Tree Release Sequences

Cut Set Components

\begin{tabular}{|c|c|c|c|c|c|c|}
\hline$x$ & 1 & $x$ & 4 & 8 & & \\
\hline$x$ & 1 & $x$ & 5 & $\times 55$ & & \\
\hline$x$ & 1 & $x$ & 3 & $\times 5$ & & \\
\hline$x$ & 1 & $x$ & 5 & $x 103$ & & \\
\hline$x$ & 1 & $\times 1$ & 16 & $\times 36$ & & \\
\hline$x$ & 1 & $\times 3$ & 35 & $\times 72$ & & \\
\hline$x$ & 1 & $\times 1$ & 17 & $\times 36$ & & \\
\hline$x$ & 1 & $\times 1$ & 18 & $\times 39$ & & \\
\hline$x$ & 1 & $\times 2$ & 20 & $\times 39$ & & \\
\hline$x$ & 1 & $\times 2$ & 22 & $\times 39$ & & \\
\hline$x$ & 35 & $\times 4$ & 43 & $\times 44$ & & \\
\hline$x$ & 1 & $\times 3$ & 37 & $\times 72$ & & \\
\hline$x$ & 1 & $\times 3$ & 38 & $\times 72$ & & \\
\hline$x$ & 1 & $\times 4$ & 40 & $\times 72$ & & \\
\hline$x$ & 11 & $\times 13$ & 13 & $\times 55$ & & \\
\hline$x$ & 3 & $\times 1$ & 11 & $\times 13$ & & \\
\hline$x$ & 11 & $\times 13$ & 13 & $\times 103$ & & \\
\hline$x$ & 18 & $\times 3$ & 31 & $\times 32$ & & \\
\hline$x$ & 20 & $\times 3$ & 31 & $\times 32$ & & \\
\hline$x$ & 22 & $\times 3$ & 31 & $\times 32$ & & \\
\hline$x$ & 37 & $\times 43$ & 43 & $\times 44$ & & \\
\hline$x$ & 38 & $\times 43$ & 43 & $\times 44$ & & \\
\hline & 40 & $\times 43$ & 43 & $\times 44$ & & \\
\hline$x$ & 1 & $\times 45$ & 45 & $\times 47$ & $\times 49$ & \\
\hline$x$ & 1 & $\times 23$ & 23 & $\times 24$ & $\times 39$ & \\
\hline$x$ & 7 & $\times 45$ & 15 & $\times 47$ & $\times 49$ & \\
\hline$x$ & 1 & $\times 45$ & 45 & $\times 47$ & $\times 50$ & \\
\hline$x$ & 1 & $x$ & 4 & $\times 6$ & $\times 15$ & \\
\hline$x$ & 1 & $x$ & 6 & $\times 12$ & $\times 55$ & \\
\hline$x$ & 1 & $x$ & 3 & $x 6$ & $\times 12$ & \\
\hline$x$ & 1 & $x$ & 6 & $\times 12$ & $\times 103$ & \\
\hline$x$ & 23 & $\times 2$ & 24 & $\times 31$ & $\times 32$ & \\
\hline$x$ & 7 & $\times 4$ & 45 & $\times 47$ & $\times 50$ & \\
\hline$x$ & 4 & $x$ & 6 & $\times 7$ & $\times 15$ & \\
\hline$x$ & 6 & $x$ & 7 & $\times 12$ & $\times 55$ & \\
\hline$x$ & 3 & $x$ & 6 & $\times 7$ & $\times 12$ & \\
\hline$x$ & 6 & $x$ & 7 & $\times 12$ & $\times 103$ & \\
\hline$x$ & 1 & $\times 2$ & 23 & $\times 26$ & $\times 30$ & $\times 46$ \\
\hline$x$ & 7 & $\times 2$ & 23 & $\times 26$ & $\times 30$ & $\times 46$ \\
\hline$x$ & 1 & $\times 2$ & 23 & $\times 24$ & $\times 30$ & $\times 48$ \\
\hline$x$ & 1 & $\times 2$ & 26 & $\times 29$ & $\times 30$ & $\times 46$ \\
\hline$x$ & 7 & $\times 2$ & 23 & $\times 24$ & $\times 30$ & $\times 48$ \\
\hline$x$ & 7 & $\times 2$ & 26 & $\times 29$ & $\times 30$ & $\times 46$ \\
\hline$x$ & 1 & $\times 2$ & 22 & $\times 23$ & $\times 30$ & $\times 48$ \\
\hline$x$ & 7 & $\times 1$ & 18 & $\times 23$ & $\times 30$ & $\times 48$ \\
\hline$x$ & 7 & $\times 2$ & 20 & $\times 23$ & $\times 30$ & $\times 48$ \\
\hline$x$ & 7 & $\times 2$ & 22 & $\times 23$ & $\times 30$ & $\times 48$ \\
\hline$x$ & 1 & $x 1$ & 18 & $\times 29$ & $\times 30$ & $\times 48$ \\
\hline$x$ & 1 & $\times 2$ & 20 & $\times 29$ & $\times 30$ & $\times 48$ \\
\hline$x$ & 1 & $\times 2$ & 22 & $\times 29$ & $\times 30$ & $\times 48$ \\
\hline$x$ & 7 & $\times 1$ & 18 & $\times 29$ & $\times 30$ & $\times 48$ \\
\hline$x$ & 7 & $\times 2$ & 20 & $\times 29$ & $\times 30$ & $\times 48$ \\
\hline$x$ & 7 & $\times 2$ & 22 & $\times 29$ & $\times 30$ & $\times 48$ \\
\hline
\end{tabular}




\section{TABLE 8.5. Listing of 10 -ton (48X) UF 6 Cylinder (Transported by Truck) Fault Tree Release Sequences. Cylinder Remains Inside the Overpack}

Cut Set Components

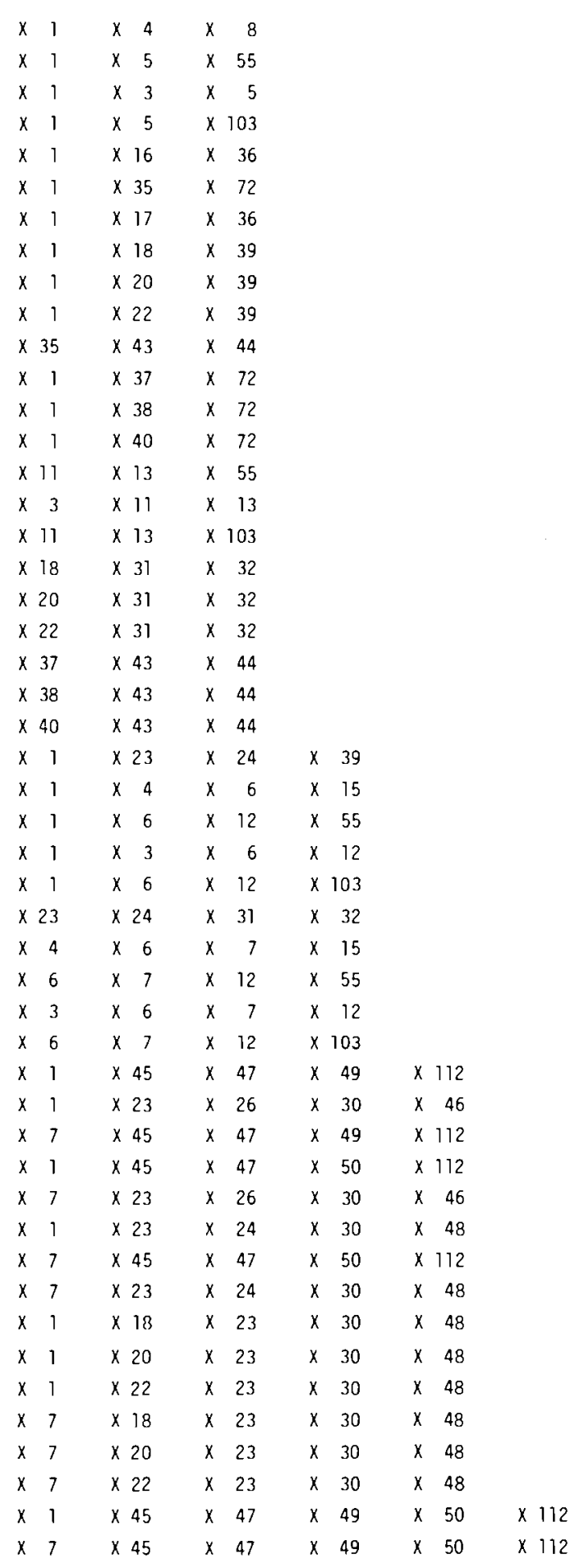


TABLE 8.6. Listing of 10 -ton (48X) $\mathrm{UF}_{6}$ Cylinder (Transported by Truck) Fault Tree Release Sequences. Cylinder is Lost from the Overpack

\begin{tabular}{|c|c|c|c|c|c|c|c|c|c|}
\hline$x$ & 1 & $x$ & 4 & $x$ & 8 & & & & \\
\hline$x$ & 1 & $x$ & 5 & $x$ & 55 & & & & \\
\hline$x$ & 1 & $x$ & 3 & $x$ & 5 & & & & \\
\hline$x$ & 1 & $x$ & 5 & $x$ & 103 & & & & \\
\hline$x$ & 1 & $x$ & 16 & $x$ & 36 & & & & \\
\hline$x$ & 1 & $x$ & & $x$ & 72 & & & & \\
\hline$x$ & 1 & $x$ & 17 & $x$ & 36 & & & & \\
\hline$x$ & 1 & $x$ & 18 & $x$ & 39 & & & & \\
\hline$x$ & 1 & $x$ & 20 & $x$ & 39 & & & & \\
\hline$x$ & 1 & $x$ & 22 & $x$ & 39 & & & & \\
\hline & 35 & $x$ & 43 & $x$ & 44 & & & & \\
\hline$x$ & 1 & $x$ & 37 & $x$ & 72 & & & & \\
\hline$x$ & 1 & $x$ & 38 & $x$ & 72 & & & & \\
\hline$x$ & 1 & $x$ & 40 & $x$ & 72 & & & & \\
\hline & 11 & $x$ & 13 & $x$ & 55 & & & & \\
\hline$x$ & 3 & $x$ & 11 & $x$ & 13 & & & & \\
\hline & 11 & $x$ & 13 & $x$ & 103 & & & & \\
\hline & 18 & $x$ & 31 & $x$ & 32 & & & & \\
\hline$x$ & 20 & $x$ & 31 & $x$ & 32 & & & & \\
\hline$x$ & 22 & $x$ & 31 & $x$ & 32 & & & & \\
\hline$x$ & 37 & $x$ & 43 & $x$ & 44 & & & & \\
\hline$x$ & 38 & $x$ & 43 & $x$ & 44 & & & & \\
\hline & 40 & $x$ & 43 & $x$ & 44 & & & & \\
\hline$x$ & 1 & $x$ & 23 & $x$ & 24 & $x$ & 39 & & \\
\hline$x$ & 1 & $x$ & 4 & $x$ & 6 & $x$ & 15 & & \\
\hline$x$ & 1 & $x$ & 6 & $x$ & 12 & $x$ & 55 & & \\
\hline$x$ & 1 & $x$ & 3 & $x$ & 6 & $x$ & 12 & & \\
\hline$x$ & 1 & $x$ & 6 & $x$ & 12 & $x$ & 103 & & \\
\hline & 23 & $x$ & 24 & $x$ & 31 & $x$ & 32 & & \\
\hline$x$ & 4 & $x$ & 6 & $x$ & 7 & $x$ & 15 & & \\
\hline$x$ & 6 & $x$ & 7 & $x$ & 12 & $x$ & 55 & & \\
\hline$x$ & 3 & $x$ & 6 & $x$ & 7 & $x$ & 12 & & \\
\hline$x$ & 6 & $x$ & 7 & $x$ & 12 & $x$ & 103 & & \\
\hline$x$ & 1 & $x$ & 23 & $x$ & 26 & $x$ & 30 & $\times 46$ & \\
\hline$x$ & 7 & $x$ & 23 & $x$ & 26 & $x$ & 30 & $\times 46$ & \\
\hline$x$ & 1 & $x$ & 23 & $x$ & 24 & $x$ & 30 & $\times 48$ & \\
\hline$x$ & 7 & $x$ & 23 & $x$ & 24 & $x$ & 30 & $\times 48$ & \\
\hline$x$ & 1 & $x$ & 18 & $x$ & 23 & $x$ & 30 & $\times 48$ & \\
\hline$x$ & 1 & $x$ & 20 & $x$ & 23 & $x$ & 30 & $\times 48$ & \\
\hline$x$ & 1 & $x$ & & $x$ & 23 & $x$ & 30 & $\times 48$ & \\
\hline$x$ & 7 & $x$ & & $x$ & 23 & $x$ & 30 & $\times 48$ & \\
\hline$x$ & 7 & & & $x$ & 23 & $x$ & 30 & $\times 48$ & \\
\hline$x$ & 7 & & 22 & $x$ & 23 & $x$ & 30 & $\times 48$ & \\
\hline$x$ & 1 & $x$ & 9 & $x$ & 23 & $x$ & 26 & $\times 27$ & $\times 52$ \\
\hline$x$ & 7 & $x$ & 9 & $x$ & 23 & $x$ & 26 & $\times 27$ & $\times 52$ \\
\hline$x$ & 1 & $x$ & 9 & $x$ & 23 & $x$ & 24 & $\times 27$ & $\times 54$ \\
\hline$x$ & 7 & $x$ & 9 & $x$ & 23 & $x$ & 24 & $\times 27$ & $\times 54$ \\
\hline$x$ & 1 & $x$ & 9 & $x$ & 18 & $x$ & 23 & $\times 27$ & $\times 54$ \\
\hline$x$ & 1 & $x$ & 9 & $x$ & 20 & $x$ & 23 & $\times 27$ & $\times 54$ \\
\hline$x$ & 1 & $x$ & 9 & $x$ & 22 & $x$ & 23 & $\times 27$ & $\times 54$ \\
\hline$x$ & 7 & $x$ & 9 & $x$ & 18 & $x$ & 23 & $\times 27$ & $\times 54$ \\
\hline$x$ & 7 & $x$ & 9 & $x$ & 20 & $x$ & 23 & $\times 27$ & $\times 54$ \\
\hline & 7 & $x$ & 9 & $x$ & 22 & $x$ & 23 & $\times 27$ & $\times 54$ \\
\hline
\end{tabular}


REFERENCES

1. P. J. Pelto, W. L. Purce11, MFAULT: A Computer Program for Analyzing Fault Trees. BNWL-2145, Battelle, Pacific Northwest Laboratories, Richland, WA, November 1977. 

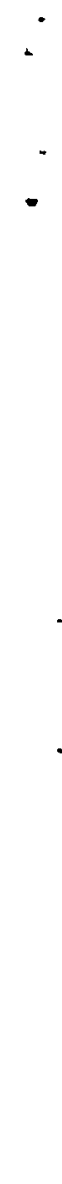


\subsection{RELEASE SEQUENCE EVALUATION}

The previous chapter presented the fault trees for the shipment of $\mathrm{UF}_{6}$ in cylinders with and without protective overpacks. The fault tree can be thought of as a compact notation for summarizing several thousand release sequences. These release sequences are the common element in the risk assessment. As shown in Figure 9.1, based on the release sequence, both the occurrence frequency and amount released (release fraction) must be determined for each release sequence. This section presents the basic data required to evaluate all release sequences.

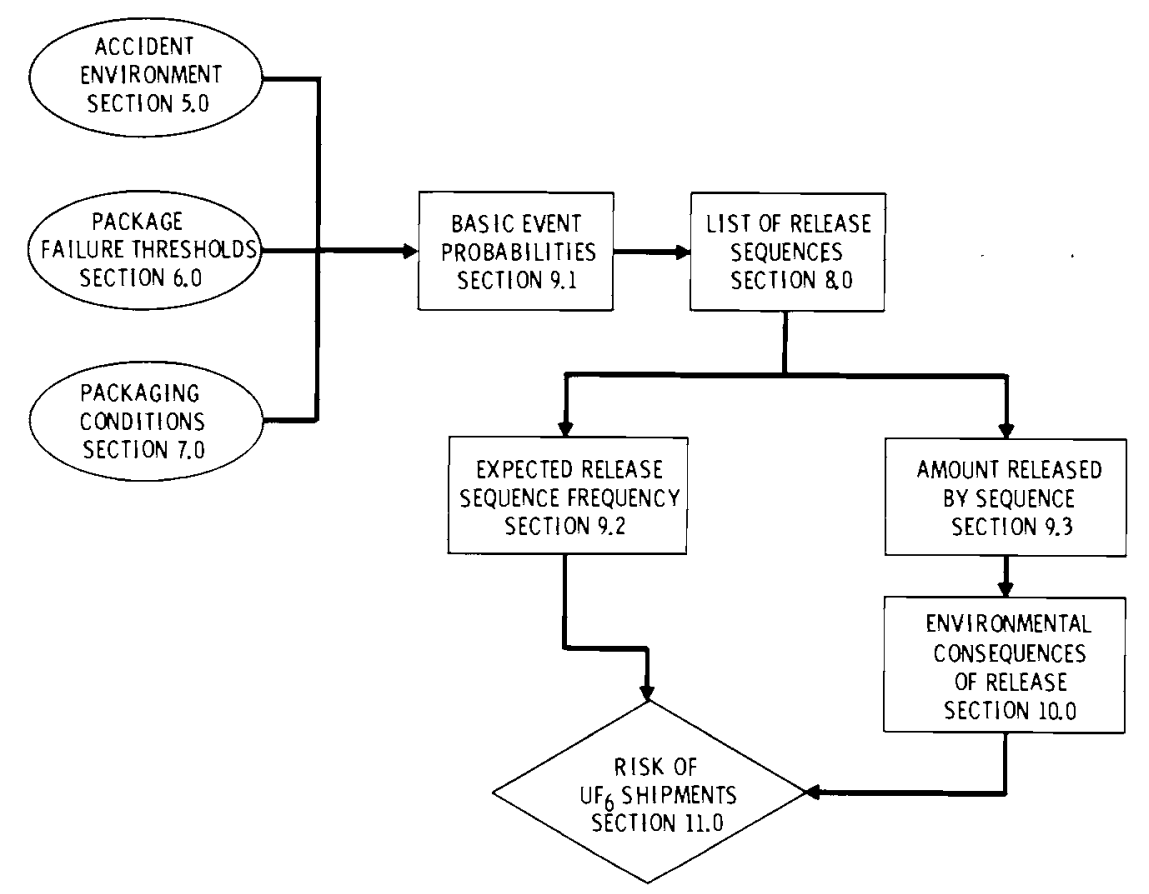

FIGURE 9.1. Remaining Steps in the Risk Evaluation

The fault trees in Section 8 were developed to a point where data on basic events could be obtained through either analysis or from survey results. The estimated basic event probabilities are presented in Section 9.1. The probability data are then used to develop the information on release sequence probabilities, which are summarized in Section 9.2. Release fractions are evaluated in Section 9.3. 


\subsection{BASIC EVENT PROBABILITIES}

The following paragraphs provide a sequential description of failure probability estimates for $\mathrm{UF}_{6}$ shipments in the five container configurations considered in this risk assessment. The numbering sequence used here corresponds to the numbering sequence used in the fault trees. Since the numbering system used in the two fault trees is identical (except that the "with overpack" fault tree has some additional events) many of the basic events will have identical probabilities. These will be noted in the text.

The analysis of shipping packages utilizing overpacks involves two segments: one which considers failure of the $\mathrm{UF}_{6}$ cylinder in an accident after it has been lost from the protective overpack; and a second which deals with failure of the cylinder while it is still within the overpack. For this reason, the descriptions of probability estimates for the packages utilizing overpacks consist of two sections, corresponding to the two segments described above.

The fault tree was developed independently of the accident environment data. In determining probabilities for specific events, it was often necessary (because of accident environment information limitations) to combine one or more events. This results in the use of zero and one for certain event probabilities to avoid double counting. These instances will be noted. In all cases, the best available information was used in determining failure event probabilities. In many instances, only rough estimates were available for certain inputs. Risk sensitivity analyses were performed to yield insight to the contributions of these events.

The explanation "not used" following an event number simply means that the event number was not used in the numbering sequence.

\subsubsection{Two and One-Half Ton (Type 30B) Cylinder Transported by Truck With Overpack}

The analysis for this cylinder consists of two parts: the first dealing with the cylinder when it is lost from the overpack, the second dealing with the cylinder which remains inside the protective outer package. 


\section{Cylinder Lost from Overpack}

Accident Occurs with Fire (XI). From data developed by Sandia, (1) it can be shown that approximately $1.6 \%$ of all truck accidents involve fire. Using a truck accident rate of $1.55 \times 10^{-6}$ accident per kilometer, it was determined that accidents involving fire could be expected at a rate of $2.48 \times 10^{-8}$ per kilometer. For an average trip length of 1050 kilometers, the rate was expressed as $2.60 \times 10^{-5}$ per shipment. It was assumed that cylinders were exposed to the fire in all truck accidents with fire.

Weld Defective from Corrosion (X2). Responses from the packaging survey did not differentiate between corroded welds and deteriorated cylinders. Therefore this event and X56, Cylinder Deteriorated, were combined, with a value being used for $X 56$. The value of $X 2$ was set at zero.

Weld Hit and Damaged During Handling (X3). Since the 30A and 30B cylinders are quite similar, the survey results of both were combined to give a greater sample size. The survey showed a total of 7 cylinders out of a sample size of 5712 which were received with damaged welds. An expected frequency of $1.23 \times 10^{-3}$ per cylinder was used.

Cylinder Nondefective (X4). For the purposes of this analysis, a conservative value of 1.00 was assumed.

Fraction of Fires Causing Sufficient Pressure to Fail Defective Cylinder (I5). For this portion of the $21 / 2$-ton cylinder analysis, it was assumed that the cylinder has been lost from the protective overpack. The failure thresholds presented in Section 6 show that a nondefective cylinder will fail after being exposed to the fire environment for approximately 29 minutes. It is very difficult to quantify the degree of defectiveness of a cylinder. Taking into account the time necessary to heat up the cylinder, heat transfer rates of $U_{6}$, etc., it was assumed that all defective cylinders would fail after 22 minutes (approximately $75 \%$ of the time for a nondefective cylinder). This assumption is conservative because the pressure tends to rise quickly shortly before the cylinder fails. The description of the fire accident environment presented in Section 5 indicates that approximately $11 \%$ of a 11 truck accident fires burn longer than 22 minutes. Therefore a fraction of 0.11 was used for this inhibit element. 
Cylinder Exposed to Force (X6). Based on material presented in Reference ?, it was determined that the cylinders were exposed to impact forces in $89 \%$ of all accidents. Therefore a frequency of 0.89 per accident was used for this event.

Accident Occurs Without Fire (X7). This element was evaluated using the same data as event $\times 1$. An expected rate of $1.53 \times 10^{-6}$ per kilometer or $1.60 \times 10^{-3}$ per $1050 \mathrm{kilometer}$ average shipment distance.

Fraction of Fires Causing Sufficient Pressure to Fail Non-Defective Cylinder (18). In Section 6, it was shown that a 2-1/2 ton cylinder exposed to the fire environment without a protective overpack could be expected to rupture from excess internal pressure after approximately 29 minutes. Fire environment information presented in Section 5 indicates that approximately $5 \%$ of all truck accident fires can be expected to last longer than this. Therefore, a fraction of 0.05 was used to describe fires capable of failing the non-defective cylinders.

Flying Object Generated in Accident (X9). Moving vehicle accidents account for $89 \%$ of a 11 truck accidents. It was conservatively assumed that puncture probes or flying objects of one type or another are present in all moving vehicle accidents. A value of 0.89 per accident was given this event.

Flying Object Strikes Cylinder (x10). Because puncture failures are lumped together in event $\times 47$, a value of 1.00 was assigned to this event.

Cylinder Defect Not Detected (X11). Since information on cylinder defects was obtained from a survey of containers actually shipped, it was assumed that these defects were not detected before or during shipment. A value of 1.00 was used for $\times 11$.

Fraction of Impact Forces Failing Defective Cylinder (112). As was the case in event I5, it was difficult to determine the "defectiveness" of a cylinder. A non-defective cylinder without overpack was assumed to fail in a drop from a height of 9 meters. It was arbitrarily assumed that the defective cylinder would fail at half this height, or 4.5 meters. Using the information presented in Section 5, 96\% of the truck accidents sampled involved impact energy changes which were less than a value corresponding to this drop height. Therefore a value of 0.04 was used for this event. 
Normal Transport Forces Cause Defective Cylinder Failure (X13). Any cylinder sufficiently defective to fail from normally imposed transport forces would most likely fail during normal handling and filling operations. This is thus a very unlikely event, and it was assigned a frequency of occurrence of $10^{-6}$ per cylinder.

Valve Properly Closed (X14). This event was conservatively assigned a probability of 1.0 .

Fraction of Impact Forces Failing Non-Defective Cylinder (I15). An impact failure threshold equivalent to a drop from 9 meters was shown in Section 6. Using Figure 5.2, approximately $98 \%$ of the accidents sampled involved energy changes due to impact of lesser or equal magnitude. A fraction of 0.02 was therefore used for this inhibit element.

Valve Not Tightly Closed (X16). No incidence of partially open valves was found in the survey. This does not mean, however, that this condition will never be present. At a 50\% confidence level, for the sample size involved, we would expect this packaging error to occur at a rate of $1.21 \times 10^{-4}$ per cylinder.

Valve Defective (X17). The survey showed that a total of 41 valves required replacement during the time period covered by the survey. It was learned that approximately $1 / 3$ of these valves were replaced due to clogged ports, etc. and did not involve defective parts. If we assume that all the remaining valves were replaced due to defects, a rate of $2.39 \times 10^{-3}$ per cylinder is indicated.

Valve and Vessel Threads Mismatched (X18). The survey showed a total of 7 cylinders received with valve threads cross threaded. This implies an expected frequency of $1.23 \times 10^{-3}$ per cylinder.

Fraction of Flying Objects Failing Defective Cylinder (I19). Due to the nature of the available information describing the puncture accident environment, it was impossible to distinguish between punctured defective and nondefective cylinders. The puncture frequency is presented in $X 47$. Therefore, the value assigned to this event is zero. 
Valve Threads Stripped (X20). A total of five examples of cylinders with stripped valve threads was found in the package survey. This implies an occurrence rate of $8.75 \times 10^{-4}$ per cylinder. This value was used for event $\mathrm{X} 20$.

Fraction of Flying Objects Failing Non-Defective Cylinder (I21). A breach caused by a flying object and puncture caused by a puncture probe were not differentiated in this analysis. Because of the nature of the puncture accident environment description, all puncture failures of both defective and non-defective cylinders will be included in event X47. Therefore, the value used for this element was zero.

Valve Assembly Loose (X22). No occurrences of loose valve assemblies were reported on the survey forms. At a $50 \%$ confidence level, an occurrence rate of $1.21 \times 10^{-4}$ per cylinder is expected.

Vessel Shipped Without Protective Valve Cover (X23). In this study, it is assumed that all 2-1/2 ton cylinders are shipped in overpacks, and therefore always shipped without a valve cover. The event was assigned a rate of 1.00 per cylinder.

Valve Hit During Handling (X24). The survey showed a total of 14 cylinders received with damaged valves. It was assumed that this failure occurred during normal handling. A value of $2.45 \times 10^{-3}$ was used for this event.

Fraction of Criticalities Failing Defective Cylinder (125). It was conservatively assumed that all criticalities would cause a failure of the cylinder. A value of 1.00 was used.

Valve Properly Situated on Cylinder (x26). This element was conservatively given a value of 1.00 .

Flying Object Strikes Valve (X27). The valve is partially protected from flying objects by the cylinder skirts. Considering the relative size of the valve to the cylinder and the angles from which the flying objects can strike the valve, few flying objects would be able to hit the valve. A value of $1.6 \times 10^{-3}$ per accident was used for this event. 
Fraction of Criticalities Failing Non-Defective Cylinder (I28). It was assumed that all criticalities would fail all cylinders, both defective and non-defective. A conservative fraction of 1.00 was used here.

Valve Cover Dislodged (X29). In this portion of the 2-1/2 ton cylinder analysis, it is assumed that the cylinder has been lost from the overpack. This means that the valve is exposed, as it was in event $X 23$. To avoid counting this type of failure twice, the value assigned to this event was zero.

Valve Exposed to Impact Force (X30). Accidents in which the cylinder receives an end-on impact force (acting on valve end) represent $67 \%$ of all accidents. It was arbitrarily assumed that in these accidents, the valve was twice as likely to be exposed to the impact force as with other types of accidents where impact forces are assumed to act. For the valve to be exposed to an impact force, the force must be applied so that it fails the cylinder skirt, which is partially protecting the valve. Forces acting within $30^{\circ}$ of "end-on" would be applied in a manner to threaten the valve. Taking all of these factors into consideration, a frequency of $1.3 \times 10^{-1}$ per accident was determined for this event.

Packaging Error Not Detected (X31). Since information on packaging errors was derived from a survey of containers actually shipped, it was assumed that the errors were not detected. A value of 1.00 was used here.

Normal Transportation Forces Cause Defective Valve to Fail (X32). Normal transportation forces usually are not of sufficient level to cause failure of a defective valve. A valve defective to the point of failing at these levels would almost certainly be discovered during routine filling operations. For this reason a frequency of $10^{-6}$ per cylinder was used.

Plug Closure Non-Defective (X33). This element was conservatively set at 1.00 .

Fraction of Fires Failing Properly Closed Valves Due to Pressure (134). Valves are rated and tested at the same level as the cylinder. It is therefore assumed that the valve will fail at the same time the cylinder fails. To avoid double counting a failure mode, the fraction used here is zero. 
Plug and Vessel Threads Mismatched (X35). The survey of packaging errors showed no occurrences of cross threaded plugs. A frequency of $1.21 \times 10^{-4}$ per cylinder (at a 50\% confidence leve1) was used here.

Fraction of Fires Failing Improperly Closed Valve by Pressure (I36). Using the results of tests and calculations presented in Appendix $C$, it was determined that the cylinder would reach atmospheric pressure after approximately 17 minutes of exposure to the fire. After that time cylinder internal pressure would increase until cylinder failure. It was assumed that all improperly closed valves would begin to leak as soon as the cylinder internal pressure exceeded atmospheric. The fraction of fires lasting long enough to cause this type of failure was found to be 0.20 .

Plug Threads Stripped (X37). No plugs were found to have stripped threads during the time period covered by the survey. At a $50 \%$ confidence level, a frequency of $1.21 \times 10^{-4}$ per cylinder would be expected.

Plug Not Tight $(\times 38)$. No loose plugs were reported in the survey. A frequency of $1.21 \times 10^{-4}$ per cylinder was assumed.

Fraction of Fires Failing Improperly Situated Valve by Pressure (I39). The assumptions made in analyzing this event are the same as those for event 136. As a result, the same fraction, 0.20 was used.

Plug Hit and Loosened During Handling $(X 40)$. This event was not observed during the time period covered by the survey. A rate of $1.21 \times 10^{-4}$ per cylinder was used, based on a $50 \%$ confidence lever.

Plug Exposed to Impact Forces (X41). Since the valve and plug are similarly located at opposite ends of the cylinder, the same value used for valve exposure to impact forces was used here. A value of 0.13 per accident was given to event $\mathrm{X} 41$.

Flying 0bject Strikes Plug (X42). Because of the size of the plug relative to the overall cylinder size, and the fact that it occupies a position on the cylinder similar to the valve, a value of $1.6 \times 10^{-3}$ (the same as for event X27) was used. 
Plug Closure Packaging Error Not Detected $(x 43)$. This element was given an expected occurrence of 1.00 since values used for package conditions were derived from survey data.

Normal Transport Forces Cause Plug to Fail (X44). A normal plug would not be expected to fail under normal transport conditions. A plug so defective as to possibly fail in the normal transportation mode would almost certainily fail or be detected during normal filling and handling operations. Because this is such an improbable event, a frequency of $10^{-6}$ per container was used.

Probe Strikes Cylinder $(X 45)$. Because a 11 cylinder punctures are considered in event $\mathrm{X} 47$, this event was assigned a frequency of 1.00 per accident.

Fraction of Impact Forces Failing Properly Situated Valve (X46). Based on the results of actual cylinder tests (References 2, 3, and 4), it was assumed that impact forces equivalent to those present in a 3-meter drop test would be sufficient to cause valve failure. Figure 5.2 indicates that a fraction of 0.05 of the impact forces are severe enough to cause this type of failure.

V/R Sufficient to Puncture Cylinder (X47). The velocity to probe radius ratio $(V / R)$ of a puncture probe is a measure of its ability to puncture the cylinder. Detailed information on the puncture environment and $V / R$ distributions for large cylinders were not available for this study. Therefore, as explained in Section 5, an estimate of the frequency of puncture based on data from the accident records of gasoline shipments was derived. A puncture frequency of $1.35 \times 10^{-4}$ per accident was determined. This represents only an estimate of the puncture environment, and to determine the full effect of using this estimate a sensitivity analysis was carried out and results shown in Section 11. Due to the nature of the analysis, it was impossible to distinguish between defective cylinders, non-defective cylinders, defective valves, non-defective valves, etc. Therefore, all of the values for the puncture events are combined here.

Fraction of Impact Forces Failing Improperly Situated Valve (I48). If the overpack is not present, the valve is exposed to impact forces without a 
protective cover. It was arbitrarily assumed that an improperly situated valve would fail at one half the failure level of a properly installed valve, a drop of 1.5 meters. The distribution curve shown in Section 5 gives a fraction of 0.07 for this event.

Puncture Probe Generated by Accident (X49). This event was conservatively assumed to occur in all accidents. Therefore a value of 1.00 was used.

Natural Puncture Probe Present $(\times 50)$. It was assumed here that puncture probes of some form are always present in the area of an accident. The value for this event was set at 1.00 .

High H/U Factor (X51). Although no occurrences were noted in the survey, a total of zero observations in a sample size of 5712 cylinder implies an occurrence rate of $1.21 \times 10^{-4}$ per cylinder at a $50 \%$ confidence level.

Fraction of Flying Objects Failing Properly Situated Valve (I52). The valve is one of the weakest points of the cylinder. If we assume that it is relatively fragile (as the skin of a gasoline tanker), then a frequency of $3.3 \times 10^{-2}$ per object strike can be used. Based on the results of tests conducted at Paducah, Kentucky on valves similar to those used on the $21 / 2$-ton cylinders, it is felt that the use of this frequency is conservative.

Packaging Error in H/U Factor Not Detected (X53). Packaging procedures for filling $U_{6}$ cylinders require that the cylinder be inspected before filling, double samples be taken and analyzed, and that the cylinder interior pressure be subatmospheric before shipment. Sufficient contaminants inside the $U_{6}$ cylinder to cause criticality at the enrichment levels considered here would be detected at any one or all of the above three steps. Only if all three of these required steps were omitted from the filling and handling procedures could the error go undetected. The probability of one of these steps being left out of the sequence is very smal1, therefore a probability of doing so was assigned a frequency of $10^{-4}$ per cylinder. The frequency of missing a11 three steps, therefore, is on the order of $10^{-12}$ per cylinder. This value was used for event $\times 53$.

Fraction of Flying Objects Failing Improperly Situated Valve (I54). An explanation of the failure frequency for properly situated valves was presented 
in event I52. Since it was impossible to assess the degree of the packaging error, it was arbitrarily assumed that forces required to fail the improperly positioned valve occur 10 times more frequently in the accident environment. A fraction of 0.33 per flying object strike was used for event I54.

Cylinder Severely Corroded (X55). Results from the container survey indicate that a total of three cylinders were removed from service due to corrosion or deterioration. Based on this, a frequency of $5.25 \times 10^{-4}$ per cylinder was used.

Cylinder Deteriorated (X56). This element was included in event X55 and its value set to zero here.

X57 Through $\times 59$. Not used.

Fraction of Criticalities Failing Properly Closed Valve (I60). It was assumed that all criticalities would cause failure of the valve. Therefore the value used here was 1.00 .

X61. Not used.

Fraction of Criticalities Failing Improperly Closed Valve (I62). For reasons set forth in the evaluation of elements I60, the value used here was set at 1.00 .

X63. Not used.

Fraction of Criticalities Failing Improperly Situated Valve (I64). As was done in elements I60 and I62, the value used here was set at 1.00.

X65 Through X69. Not used.

Fraction of Fires Failing Non-Defective Plug By Pressure (170). As was the case with fire-caused pressure failing the non-defective valve, this event has been included in the cylinder failure event. This was done because the cylinder, valve, and plug are all rated, built, and tested to the same pressure level. It is therefore impossible to say which element will cause failure of the shipping package in the fire environment. The cylinder was conservatively chosen as the failure element. The fraction used here was therefore set at zero. 
X71. Not used.

Fraction of Fires Failing Defective Plug by Pressure (I72). It was assumed that a defective plug would fail at the same level as a defective valve. For the reasons presented in the analysis of event I36, the fraction used for this event was 0.20 .

X73 Through $X 77$. Not used.

Fraction of Impact Forces Failing Defective Plug (I78). The location of the plug in the cylinder is such that any impact or flying object striking the plug would tend to drive the plug into the cylinder. It was therefore felt that a flying object would not cause failure of the plug, either defective or non-defective. Therefore the value associated with this event was zero.

X79. Not used.

Fraction of Impact Forces Failing Non-Defective Plug (I80). For the reasons detailed in the explanation of element I78, this event was also assigned a value of zero.

X81 Through $\mathrm{x} 83$. Not used.

Fraction of Flying Objects Failing Defective Plug (I84). For the reasons outlined in the description of event I78, this event was given a value of zero.

X85. Not used.

Fraction of Flying Objects Failing Non-Defective Plug (I86). For the reasons cited in the analysis of event I78, this event was assigned a value of zero.

X87 Through $\times 89$. Not used.

Fraction of Criticalities Failing Defective Plug (I90). This event was conservatively given a value of 1.00 .

X91. Not used.

Fraction of Criticalities Failing Non-Defective Plug (192). This element was conservatively assigned a fraction of 1.00 . 
X93 Through X101. Not used.

Tiedowns Fail (X102). In order for this event to contribute to the release of $\mathrm{UF}_{6}$, the cylinder must also fall from the vehicle after becoming unattached. The size of the cylinders dictates that such an event be classified as an accident. The frequency of this event was therefore included with the accident rates and this event has a value of zero to avoid double counting the event.

Weld Defective from Poor Welding Procedures (X103). Cylinder welds are inspected using $x$-ray techniques during manufacture. A weld defective enough to cause a serious weakness in the cylinder should be detected during these inspections. It is remotely possible, however, that such a weld could slip through the $Q / C$ process. For that reason a probability of $10^{-6}$ per cylinder was used.

X104 Through $108, \times 110$ Through $\times 113$. These events relate to the cylinder remaining inside the overpack during the accident. They will be covered in the next section.

Cylinder Lost from Overpack (X109). The protective overpack is designed to remain intact in a 11 but the most severe accidents. Overpack drop tests conducted at Oak Ridge, Tenressee ${ }^{(2)}$ included end-on and corner over center of gravity tests from a height of $9 \mathrm{~m}$. The overpack was able to withstand these tests without coming apart. Based on energy calculations, an impact equivalent to an 18-meter drop onto the corner of the overpack could cause shearing of the closure bolts and a release of the cylinder from the overpack. Impact forces acting in the right orientation are expected in approximately $67 \%$ of a 11 accidents (end-on impacts). Approximately $0.5 \%$ of a 11 accidents involve impact forces equivalent to an 18-meter drop. (Corresponding to a velocity change of approximately $68 \mathrm{kph}$.) Based on these observations, a frequency of $3.35 \times 10^{-3}$ per accident was determined.

\section{Cylinder Stays in Overpack}

As previously noted, the analysis of release sequences for the $21 / 2$-ton cylinder with overpack was carried out in two parts. This, the second part, deals with release sequences occurring when the cylinder remains inside the overpack during the accident. In analyzing the sequences, the following 
events were reassessed and assigned values different from those in the first part of the analysis.

Fraction of Fires Causing Sufficient Pressure to Fail Defective Cylinder (I5). In the fire environment, heat is added more slowly and evenly to a $U_{6}$ cylinder inside an overpack than when the cylinder is directly exposed. Because of this, and because of a lack of data from actual fire tests of $U_{6}$ cylinders in overpacks (to failure), the cylinder failure analysis assumed that the vessel would fail when its contents reached a temperature of $138^{\circ} \mathrm{C}$. At this temperature, the $\mathrm{UF}_{6}$ would be in a liquid state and would completely fill the container. The internal cylinder pressure was assumed to be approximately atmospheric. An exposure of 83 minutes to a fire temperature of $800^{\circ} \mathrm{C}$ was calculated as the failure point. However, the duration curve for fires shown in Section 5 is based on a fire temperature of $1000^{\circ} \mathrm{C}$. The radiant heat flux from a $1000^{\circ} \mathrm{C}$ fire is double that from a $800^{\circ} \mathrm{C}$ fire. The container failure analysis assumed that the entire surface of the overpack was exposed to the fire. However, for objects the size of UF 6 cylinders, it was felt that a smaller exposed fraction was more realistic. It was assumed for the purpose of this analysis that $50 \%$ of the surface area of the overpack was exposed to the fire. Therefore, the failure times $\left(50 \%\right.$ exposure at $1000^{\circ} \mathrm{C}$ versus $100 \%$ exposure at $800^{\circ} \mathrm{C}$ ) are identical, and the curve shown in Section 5 is suitable. Following the same line of reasoning used in the evaluation of event 15 in the first portion of the analysis (i.e., the defective cylinder will fail in $3 / 4$ the time necessary for a non-defective one) a failure time of approximately 62 minutes was calculated. The duration curve shown in Figure 5.1 gives a value of less than 0.01 for fires lasting longer than this time. Therefore a value of 0.01 was used for I5.

Fraction of Fires Causing Sufficient Pressure to Fail Non-Defective Cylinder (I8). As explained in the evaluation of event I5, a failure time of 83 minutes was calculated for a non-defective cylinder with overpack. The duration curve shown in Figure 5.1 does not go past 40 minutes. If it is assumed that the curve is linear between 40 and 83 minutes, then a fraction of approximately $9 \times 10^{-3}$ fires lasting longer than 83 minutes is indicated. This value was used for event 18. 
Fraction of Impact Forces Failing Defective Cylinder (I12). Based on the calculated failure thresholds, an overpack adds the equivalent of approximately 13.5 meters (drop height) to the failure threshold of the $21 / 2$-ton cylinder. A failure threshold of 4.5 meters was used for the defective cylinder without overpack. Adding the protection afforded by the overpack, a total failure level equivalent to an 18-meter drop was determined. Figure 5.2 shows that only about $0.5 \%$ of a 11 expected truck accidents exceed this 1 evel. A value of 0.005 was used for this event.

Fraction of Impact Forces Failing a Non-Defective Cylinder (I15). An impact force equivalent to a drop of 22.5 meters was assumed to cause failure of the cylinder-overpack combination. Forces of this intensity are not expected to occur in truck accidents. A value of $10^{-3}$ was used for this inprobable event.

Flying Object Strikes Valve (X27). Because the overpack acts as a valve protector, flying objects cannot strike the valve directly. A value of zero was used for event $\times 27$.

Valve Cover Dislodged (X29). The value used for this event was zero. Since no valve cover is used with cylinders in overpacks, no valve cover can be dislodged.

Fraction of Fires Failing Improperly Closed Valve by Pressure (I36). Earlier analyses (events 15 and I8) explained the mechanisms by which the cylinder fails explosively due to excess internal pressure. It was assumed in the first portion of the analysis that defective and improperly closed valves would fail when the pressure inside the vessel reached atmospheric. To maintain consistency, the same assumption was made here. Therefore, a defective valve will fail after an 83-minute exposure to the fire. A fraction of $9 \times 10^{-3}$ was used for this event.

Fraction of Fires Failing Improperly Situated Valve by Pressure (I39). This event is similar to event I36. The reasoning used in evaluating that event is used here also. A value of $9 \times 10^{-3}$ was used here also.

Flying Object Strikes Plug (X42). The overpack protects the plug from flying objects. If the cylinder remains inside the overpack, flying objects cannot directly strike the plug. The value assigned to this event was zero. 
Fraction of Impact Forces Failing Properly Situated Valve (I46). Tests conducted on a prototype overpack (virtually identical to those used now ${ }^{(4)}$ ) showed that in a 9-m end-on drop test, no damage was done to the cylinder inside. If we assume conservatively that this is the limit of protection given by the overpack, then an equivalent drop height to fail the valve can be determined. In the previous part of the analysis, a failure height of $3 \mathrm{~m}$ was used for the valve when the cylinder was not protected by the overpack. Therefore, it was assumed that an impact equivalent to a 12-m drop would be sufficient to cause valve failure if the cylinder remains in the overpack. The accident environment information indicates that approximately $1 \%$ of all accidents exceed this level. A value of 0.01 was used.

V/R Sufficient to Puncture Cylinder (X47). The summary of failure thresholds shown in Section 6 indicates that an increase of approximately $30 \%$ in the puncture probes energy is required to break the cylinder when it is in the overpack. Based on the frequency used to describe bare cylinder puncture failures, and arbitrarily assuming a linear puncture frequency curve, a puncture frequency of $1.04 \times 10^{-4}$ per accident was determined and used for this event. A sensitivity study was done (Section 11) to determine the effect of this value on the overall risk calculation.

Fraction of Impact Forces Failing Improperly Situated Valve (I48). The evaluation of this event is similar to that of event I46. As was done in the first portion of the analysis, a failure threshold of 1.5-m drop height was used for an unprotected improperly situated valve. Adding the protection provided by the overpack yields an expected failure threshold of $10.5 \mathrm{~m}$ for a protected valve. Forces of this magnitude are expected in about $1.5 \%$ of all accidents. A value of 0.015 was used.

Fraction of Flying Objects Failing Properly Situated Valve (I52). A flying object causing valve failure through the overpack would be classified as a puncture probe. All puncture failures were considered in the evaluation of event X47. The value used for event I52 was zero.

Fraction of Flying Objects Failing Improperly Situated Valve (I54). See Event I52. Value used here was zero. 
Fraction of Fires Failing Defective Plug By Pressure (172). Defective plugs were assumed to fail at the same pressure as defective valves. Therefore, a fraction of $9 \times 10^{-3}$ was used for this event.

Overpack Damaged From Handling (X104). No grossly damaged overpacks were observed during the survey period. At a $50 \%$ confidence level, a damaged overpack can be expected at a rate of $1.23 \times 10^{-4}$ per container.

Closure Bolts Loose (X105). Approximately 80 overpacks were received with loose closure bolts during the period covered by the survey. This implies an occurrence rate of $1.42 \times 10^{-2}$ per cylinder.

Mating Surfaces Damaged (X106). A total of twelve occurrences were observed during the survey period. A frequency of $2.13 \times 10^{-3}$ was therefore used.

Sealing Gasket Not Present (X107). Since no observations of this event were recorded, an expected frequency of $1.23 \times 10^{-4}$ per cylinder was used (at a $50 \%$ confidence level).

Sealing Gasket Deteriorated $(x 108)$. This event was noted four times on the survey resulting in a frequency of $7 \times 10^{-4}$ per cylinder.

Cylinder Lost From Overpack (X109). For this portion of the analysis, it was assumed that the cylinder remained inside the overpack. Therefore a value of zero was assigned to this event.

Impact Forces Exceed Limit of Overpack (X110). This event was included in the analysis of events $I 12$ and II5 and given a value of zero here.

Fire Sufficient to Fail Gasket ( $X 111)$. The foam rubber gasket between the halves of the overpack at the mating surface were conservatively assumed to fail in any fire situation. A value of 1.00 was used for this event.

Probe With Sufficient Force to Break Overpack (X112). The energy required to puncture the overpack is approximately $1 / 3$ that required to puncture the cylinder. Again, assuming a linear probability distribution, a probability of $4.05 \times 10^{-4}$ per accident was calculated. 
$\mathrm{UF}_{6}$ Cylinder Break Fails Overpack (X113). It was assumed that a11 accident forces causing failure of the $U_{6}$ cylinder would al so cause failure of the overpack. A value of 1.00 was used.

\subsubsection{0-Ton (Type 48X) Cylinder Transported by Truck Without Overpack}

This analysis uses the basic format set as in the $21 / 2$-ton cylinder analysis. Since both types of shipping packages are transported by truck, many of the basic event probabilities remain the same. The following paragraphs describe only the events whose probabilities are different from those used in the previous (2 1/2-ton cylinder) analysis.

Accident 0ccurs With Fire $(X 1)$. The average shipment distance for this configuration is approximately $1040 \mathrm{~km}$. Using the accident frequencies described in the previous analysis, a rate of $2.58 \times 10^{-5}$ accidents with fire per shipment was determined.

Weld Defective From Corrosion (x2). This event was included with event $X 56$ and given a value of zero here.

Weld Hit and Damaged During Handling (x3). Results of the survey indicate a rate of $1.43 \times 10^{-4}$ per container.

Cylinder Non-Defective (X4). This event was conservatively assigned a value of 1.00 .

Fraction of Fires Causing Sufficient Pressure to Fail Defective Cylinder (I5). The description of failure thresholds from Section 6 shows a failure time of 46 minutes for a non-defective $48 x$ cylinder exposed to a petroleum fire. Using the reasoning described in the bare $21 / 2$-ton cylinder analysis, a time to failure of 35 minutes was calculated for a defective cylinder. Based on the fire duration curve presented in Section $5,96 \%$ of a11 truck accident fires are expected to burn less than this time. A value of 0.04 was used.

Cylinder Exposed to Force (X6). For the reasons given in the $21 / 2$-ton cylinder analysis, this event was given a value of 0.89 per accident.

Accident 0ccurs Without Fire (x7). The same rate used in the Type 30B cylinder analysis $\left(1.53 \times 10^{-6}\right.$ per kilometer $)$ was used for this event. Based 
on an average shipment distance of $1040 \mathrm{~km}$, the expected frequency of accidents without fire is $1.59 \times 10^{-3}$ per shipment.

Fraction of Fires Causing Sufficient Pressure to Fail Non-Defective Cylinder (18). A petroleum fire of 46 minutes duration is required to overpressurize the $48 X$ cylinder, causing a cylinder rupture. Figure 5.1 shows that approximately $1.3 \%$ of all expected fires burn for this length of time. A fraction of 0.013 was used for this event.

Flying Object Generated in Accident (X9). For the reasons presented in the evaluation of this event in the 2 1/2-ton cylinder analysis, a value of 0.89 per accident was used.

Flying Object Strikes Cylinder $\left(x_{10)}\right.$. Puncture failures are considered in event $X 47$. This event was incorporated with event $X 47$. Therefore the value used here is 1.00 .

Cylinder Defect Not Detected (X11). Because frequencies of cylinder defects were derived from survey information, a value of 1.00 was conservatively applied to this event.

Fraction of Impact Forces Failing Defective Cylinder (I12). Since the same failure threshold was used for both the $48 \mathrm{X}$ and Type 30B cylinders, a fraction of 0.04 was used for this event also.

Normal Transport Forces Cause Defective Cylinder Failure (X13). This event is identical to its counterpart in the $21 / 2$-ton cylinder analysis. The same value was used for both, $10^{-6}$ per cylinder.

Valve Properly Closed (X14). A value of 1.00 was conservatively assumed for this event.

Fraction of Impact Forces Failing Non-Defective Cylinder (I15). Again, because identical impact failure thresholds were used for both $48 \mathrm{X}$ and Type $30 \mathrm{~B}$ cylinders (bare), the fraction of impact forces failing both is the same, 0.02 .

Valve Not Closed Tightly (X16). Because no events of this nature were recorded during the survey period, a value of $9.9 \times 10^{-5}$ per container (based on a $50 \%$ confidence level) was used. 
Valve Defective (X17). The survey results showed that 60 Type $48 \mathrm{X}$ cylinders had valves replaced during the period 1971-1975. It was learned that only a third of these were replaced due to defective valves; the others required replacement because of clogged ports, etc. Therefore, an expected occurrence rate of $2.86 \times 10^{-3}$ per cylinder was used.

Valve and Vessel Threads Mismatched (X18). Because no examples of this packaging defect were observed, a rate of $9.9 \times 10^{-5}$ per cylinder was used (based on a $50 \%$ confidence level).

Fraction of Flying Objects Failing Non-Defective Cylinder (I19). Because failures caused by flying objects and puncture probes are all combined in event $\mathrm{X47}$, this event was given a zero value.

Valve Threads Stripped (X20). Again, because no observations of this event were noted in the survey, a frequency of $9.9 \times 10^{-5}$ was used.

Fraction of Flying Objects Failing Non-Defective Cylinder (I21). This event was combined with event $X 47$ and given a value of zero here.

Valve Assembly Loose (X22). Loose valve assemblies were noted seven times during the survey period for a frequency of $10^{-3}$ per cylinder.

Vessel Shipped Without Protective Valve Cover (X23). A valve cover missing from a fuel cylinder would be rather conspicuous. No observations were made by those plants surveyed; therefore a value of $9.9 \times 10^{-5}$ was used with a $50 \%$ confidence level.

Valve Hit During Handling (X24). One occurrence was noted in the survey for an expected frequency of $1.43 \times 10^{-4}$ per cylinder.

Fraction of Criticalities Failing Defective Cylinder (I25). It was conservatively assumed that all criticalities would cause cylinder failure, whether the cylinder was defective or not. A fraction of 1.00 was used here.

Valve Properly Situated on Cylinder (X26). This element was conservatively assigned a value of 1.00 .

Flying Object Strikes Valve (X27). The same valve is used on all cylinders studied in the risk analysis, and on all cylinders, the valve is partially protected by the cylinder skirts. The same value for this event was used for all cylinders, i.e., $1.6 \times 10^{-3}$ per accident. 
Fraction of Criticalities Failing Non-Defective Cylinder (I28). It was assumed that all criticalities would cause cylinder failure. This element was given a value of 1.00 .

Valve Cover Dislodged (X29). Impact forces required to dislodge the valve cover were assumed to be the same as forces required to cause valve failure. A frequency of $9.50 \times 10^{-3}$ per accident was used. This is equivalent to the product of values assigned to events $X 30$ and I46.

Value Exposed to Impact Force $(\times 30)$. The analys is of this event was identical to its counterpart in the Type 30 cylinder analysis. A value of 0.19 per accident was used.

Packaging Error Not Detected (X31). Because frequencies for packaging errors were derived from observed data, this event was assumed to have a value of 1.00 .

Normal Transportation Forces Cause Defective Valve to Fail (x32). Since this event is identical to event $\times 32$ of the $21 / 2$-ton cylinder analysis, a value of $10^{-6}$ was used.

Plug Closure Non-Defective (X33). This event was given a value of 1.00 . In the context of the fault tree, this value is conservative.

Fraction of Fires Failing Properly Closed Valve by Pressure (134). This event was combined with Event 18 for reasons given in the 2 1/2-ton cylinder analysis. Its value here is zero.

Plug and Vessel Threads Mismatched (X35). Because no observations of this event were made during the survey, a value of $9.9 \times 10^{-5}$ was used.

Fraction of Fires Failing Improperly Closed Valve by Pressure (I36). Throughout the entire analysis it was assumed that defective valves and plugs would fail when the internal cylinder pressure exceeded atmospheric. From the results of tests performed on smaller cylinders ${ }^{(5)}$ it was determined that the $48 x$ cylinder would be at approximately atmospheric pressure (internally) after 27 minutes exposure to the fire. Figure 5.1 shows that less than $6 \%$ of all truck fires are expected to last that long. A value of 0.06 was used for this event. 
Plug Threads Stripped (X37). Since no stripped plug threads were observed during the survey, a value of $9.9 \times 10^{-5}$ was used.

Plug Not Tight $(\times 38)$. This event was also assigned a value of $9.9 \times 10^{-5}$ because no events were observed in the survey.

Fraction of Fires Failing Improperly Situated Valves by Pressure (I39). The evaluation of this event is identical to that of 136 . The same assumptions were made in both. The value used here, therefore, is 0.06 .

Plug Hit and Loosened During Handling (X40). This event was not observed during the survey period. A value of $9.9 \times 10^{-5}$ (at a $50 \%$ confidence leve 1 ) was used.

Plug Exposed to Impact Forces (X41). As was done in the $21 / 2$-ton cylinder analysis, this event was given the same frequency as event $\times 30$, or 0.19 per accident.

Flying Object Strikes Plug (X42). Since the valve and plug are located in similar positions on opposite ends of the cylinder, the same value was used in the plug as was used for the valve. A frequency of $1.6 \times 10^{-3}$ per accident was used.

Plug Closure Packaging Error Not Detected (X43). Because packaging closure error frequency rates were determined from survey data, this element was given a value of 1.00 .

Normal Transport Forces Cause Plug to Fail (X44). This event was given a value of $10^{-6}$. The same frequency was used for the 2 1/2-ton cylinder.

Probe Strikes Cylinder $(x 45)$. Because all cylinder punctures are considered in event $\times 47$, the value used for this event was set at 1.00 .

Fraction of Impact Forces Failing Properly Situated Valve (I46). The evaluation of this event is identical to that of event I46 in the $21 / 2$-ton cylinder analysis. Therefore an expected frequency of 0.05 per accident was used here.

V/R Sufficient to Puncture Cylinder (X47). A value of $1.34 \times 10^{-4}$ per accident was used for this event. See the $21 / 2$-ton cylinder analysis of event $\mathrm{X} 47$ for a full explanation. 
Fraction of Impact Forces Failing Improperly Situated Valve (I48). This event was handled in the same manner as its counterpart in the $21 / 2$-ton cylinder analysis. The valves used on both cylinders are the same. Assumptions concerning failure levels were also the same. A value of 0.07 was used for this event.

Puncture Probe Generated by Accident (X49). A value of 1.00 was conservatively applied to this event.

Natural Puncture Probe Present (X50). This event was also conservatively given a value of 1.00 .

High H/U Factor (X51). No occurrences of this event were recorded, therefore a frequency of $9.9 \times 10^{-5}$ per container was used.

Fraction of Flying 0bjects Failing Properly Situated Valve (152). This event was evaluted in the same manner as for the Type 30B cylinder. A value of $3.3 \times 10^{-2}$ per strike was used here also.

Packaging Error in H/U Factor Not Detected (X53). A value of $10^{-12}$ was used for this event frequency. See event $X 53$ of the $21 / 2$-ton (Type 30B) analysis for details.

Fraction of Flying Objects Failing Improperly Situated Valve (I54). A factor of 0.33 per strike was used for this event. See the analysis of event 154 in the $21 / 2$-ton cylinder section for a more complete evaluation.

Cylinder Severely Corroded (X55). No examples of this event were recorded during the survey period. At a $50 \%$ confidence level, a value of $9.9 \times 10^{-5}$ was used.

Cylinder Deteriorated (X56). This element was included in event X55 and was given a zero value here.

X57 through X59. Not used.

Fraction of Criticalities, Failing Properly Closed Valve (I60). It was conservatively assumed that all criticalities would cause valve failure. A value of 1.00 was used.

X61. Not used. 
Fraction of Criticalities failing Improperly Closed Valve (162). This event was conservatively given a value of 1.00 .

X63. Not used.

Fraction of Criticalities Failing Improperly Situated Valve (164). This event was conservatively assigned a value of 1.00 .

X65 through X69. Not used.

Fraction of Fires Failing Non-Defective Plug by Pressure (170). This event was included with the cylinder failure event. Its value here is zero. See the 2 1/2-ton cylinder analysis for further explanations.

X71. Not used.

Fraction of Fires Failing Defective Plug by Pressure (172). It was assumed that a defective plug would fail at the same pressure level as a defective valve. For reasons presented in the evaluation of event I36, a value of 0.06 was used.

X73 through $X 77$. Not used.

Fraction of Impact Forces Failing Defective Plug (I78). This event was given a value of zero. See the 2 1/2-ton cylinder evaluation for analysis.

X79. Not used.

Fraction of Impact Forces Failing Non-Defective Plug (180). This event was given a value of zero. See the $21 / 2$-ton cylinder evaluation for analysis.

X81 through X83. Not used.

Fraction of Flying Objects Failing Defective Plug (I84). For reasons cited in the 2 1/2-ton cylinder analysis, this event was given a value of zero.

X85. Not used.

Fraction of Flying Objects Failing Non-Defective Plug (I86). For reasons cited in the $21 / 2$-ton cylinder analysis, this event was given a value of zero.

$\underline{87}$ through $\times 89$. Not used. 
Fraction of Criticalities Failing Defective Plug (I90). This event was conservatively given a value of 1.00 .

X91. Not used.

Fraction of Criticalities Failing Non-Defective Plug (192). This event was conservatively assigned a value of 1.00 .

X93 through $\times 101$. Not used.

Tiedowns Fail $(x 102)$. The incidences of tiedown failure were considered to be included with the accident rate, and a value of zero was used for this event. The evaluation is detailed in the $21 / 2$-ton cylinder analysis.

Weld Defective From Poor Welding Procedure (X103). A value of $10^{-6}$ per container was used for this event, the same value used in the $21 / 2$-ton cylinder analysis.

\subsubsection{0-Ton (Type 48X) cyl inder Transported by Truck With Overpack}

The third shipping container configuration analyzed in the risk assessment was the 10-ton (Type 48X) cylinder with overpack transported by truck. The addition of an overpack changes this configuration somewhat from the previous one. However, since the same basic cylinder was used, many of the event frequencies are identical.

The analysis for the overpack cylinder configuration was handled in two parts. The first part was concerned with a cylinder which had been lost from the overpack during a transport accident. The second portion dealt with the case where the cylinder remains in the overpack during the transportation accident.

\section{Cylinder Lost From Overpack}

Since this portion of the analysis is nearly identical to the analysis performed for the bare $48 \mathrm{X}$ cylinder shipped by truck, only those events with values different from the previous analysis were addressed here. All other values remain the same, as presented in Section 9.1.2.

Accident 0ccurs with Fire (X1). Information from Sandia studies (1) show that approximately $1.6 \%$ of all truck accidents involve fire. Using a truck 
accident rate of $1.55 \times 10^{-6}$ accident per kilometer, it was determined that accidents involving fire could be expected at a rate of $2.48 \times 10^{-8}$ per kilometer. For an average trip length of 420 kilometers, the rate was expressed as $1.04 \times 10^{-5}$ per shipment. It was assumed that cylinders were exposed to the fire in all truck accidents with fire.

Accident 0ccurs Without Fire $(X 7)$. The same rate used in the Type $48 X$ cylinder analysis $\left(1.53 \times 10^{-6}\right.$ per kilometer $)$ was used for this event. Based on an average shipment distance of $420 \mathrm{~km}$, the expected frequency of accidents without fire is $6.43 \times 10^{-4}$ per shipment.

Vessel Shipped Without Protective Valve Cover (I23). Since the vessels are shipped initially in a protective overpack, no valve cover as such is used. The value used for this event is 1.00 .

Valve Cover Dislodged $(X 29)$. Since no valve cover is used, this event is impossible. The value assigned to this event was zero.

Tiedowns Fail (X102). No information is available on the frequency of tiedown failures expected during the transport of $U_{6}$ cylinders. Past accidents have shown, however, that an accident situation is usually present when the container's tiedowns fail and the container falls from the vehicle. For this study, the incidences of tiedown failure were considered to be included with the accident rate, and a value of zero was used for this event.

Cylinder Lost From Overpack (X109). A corner or end-on drop from a height of 18 meters was assumed to cause failure of the latching mechanism and allow the cylinder to escape from the overpack (see 2 1/2-ton cylinder with overpack analysis, event $\times 109)$. The fraction of accidents with impact forces acting in the right orientation is 0.67 . Approximately $5 \times 10^{-3}$ accidents involve impact forces equivalent to an 18-meter drop. A frequency of $3.35 \times 10^{-3}$ per accident was used for this event.

\section{Cylinder Remains in Overpack}

The previous portion of the 10-ton cylinder, with overpack, by truck analysis dealt with the loss of the container from the overpack during an accident. This portion of the analysis examines the changes in values assigned to the basic fault tree events when the cylinder is not lost from the overpack 
during the accident. The elements discussed below are only those whose values were changed from the values used in the first (bare cylinder) portion of the analysis. A11 other events retained their previous values.

Fraction of Fires Causing Sufficient Pressure to Fail Defective Cylinder (I5). The analysis carried out in Appendix $C$ and summarized in Section 6 estimated that a non-defective cylinder inside a protective overpack would fail after a 156-minute exposure to fire. Following the same 1 ine of reasoning used in the analysis of the 2 1/2-ton cylinder with overpack (event I5), a time to failure of 117 minutes was determined for a defective 10-ton cylinder. The duration curve in Figure 5.1 shows that less than $0.1 \%$ of al1 fires are expected to last 117 minutes or longer. A value of 0.001 was therefore used for this event.

Fraction of Fires Causing Sufficient Pressure to Fail Non-Defective Cylinder (I8). A 156 -minute exposure to a $1000^{\circ} \mathrm{C}$ fire was estimated as the failure threshold for a non-defective cylinder within an overpack. Information presented in Section 5 shows that essentially no fires are expected to burn longer than 156 minutes. A value of $1.0 \times 10^{-4}$ was used for this inhibit event.

Fraction of Impact Forces Failing Defective Cylinder (112). In previous analyses, it was assumed that a defective cylinder would fail at one half the impact failure threshold of a non-defective cylinder. In the case of the 10-ton cylinder, this corresponds to an impact equivalent of a 4.5-m drop. Analysis of the overpack showed that it raised the container's failure threshold by the equivalent of approximately $3.4 \mathrm{~m}$. Therefore, a defective cylinder protected by an overpack was assumed to fail when subjected to an impact equivalent to a drop from a height of $7.9 \mathrm{~m}$. This corresponds to a velocity change of approximately $45 \mathrm{kph}$. Using Figure 5.2 , it was determined that impacts of this severity would occur at a rate of $3.0 \times 10^{-2}$ per accident.

Fraction of Impact Forces Failing Non-Defective Cylinder (I15). A failure threshold equivalent to a drop from $12.4 \mathrm{~m}$ was calculated for a nondefective cylinder protected by an overpack. This corresponds to a velocity change of $56.5 \mathrm{kph}$. The corresponding rate for impacts of this severity is approximately $1.50 \times 10^{-2}$ per accident (from Figure 5.2). 
Flying Object Strikes Valve (X27). The valve is protected from direct flying object strikes by the overpack. A value of zero was therefore used for this event.

Fraction of Fires Failing Improperly Closed Valve by Pressure (I36). This event was analyzed in the same manner as its corresponding event in the 2 1/2-ton cylinder with overpack analysis. Time to failure for the defective or improperly closed valve is 156 minutes. The fraction of fires lasting this long was determined to be $0.01 \%$. A value of $1.0 \times 10^{-4}$ was used for this gate.

Fraction of Fires Failing Improperly Situated Valve by Pressure (I39). See event 136 for the reasoning used in the analysis of the event. A value identical to that of event 136 was used here, $1.0 \times 10^{-4}$.

Flying Object Strikes Plug (142). The plug is protected from flying object strikes by the protective overpack. A value of zero was used for this event.

Fraction of Impact Forces Failing Properly Situated Valve (I46). Using the failure threshold for a properly situated valve (a drop from $3 \mathrm{~m}$ ) and adding the protection of the overpack $(3.4 \mathrm{~m})$, a failure threshold of $6.4 \mathrm{~m}$ was determined. Figure 5.2 shows an expected frequency of $3.5 \times 10^{-2}$ per accident for the velocity change $(40 \mathrm{kph})$ associated with a drop from this height.

V/R Sufficient to Puncture Cylinder (X47). The sumary of failure thresholds presented in Section 6 indicates that an increase of approximately $60 \%$ in the puncture probe energy is required to breach the cylinder while it is in the overpack. Based on the frequency used for unprotected cylinder punctures $\left(1.34 \times 10^{-4}\right.$ per accident) and assuming that because of the increase in puncture probe energy required to breach the cylinder, the frequency is decreased by a factor of 0.6 , a puncture frequency of $8 \times 10^{-5}$ was used. Sensitivity studies were performed (see Section 11) which showed that the puncture events contributed relatively little to the overall risk, thereby justifying the use of this approximate value.

Fraction of Impact Forces Failing Improperly Situated Valve (148). An impact failure level of 1.5 meters has been used for an improperly situated 
valve. Adding the protection provided by the overpack, assumed to be $3.4 \mathrm{~m}$, a projected failure level of $4.9 \mathrm{~m}$ was determined. The fraction of impact

forces exceeding this level are expected to occur at a rate of $3.9 \times 10^{-2}$ per accident.

Fraction of Flying Objects Failing Improperly Situated Valve (I52). Because of a general lack of information with which to distinguish between flying objects and puncture probes, this element was combined with event $\times 47$. A value of zero was used here.

Fraction of Flying Objects Failing Improperly Situated Valve (I54). This event was also combined with event $\times 47$. Its value here is zero.

Fraction of Fires Failing Defective Plug by Pressure (I72). Defective valves and plugs were assumed to fail at the same pressure level. In event I36, a value of $1.0 \times 10^{-4}$ was used to describe the fraction of fires causing sufficient pressure to fail an improperly closed valve. This value was also used to describe plug failures.

Overpack Damaged From Handling $(X 104)$. No examples of this event were observed during the survey time period, therefore a value of $7.9 \times 10^{-4}$ was used (at a 50\% confidence level).

Closure Bolts Loose (X105). Again, no incidences of this occurrence were reported during the survey. Based on the sample size of 878 overpacks received, a value of $7.9 \times 10^{-4}$ per container was used.

Mating Surfaces Damaged $(X 106)$. The survey reported zero occurrences of this element. A value of $7.9 \times 10^{-4}$ per container was used.

Sealing Gasket Not Present (X107). This element was given a value of $7.9 \times 10^{-4}$ per container for reasons cited in the analysis of event $\times 106$.

Sealing Gasket Deteriorated (X108). This element was not experienced during the time period covered by the packaging survey. A value of $7.9 \times 10^{-4}$ per container was used.

Cylinder Lost From Overpack (X109). In this portion of the analysis, it was assumed that the cylinder remained inside the overpack. Therefore, a value of zero was used for event $X 109$ in this case. 
Impact Forces Exceed Limits of Overpack $(x \mid 10)$. This event was iricluded in events 112 and I15. It was given a zero value here.

Fire Sufficient to Fail Gasket (X111). As was done in the $21 / 2$-ton cylinder with overpack analysis, this event was conservatively assigned a frequency of 1.00 per fire.

Probe With Sufficient Force to Breach Overpack (x112). Using the logic discussed in the analysis of event $x 112$ of the $21 / 2$-ton cylinder with overpack analysis, a value of $2.67 \times 10^{-5}$ was determined.

$\mathrm{UF}_{6}$ Cylinder Breach Fails Overpack $(x 113)$. It was assumed that an explosive breaching of the cylinder caused by fire or criticality would also breach the overpack. A value of 1.00 was assigned to this event.

\subsubsection{4-Ton (Type 48Y) Cylinder Transported by Train}

The fourth segment of the analysis involved evaluation of the fault tree for the shipment of 14-ton (Type 48Y) cylinders (without overpacks) by train. Following is a description of the basic events input to the fault tree. The $48 Y$ clinder is very similar to the 10-ton $48 \times$ cylinder; many of the event frequencies are thus identical. Only those events whose values were changed will be described. All other values remain the same.

Accident 0ccurs With Fire (X1). The accident analysis work performed by Sandia ${ }^{(1)}$ concludes that fire will occur in train accidents at a rate of approximately $1.74 \times 10^{-8}$ per car $\mathrm{km}$. For an average trip distance of $800 \mathrm{~km}$, a frequency of $1.4 \times 10^{-5}$ per shipment is expected.

Weld Defective From Corrosion (X2). This event was included with event $X 56$ and was given a value of zero here.

Weld Hit and Damaged During Handling (X3). No occurrences of this event were reported in the survey. A value of $1.1 \times 10^{-4}$ per cylinder was assigned (at a $50 \%$ confidence level).

Cylinder Non-Defective (X4). This element was conservatively assigned a value of 1.00 .

Fraction of Fires Causing Sufficient Pressure to Fail Defective Cylinder (15). As explained in Section 6, calculations based on small 
size cylinder tests to failure indicated a 48-minute time-to-failure for a non-defective cylinder exposed to a petroleum fire. As in the previous analyses, it was assumed that all defective cylinders would fail within $75 \%$ of the time necessary to cause non-defective cylinder failures. A failure time of 36 minutes was thus determined. Fire environment information presented in Section 5 indicates that approximately $40 \%$ of all train accident fires are expected to last longer than this time. A value of 0.40 was used for this element.

Cylinder Exposed to Force $(X 6)$. This element was combined with elements 112 and 115 for the purpose of this study. Its value here is therefore 1.00 .

Accident Occurs without Fire (X7). Using an accident rate of $6.21 \times 10^{-6}$ accidents per kilometer and the fraction of accidents involving no fires, a rate of $6.20 \times 10^{-6}$ accidents without fire per kilometer was determined. For an average trip length of $800 \mathrm{~km}$, the expected occurrence frequency is $4.97 \times 10^{-3}$ per shipment.

Fraction of Fires Causing Sufficient Pressure to Fail Non-Defective Cylinder (18). As mentioned in the explanation of event I5, the fire failure threshold for a non-defective 14-ton cylinder is 48 minutes exposure to a $1000^{\circ} \mathrm{C}$ fire. Information presented in Section 5 indicates that $24 \%$ of all fires are expected to last longer than this time. A value of 0.24 was used.

Flying Object Generated in Accident (X9). This event was included with event $X 47$ and was therefore given a value of 1.00 here.

Fraction of Impact Forces Failing Defective Cylinder (I12). An impact failure threshold of $9 \mathrm{~m}$ for a non-defective cylinder was listed in Section 6 . A defective cylinder is expected to fail at half that, or $4.5 \mathrm{~m}$. This drop height corresponds to a velocity change of about $34 \mathrm{kph}$. The expected frequency of an impact force of this magnitude is $6 \times 10^{-3}$. This value was used for event I12.

Fraction of Impact Forces Failing Non-Defective Cylinder (I15). The impact failure threshold of the non-defective 14-ton cylinder is equivalent to a drop height of $9 \mathrm{~m}$, or a velocity change of $48 \mathrm{kph}$. Using the information presented in Figure 5.4, it was determined that forces of this magnitude occur at a rate of $2.50 \times 10^{-3}$ per accident. This value was used for event 115. 
Valve Not Closed Tightly (X16). No occurrences were noted during the survey period. At a $50 \%$ confidence level, with the same size involved in the survey, a rate of $1.1 \times 10^{-4}$ per cylinder can be used.

Valve Defective (X17). Results of the packaging condition survey show that 86 valves required replacement during the time period 1971-1975. It was learned that only a third of these valves required replacement because they are defective. The rest required replacement because of clogged ports, etc., and cannot be counted as defective. Based on the sample size, an expected frequency of defective valves of $4.5 \times 10^{-3}$ per container was determined.

Valve and Vessel Threads Mismatched (X18). No instances of mismatched or crossed threads were reported on the survey forms. For that reason, a value of $1.1 \times 10^{-4}$ per cylinder was assigned to the event.

Valve Threads Stripped (X20). As was the case in event $\times 18$, no instances of this packaging error were reported. Again, a value of $1.1 \times 10^{-4}$ was used for this event.

Valve Assembly Loose (X22). Nineteen instances of loose valve assemblies were noted during the survey. This implies an expected frequency of $3.0 \times 10^{-3}$ per cylinder.

Vessel Shipped Without Protective Valve Cover (X23). This element was not observed during the survey. A value of $1.1 \times 10^{-4}$ was assigned (at a $50 \%$ confidence level).

Valve Hit During Handling ( $\times 24)$. Based on the results of the packaging condition survey, a value of $7.9 \times 10^{-4}$ per cylinder was used.

Flying Object Strikes Valve (X27). A value of $1.6 \times 10^{-3}$ per accident was used. For more detail see the analysis of event X27 in the bare 10-ton cylinder, Section 9.1.2.

Valve Cover Dislodged (X29). Impact forces required to dislodge the valve cover were assumed to be the same as those required to cause valve failure. A frequency of $7.5 \times 10^{-4}$ per accident was used. This is equivalent to the product of values assigned to events $X 30$ and I46. 
Valve Exposed to Impact Force (X30). Ninety percent of all train accidents can be classified as impact or derailment accidents (the remainder are basically non-moving accidents). As in previous cylinder analyses, a $30^{\circ}$ acceptance angle was used. Assuming random orientation of the cylinder during the accident, a ratio of $7.5 \times 10^{-2}$ was determined.

Plug and Vessel Threads Mismatched (X35). No occurrences of mismatched or cross threaded plugs were noted on the survey. A value of $1.1 \times 10^{-4}$ was used.

Fraction of Fires Failing Improperly Closed Valve by Pressure (I36). As was done throughout the analysis, it was assumed that defective and improperly closed valves would leak when the internal pressure of the cylinder reached atmospheric. Using the results of small-size $U_{6}$ cylinder fire tests, it was determined that the internal pressure of the cylinder would reach atmospheric after approximately 28 minutes exposure to the fire. Results shown in Section 5 indicate that less than $58 \%$ of all expected fires will last this long. A value of 0.58 was used.

Plug Threads Stripped (X37). Based on results gathered from the container packaging survey, a value of $1.1 \times 10^{-4}$ was used for this event.

Plug Not Tight (X38). A value of $1.1 \times 10^{-4}$ was used for this event (at a $50 \%$ confidence leve 1 ).

Fraction of Fires Failing Improperly Situated Valve by Pressure (X39). This event was given the same value as event $136,5.8 \times 10^{-1}$.

Plug Hit and Loosened During Handling (X40). Since no incidences of this event were noted during the survey, a value of $1.1 \times 10^{-4}$ was used.

Flying Object Strikes Plug (X42). Flying object strikes and puncture probes were combined in event $X 47$. The value of this event is zero here.

Fraction of Impact Forces Failing Properly Situated Valve (I46). An impact force equivalent to a 3-m drop was assumed to cause valve failure. From Figure 5.4, it is evident that impact forces of this level can be expected in $1.0 \times 10^{-2}$ of all accidents. 
V/R Sufficient to Puncture Cylinder (X47). All puncture elements were combined in this event. Since no V/R distribution was available (the velocityto-radius ratio is the measure of a puncture probe's ability to break the cylinder) a single rate, based on rail accident data, was used. The train accident environment summary in Section 5 shows an expected frequency of punctures of $6.4 \times 10^{-4}$ per accident.

Fraction of Impact Forces Failing Improperly Situated Valve (I48). A defective or improperly situated valve was arbitrarily assumed to fail at a level of $1 / 2$ that of a non-defective or properly installed valve. Impact forces equivalent to a drop of $1.5 \mathrm{~m}$ can be expected in $7.5 \times 10^{-2}$ of a 11 train accidents.

Puncture Probe Generated by Accident (x49). It was determined from accident information presented in Reference 3 that $90 \%$ of al1 train accidents involve derailment or collisions (the remaining $10 \%$ are mostiy fires, or nonmoving type accidents). Only in the moving accidents would a puncture probe be generated. A value of 0.90 per accident was used for this event.

Fraction of Flying Objects Failing Properly Situated Valve (I52). Due to a lack of information concerning flying objects, this event was combined with event $\mathrm{X} 47$. The value used here is therefore zero.

Fraction of Flying Objects Failing Improperly Situated Valve (I54). This event was also combined with event $X 47$ because of lack of information on fiying object punctures. Data used to generate a frequency for $\mathrm{X} 47$ did not detail the type of puncture, i.e., puncture to cylinder or valve dislodged by puncture probe. This being the case, a value of zero was used here.

Cylinder Severely Corroded (X55). No badly corroded or deteriorated cylinders were reported during the survey period. Therefore a value of $1.1 \times 10^{-4}$ was used.

Cylinder Deteriorated (X56). This element was included with event $x 55$ and given a value of zero here.

Fraction of Fires Failing Defective Plug by Pressure (172). Because defective plugs and valves were all assumed to fail at the same level, a value of 0.58 was used here. 
Tiedowns Fail (X102). No information is available on the frequency of tiedown failures expected during the transport of $\mathrm{UF}_{6}$ cylinders. Past accidents have shown that when the container's tiedowns fail and the container falls from the vehicle, an accident is usually the result. For this study, the incidences of tiedown failure were considered to be included with the accident rate, and a value of zero used for this event.

\subsubsection{4-Ton (Type 48Y) Cylinder Transported by Truck}

The fifth and final segment of the analysis involved evaluation of the fault tree for the shipment of 14-ton (Type 48Y) cylinders (without overpacks) by truck. Following is a description of the basic events, many of which are the same as in Section 9.1.4 because of the similarity of the 10-and 14-ton cylinders. Only those events whose values were changed will be described. All other values remain the same as in the previous section.

Accident Occurs With Fire (X1). The average shipment distance for this configuration is about 375 kilometers. Using the accident frequency of $2.48 \times 10^{-8}$ per kilometer derived in Section 9.1 .1 (event $X 1$ ), a value of $9.3 \times 10^{-6}$ accidents with fires is expected.

Fraction of Fires Causing Sufficient Pressure to Fail Defective Cylinder (15). A failure time of 36 minutes was determined in the previous analysis. Information in Section 5 suggests that approximately $3 \%$ of a 7 truck accident fires are expected to last longer than this time. A value of 0.03 was used for this event.

Cylinder Exposed to Force (X6). For reasons given in Section 9.1.1, this event was given a value of 0.89 per accident.

Accident Occurs Without Fire (X7). Based on an average shipment distance of $375 \mathrm{~km}$, the expected frequency of accidents without fire is $5.74 \times 10^{-4}$ per shipment (see Section 9.1.1, event X7, for further explanation).

Fraction of Fires Causing Sufficient Pressure to Fail Non-Defective Cylinder (I8). The fire failure threshold for a non-defective 14-ton cylinder is 48 minutes exposure to a $1000^{\circ} \mathrm{C}$ fire. Information presented in Section 5 indicates that approximately $1.3 \%$ of all expected fires burn for this length of time. A fraction of 0.013 was used for this event. 
Flying Object Generated in Accident (X9). For reasons presented in Section 9.1.1, a value of 0.89 per accident was used.

Fraction of Impact Forces Failing Defective Cylinder (I12). An impact failure threshold of $4.5 \mathrm{~m}$, or $34 \mathrm{kph}$, was derived in the previous analysis for a defective cylinder. The expected frequency of an impact force of this magnitude is 0.04. This value was used for event 112 .

Fraction of Impact Forces Failing Non-Defective Cylinder (I15). The impact failure threshold of the non-defective 14-ton cylinder is equivalent to a drop height of $9 \mathrm{~m}$, or a velocity change of $48 \mathrm{kph}$. Using the information presented in Figure 5.2, it was determined that forces of this magnitude occur at a rate of 0.02 per accident. This value was used for event 175 .

Valve Cover Dislodged (X29). Impact forces required to dislodge the valve cover were assumed to be the same as those required to cause valve failure. A frequency of $6.5 \times 10^{-3}$ per accident was used. This is equivalent to the product of values assigned to events $X 30$ and $I 46$.

Valve Exposed to Impact Force $(\times 30)$. The analysis of this event was identical to its counterpart in Section 9.1.1. A value of 0.13 per accident was used.

Fraction of Fires Failing Improperly Closed Valve by Pressure (I36). In the previous analysis, a failure threshold of 28 minutes exposure to a $1000^{\circ} \mathrm{C}$ fire was determined. Data shown in Section 5 indicate that less than $6 \%$ of all expected fires will last this long. A value of 0.06 was used.

Fraction of Fires Failing Improperly Situated Valve by Pressure (X39). This event was given the same value as event $136,6.0 \times 10^{-2}$.

Fraction of Impact Forces Failing Properly Situated Valve (I46). An impact force equivalent to a $3-\mathrm{m}$ drop was assumed to cause valve failure. From Figure 5.2, it is evident that impact forces of this level can be expected in $5.0 \times 10^{-2}$ of all accidents.

V/R Sufficient to Puncture Cylinder (X47). A11 puncture elements were combined in this event, for which a value of $1.35 \times 10^{-4}$ per accident was used. See Section 9.1.1 for a full explanation. 
Fraction of Impact Forces Failing Improperly Situated Valve (I48). A defective or improperly situated valve was arbitrarily assumed to fail at one-half the level of a non-defective or properly installed valve. Impact forces equivalent to a drop of $1.5 \mathrm{~m}$ can be expected in $7 \times 10^{-2}$ of all truck accidents.

Puncture Probe Generated by Accident (x49). A value of 1.00 was conservatively applied to this event.

Fraction of Flying Objects Failing Properly Situated Valve (I52). This event was evaluated in the same manner as for the Type $30 \mathrm{~B}$ cylinder. A value of $3.3 \times 10^{-2}$ per strike was also used here.

Fraction of Flying Objects Failing Improperly Situated Valve (I54). A factor of 0.33 per strike was used for this event. See the analysis of event I54 in the $21 / 2$-ton cylinder section for a more complete evaluation.

Fraction of Fires Failing Defective Plug by Pressure (I72). Because defective plugs and valves were all assumed to fail at the same level, a value of 0.06 was used here.

\subsection{RELEASE SEQUENCE PROBABILITIES}

The basic event probabilities presented in Section 9.1 provide the basis for evaluating the probability of each release sequence identified in the fault trees. The probabilities of the release sequences for 14 -ton $\mathrm{UF}_{6}$ truck shipments are shown in Table 9.1. Lists of release sequence probabilities for the four other cases were produced but not shown. Only the release sequences with a frequency of occurrence greater than $10^{-15}$ per shipment are listed in the table. All release sequences were retained in the actual risk calculation. 
TABLE 9.1. Release Sequences and Probabilities for 14-Ton $\mathrm{UF}_{6}$ Rail Shipments

\begin{tabular}{|c|c|c|c|c|c|c|c|c|}
\hline $\begin{array}{c}\text { Release } \\
\text { Sequence } \\
\text { Probability } \\
\end{array}$ & & & \multicolumn{4}{|c|}{ Release Sequence } & & \\
\hline 3. $360 E-06$ & $x$ & 1 & $x$ & 4 & $\times 8$ & & & \\
\hline $6.160 E-10$ & $x$ & 1 & $x$ & 5 & $\times 55$ & & & \\
\hline $6.160 E-10$ & $x$ & 1 & $x$ & 3 & $\times 5$ & & & \\
\hline $5.600 E-12$ & $x$ & 1 & $x$ & 5 & $\times 103$ & & & \\
\hline $8.932 E-10$ & $x$ & 1 & $x$ & 16 & $\times 36$ & & & \\
\hline $8.932 E-10$ & $x$ & 1 & $x$ & 35 & $\times 72$ & & & \\
\hline $3.654 \mathrm{E}-08$ & $x$ & 1 & $x$ & 17 & $\times 36$ & & & \\
\hline $8.932 E-10$ & $x$ & 1 & $x$ & 18 & $\times 39$ & & & \\
\hline $8.932 \mathrm{E}-10$ & $x$ & 1 & $x$ & 20 & $\times 39$ & & & \\
\hline $2.436 \mathrm{E}-08$ & $x$ & 1 & $x$ & 22 & $\times 39$ & & & \\
\hline $1.00 \mathrm{E}-10$ & $x$ & 35 & $x$ & 43 & $\times 44$ & & & \\
\hline $8.932 E-10$ & $x$ & 1 & $x$ & 37 & $\times 72$ & & & \\
\hline $8.932 E-10$ & $x$ & 1 & $x$ & 38 & $\times 72$ & & & \\
\hline $8.932 \mathrm{E}-10$ & $x$ & 1 & $x$ & 40 & $\times 72$ & & & \\
\hline 1. $100 \mathrm{E}-10$ & $x$ & 11 & $x$ & 13 & $\times 55$ & & & \\
\hline $1.100 E-10$ & $x$ & 3 & $x$ & 11 & $\times 13$ & & & \\
\hline $1.000 \mathrm{E}-12$ & $x$ & 11 & $x$ & 13 & $\times 103$ & & & \\
\hline $1.100 E-10$ & $x$ & 18 & $x$ & 31 & $\times 32$ & & & \\
\hline $1.100 E-10$ & $x$ & 20 & $x$ & 31 & $\times 32$ & & & \\
\hline $3.000 \mathrm{E}-09$ & $x$ & 22 & $x$ & 31 & $\times 32$ & & & \\
\hline $1.100 \mathrm{E}-10$ & $x$ & 37 & $x$ & 43 & $\times 44$ & & & \\
\hline $1.100 \mathrm{E}-10$ & $x$ & 38 & $x$ & 43 & $\times 44$ & & & \\
\hline $1.100 \mathrm{E}-10$ & $x$ & 40 & $x$ & 43 & $\times 44$ & & & \\
\hline $8.064 E-09$ & $x$ & 1 & $x$ & 45 & $\times 47$ & $\times 49$ & & \\
\hline $7.056 E-13$ & $x$ & 1 & $x$ & 23 & $\times 24$ & $\times 39$ & & \\
\hline $2.857 \mathrm{E}-06$ & $x$ & 7 & $x$ & 45 & $\times 47$ & $\times 49$ & - & \\
\hline $8.960 E-09$ & $x$ & 1 & $x$ & 45 & $\times 47$ & $\times 50$ & & \\
\hline $3.500 \mathrm{E}-08$ & $x$ & 1 & $x$ & 4 & $\times 6$ & $\times 15$ & & \\
\hline $9.240 \mathrm{E}-12$ & $x$ & 1 & $x$ & 6 & $\times 12$ & $\times 55$ & & \\
\hline $9.240 E-12$ & $x$ & 1 & $x$ & 3 & $\times 6$ & $\times 12$ & & \\
\hline $8.400 E-14$ & $x$ & 1 & $x$ & 6 & $\times 12$ & $\times 103$ & & \\
\hline $8.690 E-14$ & $x$ & 23 & $x$ & 24 & $\times 31$ & $\times 32$ & & \\
\hline $3.174 E-06$ & $x$ & 7 & $x$ & 45 & $\times 47$ & $\times 50$ & & \\
\hline $1.240 \mathrm{E}-05$ & $x$ & 4 & $x$ & 6 & $x 7$ & $\times 15$ & & \\
\hline $3.274 E-09$ & $x$ & 6 & $x$ & 7 & $\times 12$ & $\times 55$ & & \\
\hline $3.274 E-09$ & $x$ & 3 & $x$ & 6 & $\times 7$ & $\times 12$ & & \\
\hline 2.976E-T & $x$ & 6 & $x$ & 7 & $\times 12$ & $\times 103$ & & \\
\hline $6.661 E-14$ & $x$ & 1 & $x$ & 23 & $\times 26$ & $\times 30$ & & 46 \\
\hline $2.783 \mathrm{E}-10$ & $x$ & 7 & $x$ & 23 & $\times 26$ & $\times 30$ & & 46 \\
\hline $1.597 \mathrm{E}-15$ & $x$ & 1 & $x$ & 23 & $\times 24$ & $\times 30$ & & 48 \\
\hline $5.355 E-12$ & $x$ & 1 & $x$ & 26 & $\times 29$ & $\times 30$ & & 46 \\
\hline $5.657 \mathrm{E}-13$ & $x$ & 7 & $x$ & 23 & $\times 24$ & $\times 30$ & & 48 \\
\hline $1.897 \mathrm{E}-09$ & $x$ & 7 & $x$ & 26 & $\times 29$ & $\times 30$ & & 46 \\
\hline $6.064 E-15$ & $x$ & 1 & $x$ & 22 & $\times 23$ & $\times 30$ & & 48 \\
\hline $7.877 \mathrm{E}-14$ & $x$ & 7 & $x$ & 18 & $\times 23$ & $\times 30$ & & 48 \\
\hline $7.877 \mathrm{E}-14$ & $x$ & 7 & $x$ & 20 & $\times 23$ & $\times 30$ & & 48 \\
\hline $2.148 \mathrm{E}-12$ & $x$ & 7 & $x$ & 22 & $\times 23$ & $\times 30$ & & 48 \\
\hline $1.031 E-15$ & $x$ & 1 & $x$ & 18 & $\times 29$ & $\times 30$ & & 48 \\
\hline $1.031 E-15$ & $x$ & 1 & $x$ & 20 & $\times 29$ & $\times 30$ & & 48 \\
\hline $2.811 \mathrm{E}-14$ & $x$ & 1 & $x$ & 22 & $\times 29$ & $\times 30$ & & 48 \\
\hline $3.652 \mathrm{E}-13$ & $x$ & 7 & $x$ & 18 & $\times 29$ & $\times 30$ & & 48 \\
\hline $3.652 E-13$ & $x$ & 7 & $x$ & 20 & $\times 29$ & $\times 30$ & & 48 \\
\hline $9.960 E-12$ & $x$ & 7 & $x$ & 22 & $\times 29$ & $\times 30$ & & 48 \\
\hline
\end{tabular}




\subsection{RELEASE FRACTIONS}

The final step in the evaluation of release sequences is the determination of release fractions. For the purpose of this risk analysis, the lists of release sequences were broken down into four categories and release fractions were assigned to each:

- Al1 release sequences involving a breach of the cylinder with no fire present were assigned a release fraction of $10^{-3}$. This value was based on interviews with personnel experienced in $U_{6}$ emergencies and information found in Reference 9. It was assumed, in this instance, that all products of the release, HF gas and particulate $\mathrm{UO}_{2} \mathrm{~F}_{2}$, would be airborne following the release, with the source at ground level. The duration of the release was assumed to be $15 \mathrm{~min}-$ utes, limited because the particulate $\mathrm{UO}_{2} \mathrm{~F}_{2}$ tends to plug up the release pathway. The fact that there is no driving force (such as a fire) to keep the cylinder pressurized also limits the release duration.

- Release sequences in which the cylinder was breached (excluding explosive ruptures) with fire present were assigned a release fraction of 0.1 . This release mechanism is similar to the failure of a valve while the cylinder is being heated in a steam chest.

It was assumed that all of the released materials would be elevated to a height of $230 \mathrm{~m}$ by the fire plume. The duration was assumed to be 20 minutes in length. Again, the amount released is limited by clogging of the release path by $\mathrm{UO}_{2} \mathrm{~F}_{2}$.

- The explosive failure of a cylinder without overpack in the fire environment was assigned two release fractions: an initial release of 0.1 with a duration of 1 minute, and a secondary release of 0.9 over a span of 4 hrs. This corresponds to case $2 a$ in Reference 9. The cylinder explodes with $10 \%$ of the $U_{6}$ in molten form, which is elevated in the fire plume to a height of $230 \mathrm{~m}$. The remaining $90 \%$ of the material is scattered on the ground around the accident site (the fire having been extinguished by the explosion) and slowly hydrolizes over the 4-hr time span. It was assumed that the $\mathrm{UO}_{2} \mathrm{~F}_{2}$ 
remained on the ground at the accident site during this second portion of the release.

- The explosive failure of a cylinder with overpack in the fire environment was also assigned two release fractions: an initial release of 0.8 with a duration of 1 minute, and a secondary release of 0.2 over a 4-hr time period. This corresponds to case $2 b$ in Reference 9. In this situation the cylinder explodes with $80 \%$ of the $\mathrm{UF}_{6}$ in molten form. This fraction is elevated in the fire plume to a height of $230 \mathrm{~m}$. The remaining $20 \%$ is broken into small solid pieces and scattered around the accident site (the fire is out) and slowly hydrolizes over the 4-hr time span. Again, it was assumed that the $\mathrm{UO}_{2} \mathrm{~F}_{2}$ resulting from this second portion of the release remained on the ground at the accident site.

Table 9.2 shows the release sequences from Table 9.1 broken down into the various categories along with assigned release fractions. Similar tables for the remaining cylinder type-transportation mode combinations are made, but not shown. 
TABLE 9.2. Release Sequences for 14-Ton Cylinder Grouped According to Release Fraction

\begin{tabular}{|c|c|c|c|c|c|c|c|}
\hline \multirow{2}{*}{$\begin{array}{c}\begin{array}{c}\text { Release } \\
\text { Sequence } \\
\text { Probability }\end{array} \\
1.100 E-10\end{array}$} & \multicolumn{7}{|c|}{ Release Sequence } \\
\hline & $\times 11$ & $\times 13$ & $x$ & 55 & & & \\
\hline $1.100 E-10$ & $x 3$ & $x \quad 11$ & $x$ & 13 & & & \\
\hline $1.000 E-12$ & $\times 11$ & $\times 13$ & & 103 & & & \\
\hline $1.100 \mathrm{E}-10$ & $\times 18$ & $\times 31$ & $x$ & 32 & & & \\
\hline $1.100 E-10$ & $\times 20$ & $\times 31$ & $x$ & 32 & & & \\
\hline $3.000 \mathrm{E}-09$ & $\times 22$ & $\times 31$ & $x$ & 32 & & & \\
\hline 1. $100 E-10$ & $\times 37$ & $\times 43$ & $x$ & 44 & & & \\
\hline $1.100 E-10$ & $\times 38$ & $\times 43$ & $x$ & 44 & & & \\
\hline 1. $100 \mathrm{E}-10$ & $\times 40$ & $\times 43$ & $\mathrm{x}$ & 44 & & & \\
\hline 1. $100 \mathrm{E}-10$ & $\times 35$ & $\times 43$ & $x$ & 44 & & & \\
\hline $2.857 \mathrm{E}-06$ & $\times 7$ & $\times 45$ & $x$ & 47 & $x$ & 49 & \\
\hline $8.690 \mathrm{E}-14$ & $\times 23$ & $\times 24$ & $x$ & 31 & $x$ & 32 & \\
\hline $3.174 E-13$ & $\times 7$ & $\times 45$ & $x$ & 47 & $x$ & 50 & \\
\hline 1. $240 E-05$ & $\times 4$ & $\times 6$ & $x$ & 7 & $x$ & 15 & \\
\hline $3.274 E-09$ & $\times 6$ & $\times 7$ & $x$ & 12 & $x$ & 55 & \\
\hline $3.274 E-09$ & $\times 3$ & $\times 6$ & $x$ & 7 & $x$ & 12 & \\
\hline $2.976 E-11$ & $\times 6$ & $\times 7$ & $x$ & 12 & & 103 & \\
\hline $5.657 \mathrm{E}-13$ & $\times 7$ & $\times 23$ & $x$ & 24 & $x$ & 30 & $\times 48$ \\
\hline $1.897 \mathrm{E}-09$ & $\times 7$ & $\times 26$ & $x$ & 29 & $x$ & 30 & $\times 46$ \\
\hline $7.877 \mathrm{E}-14$ & $\times 7$ & $\times 18$ & $x$ & 23 & $x$ & 30 & $\times 48$ \\
\hline $7.877 \mathrm{E}-14$ & $\times 7$ & $\times 20$ & $x$ & 23 & $x$ & 30 & $\times 48$ \\
\hline $2.148 \mathrm{E}-72$ & $\times 7$ & $\times 22$ & $x$ & 23 & $x$ & 30 & $\times 48$ \\
\hline $3.652 \mathrm{E}-13$ & $\times 7$ & $\times 18$ & $x$ & 29 & $x$ & 30 & $\times 48$ \\
\hline $3.652 \mathrm{E}-13$ & $\times 7$ & $\times 20$ & $x$ & 29 & $x$ & 30 & $\times 48$ \\
\hline $9.960 E-12$ & $\times 7$ & $\times 22$ & $x$ & 29 & $x$ & 30 & $\times 48$ \\
\hline $4.092 \mathrm{E}-10$ & $\times 7$ & $\times 23$ & $x$ & 26 & $x$ & 30 & $\times 46$ \\
\hline
\end{tabular}

\begin{tabular}{|c|c|c|c|c|c|c|c|c|}
\hline \multirow[b]{2}{*}{$8.932 E-10$} & \multirow[b]{2}{*}{$x$} & \multicolumn{3}{|c|}{ Release } & \multicolumn{3}{|c|}{ Sequence } & \\
\hline & & 1 & $\times 16$ & $x$ & 36 & & & \\
\hline $8.932 E-10$ & $x$ & 1 & $\times 35$ & $x$ & 72 & & & \\
\hline $3.654 E-08$ & $x$ & 1 & $\times 17$ & $x$ & 36 & & & \\
\hline $8.932 E-10$ & $x$ & 1 & $\times 18$ & $x$ & 39 & & & \\
\hline $8.932 \mathrm{E}-10$ & $x$ & 1 & $\times 20$ & $x$ & 39 & & & \\
\hline $2.436 E-08$ & $x$ & 1 & $\times 22$ & $x$ & 39 & & & \\
\hline $8.932 E-10$ & $x$ & 1 & $\times 37$ & $x$ & 72 & & & \\
\hline $8.932 E-10$ & $x$ & 1 & $\times 38$ & $x$ & 72 & & & \\
\hline $8.932 \mathrm{E}-10$ & $x$ & 1 & $\times 40$ & $x$ & 72 & & & \\
\hline $8.960 E-09$ & $x$ & 1 & $\times 45$ & $x$ & 47 & $x$ & 50 & \\
\hline $8.064 E-09$ & $x$ & 1 & $\times 45$ & $x$ & 47 & $x$ & 49 & \\
\hline $7.056 \mathrm{E}-13$ & $x$ & 1 & $\times 23$ & $x$ & 24 & $x$ & 39 & \\
\hline $3.500 \mathrm{E}-08$ & $x$ & 1 & $\times 4$ & $x$ & 6 & $x$ & 15 & \\
\hline $9.240 \mathrm{E}-12$ & $x$ & 1 & $\times 6$ & $x$ & 12 & $x$ & 55 & \\
\hline $9.240 \mathrm{E}-12$ & $x$ & 1 & $\times 3$ & $x$ & 6 & $x$ & 12 & \\
\hline $8.400 E-14$ & $x$ & 1 & $\times 6$ & $x$ & 12 & & 103 & \\
\hline $1.155 E-12$ & $x$ & 1 & $\times 23$ & $x$ & 26 & $x$ & 30 & $\times 46$ \\
\hline $1.597 \mathrm{E}-15$ & $x$ & 1 & $\times 23$ & $x$ & 24 & $x$ & 30 & $\times 48$ \\
\hline $5.355 E-12$ & $x$ & 1 & $\times 26$ & $x$ & 29 & $x$ & 30 & $\times 46$ \\
\hline $1.973 E-15$ & $x$ & 1 & $\times 22$ & $x$ & 29 & $x$ & 30 & $\times 48$ \\
\hline $6.064 E-15$ & $x$ & 1 & $\times 22$ & $x$ & 23 & $x$ & 30 & $\times 48$ \\
\hline $1.031 E-15$ & $x$ & 1 & $\times 18$ & $x$ & 29 & $x$ & 30 & $\times 48$ \\
\hline $1.031 \mathrm{E}-15$ & $x$ & 1 & $\times 20$ & $x$ & 29 & $x$ & 30 & $\times 48$ \\
\hline $2.811 \mathrm{E}-14$ & $x$ & 1 & $\times 22$ & $x$ & 29 & $x$ & 30 & $\times 48$ \\
\hline
\end{tabular}

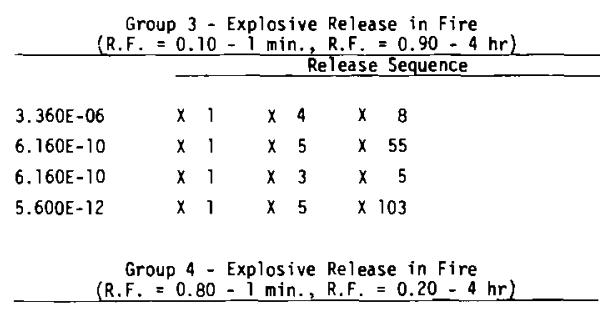

No 14-ton cylinder release sequences in this group. 


\section{REFERENCES}

1. A. W. Dennis, J. T. Foley, W. F. Hartman, and D. W. Larson, Severities of Transportation Accidents Involving Large Packages. SAND 77-0001, Sandia Laboratories, A1buquerque, NM, May 1978.

2. A. J. Mallett and C. E. Newton, Protective Shipping Package for 30-Inch-Diameter UF6 Cylinders. K-1686, Union Carbide Corporation, Oak Ridge, TN, April 1967.

3. W. R. Pedigo, et. al., Testing of Ten-Ton Uranium Hexafluoride Cylinders. Union Carbide Corporation, Ky-500, Paducah, KY, October 1965.

4. E. W. Richardson and S. Berstein, Additional Testing of Ten-Ton Uranium Hexafluoride Cylinders. KY-631, Union Carbide Corporation, Puducah, KY, September 1971.

5. A. J. Mallett, ORGDP Container Test and Development Program Fire Test of UF 6 Filled Cylinders. K-D-1894, Union Carbide Corporation, Oak Ridge, TN, January 1966.

6. USERDA, The Environmental Impact of Transportation of Nuclear Materials in the LMFBR Program (Excerpts from WASH-1535). ERDA-40, May 1975. 


\subsection{EVALUATION OF ENVIRONMENTAL CONSEQUENCES}

In Section 9, individual release sequences were identified and evaluated by determining their expected frequency of occurrence and the corresponding release fraction. At this point, a risk number could be obtained by multiplying the individual release sequence probabilities and release fractions together, and summing overal1 release sequences. The resulting risk number, however, would not be in a suitable form for comparison with other societal risks, which is one of the objectives of the risk assessment.

To express the risk in a more useful form, conversion factors must be developed to allow modification of the consequence portion of the risk number (in this case, to fatalities). The purpose of this section is to develop these conversion factors. Areas which must be evaluated include: health effects of a material release, meteorology, demography, and quantity of the release made airborne and dispersed. The final portion of this section will show how these factors are applied to the risk number.

\subsection{HEALTH EFFECTS}

When released to the atmosphere, uranium hexafluoride $\left(U_{6}\right)$ combines chemically with the moisture present in the air to form HF (hydrogen fluoride) gas and $\mathrm{UO}_{2} \mathrm{~F}_{2}$ (uranyl fluoride), a particulate. All products of a $\mathrm{UF}_{6}$ release represent a health hazard when inhaled. Hydrogen fluoride gas presents a danger which is chemical in nature only, while the effects of inhaling $\mathrm{UO}_{2} \mathrm{~F}_{2}$ are both chemical and radiological. However, for $\mathrm{UF}_{6}$ releases involving material with an enrichment of less than $10 \%{ }^{235} \mathrm{U}$, the chemical toxicity is generally considered a far greater threat than the radiotoxicity. (1) Although enrichment levels greater than 3.5-4.0\% were not considered in this analysis, this section will address both chemical and radiological hazards.

\subsubsection{Effects of Hydrogen Fluoride Gas}

Hydrogen fluoride gas presents a danger which is chemical in nature and has the potential for injurious effects to man, animal life and vegetation. Because the risk in this study is to be expressed in terms of health effects, only insults to the human body were considered. 
Much has been written concerning the health effects of HF on humans; however, precise quantification of these effects is difficult. Hydrogen fluoride gas causes severe irritation of the eyes and respiratory system. If sufficient quantities of the gas are inhaled, death from pulmonary edema can occur. HF damage is a function of both the concentration of gas inhaled and the duration of exposure. Table 10.1 gives some reported values for health effects of HF.

\section{TABLE 10.1. Health Effects of HF}

$\begin{aligned} 0.1 \mathrm{mg} / \mathrm{m}^{3} & \begin{array}{l}\text { perceptive odor concentration } \\ 2.5 \mathrm{mg} / \mathrm{m}^{3}\end{array} \\ & \begin{array}{l}\text { 8-hr daily exposure ACGIH Threshold } \\ \text { limit value }\end{array} \\ 25.0 \mathrm{mg} / \mathrm{m}^{3} & \begin{array}{l}\text { tolerable for several minutes with } \\ \text { respirator irritation }\end{array} \\ >40.0 \mathrm{mg} / \mathrm{m}^{3} & \begin{array}{l}\text { possibility of being fatal to humans } \\ \text { at 1-hr exposure }\end{array} \\ 100.0 \mathrm{mg} / \mathrm{m}^{3} & \begin{array}{l}\text { highest tolerable concentration for } \\ \text { 1 minute with severe eye and respirator } \\ \text { irritation } \\ \text { laboratory animal death from exposures }\end{array} \\ & >2 \text { 2-hr }\end{aligned}$

Because of the wide range of release durations considered in this study (1 minute to 4 hours) it was necessary to develop two sets of limits for HF health effects. The release durations were divided into two categories; short term (1ess than 20 minutes) and long term (20 minutes to 4 hours). The limits and effects assumed for each category in this study are presented in Table 10.2.

\subsubsection{Effects of Uranyl Fluoride}

Uranyl fluoride presents both a chemical and radiological hazard. The chemical effects of $\mathrm{UO}_{2} \mathrm{~F}_{2}$ involve the toxicity of both fluoride and uranium. As with HF gas, the greatest damage is caused by the effects of the fluoride compound on the respiratory system. Radiological effects result from exposure to the radioactive elements contained in the $\mathrm{UF}_{6}$, most notably the isotopes of uranium. 
TABLE 10.2. Assumed Effects of HF on Humans Short Term Release (20 Min.)

$<2.5 \frac{\mathrm{mg}}{\mathrm{m}^{3}} \quad$ no effect

$\begin{array}{ll}25.0 \frac{\mathrm{mg}}{\mathrm{m}^{3}} & \text { respiratory discomfort and minor } \\ \text { health effects }\end{array}$

$100.0 \frac{\mathrm{mg}}{\mathrm{m}^{3}} \quad \begin{aligned} & \text { health effects requiring two weeks } \\ & \text { medical care }\end{aligned}$

$400.0 \frac{\mathrm{mg}}{\mathrm{m}^{3}} \quad$ assumed fatal

Long Term Release (20 Min. - $4 \mathrm{hr}$. )

$<2.5 \frac{\mathrm{mg}}{\mathrm{m} 3} \quad$ no effect

$10.0 \frac{\mathrm{mg}}{\mathrm{m}^{3}} \quad \begin{aligned} & \text { health effects requiring two weeks } \\ & \text { medical care }\end{aligned}$

$40.0 \frac{\mathrm{mg}}{\mathrm{m}^{3}} \quad$ assumed fata 1

This study considers the shipment of two types of $\mathrm{UF}_{6}$ : unenriched and enriched. For the purpose of determining the health effects of $\mathrm{UO}_{2} \mathrm{~F}_{2}$, it was conservatively assumed that all $U_{6}$ shipped had an isotope inventory equivalent to $3.2 \%$ enriched $U_{6}{ }_{6}$. The inventory is given in Table 10.3, based on values given in ERDA-1543 ${ }^{(5)}$.

TABLE 10.3. Isotopic Composition of $3.2 \%$

$235 \mathrm{U}$ Enriched UF 6

\begin{tabular}{|c|c|}
\hline Isotope & $\mathrm{Ci} / \mathrm{Kg}-\mathrm{U}$ \\
\hline $232 \mathrm{U}$ & $4.67 \times 10^{-5}$ \\
\hline $233_{U}$ & $2.36 \times 10^{-7}$ \\
\hline $234 U$ & $3.57 \times 10^{-3}$ \\
\hline $235_{U}$ & $6.92 \times 10^{-5}$ \\
\hline $236_{U}$ & $8.84 \times 10^{-4}$ \\
\hline${ }^{238} \mathrm{U}$ & $3.21 \times 10^{-4}$ \\
\hline${ }^{239} \mathrm{Pu}$ & $2.43 \times 10^{-7}$ \\
\hline $237 \mathrm{~Np}$ & $4.32 \times 10^{-7}$ \\
\hline${ }^{106} \mathrm{Ru}$ & $4.22 \times 10^{-7}$ \\
\hline${ }^{95} \mathrm{Zr},{ }^{95} \mathrm{Nb}$ & $9.3 \times 10^{-7}$ \\
\hline${ }^{137} \mathrm{Cs}$ & $6.9 \times 10^{-8}$ \\
\hline${ }^{144} \mathrm{Ce}$ & $6.9 \times 10^{-8}$ \\
\hline${ }^{90} T C$ & $3.16 \times 10^{-5}$ \\
\hline${ }^{90} \mathrm{Sr}$ & $1.72 \times 10^{-8}$ \\
\hline
\end{tabular}


Dose conversion factors, as calculated by the computer program DACRIN, (6) for the uranium isotopes and the residual fission products and actinides are shown in Tables 10.4 and 10.5. Since $\mathrm{UO}_{2} \mathrm{~F}_{2}$ is very soluble, soluble uranium factors have been used.

TABLE 10.4. Dose to Critical Organ via Inhalation (a)
(Soluble) - Dose in $\frac{\text { Rem-m }}{C \dot{C}-\mathrm{SeC}}$

\begin{tabular}{|c|c|c|c|c|}
\hline \multirow[b]{2}{*}{ Radionuclides } & \multirow{2}{*}{$\begin{array}{c}\text { Dose Time } \\
\text { (Years) }\end{array}$} & \multicolumn{3}{|c|}{ Organ } \\
\hline & & Kidneys & Bone & Lungs \\
\hline${ }^{95} \mathrm{Zr}(\mathrm{b})$ & 50 & --- & $4.0 E+7^{(b)}$ & -- \\
\hline${ }^{95} \mathrm{Nb}$ & 50 & --- & $1.8 \mathrm{E}-4$ & --- \\
\hline${ }^{99} \mathrm{TC}$ & 50 & $8.6 \mathrm{E}-1$ & --- & -- \\
\hline${ }^{106} \mathrm{Ru}$ & 50 & $2.6 \mathrm{E}+1$ & --- & --- \\
\hline${ }^{137} \mathrm{Cs}$ & 50 & --- & $1.7 \mathrm{E}+1$ & -- \\
\hline${ }^{144} \mathrm{Ce}$ & 50 & --- & --- & 2. $0 E+2$ \\
\hline $232 \mathrm{U}$ & 50 & --- & --- & $2.5 E+4$ \\
\hline $233 \mathrm{U}$ & 50 & --- & --- & $1.6 \mathrm{E}+4$ \\
\hline${ }^{234} \mathrm{U}$ & 50 & --- & --- & $1.6 \mathrm{E}+4$ \\
\hline $235 \mathrm{U}$ & 50 & -- & -- & 1. $5 \mathrm{E}+4$ \\
\hline $236 \mathrm{U}$ & 50 & --- & -- & 1. $5 \mathrm{E}+4$ \\
\hline${ }^{238} \mathrm{U}$ & 50 & -- & --- & $1.4 E+4$ \\
\hline${ }^{237} \mathrm{~Np}$ & 50 & -- & $5.1 E+5$ & --- \\
\hline${ }^{239} \mathrm{Pu}$ & 50 & --- & $5.5 E+5$ & -- \\
\hline
\end{tabular}

(a) Task Group on Lung Dynamics Model, 7.5-hr inhalation duration, $350 \mathrm{cc} / \mathrm{sec}$. breathirg rate.

(b) $\operatorname{Read} 4.0 \times 10^{1}$. 
TABLE 10.5. Dose to Critical Organ via Inhalation (a)

\begin{tabular}{|c|c|c|c|c|}
\hline \multirow[b]{2}{*}{ Radionuclides } & \multirow{2}{*}{$\begin{array}{c}\text { Dose Time } \\
\text { (Years) }\end{array}$} & \multicolumn{3}{|c|}{ Organ } \\
\hline & & Kidneys & Bone & Lungs \\
\hline${ }^{95} \mathrm{Zr}$ & 50 & --- & -- & $1.183 \mathrm{E}+2^{(b)}$ \\
\hline${ }^{95} \mathrm{Nb}$ & 50 & -- & $1.774 \mathrm{E}-4$ & --- \\
\hline${ }^{99} \mathrm{Tc}$ & 50 & --- & -- & $1.709 E+2$ \\
\hline${ }^{106} \mathrm{Ru}$ & 50 & --- & -- & $1.076 \mathrm{E}+3$ \\
\hline${ }^{137} \mathrm{Cs}$ & 50 & -- & $1.720 E+1$ & --- \\
\hline${ }^{44} \mathrm{Ce}$ & 50 & -- & -- & $8.601 E+2$ \\
\hline${ }^{232} \mathrm{U}$ & 50 & -- & -- & $5.948 E+5$ \\
\hline $233 \mathrm{U}$ & 50 & -- & -- & $1.594 E+5$ \\
\hline $234 U$ & 50 & --- & --- & $1.562 E+5$ \\
\hline $236 \mathrm{U}$ & 50 & -- & -- & $1.449 E+5$ \\
\hline $238 U$ & 50 & --- & --- & $1.371 E+5$ \\
\hline $237 \mathrm{~Np}$ & 50 & --- & $1.930 \mathrm{E}+5$ & --- \\
\hline${ }^{239} \mathrm{~Np}$ & 50 & --- & $2.081 E+5$ & --- \\
\hline
\end{tabular}

(a) Task Group on Lung Dynariics Model - 7.5-hr inhalation duration, $350 \mathrm{cc} / \mathrm{sec}$ breathing rate.

(b) $\operatorname{Read} 1.183 \times 10^{2}$.

The chemical effects of $\mathrm{UO}_{2} \mathrm{~F}_{2}$ involve the toxicity of both fluoride and uranium. The maximum permissible concentration (MPC) (air) of fluoride particulates as $F^{-}$is $2.5 \mathrm{mg} / \mathrm{m}^{3}$. The $M P C$ of uranium is $0.210 \mathrm{mg} / \mathrm{m}^{3}$. Limits based on soluble uranium were assumed to apply to $\mathrm{UO}_{2} \mathrm{~F}_{2}$. The International Commission of Radiological Protection (ICRP) gives a value of $2.5 \mathrm{mg}$ inhaled as acceptable $\mathrm{e}^{(7)}$. Ten (10) $\mathrm{mg}$ inhaled is suggested as a maximum emergency planned occupational dose. (18) A case history of $13 \mathrm{mg}$ of $\mathrm{UO}_{2} \mathrm{~F}_{2}$ inhaled resulted in several days hospitalization, with recoverable effects. (9) Little information is available on fatal inhalation levels. One hundred (100) mg inhaled is assumed to result in eventual death. Table 10.6 gives the $\mathrm{UO}_{2} \mathrm{~F}_{2}$ levels and effects assumed for this study. 
TABLE 10.6. Assumed Limits and Effects of $\mathrm{UO}_{2} \mathrm{~F}_{2}$

$<2.5 \mathrm{mg}$ inhaled No effect
$10.0 \mathrm{mg}$ inhaled Minimal health effects
$20.0 \mathrm{mg}$ inhaled Clinical effects requiring two
weeks medical care

\subsection{METEOROLOGY}

The diffusion climatology along the transport route must be incorporated into any risk analysis where the atmosphere is an important pathway for dosage to man. The important atmospheric variables are: 1) wind direction, which indicates the initial direction of travel; 2) wind speed, which indicates the rate of transport; and 3) atmospheric stability, which indicates the rate of dilution and plume rise potential. Certain characteristics of release (e.g., height and temperature) are also important in the evaluation of the atmospheric pathway.

Assuming a postulated accident with a surface release and little or no release-related plume rise, the immediate and greatest impact will be in the region surrounding the location of the event. Transport and diffusion are often determined by local influences. Wind speeds and directions show considerable variation that cannot be always summarized by large geographic regions. Local influences include topography (surface roughness, channeling), heat island effects, and proximity to large bodies of water. The inclusion of such influences in the present analysis is not feasible, principally because the information is not available either from a data base or from current modeling capabilities.

For estimates of long-term diffusion averages, the average persistence of winds by sectors are used. Considering wind direction persistences alone, the actual sector annual-average air concentrations can be considerably higher or lower than an average. Based on reported values from 129 weather bureau surface stations in the continental U.S., the concentrations range on the order of from half to 5 times the average. The air concentrations near a particular 
population center can be expected to vary by the same factor depending on the direction of the population center from the selected route. Such a factor could be quite important in determining the effects of releases near large population centers. Over a sufficiently long route, the effects of different wind direction persistences may tend to cancel if there is a random relationship between the prevailing wind directions and population centers. The alternative of picking a route based on known diffusion climatologies to minimize risk could be beneficial; however, at the present time it is not included in the model.

The meteorological data used in this analysis are shown in Table 10.7. The values were developed from micrometeorological data collected for diffusion calculations for reactor sites. Seven sets of micrometeorological data were selected from about 26 compilations from reactor sites to account for the range of conditions that could reasonably occur along the route. The use of a single averaged distribution allows for the typical range of wind speeds without undue weighting to any particular site. Although this result cannot be expected to necessarily represent any particular portion of the route, it does represent the type of conditions that may be encountered on the average.

TABLE 10.7. Average Wind Speed/Stability Charateristics

\begin{tabular}{|c|c|c|c|c|c|c|}
\hline \multicolumn{3}{|c|}{ Wind Speed } & \multirow{2}{*}{\multicolumn{4}{|c|}{$\frac{\text { Pasquill Stability Classification }}{P_{i}}$}} \\
\hline$U_{k}$ & & & & & & \\
\hline $\mathrm{m} / \mathrm{sec}$ & $\underline{k}$ & $P_{k}$ & $B(j=1)$ & $D(j=2)$ & $E(j=3)$ & $F(j=4)$ \\
\hline 1 & 1 & 0.255 & 0.136 & 0.202 & 0.299 & 0.363 \\
\hline 3.5 & 2 & 0.508 & 0.243 & 0.274 & 0.272 & 0.211 \\
\hline 7 & 3 & 0.161 & 0.190 & 0.290 & 0.339 & 0.181 \\
\hline 10 & 4 & 0.052 & 0.240 & 0.312 & 0.358 & 0.090 \\
\hline 18 & 5 & 0.024 & 0.276 & 0.348 & 0.356 & 0.020 \\
\hline
\end{tabular}




\subsection{DEMOGRAPHY}

To determine the number of people affected by a $\mathrm{UF}_{6}$ release resulting from a transportation accident, the population distribution along the shipping route must be characterized. Population densities used in this study were originally developed for use in a study of the risk of shipping plutonium by truck. (10)

The population distribution along shipping routes was characterized by dividing the continental U.S. into four zones based roughly on population density and degree of urbanization. The zones are shown in Figure 10.1. Population densities were grouped into three classes: urban, for densely populated urban areas, suburban, for areas of moderate population density, and rural, for the nonurbanized areas. The suburban data were obtained from Bureau of the Census information for the Standard Metropolitan Statistical Area (SMSA). The SMSA includes urban areas. The population and land area of cities inside the SMSA were subtracted to obtain the data for suburban population zones.

To establish population data for the representative zones, Bureau of the Census information for 1960 was used as a base. This information was extended to 1970 with data from the 1970 census. Population projections were made to 1980,1990 , and 2000 , using the compound interest formula to model population growth. Projected population densities and land areas used in this study are presented in Table 10.8.

A second factor in the characterization of the demography is to relate the shipment route to the population zones. $\mathrm{UF}_{6}$ shipment routes were previously determined in Section 4. 


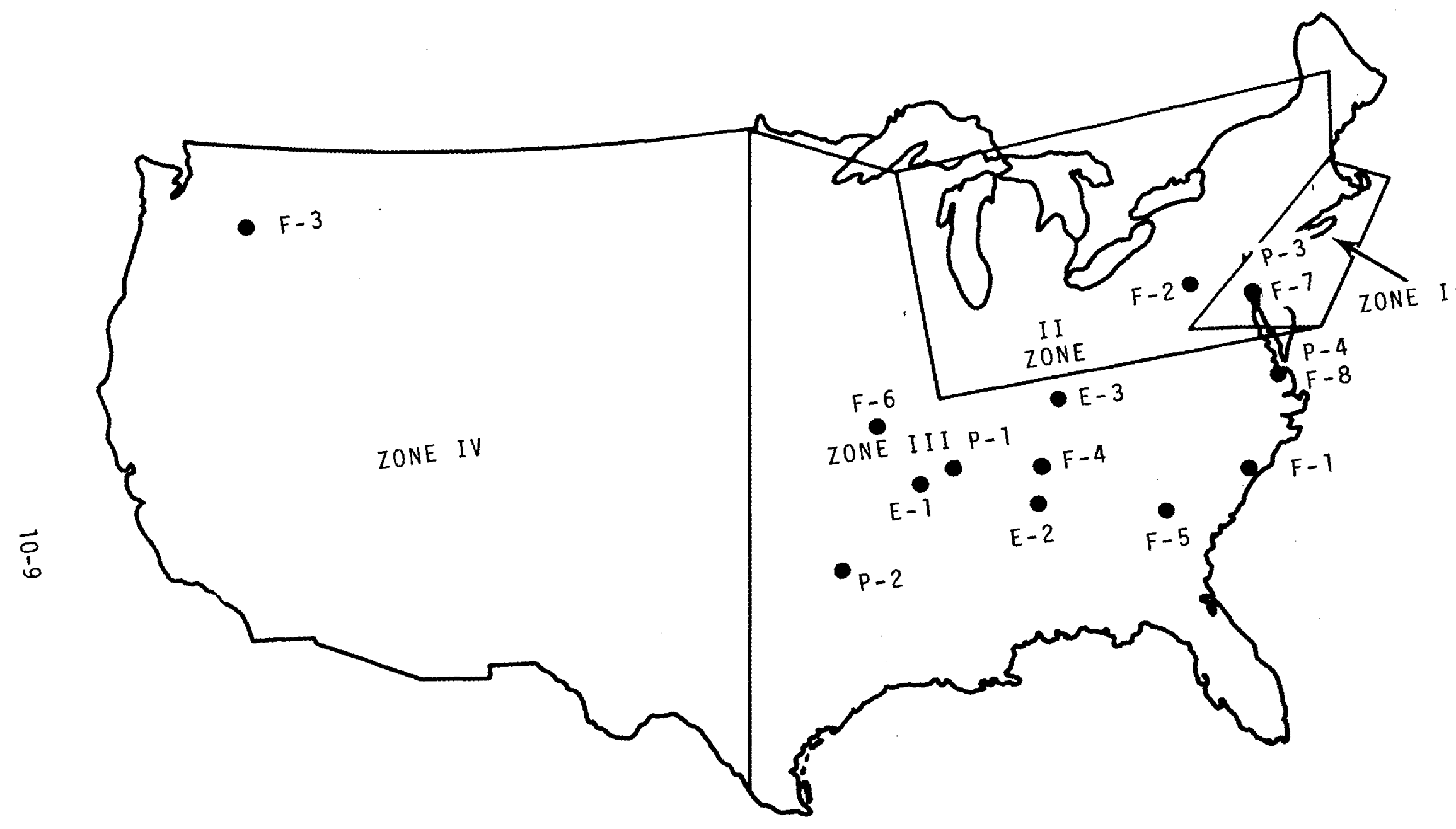

FIGURE 10.1. Population Zones 
TABLE 10.8. Projected Population Density and Land Area by Zone and Population Classes

\begin{tabular}{|c|c|c|c|}
\hline & $\begin{array}{c}\text { Zone and } \\
\text { Population } \\
\text { Classes }\end{array}$ & $\begin{array}{l}\text { Land } \\
\text { Area, \% }\end{array}$ & $\begin{array}{l}\text { Density } \\
\text { People } / \mathrm{km}^{2}\end{array}$ \\
\hline \multirow[t]{3}{*}{ I } & Urban & 3.8 & 3587 \\
\hline & Suburban (a) & 66.9 & 317 \\
\hline & Rural & 29.3 & 236 \\
\hline \multirow[t]{3}{*}{ II } & Urban & 11.5 & 1224 \\
\hline & Suburban (a) & 35.5 & 326 \\
\hline & Rural & 53.0 & 92 \\
\hline \multirow[t]{3}{*}{ I I I } & Urban & 0.8 & 1537 \\
\hline & Suburban (a) & 17.3 & 87 \\
\hline & Rural & 81.9 & 7 \\
\hline \multirow[t]{3}{*}{ IV } & Urban & 0.5 & 1695 \\
\hline & Suburban ${ }^{(a)}$ & 15.0 & 51 \\
\hline & Rural & 84.5 & 10 \\
\hline
\end{tabular}

A map with the population zones and the locations of the facilities shipping and receiving $U_{6}$ are shown in Figure 10.1. The designations $E-1$, F-1, P-1, etc., refer to the enrichment, fuel fabrication and production facilities listed in Table 10.9. (a) Distances between shipping and receiving facilities were obtained from Rand McNalley maps. (11) For each shipping route, the fraction of the route in each population zone was determined by drawing arcs of a great circle route between each shipping and receiving point and determining the fraction of the arc in each zone. This data is summarized in Table 10.10. A listing of the fractional miteage for each individual route is included in Appendix $D$.

(a) A11 material imported from or exported to foreign sources was assumed to enter the country through Baltimore or Norfolk. 
TABLE 10.9. UF 6 Shipping and Receiving Facilities

Production Plants

P-1 Metropolis, IL

P-2 Sequoyah, OK

P-3 Foreign Sources (Baltimore, MD)

P-4 Foreign Sources (Norfolk, VA)

Enrichment Plants

E-1 Paducah, KY

E-2 Oak Ridge, TN

E-3 Portsmouth, $\mathrm{OH}$

Fuel Fabrication Plants

F-1 Wilmington, NC

F-2 Apol1o, PA

F-3 Richland, WA

F-C. Erwin, TN

F-5 Columbia, SC

F-6 Hematite, M0

F-7 Foreign Receivers (Ba]timore, MD)

F-8 Foreign Receivers (Norfolk, VA)

TABLE 10.10. Fractional Mileage of Shipping Routes by Population Zone

\begin{tabular}{lllll}
\multicolumn{1}{c}{ Zone } & I & II & III & IV \\
$\begin{array}{l}\text { \% of a11 } \\
\text { Shipping Routes } \\
\text { in Zone }\end{array}$ & 5 & 12 & 80 & 3
\end{tabular}




\subsection{ATMOSPHERIC DISPERSION MODEL}

The products of a $U_{6}$ release must reach man via some pathway in his environment to present any danger to human life. For the purpose of this study, only the air pathway was considered. Although material can also reach man via food chain and aquatic pathways, the amount of material following these pathways has been found to be insignificant when compared to the air pathway. (12)

The products of the $\mathrm{UF}_{6}$ release, $\mathrm{HF}$ and $\mathrm{UO}_{2} \mathrm{~F}_{2}$, were assumed to be neutrally buoyant when airborne. In releases involving fire, the products were assumed to be carried aloft and released from the fire plume (elevated release). In instances where solid chunks of UF 6 laid on the ground and slowly hydrolized over a period of time (4 hours), it was assumed that only the HF became airborne; all $\mathrm{UO}_{2} \mathrm{~F}_{2}$ was assumed to remain on the ground.

For releases of short duration (less than a day), the time integrated air concentration at ground level was evaluated by the bivariate normal diffusion model using Pasquill diffusion parameters. (12) In equation form:

$$
E=\frac{Q}{\pi \sigma_{y} \sigma_{z} \bar{u}_{h}} \exp \left(-y^{2} / 2 \sigma_{y}^{2}\right)-\left(h^{2} / 2 \sigma_{z}^{2}\right)
$$

where:

$E$ is ground level time-integrated air concentration at point $x, y, g m ~ s e c / m^{3}$

$x$ is downwind distance measured from point of release, $m$

$y$ is crosswind distance measured horizontally from centerline of cloud, $m$

$Q$ is total release from source, $g$

$\sigma_{y}$ is crosswind lateral standard deviation of cloud concentration, $m$ $\sigma_{z}$ is crosswind vertical standard deviation of cloud concentration, $m$ 
$\bar{U}_{h}$ is average wind speed at the height of release in direction of travel, $\mathrm{m} / \mathrm{sec}$

$h$ is height of release, $m$.

The values of $\sigma_{y}$ and $\sigma_{z}$ are a function of the downwind distance $x$ and the Pasquill Stability Category existing at the time of the accident. These values are shown in Tables 10.11 and 10.12 , respectively.

TABLE 10.11. Values of $\sigma_{y}$ for Pasquill Stability Categories

\begin{tabular}{|c|c|c|c|c|c|c|}
\hline \multirow{2}{*}{$\begin{array}{l}\text { Downwind } \\
\text { Distance } \\
\text { (meters) }\end{array}$} & \multicolumn{6}{|c|}{$\sigma$ for Pasquill Type } \\
\hline & A & $\bar{B}$ & $\mathrm{C}$ & D & $E$ & $F$ \\
\hline 100 & 21 & 16 & 12 & 8.0 & 6.0 & 3.9 \\
\hline 250 & 54 & 40 & 28 & 20 & 14 & 9.8 \\
\hline 500 & 100 & 76 & 55 & 37 & 28 & 18 \\
\hline 1,000 & 200 & 150 & 110 & 72 & 52 & 36 \\
\hline 2,500 & -450 & 340 & 240 & 160 & 120 & 81 \\
\hline 5,000 & 830 & 630 & 450 & 310 & 220 & 150 \\
\hline 10,000 & 1,600 & 1,200 & 850 & 570 & 410 & 280 \\
\hline 25,000 & 3,400 & 2,600 & 1,800 & 1,200 & 880 & 610 \\
\hline 50,000 & 6,200 & 4,700 & 3,400 & 2,300 & 1,600 & 1,100 \\
\hline 100,000 & 11,000 & 8,500 & 6,300 & 4,100 & 2,800 & 2,000 \\
\hline
\end{tabular}

TABLE 10.12. Values of $\sigma_{z}$ for Pasquill Stability Categories

\begin{tabular}{|c|c|c|c|c|c|c|}
\hline \multirow{2}{*}{$\begin{array}{l}\text { Downwind } \\
\text { Distance } \\
\text { (meters) }\end{array}$} & \multicolumn{6}{|c|}{$\sigma_{2}$ for Pasquill Type } \\
\hline & $\bar{A}$ & $\mathrm{~B}$ & $\frac{101}{C}$ & D & $E$ & $F$ \\
\hline 100 & 15 & 10 & 7.8 & 4.7 & 3.0 & 1.4 \\
\hline 250 & 43 & 26 & 18 & 10 & 7.1 & 4.0 \\
\hline 500 & 140 & 57 & 34 & 19 & 13 & 7.6 \\
\hline 1,000 & 670 & 140 & 64 & 33 & 22 & 14 \\
\hline 2,500 & 2,000 & 580 & 140 & 62 & 41 & 25 \\
\hline 5,000 & 2,000 & 2,000 & 260 & 95 & 61 & 35 \\
\hline 10,000 & 2,000 & 2,000 & 440 & 140 & 84 & 47 \\
\hline 25,000 & 2,000 & 2,000 & 880 & 220 & 120 & 64 \\
\hline 50,000 & 2,000 & 2,000 & 1,400 & 320 & 140 & 79 \\
\hline 100,000 & 2,000 & 2,000 & 2,000 & 450 & 170 & 94 \\
\hline
\end{tabular}


The concentration received by an individual at point $(x, y)$ can now be obtained by specifying the wind speed, height of release, and Pasquill Stability Category. For these conditions, values of $\sigma_{y}$ and $\sigma_{z}$ at the downwind distance, $x$, can be obtained from Tables 10.11 and 10.12 by interpolation. The quantity $E / Q$ can then be calculated at point $(x, y)$ using Equation 10-1.

Amounts received by the entire population could, in theory, be calculated by locating every individual or groups of individuals and going through the above procedure until all individuals exposed to the release were included in the calculation. For this study, however, it was much simpler to determine the number of people affected by a certain level, ramely that limit of concentration causing fatality. This was done by calculating isopleths at constant timeintegrated air concentration using Equation 10-1. Then, by integration, the area enclosed by such an isopleth was determined (curves similar to those shown in Figure 10.2 can also be used to determine areas). A key assumption was that all individuals located within the isopleth representing a fatal concentration would be killed.

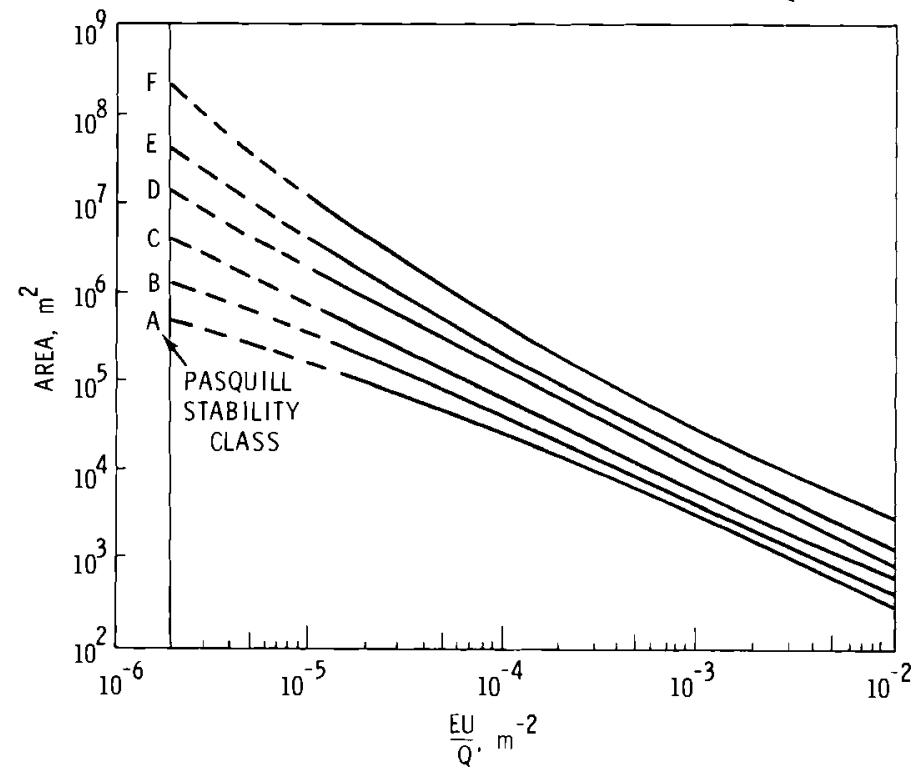

FIGURE 10.2. Area Within Isopleths for a Ground-Level Source (From Reference 13) 
In the case of a release of $\mathrm{UF}_{6}$ resulting from a transportation accident, the assumption of no evacuation near the release site would be overly conservative. HF gas generated during the release causes extreme irritation to eyes and nose at concentrations well below those assumed fatal. Thus, most of the population in the area of the release would be motivated to leave that region. Only those who are hurt or otherwise physically unable to evacuate themselves from the area would be in danger.

A study by the U.S. Environmental Protection Agency (EPA) (14) indicates that, even when faced with threatening situations, people often refuse to evacuate. Curiosity regarding the accident may override fear, and people may not leave the danger area promptly. Results of the EPA study indicate that approximately six percent of the total population affected refuses to evacuate. Other reports indicate this figure to run as high as $50 \%$.

The physical effects of the HF gas would cause most of the population to evacuate. Thus, the low figure of $6 \%$ remaining is used here. It is also assumed that another $4 \%$ of the population is physically unable to leave the danger zone. On the average, a 90\% evacuation level was assumed to prevai1 in this study. This is believed to be a conservative estimate since the irritation caused by the HF gas would probably cause a greater number of people to evacuate than otherwise.

\subsection{ESTIMATED EXPOSURE FREQUENCY}

The information presented in the previous subsections can be used as conversion factors to modify the release sequence probabilities and retease fractions developed in Section 9. The remainder of this section will show how these factors are applied in the risk calculation. The risk calculation proceeds along two parallel and interrelated paths. One path characterizes the consequences of an accidental release, and the other path determines the frequency of occurrence for each event in the consequence analysis. 
As briefly discussed in Section 3, risk is expressed by the equation:

$$
R_{i}=A F_{R_{i}} \times P_{R_{i}} \times \sum_{q} C_{E_{i, q}} \times P_{E_{q}}
$$

where $q$ represents a number of indices as indicated below.

The terms inside the first set of parentheses represent the product of the amount of material present in a shipment (A) times the fraction of that material which is lost to the environment in the $i^{\text {th }}$ release sequence $\left(F_{R i}\right)$ times the expected frequency of occurrence of the release sequence $\left(P_{R i}\right)$. A11 the information needed to evaluate these terms was developed in Section 9. The two terms in the second set of parentheses represent the consequences of a unit release $(E i, q)$ and the expected frequency of encountering a given set of environmental conditions $\left(\mathrm{PE}_{\mathrm{q}}\right)$. The primary purpose of previous parts of this section has been to determine the factors required to evaluate the consequences of a release. The information required to determine the expected frequency of a given environmental consequence has also been presented; the development of the frequency of occurrence term is shown below.

The analysis presented in this section treated the wind speed, weather stability class and population class as distributed variables. The expected frequency of encountering a given set of environmental conditions can be expressed as:

$$
P_{E_{j, k, l, m}}=P_{j / k} P_{k} P_{\ell / m} P_{m}
$$

where:

$j$ is the atmospheric stability classification index

$k$ is the wind speed index

$\ell$ is the population density index in zone $m$ of the U.S.

$m$ is the zone index for the shipping routes 
The notation $j / k$ indicates that the expected frequency of encountering the $j^{\text {th }}$ stability class is a function of the wind speed existing at the time of release. Similarly, the expected frequency of encountering the $e^{\text {th }}$ population density is dependent on the expected frequency that a shipment will pass through zone $\mathrm{m}$.

The values for the "P" in Equation (10-3) are obtained from the following tables in this section:

$$
\begin{aligned}
& P_{k} \text { - Table } 10.7 \text {, column } 3 \\
& P_{j / k} \text { - Table 10.7, columns } 4-7 \\
& P_{\ell / m} \text { - Table } 10.8 \\
& P_{m} \text { - Table } 10.10
\end{aligned}
$$

By specifying a value for $j, k, l$, and $m$, one can obtain the expected frequency that an environmental condition will be experienced during a shipment. Associated with that frequency is a corresponding value for the environmental consequences. The relationship is best summarized by the following equation for the environmental term in the risk equation:

$\sum_{q} C_{E_{i, q}} \times P_{e_{q}}=\sum_{j, k, \ell, m, n} A_{n, j, k}(\overline{E / Q})_{n, j, k} N_{\ell / m} P_{j / k} P_{k \ell} P_{/ m} P_{m}$

where:

$A_{n, j, k}$ is the area within the isopleth of concentration $(E / Q)_{n, j, k}$

$(\bar{E} / Q)_{n, j, k}$ is the time integrated air concentration received in $A_{n, j, k}$ per gram released.

$\mathrm{N}_{\ell / \mathrm{m}}$ is the population density in the release plume (Table 10.8). The subscripts and the values for $P$ in Equation 10-4 have been defined following Equation 10-3. The product $\left(\mathrm{C}_{E_{i, q}} \times \mathrm{P}_{\mathrm{E}_{q}}\right)$ has units of population health effects per gram of material released. 
Equation 10-4 summarizes the information presented in this section. In Section 11, these results will be used in conjunction with the release sequences developed in Section 9 to obtain the risk of shipping $\mathrm{UF}_{6}$ in the United States. 


\section{REFERENCES}

1. Uranium Hexafluoride: Handling Procedures and Container Criteria. ORO-651-R3, USAEC, Oak Ridge, TN, August 1972.

2. Liquid Metal Fast Breeder Reactor Program Proposed Final Environmental Statement. WASH-1535, USAEC, December 1974.

3. Chemical Safety Data Sheet SA-25, "Hydrofluoric Acid." Manufacturing Chemists Association, 1957.

4. W. Machle et a1, J. Inc. Hyg. 16:129, 1934.

5. Expansion of U.S. Uranium Enrichment Capacity. Draft Environmenta1 Statement, ERDA-1543, USERDA, June 1975.

6. J. R. Houston, D. L. Strenge and E. C. Watson, DACRIN - A Computer Program for Calculating Organ Dose From Acute or Chronic Radionuclide Inhalation. BNWL-B-389, Battelle, Pacific Northwest Laboratories, Richland, WA, 1974, (Reissued 1976).

7. Recommendations of the International Commission of Radiological Protection. ICRP Publication 6, Pergamon Press, 1962.

8. I. S. Eve, "Some Suggested Maximum Permissible Single Intakes of Uranium." Health Physics, 10:773-776.

9. H. C. Hodge, J. N. Stannard, and J. B. Hursh, Uranium, Plutonium, and Transplutonic Elements. Springer Verlag, 1973.

10. R. J. Hall et a1., An Assessment of the Risk of Transporting Plutonium Oxide and Liquid Plutonium Nitrate By Truck. BNWL-1846, Battel1e, Pacific Northwest Laboratories, Richland, WA, August 1975.

11. Rand McNally Standard Highway Mileage Guide No. 10. Household Goods Carrier's Bureau, Arlington, VA, 1973.

12. D. H. Slade, Ed. Meteorology and Atomic Energy, 1968. T10 24190, Office of Information Services, U.S. Atomic Energy Commission, Washington, DC, 1968.

13. W. F. Hilsmeirer, and F. A. Gifford, Graphs for Estimating Atmospheric Diffusion. OR0-545, U.S. Atomic Energy Commission, Oak Ridge, TN, 1962.

14. J. M. Hans, Jr. and T. C. Se11, Evacuation Risks - An Evaluation. U.S. Environmental Protection Agency, EPA-520/6-74-002, June 1974. 
$\checkmark$ . 


\subsection{THE RISK OF SHIPPING URANIUM HEXAFLUORIDE BY TRUCK AND RAIL}

In this section, the risk of shipping $U_{6}$ by truck and rail will be discussed. The risk was calculated using the methodology presented in Section 3. The probability of an accidental release occurring during transport was determined in Section 9, and the consequences of such a release were discussed in Section 10. Section 11.1 presents the risk of shipping $\mathrm{UF}_{6}$ in the reference year, based on the shipping system model given in Section 4. Major contributors to the overal1 risk are discussed in Section 11.2 and the results of sensitivity studies will be presented in Section 11.3. A discussion of multiple container failures will be presented in Section 11.4.

\subsection{RISK EVALUATION OF UF SHIPMENTS}

Because of the complex nature of the shipping system model, the risk analysis was divided into five parts, each part corresponding to one of the five shipping package configurations. The figures which were used for calculations in the aralysis are shown in Table 11.1 for each cylinder configuration. The risk involved with shipping each of the five cylinder configurations was determined; these risks were then summed to determine the overall transportation system risk.

Based on the information presented in Table 11.1, accidents involving truck shipments of $U_{6}$ (in any of the four cylinder types) would be expected to occur at a rate of three every year. Train accidents involving $\mathrm{UF}_{6}$ shipments (in 14-ton cylinders) would be expected to occur approximately twice every year. Based on the release sequence probabilities determined in Section 9, truck accidents resulting in a release (of any amount of material) are expected once every 33 years. Train accidents resulting in a release would occur once every 100 years. Accidents releasing sufficient $\mathrm{UF}_{6}$ to create a hazard (a significant release) can be expected once every 1430 years for truck shipments and once every 710 years for rai1 shipments. These results are summarized in Table 11.2 for each cylinder configuration. 
TABLE 11.1. Simplified UF 6 Shipping System Model

\begin{tabular}{|c|c|c|c|c|c|c|c|c|}
\hline $\begin{array}{l}\text { Shipping } \\
\text { Container }\end{array}$ & $\begin{array}{c}\text { Transport } \\
\text { Mode }\end{array}$ & $\begin{array}{c}\text { Amount/ } \\
\text { Container (MT) }\end{array}$ & $\begin{array}{c}\text { Conta iners/ } \\
\text { Shipment } \\
\end{array}$ & $\begin{array}{c}\text { Shipment } \\
\text { Origin/ } \\
\text { Destination }\end{array}$ & $\begin{array}{l}\text { Material } \\
\text { Shipped/ } \\
\text { Year (MT) }\end{array}$ & 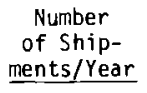 & $\begin{array}{c}\text { Average } \\
\text { Shipment } \\
\text { Distance }(\mathrm{km}) \\
\end{array}$ & Accident $/ \mathrm{km}$ \\
\hline \multirow[t]{2}{*}{$\begin{array}{l}2.5 \text {-ton }(30 \mathrm{~B}) \\
\text { With Overpack }\end{array}$} & Truck & 2.28 & 5 & $\begin{array}{l}\text { Enrichment/ } \\
\text { Fabrication }\end{array}$ & 7,460 & 653 & 1,050 & $1.55 \times 10^{-6}$ \\
\hline & & & & $\begin{array}{l}\text { Enrichment/ } \\
\text { Exports }\end{array}$ & & & & \\
\hline $10-\tan (48 x)$ & Truck & 9.54 & 2 & $\begin{array}{l}\text { Conversion/ } \\
\text { Enrichment }\end{array}$ & 9,000 & 472 & 1,040 & $1.55 \times 10^{-6}$ \\
\hline $\begin{array}{l}\text { 10-ton }(48 x) \\
\text { With Overpack }\end{array}$ & Truck & 9.54 & 1 & $\begin{array}{l}\text { Enrichment/ } \\
\text { Enrichment }\end{array}$ & 1,340 & 141 & 420 & $1.55 \times 10^{-6}$ \\
\hline 14 -ton (48Y) & Truck & 12.5 & 1 & $\begin{array}{l}\text { Conversion/ } \\
\text { Enrichment }\end{array}$ & 21,820 & 1.746 & 375 & $1.55 \times 10^{-6}$ \\
\hline \multirow[t]{2}{*}{$14-\operatorname{ton}(48 Y)$} & Rail & 12.5 & 4 & $\begin{array}{l}\text { Import/ } \\
\text { Enrichment }\end{array}$ & 12,000 & 420 & 800 & $6.21 \times 10^{-5}$ \\
\hline & & & & $\begin{array}{l}\text { Enrichment/ } \\
\text { Enrichment }\end{array}$ & & & & \\
\hline
\end{tabular}

TABLE 11.2. Summary of $\mathrm{UF}_{6}$ Shipping System Risks

\begin{tabular}{|c|c|c|c|c|c|}
\hline $\begin{array}{l}\text { Shipping } \\
\text { Container }\end{array}$ & $\begin{array}{l}\text { Transport } \\
\text { Mode }\end{array}$ & $\begin{array}{l}\text { Probability } \\
\text { of Accident } \\
\text { (events/year) }\end{array}$ & $\begin{array}{r}\text { Probability } \\
\text { of Release } \\
\text { (events/year) } \\
\end{array}$ & $\begin{array}{c}\text { Probability } \\
\text { of Significant } \\
\text { Release } \\
\text { (events/year) } \\
\end{array}$ & $\begin{array}{c}\text { Probability of } \\
\text { Release Resulting } \\
\text { In } \geqq 1 \text { Death }\end{array}$ \\
\hline $\begin{array}{l}2.5 \text {-ton (30B) } \\
\text { With Overpack }\end{array}$ & iruck & 1.06 & $4.6 \times 10^{-4}$ & $3.1 \times 10^{-4}$ & $1.4 \times 10^{-7}$ \\
\hline $10-\tan (48 x)$ & Truck & $7.6 \times 10^{-1}$ & $1.0 \times 10^{-2}$ & $1.6 \times 10^{-4}$ & $3.4 \times 10^{-6}$ \\
\hline $\begin{array}{l}\text { 10-ton }(48 x) \\
\text { With Overpack }\end{array}$ & Truck & $9.2 \times 10^{-2}$ & $3.1 \times 10^{-5}$ & $1.9 \times 10^{-5}$ & $4.1 \times 10^{-7}$ \\
\hline $14-\tan (48 \mathrm{Y})$ & Truck & 1.01 & $2.0 \times 10^{-2}$ & $2.1 \times 10^{-4}$ & $4.5 \times 10^{-6}$ \\
\hline 14 -ton (48Y) & Rail & 2.09 & $1.0 \times 10^{-2}$ & $1.4 \times 10^{-3}$ & $9.7 \times 10^{-5}$ \\
\hline
\end{tabular}

Risk spectrum curves for the five individual container configurations are shown in Figure 11.1, along with the risk spectrum for the entire shipping system for the reference year. The shipment of $U_{6}$ in 14-ton cylinders by rail contributes the greatest portion to the total system risk (especially in the high consequence portion of the spectra). The high risk for rail shipments stems primarily from the severe fire accident environment for rail. In a train accident with fire, $24 \%$ of the fires are of sufficient duration (48 min) to fail a nondefective $48 Y$ ( 14 -ton) $U_{6}$ cylinder. However, only 1.3 percent of the fires in a truck accident are of this duration. Since 
the explosive failure of a cylinder was found to have the most severe consequences, the rail shipments of $U_{6}$ were found to have the highest risk. Thus, the total and 14-ton cylinder by rail risk curves are virtually identical. Figure 11.2 shows the $U_{6}$ shipment risk spectrum in perspective with other risks, including those from previous risk assessment studies in this series. $(1,2,3)$

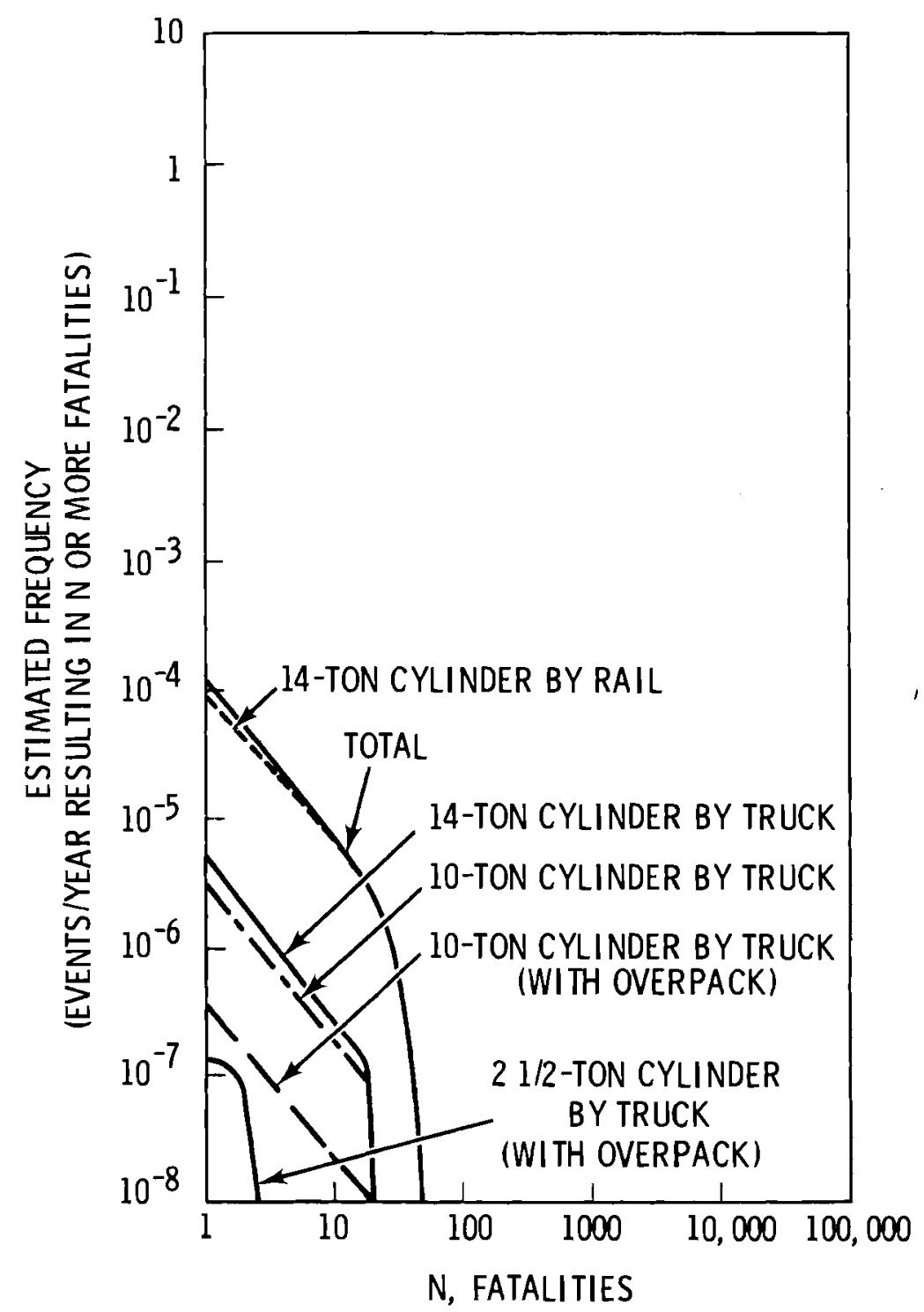

FIGURE 11.1. Risk Spectra for Individual Transport Modes and Total for Shipping System 


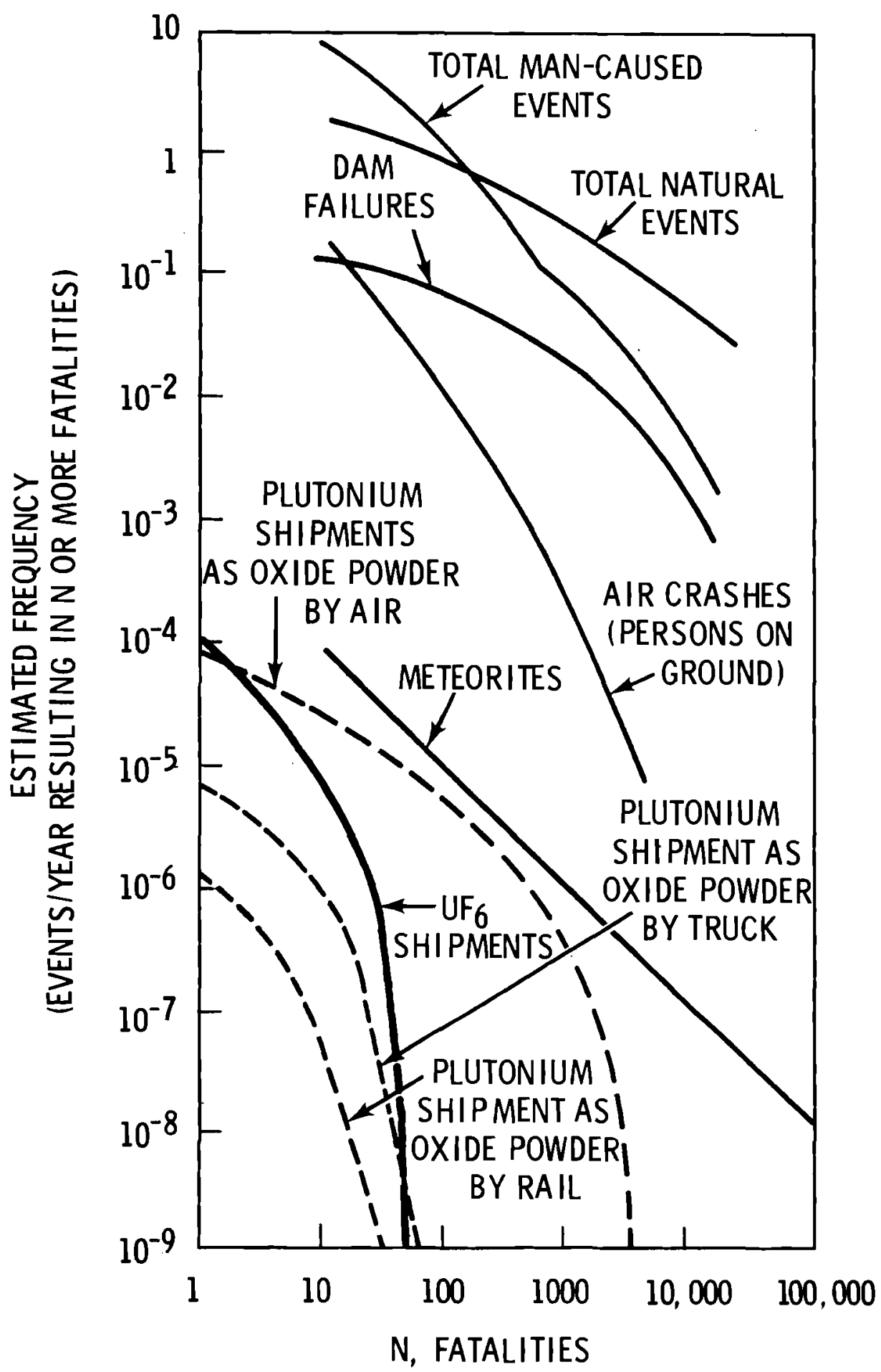

FIGURE 11.2. Risk Spectrum for Shipment of $\mathrm{UF}_{6}$ and 0ther Risk Spectra 
The results of this study indicate that the risk of shipping $U_{6}$ by truck and rail is generally higher than the risk of shipping plutonium by truck and rail, but lower than the risk of shipping plutonium by air. At the low consequence-high probability end of the spectrum, the risks of shipping plutonium by air and $U_{6}$ are similar, while at the high consequence-low probability end, the $U_{6}$ risk is similar to that for shipping plutonium oxide by truck and rail. The risk of shipping $U_{6}$ is well below the spectrum presented for man-caused events. Again, it should be noted that these spectra do not differentiate between latent (long-term) and acute (short-term) fatalities.

\subsection{MAJOR CONTRIBUTORS TO OVERALL RISK}

During the analysis of each of the five container configurations, the release sequences determined in Section 9 were grouped into four categories corresponding to the four release fractions described in Section 9.3. In evaluating the release sequences in each of these four groups, three effects of the released materials were addressed: the chemical effects of HF gas and the chemical and radiological effects of $\mathrm{UO}_{2} \mathrm{~F}_{2}$.

For all cylinder configurations, it was found that only release sequences in which the cylinder failed explosively in a fire presented a significant potential for producing fatalities. These release sequences correspond to the third and fourth release fraction groups described in Section 9.3. In all other release sequences, materials released were either dispersed and diluted so thoroughly that a lethal level could be found only at the source point, or the materials were not dispersed from the accident at all. Furthermore, only HF gas was found to produce fatalities. Radiation doses from $\mathrm{UO}_{2} \mathrm{~F}_{2}$ were insufficient to present a chemical hazard.

The release sequence scenarios describing the explosive release of $U_{6}$ in a fire consist of an early release of short duration ( $1 \mathrm{~min}$ ) followed by a long term release $(4 \mathrm{hr}$ ). Materials released during the short term release are elevated to a height of 230 meters by the fire. Large chunks of solid $\mathrm{UF}_{6}$ 
slowly hydrolizing on the ground characterize the long term portion of the releases. In both cases, the lethal concentrations of HF gas result from the long term release.

To summarize, all release sequences contributing significantly to the risk of shipping $U_{6}$ include the explosive failure of the cylinder in a fire. Only the HF gas, released over a 4-hr period following the failure of the cylinder, is in sufficient concentrations to cause fatalities. All other release sequences release insufficient material to cause fatalities.

\subsection{RISK SENSITIVITY STUDIES}

Before discussing the sensitivity of the risk evaluation to the value of certain system parameters, it is important to point out a fundamental sensitivity of the risk evaluation. The calculated risk is a function of the shipping assumptions. Use of different shipping routes, different containers, changes in the predicted industry growth rate, etc., would result in a different risk. In general, reevaluation of the risk would be required for these changed conditions.

Risk sensitivity evaluations permit analysis of the importance of the various factors that contribute to the risk. They can be used to: 1) identify and quantify the effects of the major contributors to the risk; 2) identify ways to decrease the uncertainty in the risk evaluation, and 3) study the effects of possible design or regulatory changes on the risk. Most sensitivity studies are performed by repeating the risk calculation with a changed value for the parameter of interest. In general, the dependence of the risk on a particular parameter is complex; although in some cases, the parameter enters simply into the risk calculation and the sensitiyity can be determined directly.

For this risk assessment, the area presenting the greatest uncertainty is the evacuation of people from the vicinity of the accident. Hydrogen fluoride gas is highly irritating to the eyes and nose in concentrations far below that necessary to cause physical damage. Thus, it appears that only those individuals incapable of self-evacuation (invalids or those trapped in the accident wreckage) would be in grave danger. To test the effects of 
evacuation levels on the risk of shipping $\mathrm{UF}_{6}$, sensitivity studies assuming no evacuation, $95 \%$ evacuation, and $99 \%$ evacuation were carried out. The results of these sensitivity analyses are compared graphically with the base case (which assumed 90\% evacuation) in Figure 11.3 and tabulated in Table 11.3.

In Section 5, the accident environment was described. One portion of the accident environment (the puncture environment), for both truck and rail accidents was determined using available existing accident data. The effects of using the assumed puncture rates in the risk assessment will be examined here.

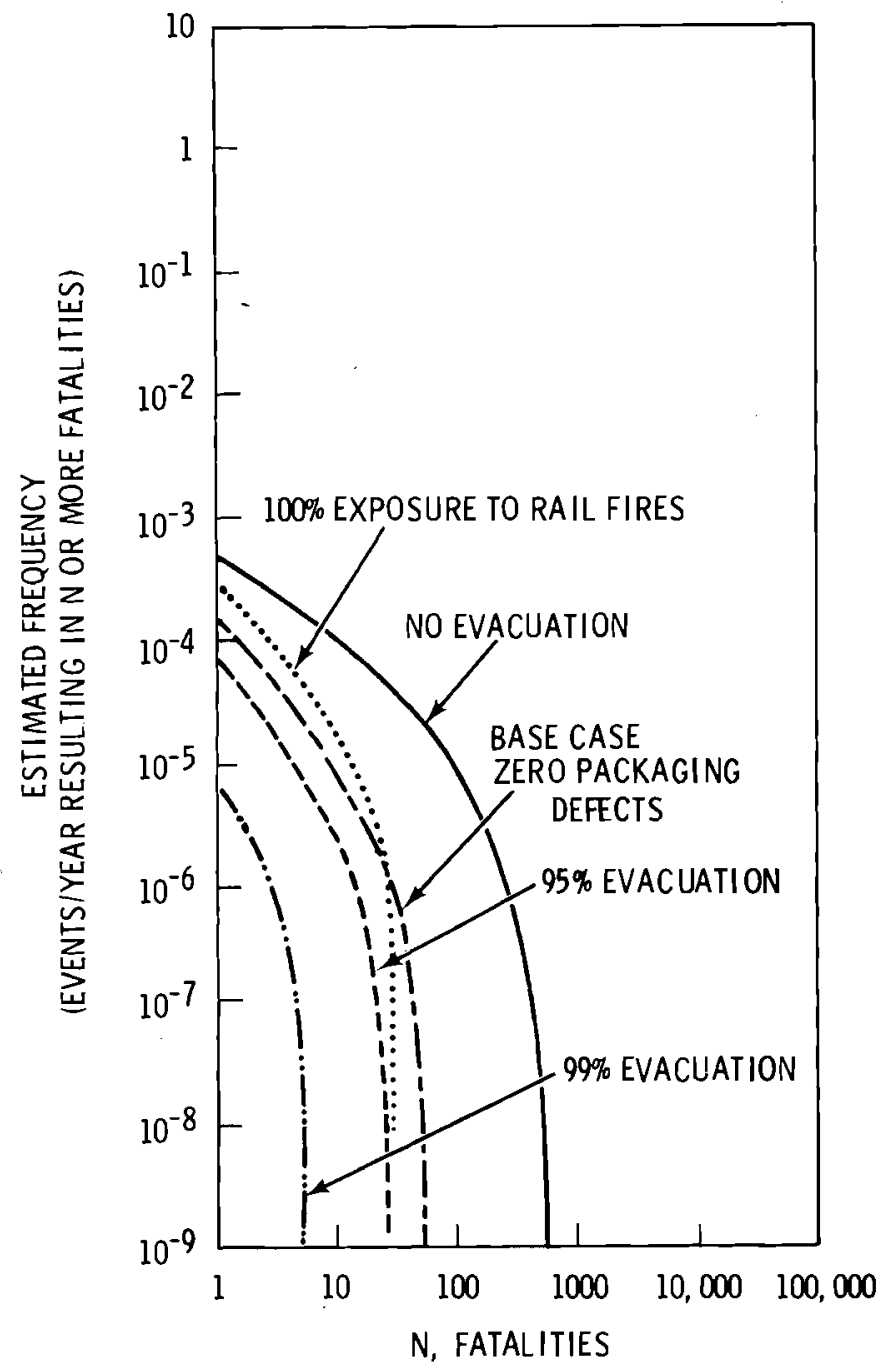

FIGURE 11.3. Risk Spectra for Sensitivity Cases 
TABLE 11.3. Risk Sensitivity Cases for $\mathrm{UF}_{6}$ Shipments

Risk Level

\section{(Estimated Annual}

Description of

Sensitivity Case

Base Case ${ }^{(a)}$

No Evacuation

95\% Evacuation

99\% Evacuation

$100 \%$ Exposure to

Rail Fires

No Packaging

Defects
Frequency of Occurrence of One or More Fatalities)

$1.09 \times 10^{-4}$

$5.19 \times 10^{-4}$

$7.59 \times 10^{-6}$

$3.31 \times 10^{-4}$

$1.05 \times 10^{-4}$
$6.22 \times 10^{-5}$
Risk Level

Relative to

Base Case

4.76

0.57

0.07

3.04

1.00

(a) Based on Shipping Mode1 (Section 4) and 90\% Evacuation

In the previous subsection (11.2), the main contributors to the risk were discussed. In the risk analysis, it was determined that only originally intact cylinders failing explosively in a fire contributed to the risk of shipping $\mathrm{UF}_{6}$. Cylinders punctured in the accident did not contribute to the calculated overall risk. Therefore, the risk assessment is insensitive to the puncture rate assumed in Section 5 .

The sensitivity of the risk to the presence of fire in a rail accident was tested. All of the cars in a train are not expected to be exposed to the fire, because of the size of the train relative to the fire size. In Section 5 , it was shown that the car carrying $\mathrm{UF}_{6}$ cylinders would be directly exposed to the fire in 14\% of al1 rail accidents involving fire. To test this assumption a sensitivity study was carried out in which it was assumed that the cylinders would be exposed to the fire in $100 \%$ of all rail accidents involving a shipment of $U_{6}$ (a highly conservative assumption). The results are shown in Figure 11.3 and Table 11.3 .

A final sensitivity study was carried out to determine the effects of packaging errors on the risk. The case was evaluated with the assumption of 
no packaging errors present during the shipment. The results of the sensitivity analysis show that the risk is insensitive to packaging errors.

\subsection{MULTIPLE CONTAINER FAILURE ANALYSIS}

The evaluation presented in Section 11.2 assumed that only one container failed in an accident, but at an accident frequency multiplied by the number of containers in the shipment. The analysis did not include the possibility of multiple container failures in a single accident. Because fire is the only portion of the accident environment which can cause significant releases of $U_{6}$ with the potential for causing fatalities, the possibility of multiple container failures must be addressed.

To determine the effects of multiple container fire failures on the risk of transporting $U_{6}$, a special sensititivity study was carried out. The study was based on the following assumptions:

1. All fires were assumed to be petroleum fires.

2. Fuel pools were assumed to be circular.

3. The fuel source was assumed to be located at one end of the transport vehicle.

4. Cylinders were assumed to remain in position on the transport vehicle.

5. Train tank car fue1, when involved, is spread uniformly over an area varying from 56 to 465 square meters, averaging 185 square meters with a cumulative distribution function (cdf) given by

$$
1-\mathrm{e}^{-\left[\frac{(10.76)(A)-600}{1465}\right]^{1.28}}
$$

where $A$ is the area in square meters. (4)

6. When diesel fuel from locomotives is involved in the fire, it is dispersed uniformly over 46 to 93 square meters with an expected value of 65 square meters and a cdf given by

$$
1-e^{-}\left[\frac{(10.76)(A)-500}{252}\right]^{1.6}
$$

where $A$ is the area in square meters. (4) 
7. Fuel from a truck/truck (nontanker) collision is distributed uniformly with equal probability over $4 \mathrm{~m}^{2}$ to $19 \mathrm{~m}^{2}$. (4)

8. Fuel from a truck/tanker collision is spread uniformly and with equal probability over $5 \mathrm{~m}^{2}$ to $47 \mathrm{~m}^{2}$. (4)

9. Cylinders were assumed to be exposed to the fire if they were completely inside the circumference of the fuel pool (see Figure 11.4).

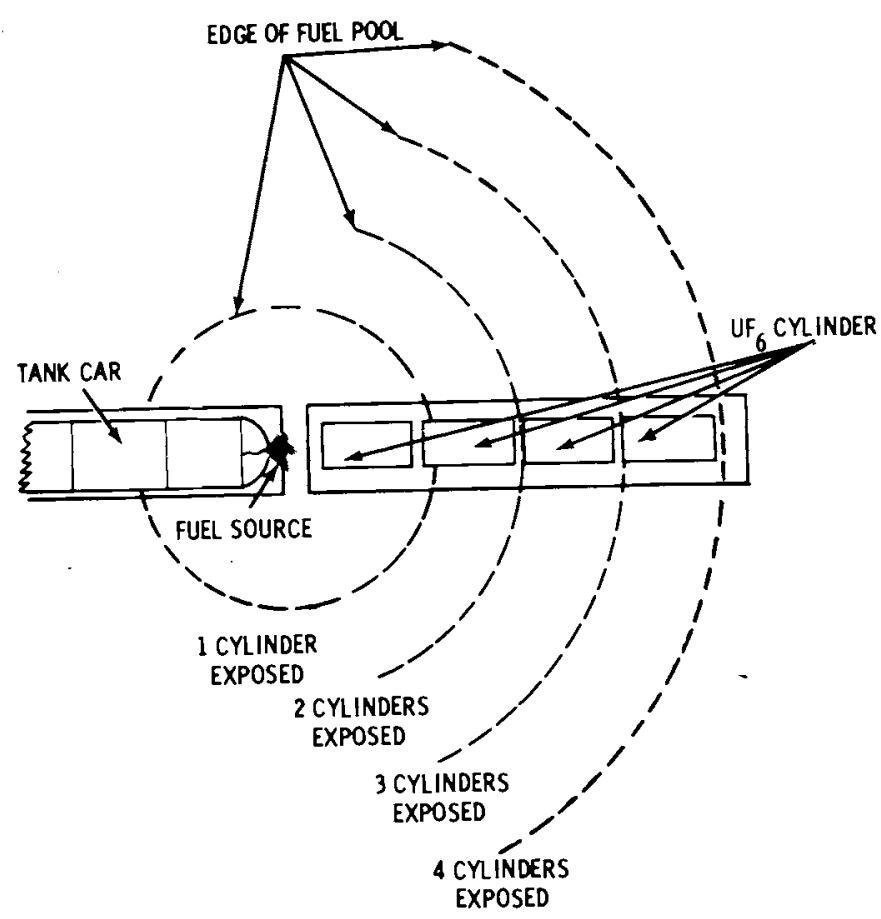

FIGURE 11.4. Number of Cylinders Exposed to Fire as Related to Fuel Pool Size

The above assumptions were used to determine the probability of a certain number of cylinders being exposed to the fire. Analyses were made ranging from one cylinder to all cylinders in a shipment being exposed and failing. Consequences were evaluated in the same manner as for the base case.

The results of this supplemental sensitivity study are shown in Figure 11.5 along with the results of the evaluation performed in Section 11.2. The assumption of independent container failures is nonconservative by about a factor of 1.5 at the high consequence-low probability end of the 
spectrum, but conservative by a factor of approximately 2.5 at the low consequence-high probability end. Based on the results of the multiple container failure analysis, the inclusion of multiple container failure data would not seriously distort the risk spectrum obtained from individual container failure analysis.

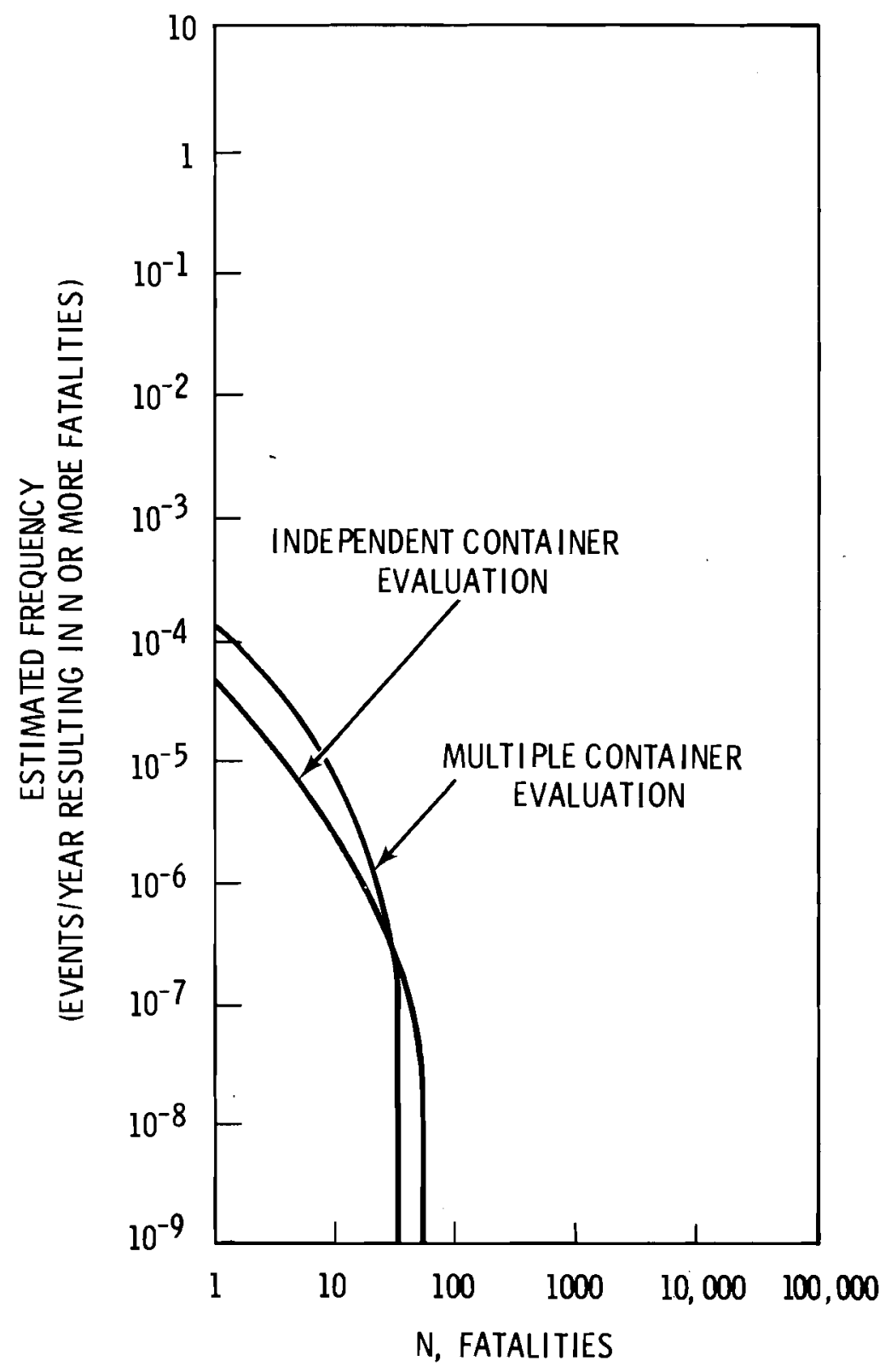

FIGURE 11.5. Risk Spectrum of Single and Multiple Container Failure Evaluations 


\section{REFERENCES}

1. T. I. McSweeney, R. J. Hall et al., An Assessment of the Risk of Transporting Plutonium 0xide and Liquid Plutonium Nitrate by Truck. BNWL-1846, Battelle, Pacific Northwest Laboratories, Richland, WA, August 1975.

2. R. J. Hall et al., An Assessment of the Risk of Transporting Plutonium Dioxide and Liquid Plutonium Nitrate by Train. BNWL-1996, Battelle, Pacific Northwest Laboratories, Richland, WA, February 1977.

3. T. I. McSweeney and J. F. Johnson, An Assessment of the Risk of Transporting Plutonium Dioxide by Cargo Aircraft. BNWL-2030, Battelle, Pacific Northwest Laboratories, Richland, WA, June 1977.

4. A. W. Dennis, J. T. Foley, W. F. Hartman and D. W. Larson, Severities of Transportation Accidents Involving Large Packages. SAND 77-0001, Sandia Laboratories, Albuquerque, NM, May 1978. 


\section{APPENDIX A}

\section{$\underline{U F}_{6}$ SHIPPING CONTAINER AND TRANSPORT MODE DESCRIPTION}

Essentially all $\mathrm{UF}_{6}$ shipments are currently made by either truck or rail. A third mode, piggyback (a combination of truck and rai1), is sometimes used, but was not considered in this study. All shipments are made in containers meeting Department of Transportation (DOT) specifications and built to standards outlined in ANSI N14.1-1971.

\section{UF $_{6}$ SHIPPING CYLINDERS}

Although a variety of containers are available for shipping $\mathrm{UF}_{6}$, only three were considered in this study: the $30 \mathrm{~B}$ (2 1/2-ton) cylinder, the $48 \mathrm{X}$ (10-ton cylinder, and the $48 Y$ (14-ton) cylinder. Another $21 / 2$-ton $\mathrm{UF}_{6}$ cylinder, the $30 \mathrm{~A}$, is currently in use and will be described here. It was not considered as part of the study, however, for two reasons: 1). The 30B was designed to replace the $30 \mathrm{~A}$; this changeover should be nearly complete in the early $1980 \mathrm{~s}$, the reference time for the analysis, and 2) the $30 \mathrm{~A}$ and $30 \mathrm{~B}$ are basically similar models. The $30 \mathrm{~B}$ was chosen as a representative $21 / 2$-ton cylinder to reduce the number of cylinders analyzed.

Each cylinder is presented and described in Figures and Tables A.1 through A.4. More detailed information, including engineering drawings, can be found in Reference 1.

\section{PROTECTIVE OVERPACKS}

Except for exempt quantities of fissile material, cylinders containing $\mathrm{UF}_{6}$ enriched to greater than $1.0 \mathrm{wt} \%{ }^{235} \mathrm{U}$ must be shipped in protective outer packages. Provisions to adequately separate $\mathrm{UF}_{6}$ containers, protect against accident conditions, and assure criticality prevention have been incorporated in the designs of the protective outer packages. Protective outer packages which have been designed and tested in accordance with applicable DOE and DOT regulations for $\mathrm{UF}_{6}$ cylinder models $30 \mathrm{~A}, 30 \mathrm{~B}$, and $48 \mathrm{X}$ are shown in Figures A.5 and A.6. 


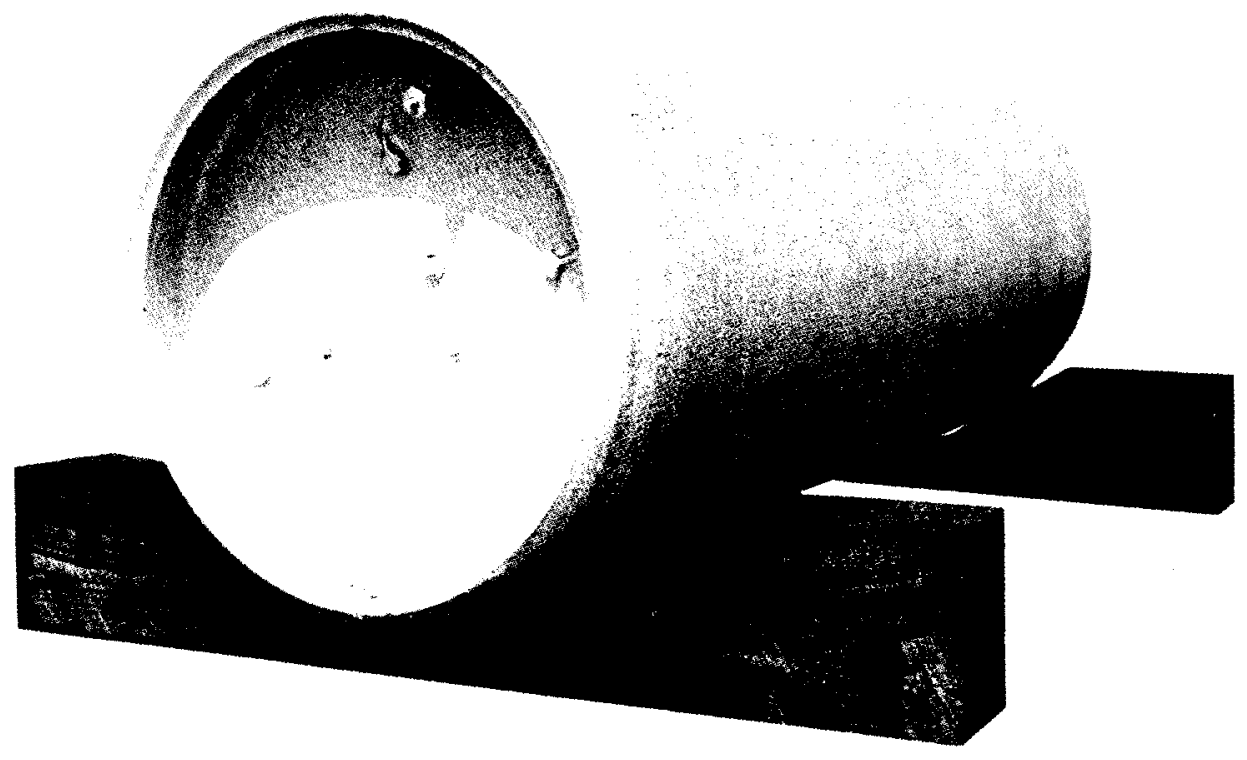

FIGURE A.1. UF 6 Cylinder Model 30A

TABLE A.1. General Data for UF Cylinder Mode1 30A Other Descriptive Terminology Used - 2 1/2-ton UF 6 , 1-ton Chlorine

\author{
Nominal Diameter \\ Nominal Length \\ Wall Thickness \\ Head Thickness \\ Nominal Tare Weight \\ Maximum Net Weight \\ Nominal Gross Weight \\ Minimum Volume \\ Basic Material of Construction \\ Service Pressure \\ Hydrostatic Test Pressure \\ Isotopic Content Limit
}

$76.2 \mathrm{~cm}$ (30 in.)

$205.74 \mathrm{~cm}(81$ in.)

$1.03 \mathrm{~cm}(13 / 32$ in.)

$1.91 \mathrm{~cm}(3 / 4 \mathrm{in.})$

$635 \mathrm{~kg}(1,400 \mathrm{lb})$

$2245 \mathrm{~kg}(4,950 \mathrm{1b})$

$2880 \mathrm{~kg}(6,350 \mathrm{1b})$

$.73 \mathrm{~m}^{3}(25.65 \mathrm{cu} f \mathrm{t})$

Steel

$21.32 \times 10^{6} \frac{\mathrm{N}_{2}}{\mathrm{~m}^{2}}$ (192 psig)

$3.45 \times 10^{6} \frac{\mathrm{N}^{2}}{\mathrm{~m}^{2}}$ (500 psig)

$5.0 \%{ }^{235} \cup \operatorname{Max}$ with Moderation Control 


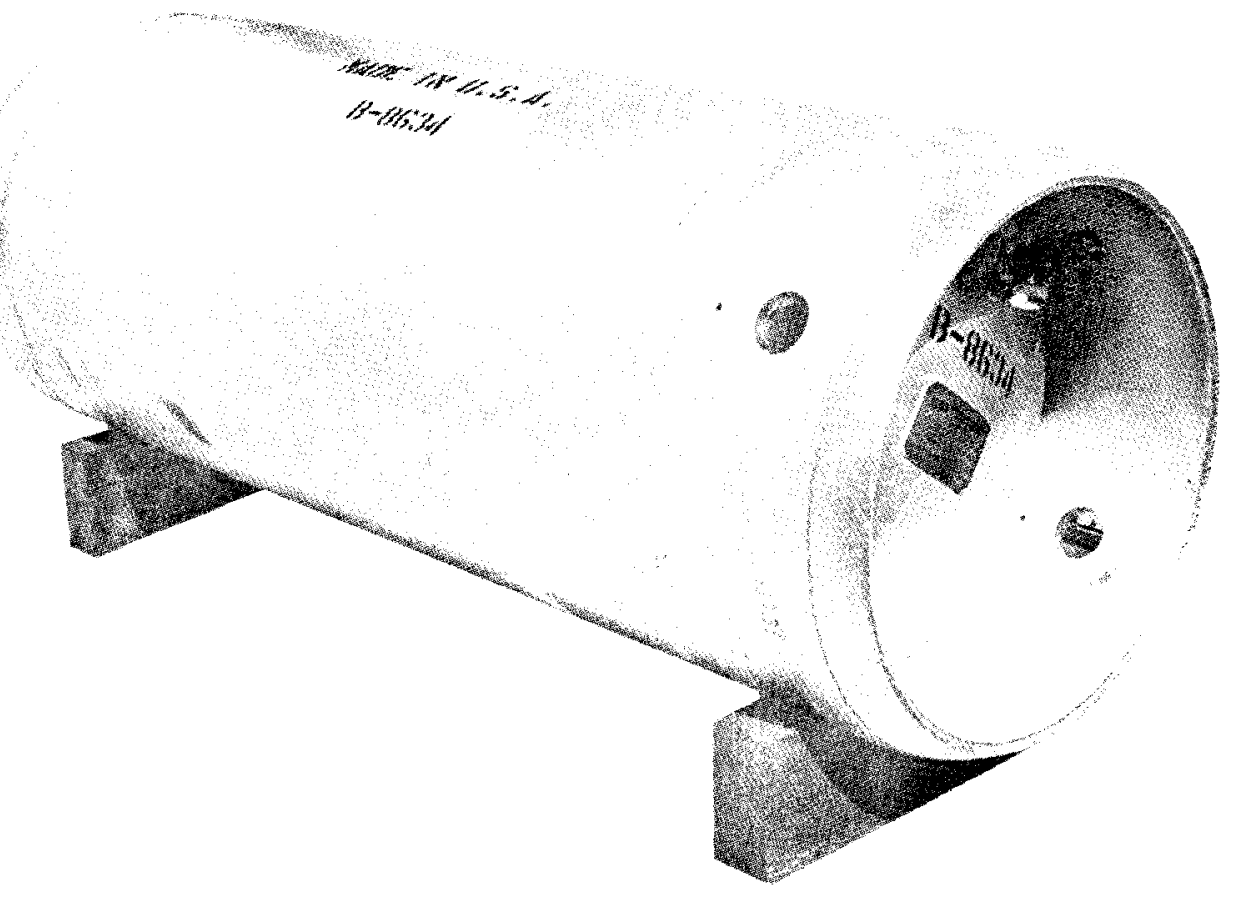

FIGURE A.2. UF 6 Cyilinder Model 30B

TABLE A.2. General Data for $\mathrm{UF}_{6}$ Cylinder Model 30B Other Descriptive Terminology Used - 2 1/2-ton

Nominal Diameter
Nominal Length
Wall Thickness
Nominal Tare Weight
Maximum Net Weight
Nominal Gross Weight
Minimum Volume
Basic Material of Construction
Service Pressure
Hydrostatic Test Pressure
Isotopic Content Limit

Nominal Diameter

$76.2 \mathrm{~cm}$ (30 in.) $205.74 \mathrm{~cm}$ (81 in.)

$1.27 \mathrm{~cm}(1 / 2$ in. $)$ $635 \mathrm{~kg}(1,400 \mathrm{lb})$ $2277 \mathrm{~kg}(5,020 \mathrm{lb})$ $2912 \mathrm{~kg}(6,420 \mathrm{lb})$ $0.74 \mathrm{~m}^{3}$ (26 cu ft) Steel 21.38 $\times 10^{6} \frac{\mathrm{N}_{2}}{\mathrm{~m}^{2}}$ (200 psig) $2.76 \times 10^{6} \frac{\mathrm{N}^{2}}{\mathrm{~m}^{2}}$ (400 psig) $5.0 \% 235$ Uax With Moderation Control 


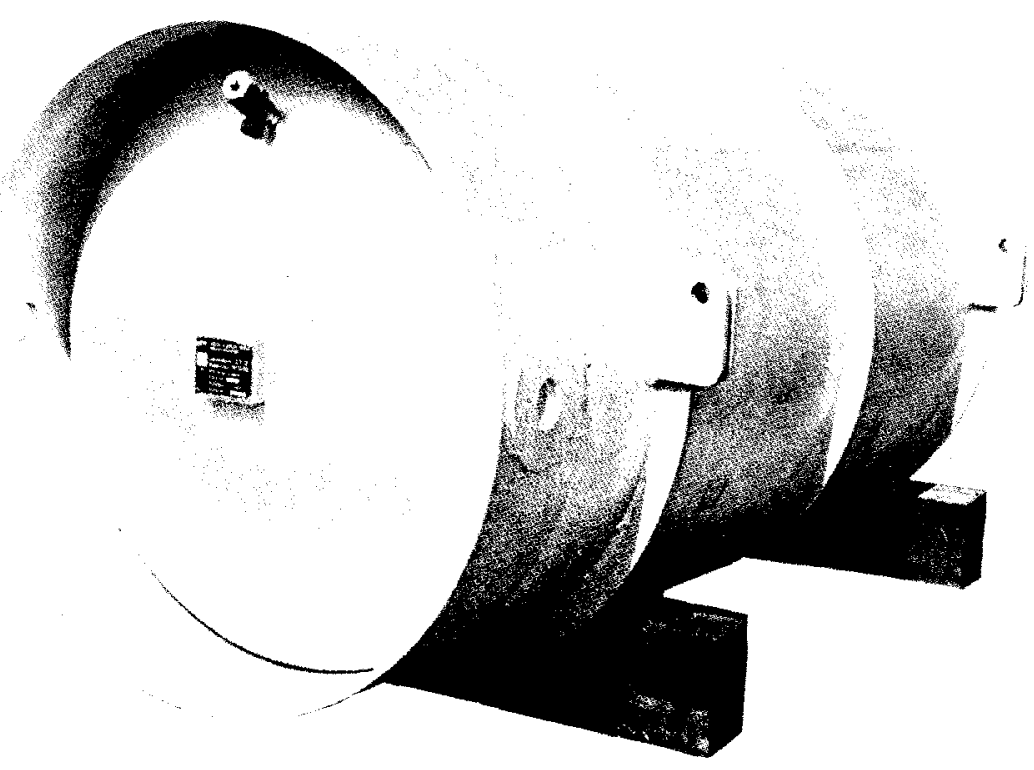

FIGURE A.3. UF 6 Cylinder Model $48 \mathrm{X}$

TABLE A.3. General Data for UF 6 Cylinder Model 48X 0ther Descriptive Terminology Used - 10-ton

Nominal Diameter

Nominal Length

Wa11 Thickness

Nominal Tare Weight

Maximum Net Weight

Nominal Gross Weight

Minimum Volume

Basic Material of Construction

Service Pressure

Hydrostatic Test Pressure

Isotopic Content Limit
$122 \mathrm{~cm}$ (48 in.)

$307 \mathrm{~cm}$ (121 in.)

$1.59 \mathrm{~cm}$ (5/8 in.)

$2041 \mathrm{~kg}(4,500 \mathrm{lb})$

$9539 \mathrm{~kg}(21,030 \mathrm{1b})$

$11580 \mathrm{~kg}(25,530 \mathrm{lb})$

$3.08 \mathrm{~m}^{3}(108.9 \mathrm{cu} \mathrm{ft})$

Stee 1

$1.38 \times 10^{6} \frac{\mathrm{N}_{2}}{\mathrm{~N}^{2}}(200 \mathrm{psig})$

$2.76 \times 10^{6} \frac{\mathrm{N}}{\mathrm{m}^{2}}$ (400 psig)

$4.5 \%{ }^{235} \mathrm{U}$ Max with Moderation Control 


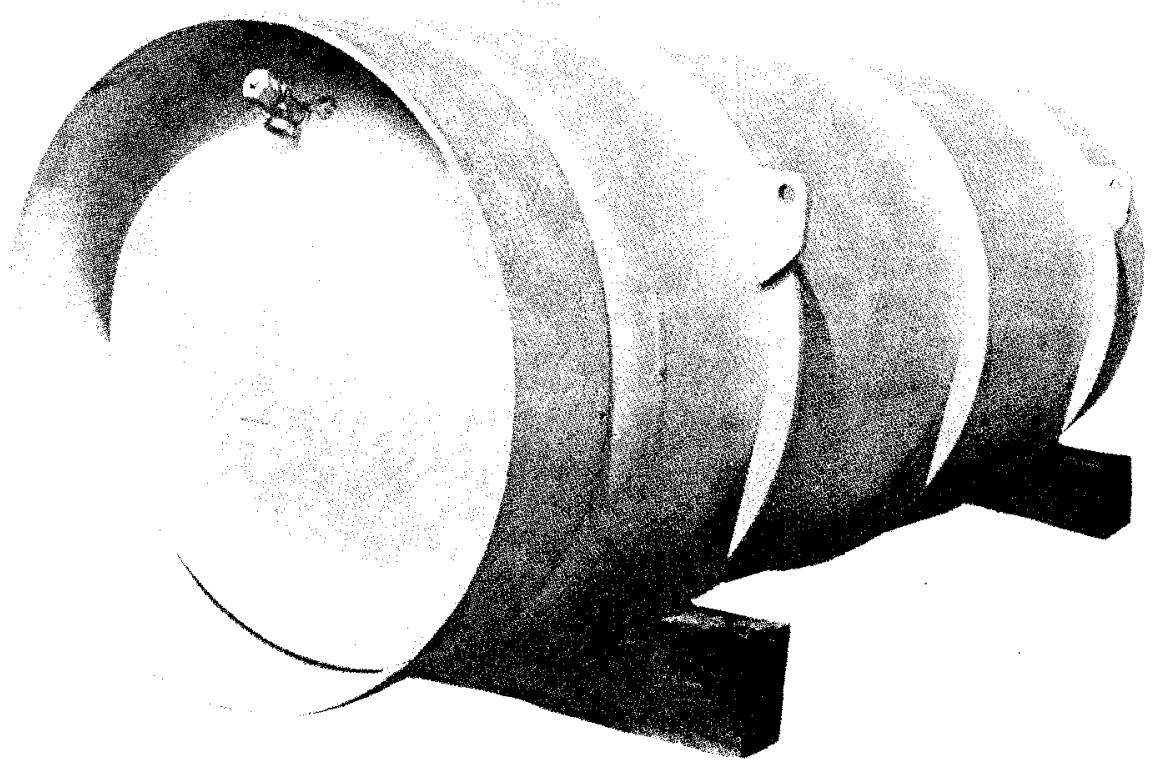

FIGURE A.4. UF 6 Cylinder Model 48Y

TABLE A.4. General Data for $\mathrm{UF}_{6}$ Cylinder Model 48Y Other Descriptive Terminology Used - 14-ton

\author{
Nominal Diameter \\ Nominal Length \\ Wall Thickness \\ Nominal Tare Weight \\ Maximum Net Weight \\ Nominal Gross Weight \\ Minimum Volume \\ Basic Material of Construction \\ Service Pressure \\ Hydrostatic Test Pressure \\ Isotopic Content Limit
}
$122 \mathrm{~cm}$ (48 in.)
$381 \mathrm{~cm}$ (150 in.)
$1.59 \mathrm{~cm}$ (5/8 in.)
$2359 \mathrm{~kg}(5,200 \mathrm{lb})$
$12,501 \mathrm{~kg}(27,560 \mathrm{1b})$
$14,860 \mathrm{~kg}(32,760 \mathrm{lb})$
$4.04 \mathrm{~m}^{3}$ (142.7 cu ft)
Steel
$1.38 \times 10^{6} \frac{\mathrm{N}_{2}}{\mathrm{~m}^{2}}$ (200 psig)
$2.76 \times 10^{6} \mathrm{~N}^{2}$ (400 psig)
$4.5 \%{ }^{235} \mathrm{U}$ Max With Modera- tion Control 


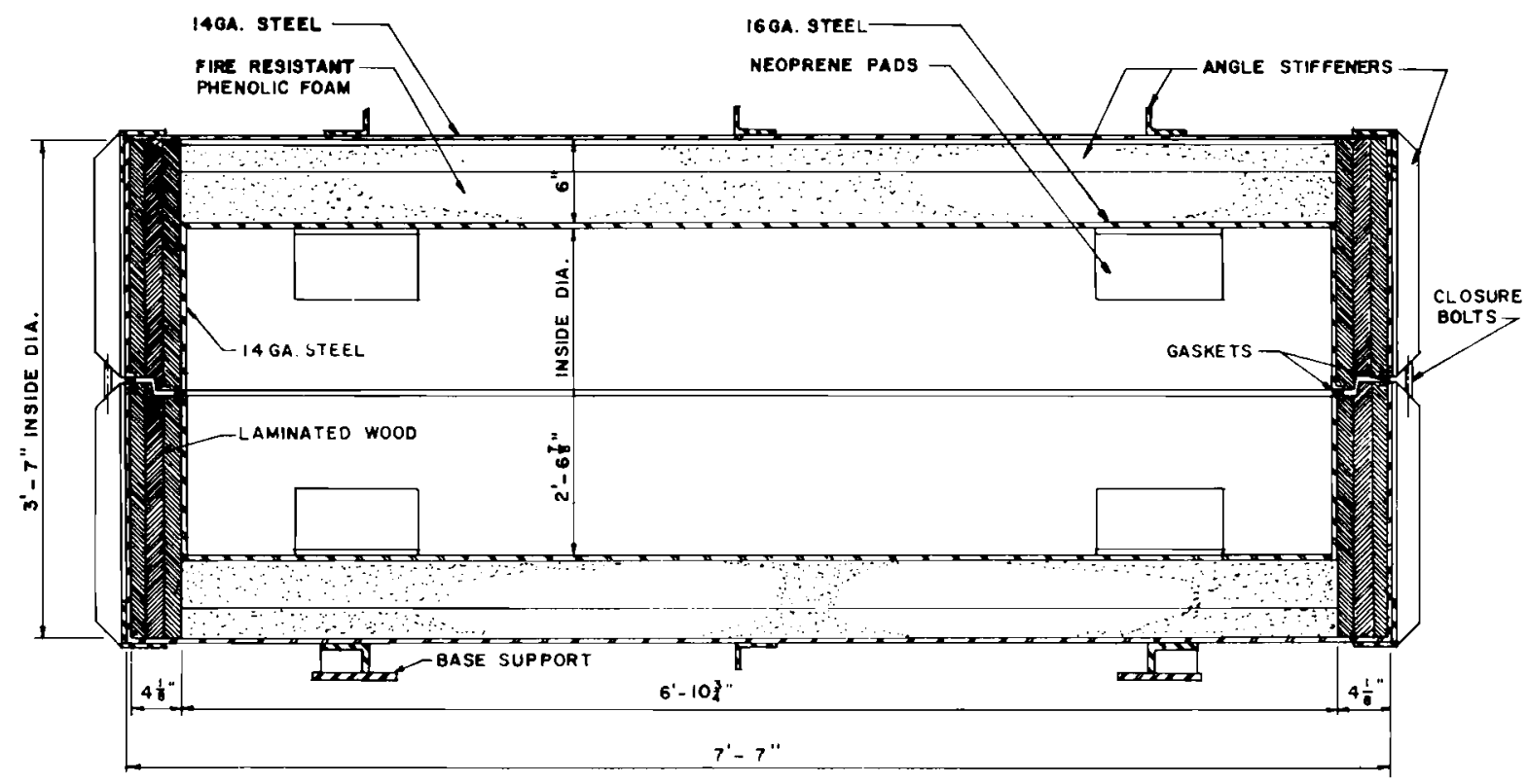

AVERAGE HEIGHTS

SHIPPING CONTAINER WEIGHT $\cdots-1750$ LBS FILLED 30" CYLINDER 6400 LES.

TOTAL WEIGHT 8150 LES

FIGURE A.5. Horizonta11y-Loaded Protective Outer Package for UF6 Cylinder Models 30A and 30B (From Reference 1) 

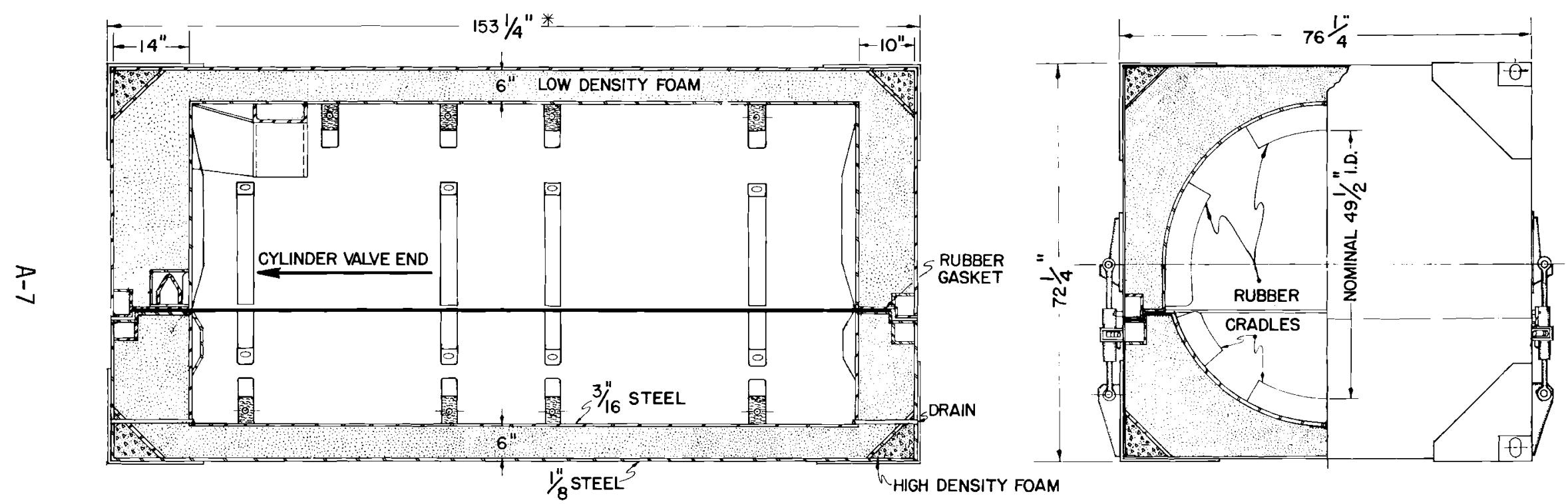

* projected overall length of future packages to APPROXIMATE WEIGHT ACCOMMODATE MODEL $48 \times$ TYPE CYLINDER

$$
\begin{array}{cc}
\text { SHIPPING CONTAINER } & 10,500 \text { LBS } \\
\text { FILLED CYLINDER } & 25,500 \text { LBS } \\
\text { TOTAL } & 36,000 \text { LBS }
\end{array}
$$

FIGURE A.6. Protective Shipping Package for $\mathrm{UF}_{6}$ Cylinder Model 48X (From Reference 1) 


\section{TRANSPORT MODES}

Most $\mathrm{UF}_{6}$ shipments are currently made by truck or railcar. For repetitive bulk shipments, particularly of the larger cylinders, transportation safety is promoted through the use of specially designed trucks. Railcars have been designed to accommodate four Model $48 \mathrm{X}$ or $48 \mathrm{Y}$ cylinders, and up to sixteen $30 \mathrm{~A}$ or $30 \mathrm{~B}$ cylinders. Heavy-duty tiedown devices and saddles are utilized. Typical examples of appropriate equipment are shown in Figures A.7 through A.10. Each full cylinder must be shipped in a protective shipping package or be equipped with a valve protector. Each valve protector and each protective package containing a UF 6 cylinder is secured with a numbered seal before shipment. Uranium hexafluoride is shipped only after it has solidified and the vapor pressure of the cylinder is below one atmosphere. 


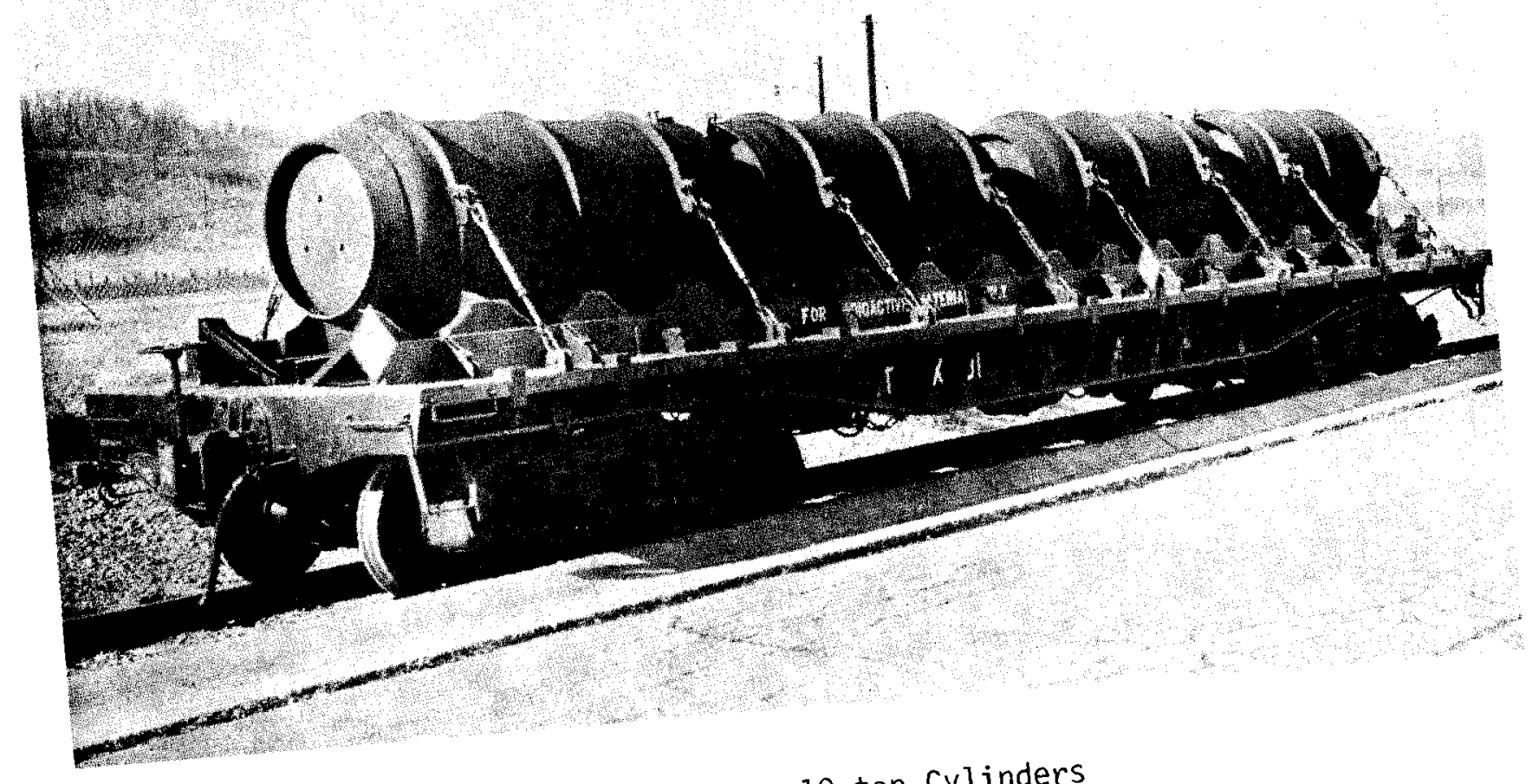

FIGURE A.7. Four 10-ton Cylinders

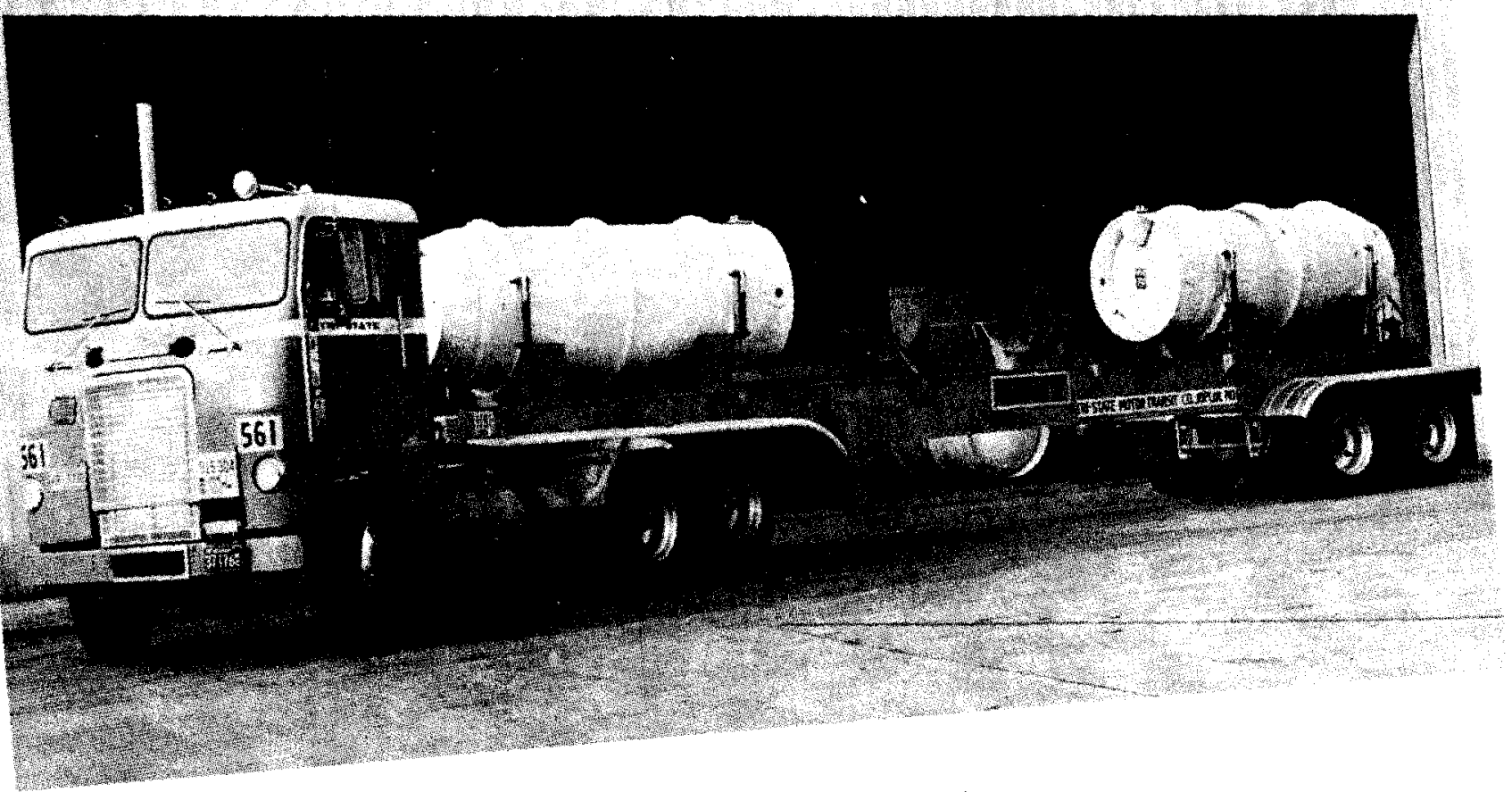

FIGURE A.8. Two 10-ton Cylinders 


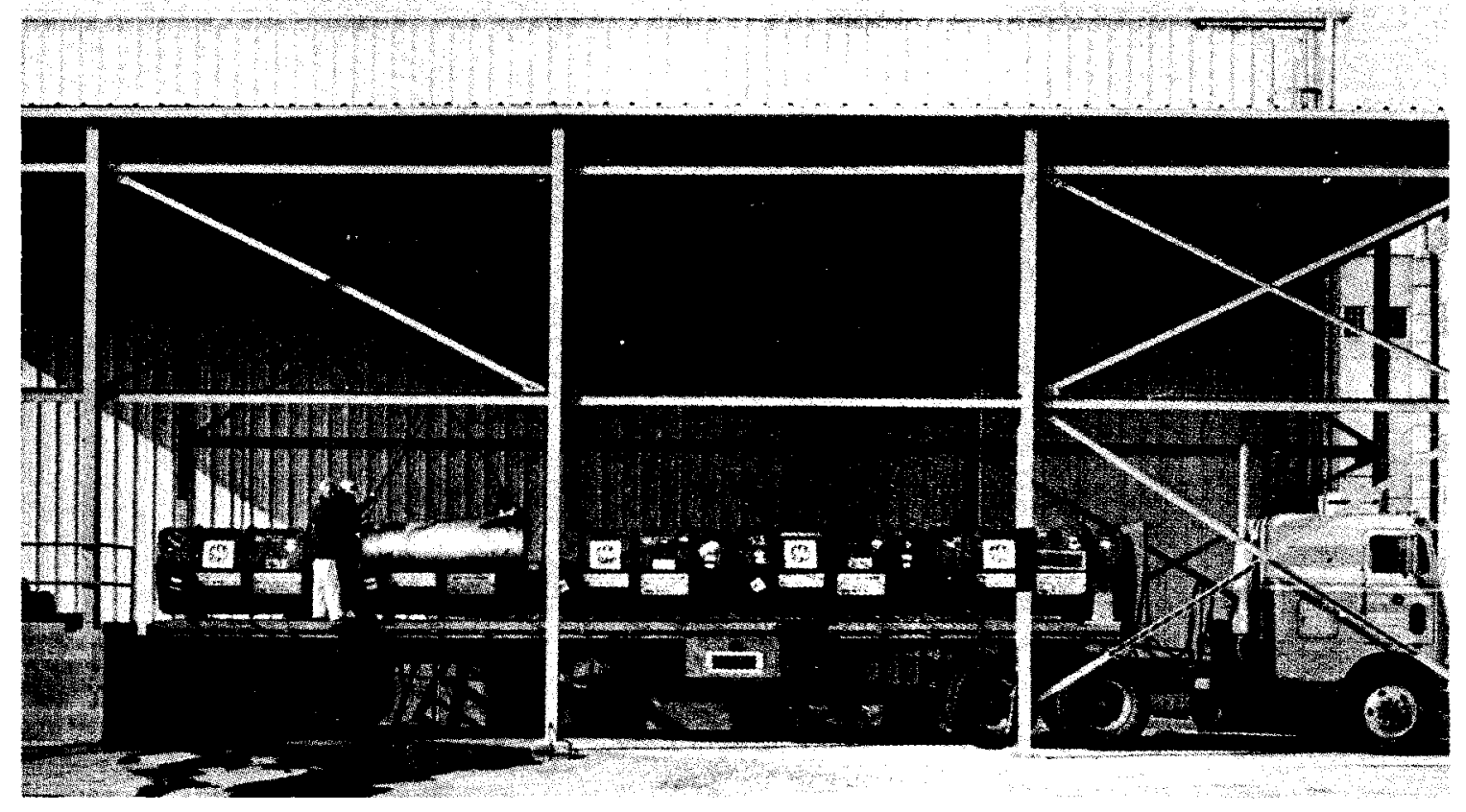

FIGURE A.9. Five 2 1/2-ton Cylinders in Protective Outer Packages

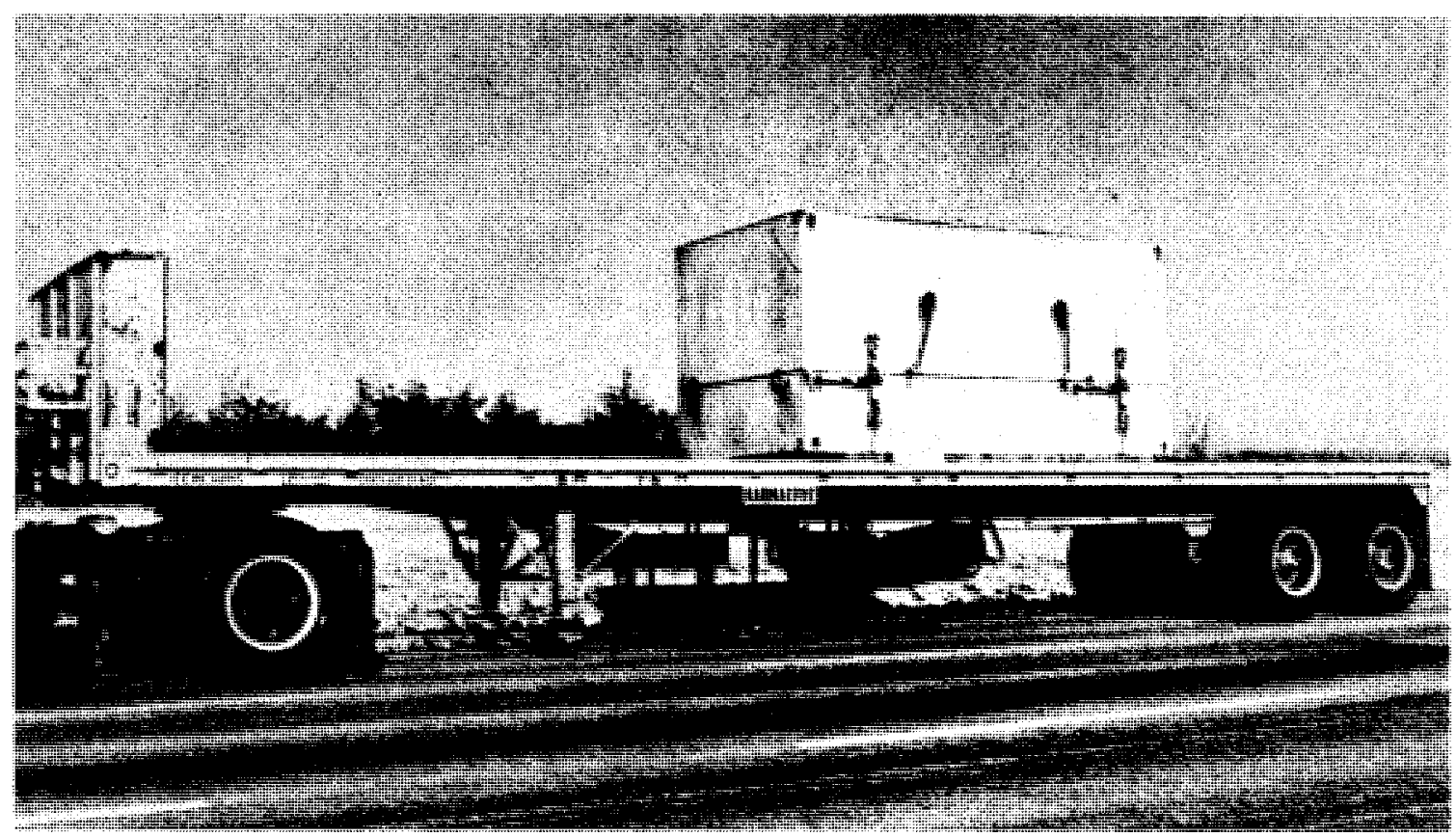

FIGURE A.10. One 10-ton Cylinder in a Protective Outer Package 


\section{REFERENCES}

1. Uranium Hexafluoride: Handling Procedures and Container Criteria. OR0-651 (Rev.4), U.S. Energy Research and Development Administration Oak Ridge Operations Office, Oak Ridge, TN, April 1977. 



\section{PROPERTIES OF UF}

General information on the properties of uranium hexafluoride is presented below:

$\begin{array}{ll}\text { Sublimation Point }\left(1.01 \times 105 \mathrm{~N} / \mathrm{m}^{2}\right) & 56.6^{\circ} \mathrm{C} \\ \text { Triple Point } & 151.7 \times 10^{5} \mathrm{~N} / \mathrm{m}^{2}, 64^{\circ} \mathrm{C} \\ \text { Density, Solid }\left(20^{\circ} \mathrm{C}\right) & 5090.67 \mathrm{~kg} / \mathrm{m}^{3} \\ \text { Liquid }\left(64^{\circ} \mathrm{C}\right) & 3647.4 \mathrm{~kg} / \mathrm{m}^{3} \\ \text { Liquid }\left(121^{\circ} \mathrm{C}\right) & 3256.55 \mathrm{~kg} / \mathrm{m}^{3} \\ \text { Heat of Sublimation }\left(64^{\circ} \mathrm{C}\right) & 135,373.22 \mathrm{~J} / \mathrm{kg} \\ \text { Heat of Fusion }\left(64^{\circ} \mathrm{C}\right) & 54,661.01 \mathrm{~J} / \mathrm{Kg} \\ \text { Heat of Vaporization }\left(64^{\circ} \mathrm{C}\right) & 81,642.61 \mathrm{~J} / \mathrm{kg} \\ \text { Heat of Solution in Water }\left(25^{\circ} \mathrm{C}\right) & 600,573.28 \mathrm{~J} / \mathrm{kg} \\ \text { Heat Evolved } & \\ \text { Critical Pressure } & 4.61 \times 10^{6} \mathrm{~N} / \mathrm{m}^{2} \\ \text { Critical Temperature } & 230.22^{\circ} \mathrm{C}\end{array}$

At room temperature, $\mathrm{UF}_{6}$ is a white, volatile solid. At a temperature of $64^{\circ} \mathrm{C}$ and a pressure of $1.52 \times 10^{5} \mathrm{~N} / \mathrm{m}^{2}, \mathrm{UF}_{6}$ melts to form a colorless liquid of high density. The pressure-temperature and density-temperature relations for $\mathrm{UF}_{6}$ are presented in Figures B.1 and B.2. More detailed information on the chemical and physical properties of $\mathrm{UF}_{6}$ can be found in References 1 and 2.

Uranium hexafluoride is a highly reactive material which reacts chemically with water, ether, and alcohol to form soluble reaction products. It reacts with most organic compounds and with many metals; however, its reactivity with most saturated fluorocarbons is low. $\mathrm{UF}_{6}$ does not react with oxygen, nitrogen, or dry air, and it is sufficiently inert to aluminum, copper, Monel nickel, and aluminum bronze that they can be exposed to $\mathrm{UF}_{6}$ without excessive corrosion. 


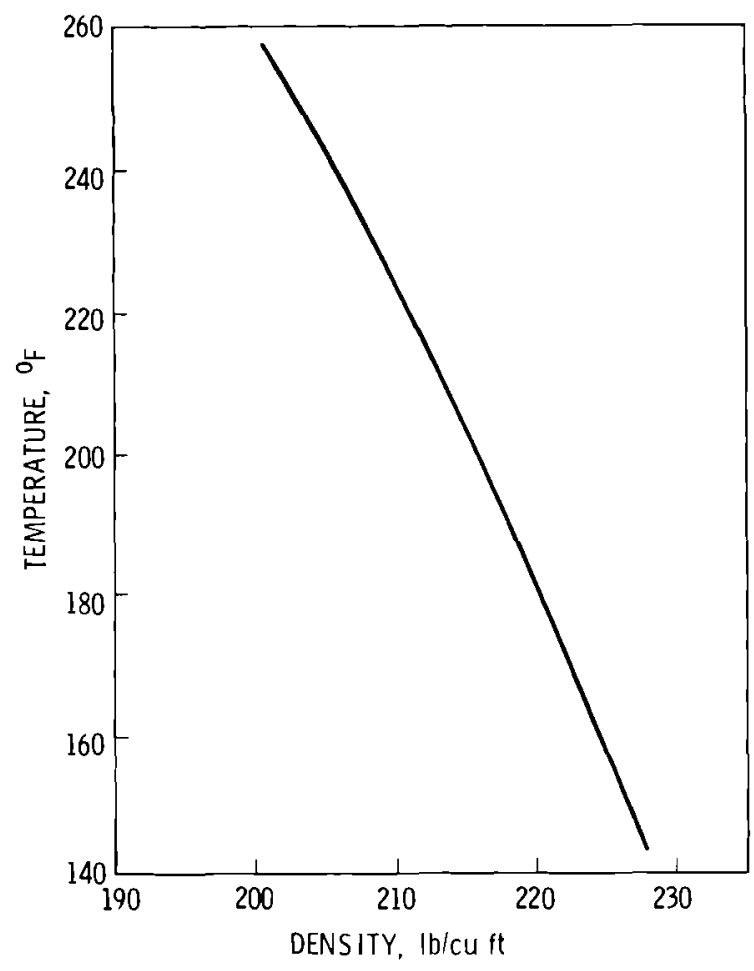

FIGURE B.1. Density of Liquid UF 6 (From Reference 3)

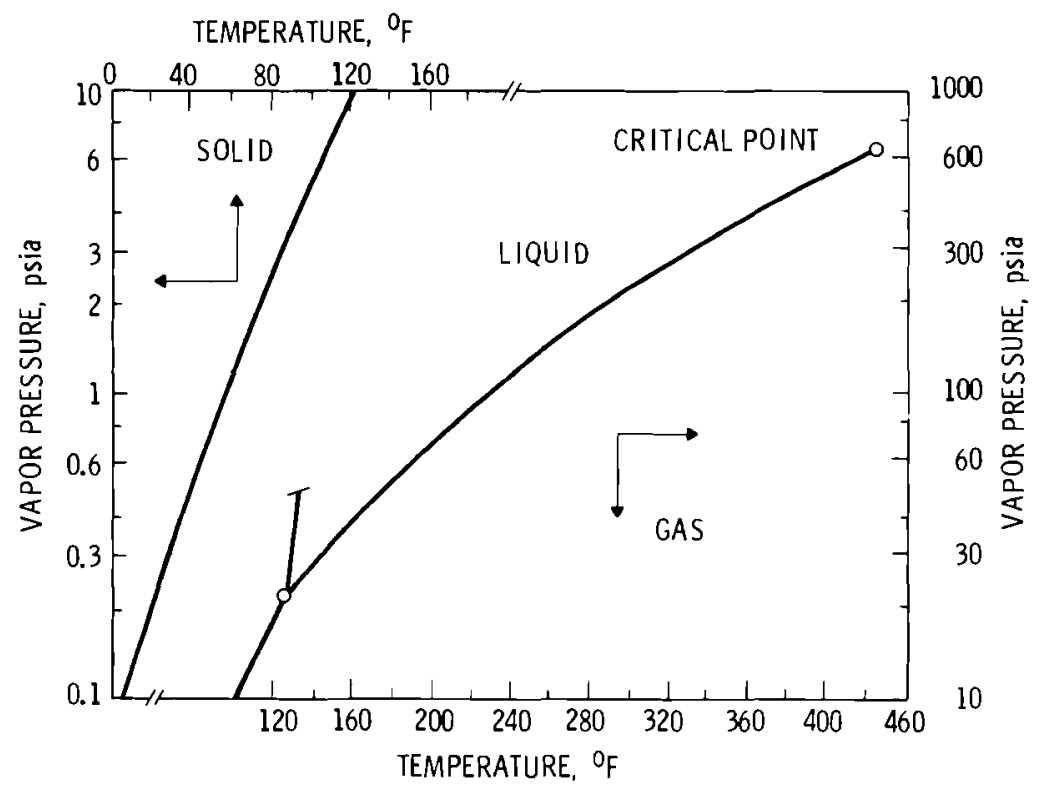

FIGURE B.2. Phase Diagram of $\mathrm{UF}_{6}$ (From Reference 3) 
Gaseous uranium hexafluoride, when released to the atmosphere, reacts quickly with the atmospheric moisture to form $\mathrm{HF}$ gas and particulate $\mathrm{UO}_{2} \mathrm{~F}_{2}$, which tends to settle on surfaces. The corrosive properties of $\mathrm{UF}_{6}$ and $\mathrm{HF}$ are such that exposure to a severe release can result in temporary lung impairment and skin burns. The inhalation of fumes from very large releases for more than a few breaths may result in temporary lung impairment soon after the exposure, and in some instances, mild but repairable kidney damage within a few days. Water-soluble uranium compounds such as $\mathrm{UO}_{2} \mathrm{~F}_{2}, 1$ ike most heavy metal compounds, are toxic to the kidneys when ingested or inhaled in large quantities. For uranium of ${ }^{235} \mathrm{U}$ enrichment less than $10 \%$, the chemical toxicity is more important than the radiotoxicity (3). The $\mathrm{UO}_{2} \mathrm{~F}_{2}$ which forms quickly during a release to the atmosphere is easily visible as a white cloud. A concentration of $1 \mathrm{mg}$ of $\mathrm{UO}_{2} \mathrm{~F}_{2}$ per cubic meter of air is visible; the cloud from large releases may obscure vision. 


\section{REFERENCES}

1. J. J. Katy, and E. Rabinowitch, The Chemistry of Uranium. New York, McGraw Hi11, 1951 .

2. D. R. Llewellyn, "Some Physical Properties of Uranium Hexafluorides" J. Chem. Soc. 28-36, 1953.

3. Uranium Hexafluoride: Handling Procedures and Container Criteria, OR0-651 (Rev. 3), U.S. Atomic Energy Commission, Oak Ridge Operations Office, Oak Ridge, TN, August 1972. 


\section{APPENDIX C}

\section{FAILURE THRESHOLD DETERMINATION FOR UF ${ }_{6}$ CONTAINERS}

This appendix describes the methods used to estimate the UF 6 container failure thresholds presented in Section 6.0 of the text of this report. Since a number of physical tests have been conducted on these containers, $(1,2,3,4)$ the failure thresholds were largely estimated based on the results of these tests. For accident environments where the tests did not approach the failure levels of the containers, analytical methods were used to estimate failure thresholds.

Four containers were considered in this study:

- $30 \mathrm{~B}$ (2 1/2-ton) cylinder with overpack

- $48 \times(10-$ ton) cylinder with overpack

- $48 \times(10-$ ton) cylinder without overpack

- 48Y (14-ton) cylinder without overpack

A complete description of these cylinders and overpacks is presented in Appendix A. Values of physical properties of $U_{6}$ used in this appendix were taken from Appendix B.

As was explained in Section 5.0 of the text, only three accident forces were found to be severe enough to significantly threaten the UF ${ }_{6}$ containers: fire, impact, and puncture. This appendix will show how the cylinder failure thresholds for each one of these forces were determined.

$\underline{\text { FIRE }}$

Cylinder failure in the fire environment is a result of excess internal pressure caused by the large coefficient of thermal expansion of $\mathrm{UF}_{6}$. As heat is added to $U_{6}$ in a closed container, its temperature first rises to $64^{\circ} \mathrm{C}$, the point at which it melts, and its vapor pressure increases to $151.7 \times 10^{5} \mathrm{~N} / \mathrm{m}^{2}$. If heat is added slowly, as in an autoclave, the solid and liquid $U F_{6}$ will remain at $64^{\circ} \mathrm{C}$ until all of the solid melts, after which 
time both the temperature of the liquid and its vapor pressure will again continue to rise. Since $U_{6}$ shows such a large decrease in density upon melting, most of the void space (available because of the increase in density of $U F_{6}$ as it goes from liquid to solid during filling) in the cylinder becomes filled with liquid $U_{6}$ at the melting point. The liquid continues to expand upon heating until it reaches about $138^{\circ} \mathrm{C}$, when it will completely fill the container. The vapor pressure of $\mathrm{UF}_{6}$ at this temperature is about $1.03 \times 10^{6} \mathrm{~N} / \mathrm{m}^{2}$, wel1 below the design pressure of the cylinders considered here. Additional increases in temperature will cause a very rapid rise in the system pressure because the liquid $U_{6}$ has no more space in which to expand. The cylinder then ruptures as a result of hydraulic pressure.

A series of fire tests on small UF ${ }_{6}-f i l l e d$ cylinders was conducted in 1965 at the Oak Ridge Gaseous Diffusion Plant. (4) In these tests, the cylinders were exposed to flames from a pool of burning diesel fuel which provided a temperature of approximately $815^{\circ} \mathrm{C}$. The largest cylinder tested was made of nickel, contained $111 \mathrm{~kg}$ of $\mathrm{UF}_{6}$, and measured $20.3 \mathrm{~cm}$ ID $X 0.48 \mathrm{~cm}$ thick $\times 122 \mathrm{~cm}$ long (volume $=0.04 \mathrm{~m}^{3}$ ). The cylinder exploded 8.5 min after the fire was started.

Since it was difficult to accurately model the complex transient heat flux into the cylinder and the multiphase conditions inside the cylinder, the results of the small size cylinder tests were used to estimate the failure thresholds of the larger cylinders. Analysis of the 48Y (14-ton) cylinder was carried out in Reference 5, with a resulting failure time of 48 min. Using the same method, failure times for the other cylinders without overpack protection were found to be $29 \mathrm{~min}$. for the $30 \mathrm{~B}(2-1 / 2$-ton) cylinder and $46 \mathrm{~min}$. for the $48 x(10-$ ton) cylinder.

Failure times for cylinders protected by overpacks were not so easily derived. Due to the design and insulating characteristics of the overpacks, heat transferred to the cylinder much more slowly. This allows the UF 6 to slowly melt and fill the cylinder. It was conservatively assumed, for the purposes of this analysis, that the cylinder would rupture hydraulically when the $U_{6}$ inside completely filled the container. Using cylinder specifications from Appendix $A$, it was determined that the density of $U_{6}$ 
at rupture was $3092 \mathrm{~kg} / \mathrm{m}^{3}$. Based on the physical properties of $\mathrm{UF}_{6}$ given in Appendix B, this corresponds to a temperature of $138^{\circ} \mathrm{C}$.

The amount of heat required to raise the temperature of the $U F_{6}$ to $138^{\circ} \mathrm{C}$ was found using the following relation:

$$
Q=C_{\nu}\left(T_{\text {fusion }}-T_{\text {ambient }}\right)+Q_{\text {fusion }}+C_{\nu}\left(T_{U F_{6}}-T_{\text {fusion }}\right)
$$

where:

$Q$ is the heat required to raise the $U_{6}$ to $T_{U F_{6}}(\mathrm{~J} / \mathrm{kg})$

$C_{\nu}$ is the heat capacity of $\mathrm{UF}_{6}$ from Reference $6\left(4.187 \times 10^{2} \mathrm{~J} / \mathrm{kg} \cdot \mathrm{K}\right)$

$\mathrm{T}_{\text {fusion }}$ is the fusion temperature (337 $\mathrm{K} \odot 1.52 \mathrm{~N} / \mathrm{m}^{2}$ - Appendix B)

$\mathrm{T}_{\text {ambient }}$ is the ambient temperature (assumed $294^{\circ} \mathrm{K}$ )

$Q_{\text {fusion }}$ is the heat of fusion $\left(5.467 \times 10^{4} \mathrm{~J} / \mathrm{kg}\right.$ - Appendix B)

$$
\begin{aligned}
Q= & \left(4.187 \times 10^{2}\right)(337-294)+5.467 \times 10^{4} \\
& +\left(4.187 \times 10^{2}\right)(411-337)=1.04 \times 10^{5} \mathrm{~J} / \mathrm{kg}
\end{aligned}
$$

This value is applicable for both the $30 \mathrm{~B}$ and $48 \mathrm{X}$ cylinders with overpack.

The system used to model the flow of heat into the cylinder can be modeled as such:

FIRE

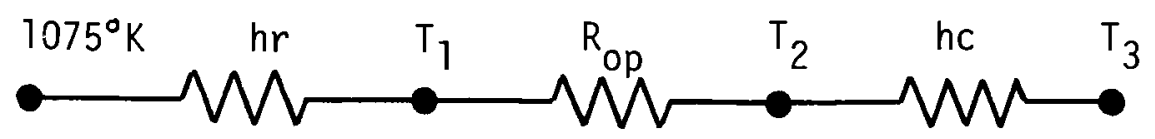

$\mathrm{UF}_{6}$

where:

$\mathrm{hr}$ is radiation heat transfer coefficient $\left(\mathrm{W} / \mathrm{k} \cdot \mathrm{m}^{2}\right)$

$R_{\text {op }}$ is overpack thermal resistance $\left(K \cdot \mathrm{m}^{2} / W\right.$ )(zero if no overpack)

$h c$ is convective heat transfer coefficient $\left(W / K \cdot m^{2}\right)$

$$
\text { (cylinder wal1 - UF }{ }_{6} \text { ) }
$$


$\mathrm{T}_{1}$ is overpack exterior temperature $(\mathrm{K})$

$T_{2}$ is cylinder wall temperature $(K)$

$T_{3}$ is $U F_{6}$ temperature $(K)$

Values for the parameters $h r$ and $R_{o p}$ were relatively easy to determine, using ordinary heat transfer tables. The parameter hc was more difficult to determine due to the complex transfer of heat from the hot cylinder wall to rapidly vaporizing $U_{6}$. The Oak Ridge experimental data ${ }^{(4)}$ were used to determine a value for the coefficient. Temperatures at the time of the cylinder rupture were:

$$
\begin{aligned}
& T_{\text {fire }}=1075^{\circ} \mathrm{K} \\
& T_{\text {Cyl }}=T_{1}=T_{2}=811^{\circ} \mathrm{K} \\
& T_{U_{6}}=T_{3}=450^{\circ} \mathrm{K}
\end{aligned}
$$

A heat balance was determined:

$$
q=\delta \xi\left[\left(T_{\text {fire }}\right)^{4}-\left(T_{c y l}\right)^{4}\right]=h c\left(T_{c y 1}-T_{U F_{6}}\right)
$$

where:

$q$ is heat flow $\left(W / m^{2}\right)$

$\delta$ is Stefan-Boltzmann constant $\left(5.99 \times 10^{-8} \mathrm{~W} / \mathrm{m}^{2} \cdot \mathrm{K}^{4}\right)$

$\xi$ is the grey body shape factor

$\xi$ can be determined using the following relation:

$$
\xi=\left[\frac{1}{\varepsilon_{\text {fire }}}+\frac{1}{\varepsilon_{\text {cyl }}}-1\right]^{-1}
$$

where:

$$
\begin{aligned}
& \varepsilon_{\text {fire }} \text { is the emissivity of the fire }(0.9 \text { from 10CFR71) } \\
& \varepsilon_{\text {cyl } 1} \text { is the emissivity of the cylinder }(0.8 \text { from 10CFR71) } \\
& \xi \xi=0.73
\end{aligned}
$$


Substituting into $(\mathrm{C}-2)$

$$
\begin{aligned}
& q=\left(5.699 \times 10^{-8}\right)(0.73)\left[(1075)^{4}-(811)^{4}\right]=3.756 \times 10^{4} \mathrm{~W} / \mathrm{m}^{2} \\
& h_{C}=\frac{q}{(311-450)}=1.04 \times 10^{2} \frac{W}{\mathrm{~m}^{2} \mathrm{~K}}
\end{aligned}
$$

This value for $h_{c}$ plus a value of $1.25 \frac{\mathrm{W}}{\mathrm{m} k}$ for the conductivity of the overpack material (from Reference 7) were input to the heat transfer model. The overpack insulating foam thickness is $15.2 \mathrm{~cm}$. A heat balance was established:

$$
\begin{aligned}
q=q_{1075 \rightarrow T_{1}}={ }^{q_{T_{1}}} \rightarrow 450 \\
\mathrm{q}_{\mathrm{T}_{1} \rightarrow 450}=\left(\mathrm{T}_{1}-450\right)\left[\frac{0.152}{1.25}+\frac{1}{1.04 \times 10^{2}}\right]^{-1}=\left(\mathrm{T}_{1}-450\right)(7.60) \\
\mathrm{q}_{1075 \rightarrow \mathrm{T}_{1}}=\left(5.699 \times 10^{-8}\right)(0.73)\left[(1075)^{4}-\left(\mathrm{T}_{1}\right)^{4}\right] \\
=\left(4.16 \times 10^{-8}\right)\left[(1075)^{4}-\left(\mathrm{T}_{1}\right)^{4}\right]
\end{aligned}
$$

Solving the two equations simultaneously, a value of $1050^{\circ} \mathrm{K}$ was determined for $T_{1}$. The heat flow in this case was $4839 \frac{\mathrm{W}}{\mathrm{m}^{2}}$.

The time to failure was determined using the relationship:

$$
q A t=Q m
$$

where:
$A$ is the overpack surface area $\left(\mathrm{m}^{2}\right)$
$t$ is the time to failure (sec)
$m$ is the mass of $\mathrm{UF}_{6}(\mathrm{~kg})$

The surface area of the overpack was determined from information presented in Appendix $A$ to be $9.8 \mathrm{~m}^{2}$. Likewise, the value of $\mathrm{m}$ was found to be $2277 \mathrm{~kg}$.

$$
t=\frac{Q m}{q A}=\frac{\left(1.04 \times 10^{5}\right)(2277)}{(4839)(9.8)}=4993 \mathrm{sec}=83 \mathrm{~min}
$$

A similar calculation was carried out for the $48 \mathrm{x}$ cylinder with overpack. The failure time was determined to be 156 min. 
IMPACT

Impact failure threshold estimates for the various cylinders were based mainly on the results of physical tests. This was found to be necessary because of the difficulty of accurately modeling the deformation and rupture of cylinders filled with solid $\mathrm{UF}_{6}$. In most cases, these thresholds are felt to be conservative. The four cylinders considered in the study were considered individually and the results are presented below. Failure thresholds were calculated only for configurations corresponding to a horizontal drop.

30B (2 1/2-Ton) Cylinder with Overpack

For shipments of $\mathrm{UF}_{6}$ at enrichment levels below $1 \mathrm{wt} \%{ }^{235} \mathrm{U}$, packaging need only conform to Type A standards. At enrichment levels greater than $1 \%$, cylinders must be shipped in protective outer packages to provide adequate spacing of cylinders, protect against accident conditions and assure criticality prevention. At this level, packages must be able to pass all Type B shipping container standards. Tests on a prototype overpack similar to those in use today have been conducted. (3) However, in no instance was the cylinder breached in these tests. Therefore, the impact failure threshold estimates for the 30B cylinder with overpack are derived from analysis.

For the purpose of this analysis, it was conservatively assumed that the cylinder fails when the overpack has been completely deformed. This condition is shown in Figure C.1. The shaded area indicates the material deformed in absorbing the impact energy.

As a first step in the analysis, the cross-sectional area of the deformed portion of the cylinder was evaluated.

$$
\begin{aligned}
\theta=\cos ^{-1} \frac{38.1}{53.34} & =44.4^{\circ} \\
\text { AREA DEFORMED } & =\left(\pi R_{\text {op }}^{2} \frac{2 \theta}{36} \overline{0}\right)-\left(R_{\text {cy } 1} \times R_{\text {op }} \sin 44.4^{\circ}\right) \\
& =\pi(53.34)^{2} \frac{88.8}{360}-(38.1)(53.34)(0.70) \\
& =782.9 \mathrm{~cm}^{2}
\end{aligned}
$$




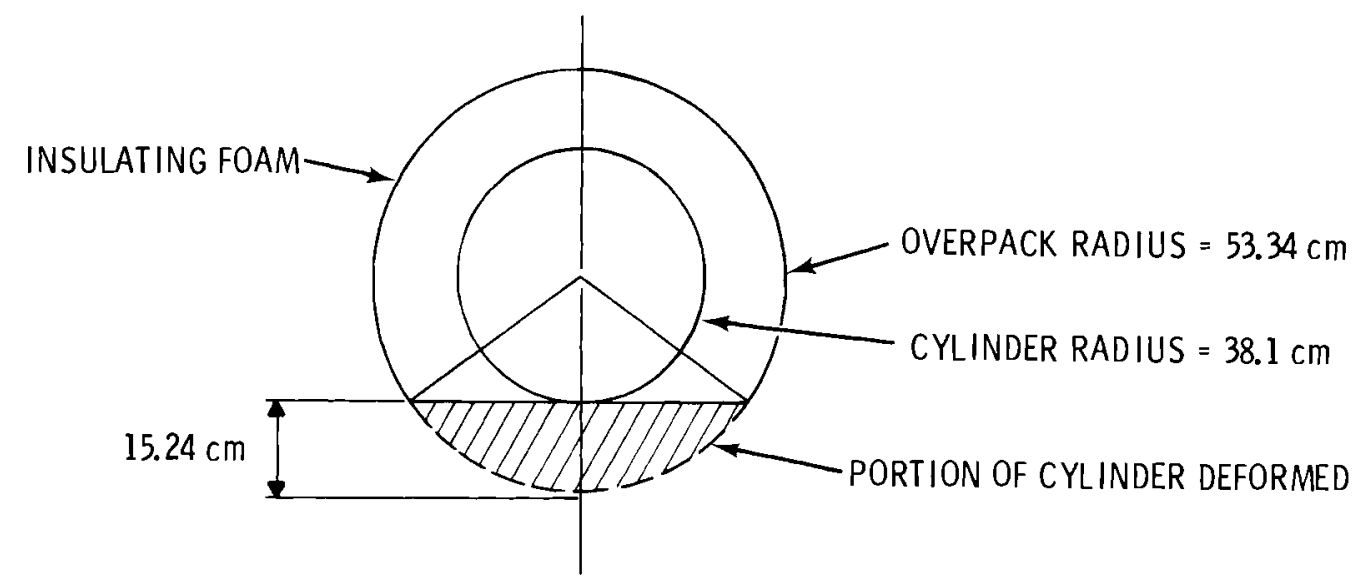

END VIEW OF DEFORMED SHIPPING PACKAGE

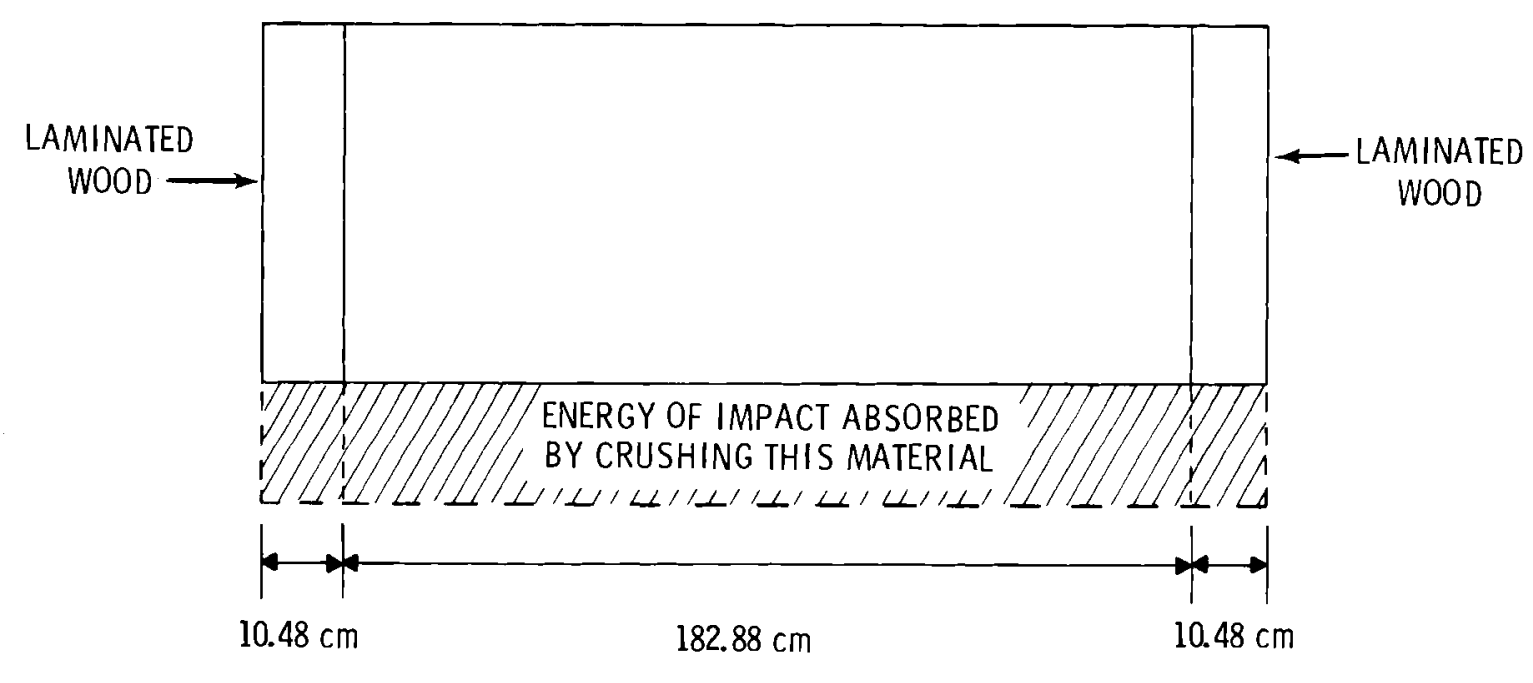

SIDE VIEW OF DEFORMED SHIPPING PACKAGE

FIGURE C.1. Diagram of $30 \mathrm{~B}$ Cylinder with Overpack Parted by Impact Forces 
From Figure C.1, the impact energy is absorbed by crushing the overpack material. This material consists of laminated wooden end plate and insulating foam in the annulus between the cylinder and overpack covering.

$$
E_{T}=E_{W}+E_{F}
$$

where:

$E_{T}$ is the total energy absorbed (Joules)

$E_{W}$ is the energy absorbed in crushing the wooden end plate

$E_{F}$ is the energy absorbed in crushing the foam

$$
\begin{aligned}
& E_{W}=\left(\text { AREA DEFORMED) }(\operatorname{LENGTH})(2)\left(C R_{W}\right)\right. \\
& E_{F}=\left(\text { AREA DEFORMED) }(\operatorname{LENGTH})\left(C R_{F}\right)\right.
\end{aligned}
$$

where:

AREA DEFORMED is the derived cross-sectional area from (C-5)

LENGTH is the length of the particular segment

$C R_{W}$ is the crush strength of wood $\left(4.14 \times 10^{7} \mathrm{~N} / \mathrm{m}^{2}\right)$

$\mathrm{CR}_{\mathrm{F}}$ is the crush strength of foam $\left(9.65 \times 10^{5} \mathrm{~N} / \mathrm{m}^{2}\right.$ - Reference 8$)$

$$
\begin{aligned}
E_{T}= & E_{W}+E_{F}=(782.9)(2)(10.48)\left(4.14 \times 10^{7}\right) \\
& +(782.9)(182.88)\left(9.65 \times 10^{5}\right)=8.17 \times 10^{5} \text { Joules }
\end{aligned}
$$

Using the basic equation for potential energy

$$
E=m g h
$$

and information on the overpack from Appendix $A$, the drop height necessary to cause the deformation can be found.

$$
h=\frac{E}{m g}=\frac{8.17 \times 10^{5}}{(3.70)(9.80665)}=22.5 \mathrm{~m} .
$$


Therefore, the conservative impact failure threshold for the $30 \mathrm{~B} \mathrm{UF}{ }_{6}$ cylinder with overpack is an impact with a force equivalent to that experienced in a 22.5-m drop onto an unyielding surface.

48X (10-Ton) Cylinder Without Overpack

Impact (drop) tests have been performed on 10 -ton $\mathrm{UF}_{6}$ cylinders at Paducah, KY. In these tests, two versions of the 10-ton cylinder were evaluated, a heavy-wall version (nearly identical to the $48 \mathrm{X}$ cylinders) and a thin-wall design with a wall thickness one-half that of the heavywall cylinder.

During the tests, the thin-walled cylinders were dropped from heights of 3,6 , and $9 \mathrm{~m}$ without rupturing.

The heavy-walled cylinder was dropped once from a height of $6 \mathrm{~m}$ with no leakage. The deformation of the heavy-walled cylinder after the 6-m drop was similar to that of the thin-walled cylinder dropped from $3 \mathrm{~m}$. Considering the energy required to deform the thin-walled cylinder, it is reasonable to expect the heavy-walled cylinder to survive a drop of $9 \mathrm{~m}$. No further evaluations could be made and justified. Therefore, it was conservatively assumed that the impact failure threshold for the 40x cylinder without overpack was equivalent to the impact experienced by the cylinder in a 9 -m fall onto an unyielding surface.

\section{X (10-Ton) Cylinder with Overpack}

The addition of a protective overpack to the standard 48X cylinder qualifies it for use in the shipment of UF ${ }_{6}$ to enrichment levels of $4.5 \mathrm{wt} \%$ ${ }^{235} \mathrm{U}$. In this configuration, the shipping package is designed to withstand all Type $B$ qualification tests.

Evaluation of the additional impact protection provided by the overpack was carried out in the same manner as for the 30B cylinder with overpack. The analysis was based on a prototype of the Paducah Tiger overpack ${ }^{(8)}$ which is for all purposes identical to those in use today. The results of the analysis showed that the overpack added protection equivalent to an additional $3.4 \mathrm{~m}$ in drop height. This represents a failure threshold for a $48 \mathrm{x}$ cylinder with overpack equivalent to a drop from $12.4 \mathrm{~m}$. 
$\underline{48 Y}$ (14-Ton) Cylinder Without Overpack

The $48 \mathrm{X}$ and $48 \mathrm{Y}$ cylinders are very similar except that the $48 \mathrm{Y}$ cylinder is $74 \mathrm{~cm}$ longer than the 48X. 0therwise, for this analysis they are identical. The gross weights per unit length for both cylinders are nearly equal. Since the deformed shape after impact is nearly constant along the cylinder axis, it is reasonable to assume that the $48 \mathrm{Y}$ could withstand a horizontal drop from the same height as the $48 \mathrm{X}$ cylinder. Therefore, the impact failure threshold of the bare $48 Y$ cylinder was given a value equivalent to the impact forces experienced in a drop from $9 \mathrm{~m}$.

\section{PUNCTURE}

As in the previous failure threshold analysis, results from actual tests were used to determine puncture failure thresholds wherever possible. A11 puncture failure thresholds were expressed in terms of an equivalent drop height onto a $15.24-\mathrm{cm}$ diameter puncture probe.

\section{$30 \mathrm{~B}(2-1 / 2-T o n)$ Cylinder with Overpack}

Results of tests conducted at Oak Ridge, TN on a prototype overpack (3) similar to those in use today were used as a starting point in this analysis. When dropped from a height of approximately $1 \mathrm{~m}$, the overpack sustained minor damage but the cylinder inside was undamaged. To determine a drop height which would cause a cylinder failure, the bare cylinder (without overpack) was analyzed. Using equations and procedures described in Reference 9 it was possible to determine that a drop of $3.2 \mathrm{~m}$ onto the puncture probe was sufficient to puncture the bare cylinder. Assuming that an additional 1-m in drop height would be sufficient to rupture the overpack, an overal1 drop height of $4.2 \mathrm{~m}$ was estimated as the failure threshold of the cylinder and overpack.

\section{X (10-Ton) Cy 1 inder Without Overpack}

Tests conducted at Paducah, KY on cylinders nearly identical to the $48 \mathrm{X}$ showed that this cylinder could be breached in a puncture drop of $1 \mathrm{~m}$ if the probe hit the cylinder in the right orientation. During the test, a 48-in diameter heavy-wall cylinder failed when the probe struck the cylinder 
immediately adjacent to a stiffening ring. A mathematical analysis of the cylinder puncture (see 30B analysis) was carried out with the results predicting survival of the cylinder in a puncture drop test of $1.4 \mathrm{~m}$. This analysis, however, did not take into account the effects of the stiffening rings. The value used for puncture failure of the bare $48 \mathrm{X}$ in this study was a 1-m drop onto a standard puncture pin. This assumption is conservative because not every accidental puncture will occur next to a stiffening ring. 48X (10-Ton) Cylinder with Overpack

Tests on a prototype of the Paducah Tiger overpack were conducted as part of $i$ ts development and certification program. (8) As part of the testing, the overpack (with cylinder) was dropped from a height of $1 \mathrm{~m}$ onto a standard puncture probe. This test resulted in a cylinder penetration (dent) of $3.81 \mathrm{~cm}$ by the probe. From the results of other tests on the bare cylinder (1) a penetration of $10.16 \mathrm{~cm}$ was determined to result in a breach of the container. If we assume that no additional energy absorption due to the overpack occurs during penetration of the remaining $6.35 \mathrm{~cm}$, the drop height required to breach the container in the overpack can be determined.

$$
h=100+\frac{6.35}{10.16}(100)=163 \mathrm{~cm}=1.63 \mathrm{~m}
$$

A puncture drop height of $1.63 \mathrm{~m}$ was estimated as the $48 \mathrm{X}$ with overpack puncture failure threshold.

\section{$48 Y$ (14-Ton) Cylinder Without Overpack}

Based on the results presented for the $48 \mathrm{X}$ cylinder, the structural similarities of the two cylinders, and the relationship of puncture energies of the different masses, a failure threshold equivalent to a $79.5 \mathrm{~cm}$ puncture drop was estimated. 


\section{REFERENCES}

1. W. R. Pedigo et a1., Testing of Ten-Ton Uranium Hexafluoride Cylinders. KY-500, Union Carbide Corporation, Nuclear Division, Paducah, KY, October 1965.

2. E. W. Richardson and S. Bernstein, Additional Testing of Ten-Ton Uranium Hexafluoride Cylinders. KY-631, Union Carbide Corporation, Nuclear Division, Paducah, KY, September 1971.

3. A. J. Mallett and C. E. Newlon, Protective Shipping Packages for 30-InchDiameter UF Cylinders. K-1686, Union Carbide Corporation, Nuclear Division, Oak Ridge, TN, April 1967.

4. A. J. Mallett, ORDGP Container Test and Development Program Fire Tests of UF Filled Cylinders. K-D-1894, Union Carbide Corporation, Nuclear Division, Oak Ridge, TN, January 1966.

5. U.S. Atomic Energy Commission, Liquid Metal Fast Breeder Reactor Program Environmental Statement, Vol. II. WASH-1535, December 1974.

6. Toulouhian and Dewitt, Thermophysical Properties of Matter. The TPRC Data Series, Volume 5, IF I Plenum, New York, NY.

7. Handbook of Heat Transfer. W. M. Rohsenow and J. P. Hartnett, editors, McGraw Hi11, 1973 edition.

8. L. J. Hansen, "The Paducah Tiger: A Type B Overpack for Ten-Ton Uranium Hexafluoride Shipments." Proceedings of the 4th International Symposium on Packaging and Transportation of Radioactive Materials, Conf-740901, September 1974.

9. L. B. Shappert, Cask Designer's Guide. ORNL-NSIL-68, Oak Ridge National Laboratory, Oak Ridge, TN, February 1970. 
This appendix contains a complete listing of the fractional mileage of a 11 shipping routes considered in this study. The percentage of each route lying in each population zone is given in Table D.1. Table D.2 is a listing of the shipping and receiving facilities used in TabTe D.l. 
TABLE D.1. Fractional Mileage of Shipping Routes by Population Zones (Values in Percent)

\begin{tabular}{|c|c|c|c|c|c|}
\hline $\begin{array}{r}\text { Facil } \\
\text { (See Ta }\end{array}$ & $\begin{array}{l}\text { ies } \\
\text { e D. } 2 \text { ) }\end{array}$ & & $\mathrm{pu}$ & on $\mathrm{Zc}$ & \\
\hline From & To & I & I I & I I I & IV \\
\hline P-1 & E-1 & -- & -- & 100 & -- \\
\hline$P-1$ & $E-2$ & -- & -- & 100 & -- \\
\hline P-1 & $E-3$ & -- & -- & 100 & -- \\
\hline P-2 & $E-1$ & -- & -- & 100 & -- \\
\hline P-2 & $E-2$ & -- & - & 100 & -- \\
\hline$P-2$ & $E-3$ & -- & -- & 100 & -- \\
\hline$P-3$ & $E-1$ & 29 & 5 & 66 & -- \\
\hline$P-3$ & $E-2$ & 24 & -- & 76 & -- \\
\hline$P-3$ & $E-3$ & 45 & 40 & 15 & -- \\
\hline P-4 & $E-1$ & -- & -- & 100 & -- \\
\hline P-4 & $E-2$ & -- & -- & 100 & -- \\
\hline P-4 & $E-3$ & -- & -- & 100 & -- \\
\hline$E-1$ & $\mathrm{E}-2$ & -- & -- & 100 & -- \\
\hline E-1 & $E-3$ & -- & -- & 100 & -- \\
\hline$E-2$ & $E-3$ & -- & -- & 100 & -- \\
\hline$E-2$ & $F-1$ & -- & -- & 100 & -- \\
\hline$E-2$ & $F-2$ & -- & 41 & 59 & -- \\
\hline$E-2$ & $F-3$ & -- & -- & 37 & 63 \\
\hline$E-2$ & $F-4$ & -- & -- & 100 & -- \\
\hline$E-2$ & $F-5$ & -- & -- & 100 & -- \\
\hline$E-2$ & F-6 & -- & -- & 100 & -- \\
\hline$E-2$ & $F-7$ & 24 & -- & 76 & -- \\
\hline$E-2$ & $F-8$ & -- & -- & 100 & -- \\
\hline$E-3$ & F-1 & -- & -- & 100 & -- \\
\hline$E-3$ & $\mathrm{~F}-2$ & -- & 90 & 10 & -- \\
\hline$E-3$ & $\mathrm{~F}-3$ & -- & -- & 38 & 62 \\
\hline$E-3$ & $F-4$ & -- & -- & 100 & -- \\
\hline$E-3$ & $F-5$ & -- & -- & 100 & -- \\
\hline$E-3$ & $F-6$ & -- & -- & 100 & -- \\
\hline$E-3$ & F-7 & 46 & 41 & 13 & -- \\
\hline$E-3$ & $F-8$ & -- & -- & 100 & -- \\
\hline
\end{tabular}


TABLE D.2. UF 6 Shipping and Receiving Facilities

Production Plants

P-1 Metropolis, IL

P-2 Sequoyah, OK

P-3 Foreign Sources (Baltimore, MD)

P-4 Foreign Sources (Norfolk, VA)

Enrichment Plants

E-1 Paducah, KY

E-2 Oak Ridge, TN

E-3 Portsmouth, $\mathrm{OH}$

Fuel Fabrication Plants

F-1 Wilmington, NC

F-2 Apol 10, PA

F-3 Richland, WA

F-4 Erwin, TN

F-5 Columbia, SC

F-6 Hematite, M0

F-7 Foreign Receivers (Baltimore, MD)

F-8 Foreign Receivers (Norfolk, VA) 


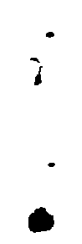


No. of

Copies

$\underline{\text { OFFSITE }}$

A. A. Churm

Chicago Patent Group

DOE Chicago Operations Office

9800 South Cass Avenue

Argonne, IL 60439

163 DOE Technical Information Center

K. A. Trickett

Division of Reactor Development and Demonstration

Department of Energy

Germantown, MD 20014

25 W. Brobst

Transportation Branch

Division of Environmental Control Technology

Department of Energy

Washington, DC 20545

J. Counts

Transportation Branch

Division of Environmental

Control Technology

Department of Energy

Washington, DC 20545

M. Chais

Transportation Branch

Division of Environmental Control Technology

Department of Energy

Washington, DC 20545

R. F. Garrison

Transportation Branch

Division of Environmental

Control Technology

Department of Energy

Washington, DC 20545
No. of

Copies
J. A. Sisler

Transportation Branch

Division of Environmental

Control Technology

Department of Energy

Washington, DC 20545

E. C. Hardin, Jr.

Office of the Assistant

Secretary for Energy Technology

Department of Energy

Washington, DC 20545

R. M. Moser

DOE Chicago Operations Office

9800 South Cass Avenue

Argonne, IL 60439

W. G. O'Quinn

DOE Savannah River Operations Office

P.0. Box A

Aiken, SC 29801

N. Stetson

DOE Savannah River Operations Office

P.0. Box A

Aiken, SC 29801

L. L. Turner

DOE Savannah River Operations Office

P.0. Box A

Aiken, SC 29801

D. Davis

DOE Albuquerque Operations Office

P.0. Box 5400

Albuquerque, NM 87115 
No. of

Copies

J. A. Lamb

DOE Oak Ridge Operations

Office

P.0. Box E

Oak Ridge, TN 37830

J. J. Schreiber

DOE Oak Ridge Operations

Office

P.0. Box E

Oak Ridge, TN 37830

G. R. Swinde 11

International Atomic Energy Agency

A-1011 Vienna, AUSTRIA

J. L. Russe 11

Office of Radiation Programs

AW-459, EPA

401 M St. S.W.

Washington, DC 20460

G. W. Cunn ingham

Director, Nuclear Energy

Programs

Department of Energy

Washington, DC 20545

T. K. Keenan

University of California

Los Alamos Scientific Laboratory

P.0. Box 1663

Los Alamos, NM 87545

T. A. Butler

University of California

Los Alamos Scientific Laboratory

P.0. Box 1663

Los Alamos, NM 87545

G. Kinchin

UKAEA

Risley, Lancaster

ENGLAND
No. of

Copies

L. Benner

National Transportation

Safety Board

Department of Transportation

Washington, DC 20594

E. J. Wilson

Department of Transport

Dangerous Goods Branch

2 Marsham St.

London SW 1

ENGLAND

Ichiro Yabe

Nuclear Safety Research

Association

Room 1037, National Press

Building

14 th and F St. N.W.

Washington, DC 20004

A. L. Schmieg

National Transportation

Safety Board

Department of Transportation

Washington, DC 20594

P. J. Eicker

Sandia Laboratories, Livermore

Livermore, CA 94550

J. W. Langhaar

E. I. Dupont de Nemours \& Company

Savannah River Plant

Aiken, SC 29801

L. D. Santman

Materials Transportation Bureau

Department of Transportation

2100 Second St. S.W.

Washington, DC 20590

A. Grella

Department of Transportation

Materials Transportation Bureau

2100 Second St. S.W.

Washington, DC 20590 
Dr. H. C. Thompson

Battelle Memorial Institute

Washington Operations

20301 M St. N.W.

Washington, DC 20036

W. Rowe

Environmental Protection Agency

401 M St.

Washington, DC 20460

A. J. Nertney

Aerojet Nuclear Company

550 2nd St.

Idaho Falls, ID 83401

Dr. J. Jacquemin

Office of Minister für Arbeit, Gesundheit, und Sociales des Landes NRW

Landeshaus

4000 Dusseldorf

FEDERAL REPUBLIC OF GERMANY

C. Starr

Electrical Power Research Inst.

P.0. Box 10412

Palo Alto, CA 94304

C. Comar

Electrical Power Research Inst.

P.0. Box 10412

Palo Alto, CA 94304

E. Zebrowski

Electrical Power Research Inst.

P.0. Box 10412

Palo Alto, CA 94304

R. Williams

Electrical Power Research Inst.

P.0. Box 10412

Palo Alto, CA 94304

Combustion Engineering, Inc.

Windsor, CT 06095
J. Desmond

Babcock \& Wilcox, Co.

P.0. Box 1260

Lynchburg, WA 24505

C. Woods

Babcock \& Wilcox Co.

P.0. Box 1260

Lynchburg, VA 24505

Prof. Norman C. Rasmussen

Massachusetts Institute of Technology

Cambridge, MA 02139

J. K. Cole

Sandia Laboratories

P.0. Box 5800

Albuquerque, NM 87115

J. T. Foley

Sandia Laboratories

P.0. Box 5800

A1buquerque, NM 87115

J. Freedman

Sandia Laboratories

P.0. Box 5800

Albuquerque, NM 87115

W. F. Hartmann

Sandia Laboratories

P.0. Box 5800

Albuquerque, NM 87115

R. M. Jefferson

Sandia Laboratories

P.0. Box 5800

Albuquerque, NM 87115

R. Luna

Sandia Laboratories

P.0. Box 5800

Albuquerque, NM 87115

T. G. Priddy

Sandia Laboratories

P.0. Box 5800

Albuquerque, NM 87115 
A. W. Snyder

Sandia Laboratories

P.0. Box 5800

Albuquerque, NM 87115

R. Yoshimura

Sandia Laboratories

P.0. Box 5800

Albuquerque, NM 87115

R. F. Barker

Nuclear Regulatory Commission

Washington, DC 20555

C. B. Bartlett

Nuclear Regulatory Commission

Washington, DC 20555

S. H. Hanauer

Nuclear Regulatory Commission Washington, DC 20555

S. Levine

Nuclear Regulatory Commission Washington, DC 20555

R. B. Minogue

Nuclear Regulatory Commission

Washington, DC 20555

C. McDonald

Nuclear Regulatory Commission

Washington, DC 20555

W. E. Vesely

Nuclear Regulatory Commission Washington, DC 20555

I. Wall

Nuclear Regulatory Commission Washington, DC 20555

M. J. Steindler

Argonne National Laboratory

9700 South Cass Avenue

Argonne, IL 60439
Bill Pardue

Battelle Memorial Institute

Office of Nuclear Waste

Isolation

505 King Avenue

Columbus, $\mathrm{OH} 43201$

R. A. Robinson

Battelle Memorial Institute

Office of Nuclear Waste

Isolation

505 King Avenue

Columbus, $\mathrm{OH} 43201$

Atomics International

8900 DeSoto Avenue

Conoga Park, CA 91304

A. L. Kaplan

General Electric Co.

Nuclear Fuel Division

P.0. Box 780

Wilmington, NC 28401

G. Lapier

Babcock \& Wilcox Co.

Apo 110, PA 15613

R. D. Seagren

Union Carbide Corporation

Oak Ridge National Laboratories

P.0. Box $X$

Oak Ridge, TN 37830

L. Shappert

Union Carbide Corporation

Oak Ridge National Laboratories

P.0. Box $X$

Oak Ridge, TN 37830

J. Duckworth

Nuclear Fuel Service, Inc.

P.0. Box 124

West Valley, NY 14171

G. L. Stukenbroeker

N. L. Industries, Inc.

Nuclear Transportation Dept.

P.0. Box 2046

Wilmington, DE 19899 
No. of

Copies

J. R. Marsha 11

Union Carbide Corporation

Oak Ridge National Laboratory

P.0. Box $X$

Oak Ridge, TN 37830

M. M. Heiskel

Union Carbide Corporation

Oak Ridge National Laboratory

P.0. Box $X$

Oak Ridge, TN 37830

H. G. Shealy

Bureau of Radiological Health

South Carolina Department of Health and Environmental Control

Columbia, SC 29405

J. S. Corbett

ChemNuclear Systems, Inc.

P.0. Box 1866

Bellevue, WA 98009

J. A. Hebert

Battelle Seattle Research Center

P.0. Box 5395

Seattle, WA 98105

P. T. Tuite

Hittman Nuclear and Development Corporation

9190 Red Branch Rd.

Columbia, MD 21045

D. A. Edling

Mound Laboratories

P.0. Box 32

Miamisburg, $\mathrm{OH} 45342$

J. W. Doty

Mound Laboratories

P.0. Box 32

Miamisburg, OH 45342
No. of

Copies

D. Okrent

Department of Engineering and Applied Science

University of Cal ifornia

Los Angeles, CA 90024

2 L. Forrest

Cal ifornia Energy Resources Conservation and Development Commission

1111 Howe Avenue

Sacramento, CA 95825

R. H. Jones

Transportation Systems

Nuclear Energy Programs

Division

General Electric Company

175 Curtner Avenue

San Jose, CA 95125

M. Gordon

Atomic Industrial Forum

7101 Wiscons in Ave.

Washington, DC 20014

A. L. Babb

Department of Nuclear Engineering

Benson Hall

University of Washington

Seattle, WA 98195

W. S. Fellows

Southern Interstate Nuclear Board

One Exchange Place, Suite 1230

Atlanta, GA 30341

D. G. Maxwe 11

N. L. Industries

Nuclear Division

Foot of West Street

Wilmington, DE 19801

W. R. Teer

Transnuclear Inc.

One N. Broadway

White Plains, NY 10601 
No. of

Copies

S. Hartwig

Battelle Institute, e.v.

Am Romerhof 35

600 Frankfurt Ma in 90

GERMANY

M. Stammler

Battelle Institute, e.v.

Am Romerhof 35

600 Frankfurt Ma in 90

GERMANY

R. S. Lowrie

Union Carbide Corporation

Office of Waste Isolation

P.0. Box $Y$

Oak Ridge, TN 37830

J. L. Ridihalgh

Ridihalgh, Eggers \& Associates

2112 Iuka Avenue

Columbus, $\mathrm{OH} 43201$

S. C. Cohn

Teknekron

4701 Sangamore Rd.

Washington, DC 20016

I. N. Lafontaine

Belgonucleaire

Rue de Champ de Mars 25

B-1050 Bruxelles

BELGIUM

K. R. Shultz

Atomic Energy Control Board

P.0.B. 1046

0ttawa KIP $5 S 9$

CANADA

W. R. Taylor

Atomic Energy of Canada Ltd.

Chalk River Laboratories

Chalk River, Ontario KOJIJ0

CANADA
No. of

Copies

Y. Sousselier

CEA/CEN

B.P. No. 6

F-92260 Fontenay-aux-Roses

FRANCE

H. Hubner

Bundesanstalt für Materialprufung

Unter den Eichen 87

D-1000 Berl in 45 (West)

GERMANY, FED. REPUBLIC

B. Schulz-Forberg

Bundesanstalt für Materialprufung

Unter den Eichen 87

D-1000 Berlin 45 (West)

GERMANY, FED. REPUBLIC

H. F. McDonald

CEGB

Berkeley Nuclear Labs

Berkeley

Gloucestershire GL139PB

UNITED KINGDOM

R. G. Deshpande

lsotope Division

Bhabha Atomic Research Centre

Trombay, Bombay 400085

INDIA

S. Aoki

Research Laboratory for Nuclear Reactors

Tokyo Institute of Technology

Ookayama, Meguroku, Tokyo 152

JAPAN

G. D. Bell

United Kingdom Atomic Energy

Authority

Safety and Reliability

Directorate

Warrington WA3 4NE

UNITED KINGDOM 
No. of

Copies

A. Onedera

Hitachi Shipbuilding and

Engineering Co., Ltd.

5-4 Sakurajima, Kitano-cho

Konohana-ku, Osaka-shi

JAPAN

K. I keda

Science and Technology Agency

2-2-1 Kasumigaseki,

Chiyoda-ku, Tokyo

JAPAN

M. Tomlinson

White Shell Nuclear Research

Establ ishment

Pinewa, Manitoba ROE ILO

CANADA

S. A. Mayman

Fuel Recycle Waste

Management Program

Whiteshell Nuclear Research

Establishment

Pinewa, Manitoba ROE ILO

CANADA

Dr. R. Girardi

Euratom

21020 Centro Euratomdi

Ispra (Varesse)

ITALY

Ake Hultgren

AB Atomenergi, Studsvik

Fack

S-611 ol Nyköping 1

SWEDEN

B. Gustafson

c/o Ake Hultgren

AB Atomenergi, Studsvik

Fack

S-611 ol Nyköping 1

SWEDEN
No. of

Copies

Dr. Schmidt-Kuester

Beim Bundesminister für

Forschung and Technologie

Stresemannstrasse 2

5300 Bonn

GERMANY

W. J. Shelley

Kerr-McGee Corporation

Oklahoma City, OK

R. W. Peterson

Battelle Memorial Institute

Office of Nuclear Waste

Isolation

505 King Avenue

Columbus, $\mathrm{OH} 43201$

A. Carson

General Electric Company

175 Curtner Avenue

San Jose, CA 95125

R. A. Koynenburg

University of Cal ifornia

Lawrence Livermore Laboratories

P.0. Box 808

Livermore, CA 94551

R. E. Best

Nuclear Assurance Corporation

24 Executive Park West

Atlanta, GA 30329

W. E. Pollock

Oregon Department of Energy

Salem, OR 97301

K. Woods

Oregon Department of Energy

Salem, OR 97301

W. M. Rogers

Western Interstate Nuclear

Board

1300 Carr

Denver, CO 80226 
No. of

Copies

G. P. Jones

University of Southern

Cal ifornia

University Park

Los Angeles, CA 90007

L. L. Philipson

University of Southern

Cal ifornia

University Park

Los Angeles, CA 90007

C. V. Hodges

Holmes \& Narver

400 E. Orangethrope Ave.

Anaheim, CA 92801

E. A. Straker

Science Applications, Inc.

P.0. Box 2351

La Jolla, CA 92038

R. C. Erdman

Science Applications, Inc.

2680 Hanover St.

Palo Alto, CA 94304

N. C. Harris

Imperial Chemical Industries, Ltd.

Mond Division

P.0. Box No. 7 Brunner House

Winnington Northwich

Cheshire CW8 40J

ENGLAND

G. Waymire

Exxon Nuclear Company, Inc.

P.0. Box 3990

MS $8 A-68$

Seattle, WA 98124

J. F. Johnson

Kenworth Trucking

P.0. Box 1000

Kirkland, WA 98033
No. ot

Copies

W. L. Goodwin

Mgr. R. \& E. Services

Westinghouse Nuclear Fuels

Division

P.0. Drawer R

Columbia, SC 29250

J. C. Taylor

Union Carbide Corporation

P.0. Box 1410

Paducah, KY 42001

H. J. Culbert

M.S. 341

Union Carbide Corporation

Nuclear Division

O.R.G.0.P

Oak Ridge, TN 37830

T. Meslin

CEPN

Boite Postale No. 48

92260 Fontenay-aux-Roses

FRANCE

J. A. Buck

Nuclear Fuel Services

Erwin, TN 37650

D. Miller

Nuclear Fuel Services

Erwin, TN 37650

B. Miller

Combustion Engineering, Inc.

P.0. Box 107

Hematite, M0 63047

V. J. DeVito

Goodyear Atomic Corporation

P.0. Box 628

Piketon, $\mathrm{OH} 45661$

J. W. Arendt

ORNL/K-25

Oak Ridge, TN 37830 
No. of

Gopies

C. A. Mayer

Tri-State Motor Transit Co., Inc.

P.0. Box 113

Jopl in, MO 64801

\section{J. Edlow}

Edlow International

1100 17th Street N.W.

Washington, DC

W. F. Black

Hazardous Materials Branch

Federal Railroad Administration

Department of Transportation

Washington, DC

Dr. C. Furber

Research and Test Department Association of American Railroads 1920 L Street N.W.

Washington, DC 20036

R. R. Raw

Materials Transportation Bureau U.S. Department of Transportation Washington, DC 20545

E. P. Goldfinch

Safeguards Branch

Nuclear Health and Safety Department

Courtenay House

18 Warwick Lane

London F C4P 4EB

UNITED KINGDOM
No. of

Copies

ONSITE

6 DOE Richland Operations Office

T. A. Bauman

R. B. Goranson

P. E. Lamont

J. M. Peterson

H. E. Ransom

D. J. Squires

3 Rockwe11 Hanford Company

W. G. Bevan

W. M. Harty

D. D. Woodrich

3 United Nuclear Industries, Inc.

J. A. Adams

P. A. Crosetti

T. E. Dabrowski

2 Washington Public Power Supply System

G. F. Bailey

J. B. Vetrano

3 Exxon Nuclear Company, Inc.

E. Mays

R. Nilsen

R. K. Robinson

Hanford Engineering Development Laboratory

A. W. DeMerschman 
No. of

Copies

56 Pacific Northwest Laboratory

W. B. Andrews

W. J. Bair

C. L. Brown

N. M. Burleigh (25)

S. H. Bush

N. E. Carter

J. G. DeSteese

H. K. Elder

A. L. Frankl in

C. A. Geffen

R. J. $\mathrm{Hall}$

H. Harty

S. W. Heaberlin

H. L. Henry

W. S. Kelley

S. N. Liu

T. I. McSweeney

J. Mishima

E. S. Murphy

R. E. Rhoads

J. W. Voss

E. C. Watson

R. D. Widrig

L. D. Williams

W. K. Winegardner

Technical Information (5)

Publishing Coordination (2) 